\title{
LA-UR-15-23589
}

Approved for public release; distribution is unlimited.

Title: $\quad$ Fire Hazard Analysis of Technical Area 53 Building 1

Author(s): $\quad$ Noakes, Brett L.

Intended for: $\quad$ Masters Degree Project- Culminating Experience

Issued: 2015-05-13 
Disclaimer:

Los Alamos National Laboratory, an affirmative action/equal opportunity employer,is operated by the Los Alamos National Security, LLC for the National NuclearSecurity Administration of the U.S. Department of Energy under contract DE-AC52-06NA25396. By approving this article, the publisher recognizes that the U.S. Government retains nonexclusive, royalty-free license to publish or reproduce the published form of this contribution, or to allow others to do so, for U.S. Government purposes. Los Alamos National Laboratory requests that the publisher identify this article as work performed under the auspices of the U.S. Departmentof Energy. Los Alamos National Laboratory strongly supports academic freedom and a researcher's right to publish; as an institution, however, the Laboratory does not endorse the viewpoint of a publication or guarantee its technical correctness. 


\section{Fire Hazard Analysis of Technical Area 53 Building 1}

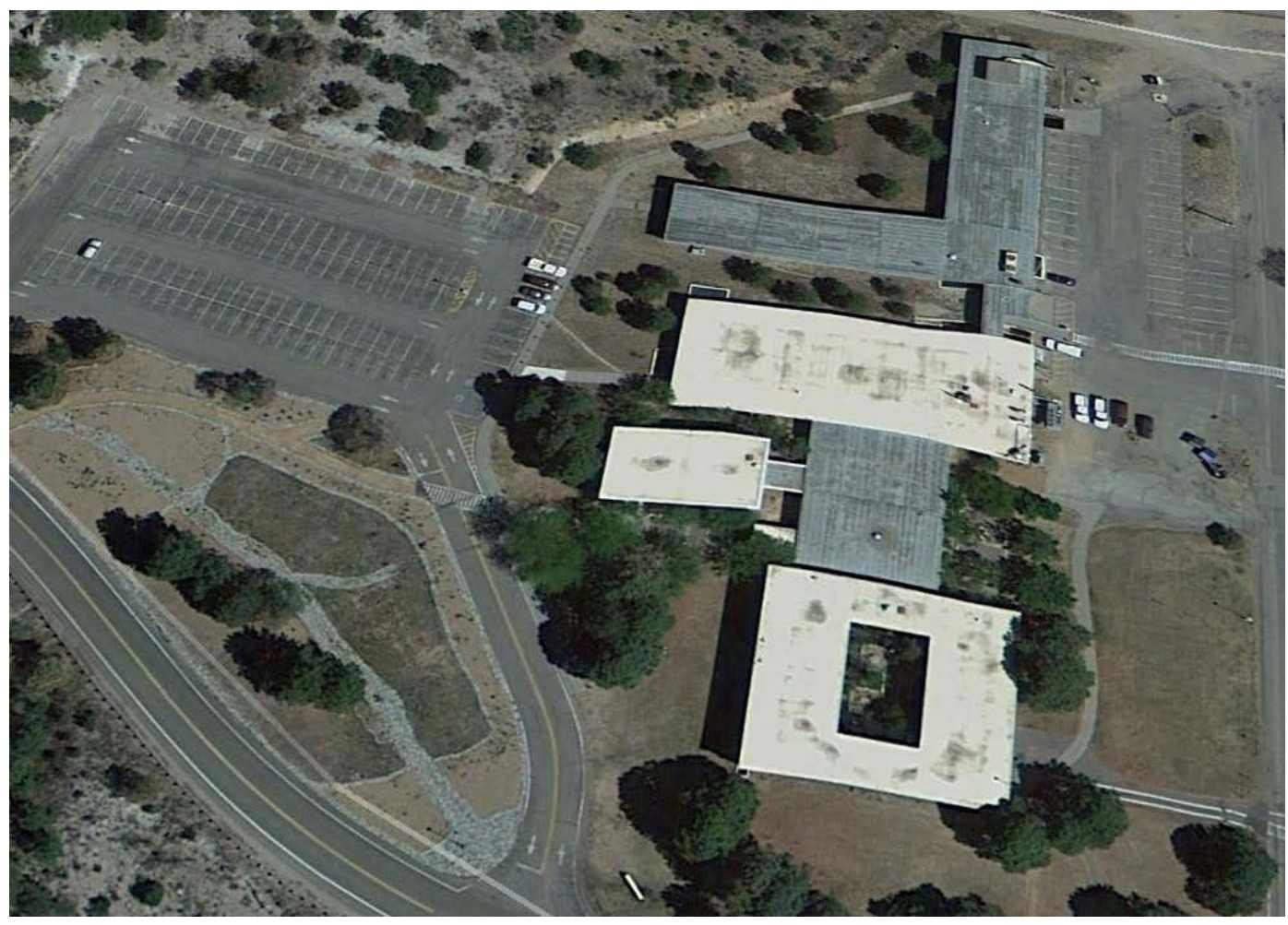

By: Brett Noakes 


\section{Statement of Disclaimer}

This project report is a result of a class assignment; it has been graded and accepted as fulfillment of the course requirements. Acceptance of this report in fulfillment of the course requirements does not imply technical accuracy or reliability. Any use of information in this report is done at the risk of the user. These risks may include, but may not be limited to, catastrophic failure of the device or infringement of patent or copyright laws. California Polytechnic State University at San Luis Obispo and its staff cannot be held liable for any use or misuse of the project. 


\begin{abstract}
This is an analysis of a 1970's vintage building as it is compared to current building codes and standards. The purpose of this document is to assess if the current, as found construction of an existing building could achieve the sometimes more restrictive modern building codes. Both a prescriptive analysis and a performance-based analysis were completed to verify life-safety concerns and criteria as well as construction criteria. The prescriptive analysis compared existing, as found construction to current codes and standards while the prescriptive analysis used modern fire modeling techniques to see how likely fire scenarios would challenge the structure, if at all.
\end{abstract}

Key Words: Life Safety Code, RSET, ASET, Performance Based Design, Fire Dynamics Simulator (FDS), PyroSim, Pathfinder 


\section{Contents}

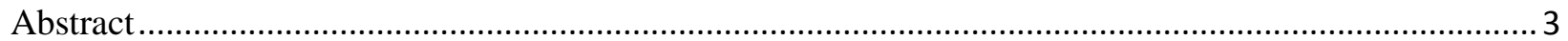

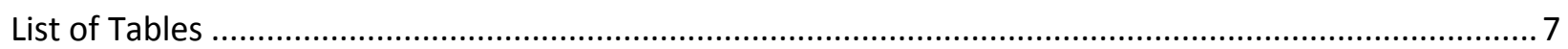

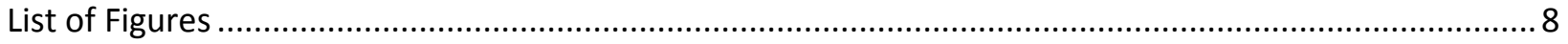

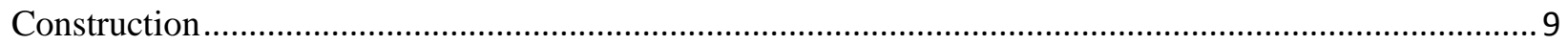

Fire Areas

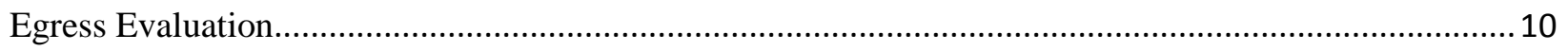

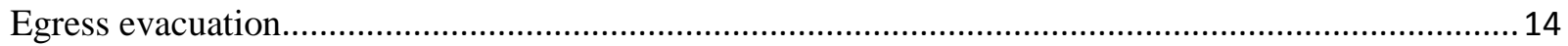

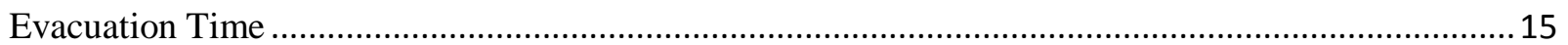

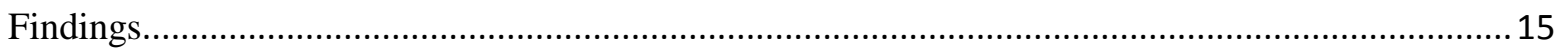

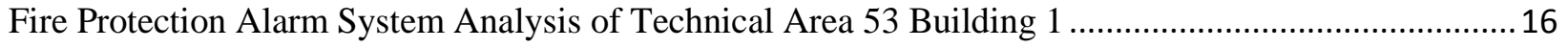

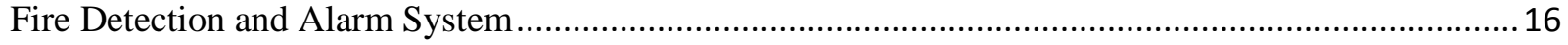

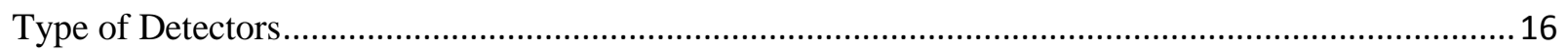

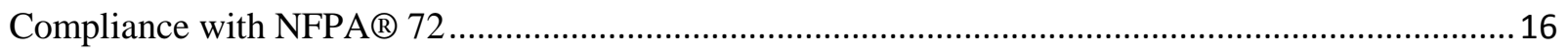

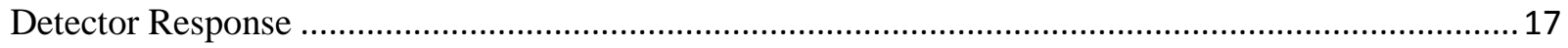

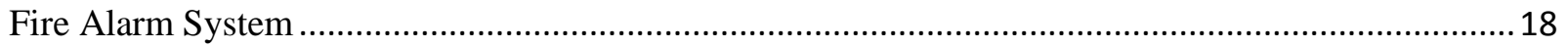

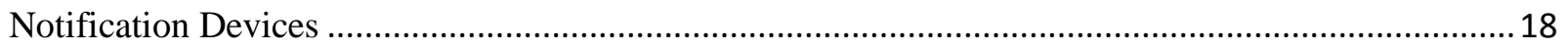

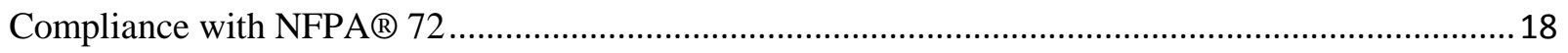

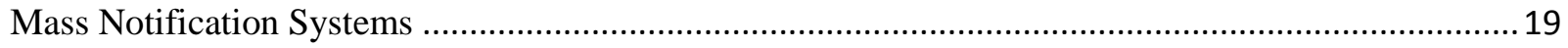

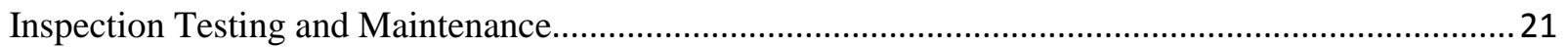

Fire Protection System Analysis of Technical Area 53 Building 1 ..................................................... 21

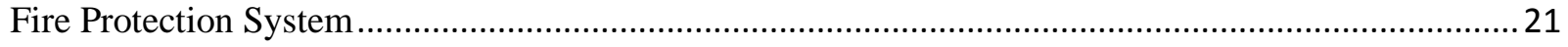

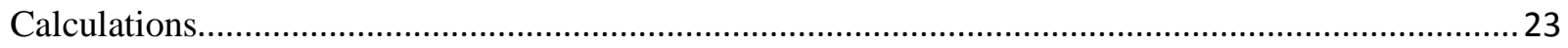

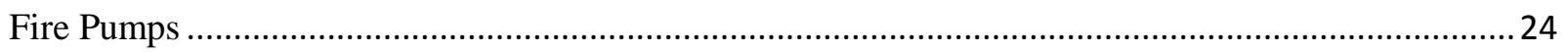

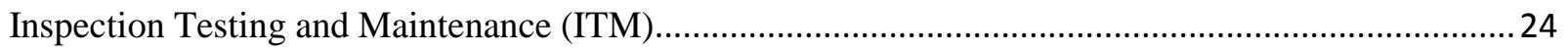

Fire Protection Structural Analysis of Technical Area 53 Building 1 ...................................................25

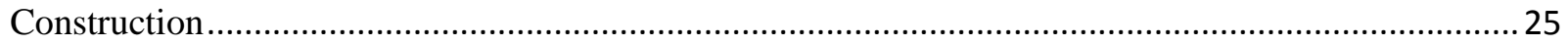

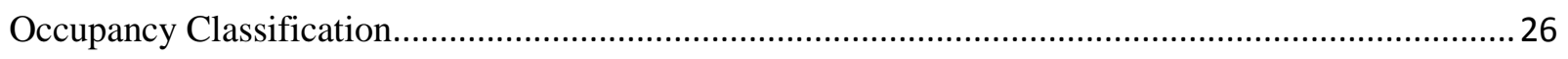

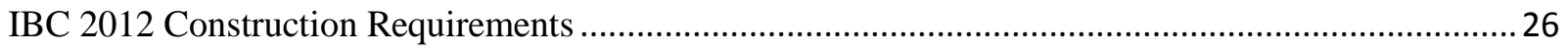

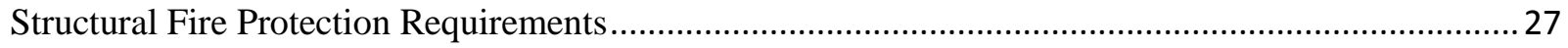

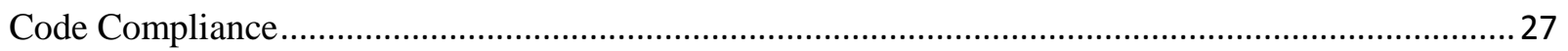

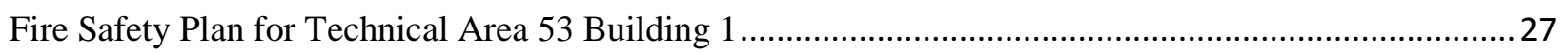


Procedure for Reporting Fires and Evacuation of Building ............................................................ 27

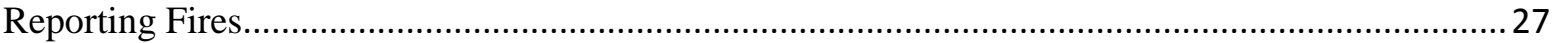

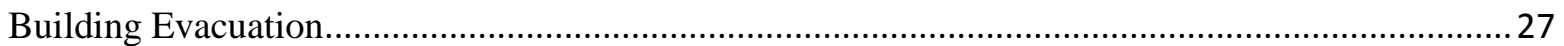

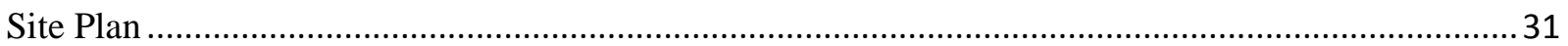

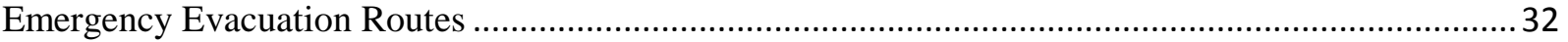

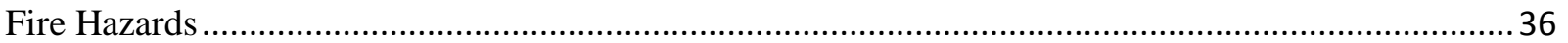

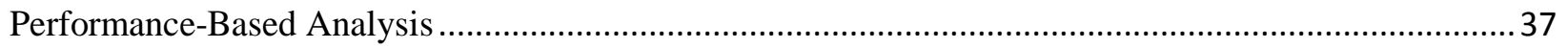

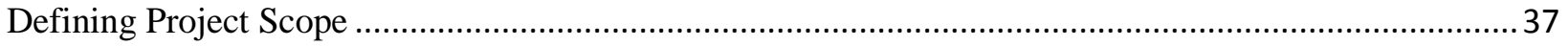

Identifying Goals and Defining Stakeholder Objectives .................................................................... 37

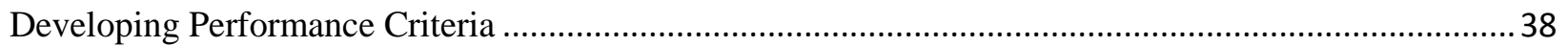

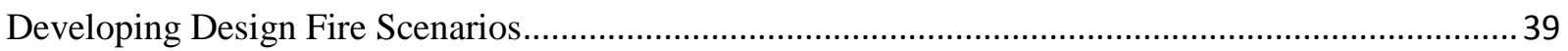

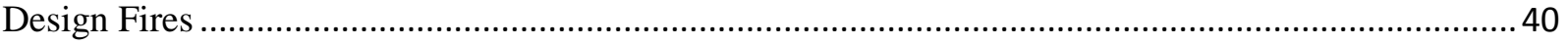

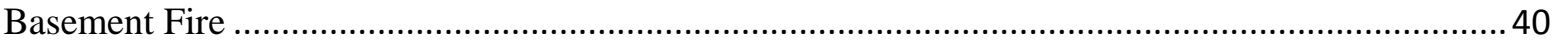

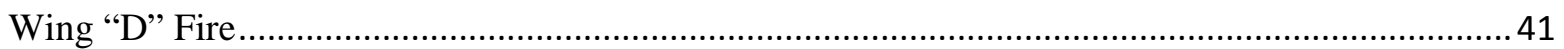

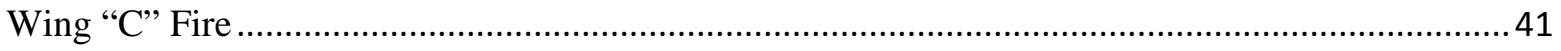

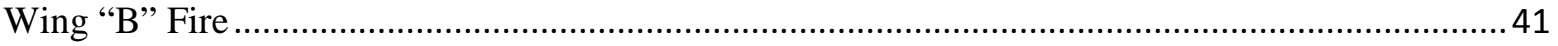

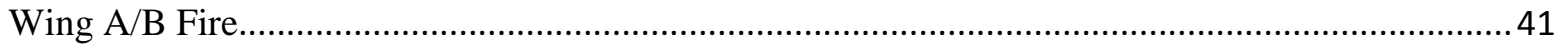

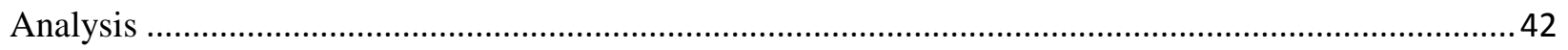

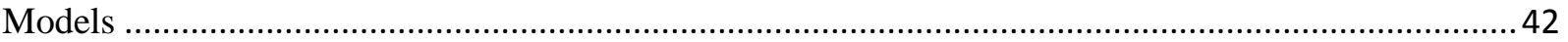

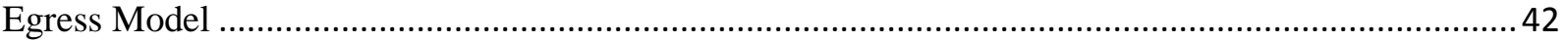

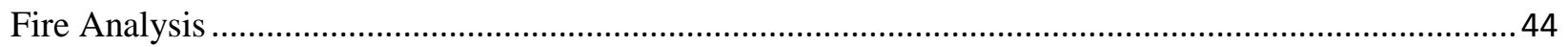

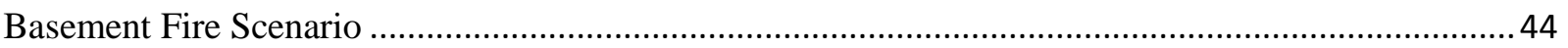

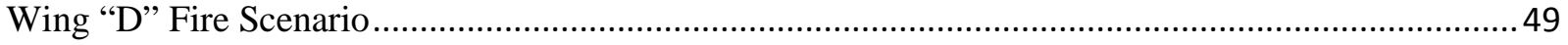

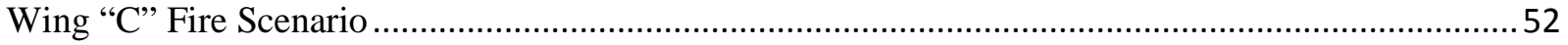

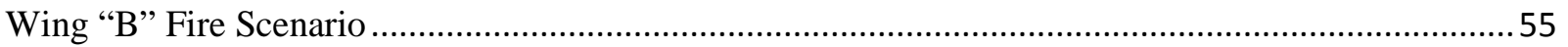

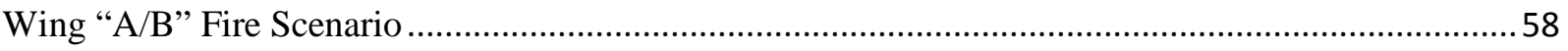

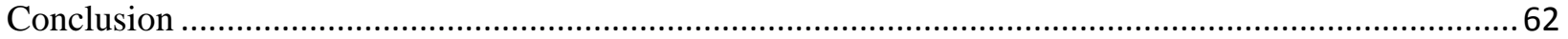

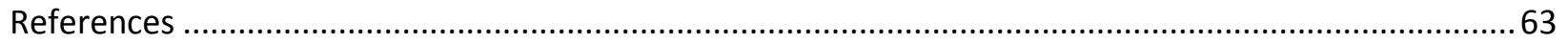

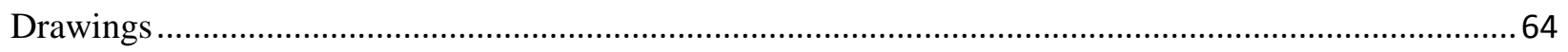

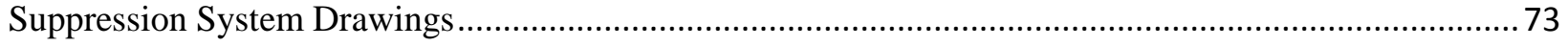

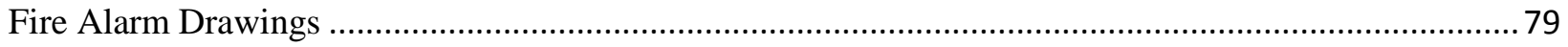

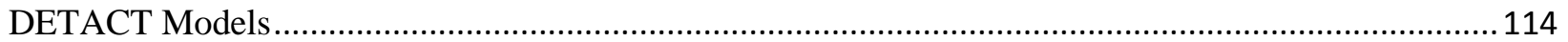




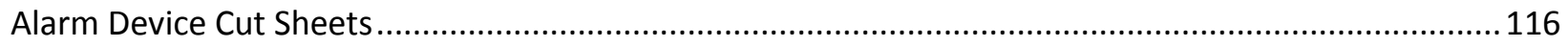

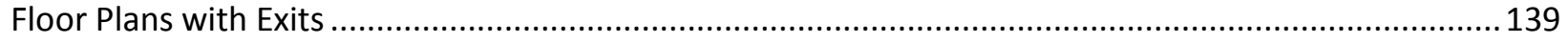

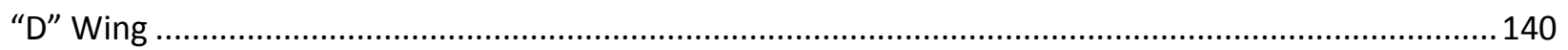

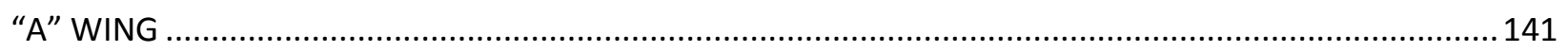

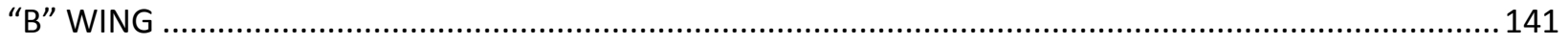

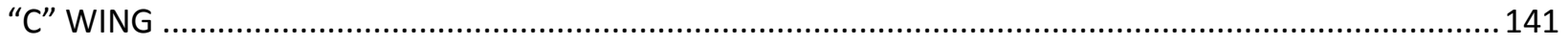

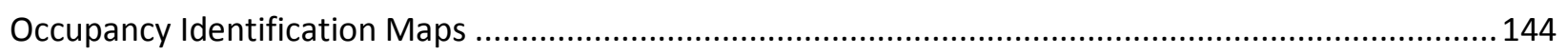

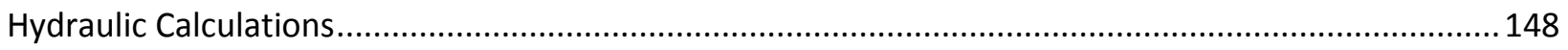




\section{List of Tables}

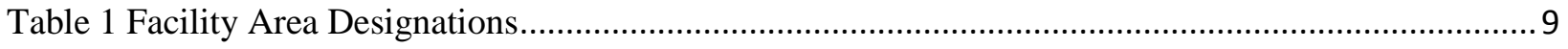

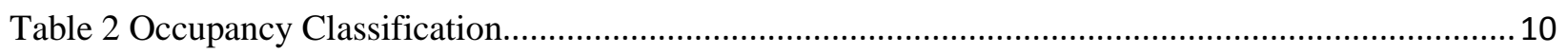

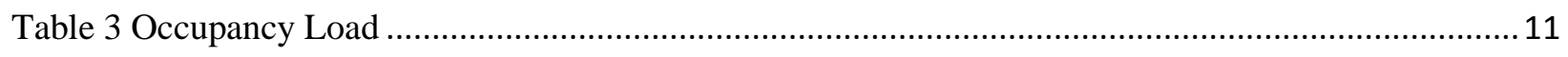

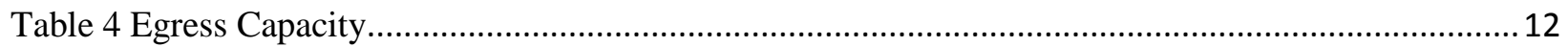

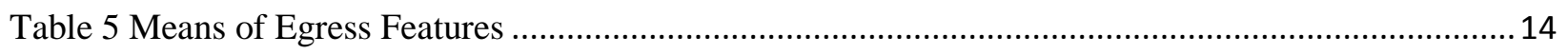

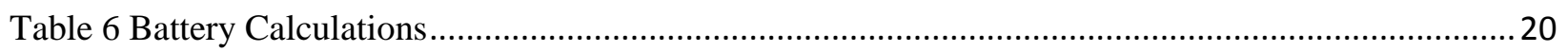

Table 7 Fire Protection Features Automatic Fire Sprinkler Systems .................................................... 22

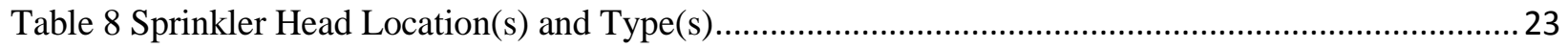

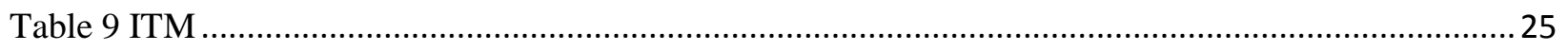

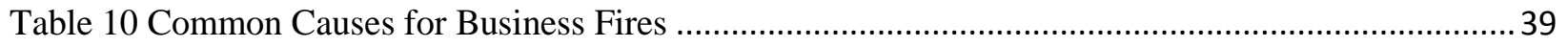

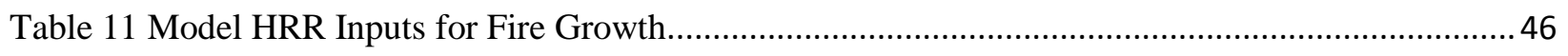

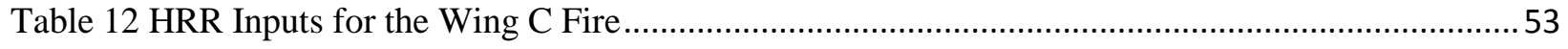

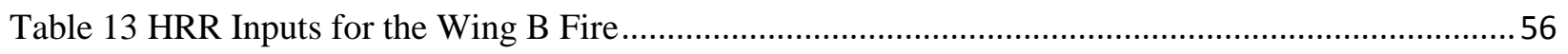

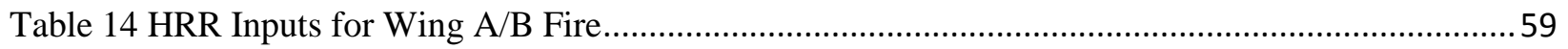




\section{List of Figures}

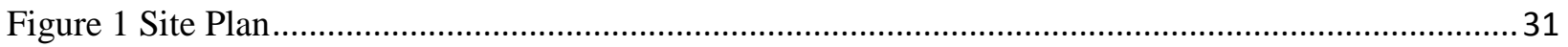

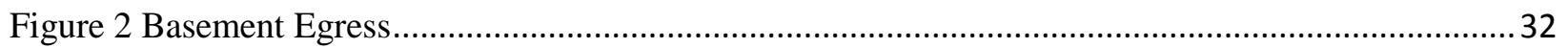

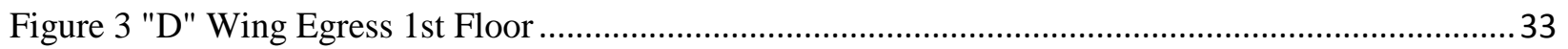

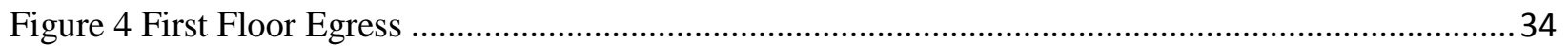

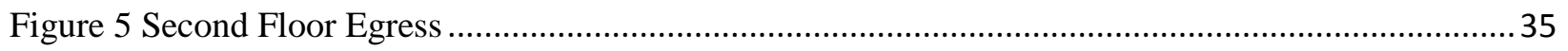

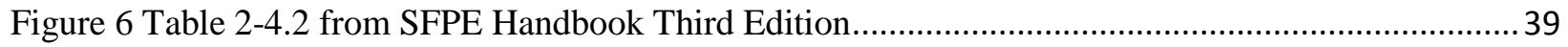

Figure 7 Pathfinder model at the beginning of egress simulation........................................................ 43

Figure 8 Screen shot of Pathfinder model showing all three levels of Building 1 ................................. 44

Figure 9 Pathfinder model showing all occupants have exited.......................................................... 44

Figure 10 Photo of Similar Fuel Package from Dreamstime.com ........................................................... 45

Figure 11 Table 3-1.5 HRR Values of Palletized and Rack Storage Commodities Tested at FMRC for

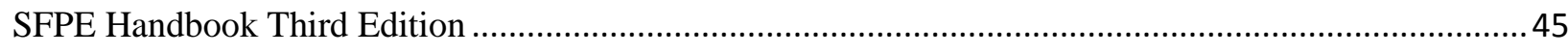

Figure 12 Highest Temperatures for Basement Scenario …............................................................. 47

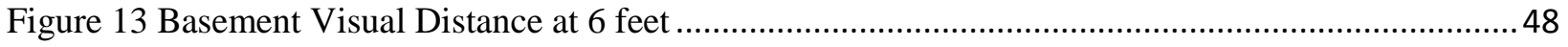

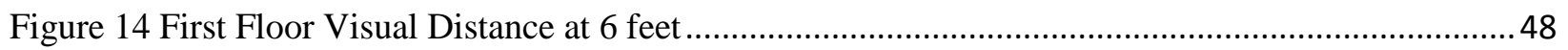

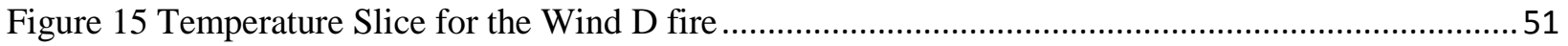

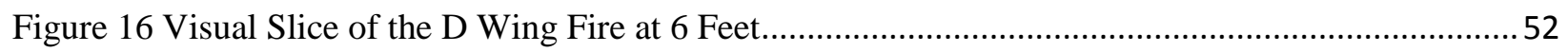

Figure 17 HRR Curve of Two men's Jackets from SFPE Handbook Third Edition..................................53

Figure 18 Temperature Slice of the Wing C Fire.............................................................................. 54

Figure 19 Visual Slice of the Wing C Fire at 6 feet...........................................................................5 54

Figure 20 Screen Shot of the HRR Curves Measured During the Experiments with Dry Powder

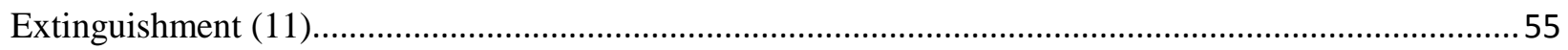

Figure 21 Temperature Slice File for Wing B fire .......................................................................... 57

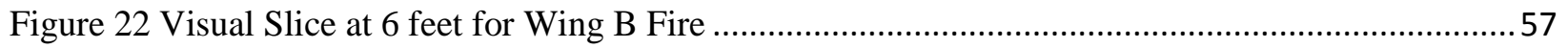

Figure 23 HRR Curve for Trash Bags from SFPE Handbook Third Edition. .........................................59

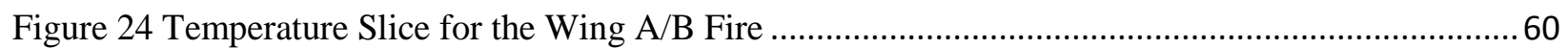

Figure 25 Visual Slice at 6 Feet for the First Floor of wing A/B.......................................................6 60

Figure 26 Visual Slice at 6 Feet for the Second Floor of Wing A .......................................................61 
Table 1 Facility Area Designations

\begin{tabular}{|l|l|l|}
\hline Area & \multicolumn{1}{|c|}{ Building } & \multicolumn{2}{l|}{ Description } \\
\hline 1. & & $\begin{array}{l}\text { A Wing, Administrative Offices } \\
\text { B Wing, Assembly (Auditorium), Lounge, Café, Offices }\end{array}$ \\
\hline 2. & TA-53-1 & $\begin{array}{l}\text { C Wing, Offices, Basement Area additional work spaces } \\
\text { and Mechanical Space(s) }\end{array}$ \\
\hline 3. & & $\begin{array}{l}\text { D Wing, Offices, and Basement Area with additional } \\
\text { work space and Mechanical Space(s) }\end{array}$ \\
\hline 4. & &
\end{tabular}

\section{Construction}

Building 1 is an approximately 76,600 square foot building that has a fully compliant NFPA® 13 suppression system and the following construction makeup. Construction on Building 1 was completed in 1971. It consists of cast-in place concrete, concrete tee, concrete block and steel joists. The exterior walls are concrete block with significant (30-40\%) insulated spandrel glass openings. Foundation walls, tunnels, and footers are cast-in place concrete. Floor/ceiling assemblies between floors are concrete tee construction. The roof/ceiling assemblies are steel joists covered with (4 inches) lightweight concrete. If not for the unprotected steel construction, the facility would be entirely of fire resistive construction (Type I).

"A" Wing is two stories, one at grade and one above with a roughly 4' by 4' utility tunnel running around the perimeter and below grade. " $\mathrm{B}$ " Wing is one story throughout, though the Auditorium (B105) has a projector mezzanine; there is also a utility tunnel under "B" Wing. "C" Wing is one story with a full basement below grade. Access to the basement is through two interior stairwells, one exterior stair, two exterior airway (ventilation only), and through a connection to the "D" Wing basement. "D" Wing is similarly a single story with a partial basement under the North-South leg. Access to the " $D$ " Wing basement is through one interior stairwell, two exterior airways (ventilation only), a freight elevator and a hoistway, and a connection to the "C" Wing basement.

\section{Fire Areas}

The facility was likely intended to be separated between floors, between " $\mathrm{B}$ " and " $C$ " Wings, between " $\mathrm{C}$ " and " $\mathrm{D}$ " Wings and between the inactive chemical labs in " $\mathrm{D}$ " wing and the balance of the facility. The door labels installed between "B" and "C" Wing have been painted over and the rating is not evident; they are assumed to carry a minimum 45 minute rating based on the materials and construction. This is the same configuration for the doors between "C" and "D" wing. The doors between " $\mathrm{D}$ " Wing and the area intended to be a chemical laboratory are oversized fire doors. Though not specifically listed, these doors are of a very similar 
construction to fire doors and are expected to provide some nominal fire resistance. In general, these separations are beneficial - if not required - and should be maintained.

With the uncertainties and known deficiencies in the fire doors, the facility will be treated as one fire area; however, any fire separations provided in the original construction should be maintained.

\section{Egress Evaluation}

The facility's layout with respect to emergency egress was evaluated with respect to NFPA® 101, 2012 edition (1). The evaluation included, but was not limited, to travel distances, common paths of travel, dead end travel and passive fire resistance for egress enclosures. The quantitative analysis will include a comparison of compliance codes (e.g. total travel distance: actual and required maximum).

\section{Table 2 Occupancy Classification}

\begin{tabular}{|c|c|c|c|c|c|c|}
\hline Area & Assembly & Business & Industrial & Storage & $\begin{array}{l}\text { Special } \\
\text { Structure }\end{array}$ & $\begin{array}{l}\text { Mixed } \\
\text { Occupancy }\end{array}$ \\
\hline 1. & $\mathrm{~N} / \mathrm{A}$ & $\overline{\text { All }}$ & $\overline{\mathrm{N} / \mathrm{A}}$ & $\overline{\mathrm{N} / \mathrm{A}}$ & $\mathrm{N} / \mathrm{A}$ & $\mathrm{N} / \mathrm{A}$ \\
\hline 2. & $\begin{array}{l}\text { Lecture, Café, } \\
\text { Lounge }\end{array}$ & $\begin{array}{l}\text { Incidental } \\
\text { Office Space }\end{array}$ & $\mathrm{N} / \mathrm{A}$ & $\bar{N} / \mathrm{A}$ & $\mathrm{N} / \mathrm{A}$ & $\mathrm{N} / \mathrm{A}$ \\
\hline 3. & & Offices & $\overline{\mathrm{N} / \mathrm{A}}$ & Basement & N/A & $\overline{\mathrm{N} / \mathrm{A}}$ \\
\hline 4. & & Offices & $\mathrm{N} / \mathrm{A}$ & Basement & N/A & $\mathrm{N} / \mathrm{A}$ \\
\hline
\end{tabular}


Table 3 Occupancy Load

\begin{tabular}{|c|c|c|c|c|c|}
\hline Area & $\begin{array}{l}\text { Net Square } \\
\text { Footage }\end{array}$ & $\begin{array}{l}\text { Occupant } \\
\text { Load }\end{array}$ & $\begin{array}{l}\text { NFPA® } \\
\text { criteria }\end{array}$ & Actual Load & Comment(s) \\
\hline 1. & 16959 & 170 & $100 \mathrm{ft}^{2} /$ person & $<100$ & Offices \\
\hline \multirow[t]{4}{*}{2.} & 2358 & 24 & $100 \mathrm{ft}^{2} /$ person & $<12$ & Offices \\
\hline & 2202 & 156 & $\overline{\text { Fixed Seating }}$ & $\overline{\mathrm{N} / \mathrm{A}}$ & Lecture \\
\hline & 2875 & 575 & $5 \mathrm{ft}^{2} /$ person & $<50$ & Lounge/Reception \\
\hline & 1364 & 91 & $\begin{array}{l}15 \mathrm{ft}^{2} / \text { person } \\
\text { (less } \\
\text { concentrated) }\end{array}$ & $\overline{<48}$ & Café, only 48 seats available. \\
\hline \multirow[t]{2}{*}{3.} & $\begin{array}{l}11988\left(1^{\text {st }}\right. \\
\text { floor) }\end{array}$ & 120 & $100 \mathrm{ft}^{2} /$ person & $<50$ & Offices \\
\hline & $\begin{array}{l}11988 \\
\text { (basement) }\end{array}$ & 120 & & $<20$ & \\
\hline \multirow[t]{2}{*}{4.} & $\begin{array}{l}15,008\left(1^{\text {st }}\right. \\
\text { floor })\end{array}$ & 151 & $100 \mathrm{ft}^{2} /$ person & $<50$ & Offices \\
\hline & $\begin{array}{l}8746 \\
\text { (basement) }\end{array}$ & 88 & & & \\
\hline
\end{tabular}


Table 4 Egress Capacity

\begin{tabular}{|c|c|c|}
\hline Area & Exit & $\begin{array}{l}\text { Capacity (NFPA }{ }^{\circledR} 101 \text { Table 7.3.3.1) Stairs Capacity } \\
\text { Factor .3, } \\
\text { Door Capacity Factor . } 2\end{array}$ \\
\hline 1. & $\begin{array}{l}\text { SE } 40 \text { inch door }\left(1^{\text {st }}\right) \\
\text { East main door }\left(1^{\text {st }}\right) 72 \text { inch } \\
\text { X } 2\end{array}$ & $\begin{array}{l}195 \\
720\end{array}$ \\
\hline $\begin{array}{l}\text { Total } \\
\text { Available } \\
\text { Required }\end{array}$ & & $\begin{array}{l}915 \\
170\end{array}$ \\
\hline 2. & $\begin{array}{l}\text { East main door } 72 \text { inch X } 2 \\
\text { North } 34 \text { inch door of } \\
\text { auditorium } \\
\text { South } 34 \text { inch door of } \\
\text { auditorium } \\
\text { Café } 72 \text { inch door }\end{array}$ & $\begin{array}{l}720 \\
170 \\
170 \\
360\end{array}$ \\
\hline $\begin{array}{l}\text { Total } \\
\text { Available } \\
\text { Required }\end{array}$ & & 8420 \\
\hline 3. & $\begin{array}{l}\text { West } 72 \text { inch door } \\
\text { Northeast } 72 \text { inch doors X } 2\end{array}$ & $\begin{array}{l}360 \\
720\end{array}$ \\
\hline $\begin{array}{l}\text { Total } \\
\text { Available } \\
\text { Required }\end{array}$ & & 1080 \\
\hline 4. & $\begin{array}{l}\text { West } 36 \text { inch door }\left(1^{\text {st }}\right) \\
\text { South } 72 \text { inch doors }\left(1^{\mathrm{st}}\right) \\
\text { North } 72 \text { inch door }\left(1^{\mathrm{st}}\right) \\
\text { NW } 72 \text { inch door }\left(1^{\mathrm{st}}\right) \\
\text { NE } 72 \text { inch door }\left(1^{\mathrm{st}}\right)\end{array}$ & $\begin{array}{l}180 \\
720 \\
360 \\
360 \\
360\end{array}$ \\
\hline $\begin{array}{l}\text { Total } \\
\text { Available } \\
\text { Required }\end{array}$ & & 1980 \\
\hline Basement & West 44 inch stair & 146 \\
\hline
\end{tabular}




\begin{tabular}{|l|l|l|}
\hline & Center 40 inch stair & 133 \\
& Exterior 38 inch stair & 126 \\
& North 44 inch stair & 146 \\
\hline Total & & 551 \\
Available & & 208 \\
\hline
\end{tabular}

The egress capacity in Table 4 was calculated using the most restrictive component of each particular egress system.

Based on the lay out of the facilities exits and their calculated egress capacity the egress components of this facility were found to be acceptable according to NFPA ${ }^{\circledR} 101$ (1).

The Doors between wings " $\mathrm{B}$ " and " $\mathrm{C}$ " and the doors between wings " $\mathrm{C}$ " and " $\mathrm{D}$ " would be acceptable places for horizontal exits and may have originally been designed to be horizontal exits, however the institutional history for buildings of this vintage is that rated walls have been breached without proper penetration seals. During the walkdown of this building a full inspection of these walls was not completed and therefore cannot be verified that these would still qualify as horizontal exits.

Corridors and stairways are not required to have any rating in accordance with NFPA $®, 101$ 39.3.6. (1) The finish requirements for exits and corridors is Class A or Class B (NFPA® 101 39.3.3.2.1) (1) with other areas allowed to be Class A, Class B, and Class C (NFPA® 101 39.3.3.2.2) (1).

Exit signs are placed as shown in the Occupancy Identification Maps located at the end of this report and are located in accordance with NFPA ${ }^{\circledR} 101$ 7.10.1.2.1 (1)

All aspects of the egress system for this building meet the prescriptive requirements of NFPA ${ }^{\circledR}$ 101 for Existing Business Occupancy. 
Table 5 Means of Egress Features

\begin{tabular}{|c|c|c|c|c|c|c|}
\hline & Exit Stairs & Travel & Common & Dead End & Exit Signs & Emergency \\
\hline Area & $\begin{array}{l}\text { Enclosed } \\
(\mathrm{Y} / \mathrm{N})\end{array}$ & To Exit & Of Travel & $\begin{array}{l}\text { Corridor } \\
\text { Length }\end{array}$ & $\begin{array}{l}\text { Illuminated } \\
(\mathrm{Y} / \mathrm{N})\end{array}$ & Lighting \\
\hline \begin{tabular}{|l|} 
NFPA® \\
101 \\
Req.
\end{tabular} & & $\begin{array}{l}300 \mathrm{ft} . \\
\text { Sprkd. Bld }\end{array}$ & $100 \mathrm{ft}$. & $50 \mathrm{ft}$. & & \\
\hline 1. & $\begin{array}{l}\text { (2) Stairs } \\
(1) \\
\text { Enclosed }\end{array}$ & $<100 \mathrm{ft}$. & $<20 \mathrm{ft}$. & None & Tritium & $\mathrm{Y}$ \\
\hline 2. & None & $<100 \mathrm{ft}$. & $<20 \mathrm{ft}$. & None & Tritium & $\bar{Y}$ \\
\hline 3. & $\begin{array}{l}\text { (3) Stairs } \\
\text { (2) } \\
\text { Enclosed }\end{array}$ & $\begin{array}{l}<150 \mathrm{ft} . \\
.\end{array}$ & $75 \mathrm{ft}$. & $36 \mathrm{ft}$. & Tritium & $\bar{Y}$ \\
\hline 4. & $\begin{array}{l}(1) \\
\text { Enclosed } \\
\text { Stair }\end{array}$ & $<150 \mathrm{ft}$. & $70 \mathrm{ft}$. & $36 \mathrm{ft}$. & Tritium & $\overline{\mathrm{Y}}$ \\
\hline
\end{tabular}

\section{Egress evacuation}

The typical occupants of this building are people in good general health with the ability to move at an appropriate pace to self-evacuate. The response to a fire will most likely be delayed for the following reasons. First, drills and maintenance are performed on the notification system at regular intervals and even though prior notification is usually communicated to occupants before maintenance begins with an approximate time of completion and a follow-up announcement that the test is over. This process lends itself to complacency with regards to immediate response to alarms resulting in additional stimulation needed to get people moving. This could be peers walking by, the smell of smoke, or someone yelling this is not a drill.

Secondly, some individuals may be working with sensitive information and feel the need to secure it before they attempt to egress. This is not required by procedure but if not done the notification process after the event could take a while motivating individuals to secure before leaving.

Thirdly, this building is located in the northern mountains of New Mexico and is susceptible to inclement weather resulting in additional delays as people gather their belongings before they leave.

The estimated delay for these pre-movement delays would be in the range of 2 to 3 minutes. 


\section{Evacuation Time}

Assuming that for a worst case scenario the total allowed occupant load was in the building, and that everyone left immediately at the same time during the event and used all exits in balance, an approximate egress time could be calculated. Calculating time would be based on the time it takes the required number of occupants out the most restrictive exit.

Total Occupants $=1703$

Number of Exits $=14$

1703/14= 122 people per door

Most restrictive door is a 36 inch door.

A 36 inch door has 6 inches of boundary layer on each side of the door (NFPA ${ }^{\circledR}$ HB $20^{\text {th }}$ Edition Table 4.2.4) (2)leaving and effective width of 2 feet.

From Table 4.2.8 (NFPA® HB) the Maximum Specific Flow for doors is 24 people/minute/ft. of effective width. (2)

$24 \times 2=48$ people per minute through the door

$122 / 48=2.5$ minutes total egress time

When you add in the 3 minutes (worst case) for the pre-movement time you get an egress time of 5.5 minutes.

This however is unlikely because you cannot assume that all people will use every exit equally. The larger exits can accommodate more people than are usually present during normal operating times. The egress times for this building are most likely less than calculated. Occupant loads are much less than calculated.

For tenability of the occupants during a fire event it is realistically not likely for an untenable environment to happen that would prevent or block an egress path. This building is fully sprinkler protected with nonhazardous uses and a well laid out egress system. The only tenability issues would be keeping smoke above 5 feet for a smoldering fire that is not yet hot enough to activate the sprinkler system, however this scenario happening without someone being alerted quickly is unlikely during normal business hours.

\section{Findings}

During the walk-down of the facility it was noticed that the North most exit's external stairs were not properly maintained for the recent winter weather and that the steps do not lead to a proper public way. NFPA® 101 (2012) (1)

7.1.10.1* General. Means of egress shall be continuously maintained free of all obstructions or impediments to full instant use in the case of fire or other emergency. 
7.7.1* Exit Termination. Exits shall terminate directly, at a public way or at an exterior exit discharge, unless otherwise provided in 7.7.1.2 through 7.7.1.4. (1)

Fire Protection Alarm System Analysis of Technical Area 53 Building 1

Fire Detection and Alarm System

The fire detection and alarm system in TA-53-1 was updated in 2004/2005. New manual pull stations, smoke detectors, individually addressable modules (IAM), booster power supplies (BPS), conduit and conductors were installed. All devices report to a new Edwards Systems Technologies (EST, GE Infrastructure) Model QS4 Fire Control Panel. This panel activates devices on two internally-driven notification appliance circuits (NAC) and two external BPS units and their associated notification appliances. This system also communicates with the fire dispatch center through two dedicated phone lines.

The HVAC controls, elevator controls, and mechanical interface devices (i.e. flow switches, tamper switches) were not upgraded or added. Where such devices previously existed - as in the case of water flow detection and valve supervision - the existing devices were connected to new IAM that report to the new panel.

\section{Type of Detectors}

There are two types of detectors located within this building. The first being the fire suppression system and the second being some strategically placed smoke detection.

The primary way of detection for this building would be the NFPA ${ }^{\circledR} 13$ compliant sprinkler system. Each sprinkler contains a sacrificial element that when heated to $212^{\circ} \mathrm{F}$ will break and allow water to be discharged. This discharge of water will activate the suppression system pressure switch located at the riser. This switch is constantly monitored by the building fire alarm panel and upon receipt of the signal, will initiate the building notification appliances and report the condition to a constantly attended location for dispatch of the fire department.

The second type of detection in this facility is photoelectric area smoke detectors manufactured by General Electric, model SIGA-PS. These detectors are placed in the telecommunication room, the computer room, and above the FACP. These devices are strategically placed for asset protection.

\section{Compliance with NFPA ${ }^{\circledR} 72$}

As stated previously the fire suppression system is fully compliant with NFPA® 13 . The suppression system consists of standard response heads rated for $212^{\circ} \mathrm{F}$ with a spacing of $12^{\prime} \mathrm{X}$ 12 '.

The smoke detectors are strategically placed for asset protection by way of early warning. The telecommunication room is a space of $20^{\prime}$ X $40^{\prime}$ and is protected by two detectors. This configuration is compliant with NFPA ${ }^{\circledR} 72$. In the computer room there are a total of three 
detectors, one ceiling mount and two under floor mounted. The ceiling mount detector is protecting an area of $16^{\prime} \mathrm{X} 30^{\prime}$ ' while the two underfloor detectors protect the same area. It is assumed that the under floor area is used for routing of cabling and cooling plenum for the equipment. Without having document history it is assumed the two detectors are required based on hazard protection in accordance with NFPA ${ }^{\circledR} 72$ (2013) 17.7.3.1.3. (3) The last location of a smoke detector is above the FACP which is a NFPA ${ }^{\circledR} 72$ requirement.

\section{Detector Response}

Fire scenario 1: For this fire scenario there was a stack of collapsed cardboard boxes with some other incidental trash found in the basement near the stairs during my walk downs of this building. Assuming this fuel package ignites, what would be the response characteristics of the suppression system?

The input parameters for the DETACT model are as follows:

Ceiling Height $=9^{\prime}=2.7 \mathrm{~m}$

Room Width $=14^{\prime}=4.2 \mathrm{~m}$

Radial distance based on $12 \mathrm{X} 12$ spacing $=16.7^{\prime}=5.1$ assuming worst case

Note: The actual location of the head in relation to the fuel package is directly above it.

$20^{\circ} \mathrm{C}$ ambient

$212^{\circ} \mathrm{F}$ head $=100^{\circ} \mathrm{C}$

Sprinkler RTI of 100

"t-squared fire” with a medium growth rate as indicated by Table B.2.3.2.6.2 (a) for item 9

Note: Stack is only 3 feet tall.

With these conditions the DETACT model predicts the sprinkler will activate at approximately 380 seconds with a HRR of approximately $1600 \mathrm{kw}$. This would be under worst case conditions. In actuality the sprinkler is located above the fuel package and would most likely have faster response. However with these results I think the fire would be adequately suppressed.

Fire scenario 2: In this scenario I assume there is an equipment failure in the computer room with ignition of computer components. What would be the response characteristics of the smoke detector located on the ceiling of that room?

The input parameters for the DETACT model for scenario 2 are as follows: Treating the smoke detector as a super sensitive heat detector.

Ceiling Height $=9^{\prime}=2.7 \mathrm{~m}$ 
Room Width $=30^{\prime}=9.1 \mathrm{~m}$

Radial distance based on detector in center of room and fire at edge $=34^{\prime}=10.3$ assuming worst case

$20^{\circ} \mathrm{C}$ ambient

Detector activation is based on a rise in temperature of $7.2^{\circ} \mathrm{C}$ from Table B.4.7.5.3 (NFPA® ${ }^{\circledR 2}$ ) for PVC (3). Assuming the PVC was the closest to the plastics contained in computer equipment.

No RTI

“t-squared fire” with a Fast growth rate as indicated by Table B.2.3.2.6.2 (a) (NFPA® 72) for item 16 (3)

The DETACT model shows the detector will activate in 41 seconds with a HRR of $79 \mathrm{kw}$.

\section{Fire Alarm System}

The fire panel is Edwards Systems Technologies (EST, GE Infrastructure) Model QS4 Fire Control Panel. This panel activates devices on two internally-driven notification appliance circuits (NAC) and two external BPS units and their associated notification appliances. This system also communicates with the fire dispatch center through two dedicated phone lines through a digital alarm communicator transmitter (DACT).

All signals are transmitted off the site to a central station and then dispatched accordingly. All trouble and supervisory signals are dispatched to on call fire alarm elections to be investigated. All alarm signals are dispatched to the county from the central station and they dispatch emergency personnel.

\section{Notification Devices}

The only notification devices are the General Electric Field Configurable Horns and StrobesGenesis Series. These are used both as horns and strobes and as strobe only devices. They are field configurable for both horns and strobe candela rating. The strobe ratings are $15 \mathrm{~cd}, 30 \mathrm{~cd}$, $75 \mathrm{~cd}$, and 110cd rating. The horns are somewhat configurable in that they have a high output level of $99 \mathrm{~dB}$ at 10 feet and low output level of $94 \mathrm{~dB}$.

\section{Compliance with NFPA ${ }^{\circledR} 72$}

This building is mostly an office building; most of the notification appliances are located in the corridors. The spacing in the corridors is compliant with the corridor strobes being set to 15cd. All public (lobbies, restrooms, and conference rooms) areas also have appropriate notification devices for the size of their rooms.

Using the 6dBA rule of thumb the devices under the most demand are located in a mechanical room in the basement.

Room size is $60^{\prime} \mathrm{X} 60^{\prime}$ 
The horn produces $99 \mathrm{~dB}$ at 10 feet so the $\mathrm{dB}$ level at 80 feet would be $81 \mathrm{~dB}$.

Requirements for the space are $15 \mathrm{~dB}$ above ambient back ground noise which for mechanical rooms is $85 \mathrm{dBA}$ average From Table A.18.4.3. This means you need $100 \mathrm{~dB}$ in the room.

The max $\mathrm{dB}$ allowed is 110 which is what the devices are set to, therefore sounds levels for this room have reached the max.

Table 18.5.5.4.1 (a) stated a room of this size can be covered by one 135cd strobe or four 30cd strobes.

This area is cover by two 110 cd strobes which is in excess of the code requirement.

\section{Mass Notification Systems}

This building does not have a mass notification system, however the laboratory as a whole uses emergency text message and emergency email notification to notify the population of an emergency. 
Table 6 Battery Calculations

\begin{tabular}{|c|c|c|c|c|c|}
\hline Number & Device & \multicolumn{3}{|c|}{ Current } & \multirow[t]{2}{*}{ Total } \\
\hline & NAC \#1 & Stand by & Total & Alarm & \\
\hline 11 & HS 15cd & & & .081 & .891 \\
\hline 4 & S 15cd & & & .059 & .224 \\
\hline 1 & $75 c d$ & & & .152 & .152 \\
\hline \multirow[t]{3}{*}{ NAC \#1 } & & & & & 1.279 amps \\
\hline & & 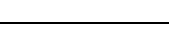 & 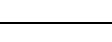 & 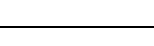 & 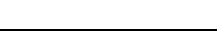 \\
\hline & NAC\#2 & & & & \\
\hline 9 & HS 15cd & & & .081 & .729 \\
\hline 2 & S 15cd & & & .059 & .118 \\
\hline NAC \#2 & & & & & .847 amps \\
\hline \multicolumn{6}{|c|}{ Control Panel } \\
\hline 1 & $\begin{array}{l}\text { Quick-Start } \\
\text { CPU }\end{array}$ & .117 & .117 & .135 & .135 \\
\hline 1 & PS6 & .072 & .072 & .096 & .096 \\
\hline 1 & SLIC controller & .033 & .033 & .057 & .057 \\
\hline 1 & DACT & .013 & .013 & .026 & .026 \\
\hline \multicolumn{6}{|c|}{$\begin{array}{l}\text { Initiating } \\
\text { Devices }\end{array}$} \\
\hline 8 & $\begin{array}{l}\text { Smoke } \\
\text { Detectors }\end{array}$ & .000045 & .0004 & .000045 & .00036 \\
\hline 21 & Pull Stations & .000396 & .0083 & .00068 & .01428 \\
\hline 10 & $\begin{array}{l}\text { Single Input } \\
\text { Module }\end{array}$ & .00025 & .0025 & .0004 & .004 \\
\hline 1 & $\begin{array}{l}\text { Dual Input } \\
\text { Module }\end{array}$ & .000396 & .0004 & .00068 & .00068 \\
\hline \multicolumn{6}{|l|}{$\begin{array}{l}\text { Output } \\
\text { Devices }\end{array}$} \\
\hline 2 & $\begin{array}{l}\text { Single Channel } \\
\text { Riser Module }\end{array}$ & .000223 & .0004 & .0001 & .0002 \\
\hline 1 & $\begin{array}{l}\text { Output Relay } \\
\text { Module }\end{array}$ & .0001 & .0001 & .0001 & .0001 \\
\hline NAC \#1 & & & & & 1.279 amps \\
\hline NAC \#2 & & & & & .847 amps \\
\hline Total & & & .2507 & & \begin{tabular}{|l}
2.46 amps \\
\end{tabular} \\
\hline
\end{tabular}


Laboratory requires 24 hours of standby power .2507 X 24 hours $=6 \mathrm{AH}$ required

Laboratory requires 10 minutes of alarm 10/60 $=.16667 \mathrm{X} 2.46=.410 \mathrm{AH}$ required

$$
6+.410=6.410 \mathrm{AH} \text { (derate by 20\%) X 1.2= } 7.692 \text { amp hours required. }
$$

This System is supplied by two 12 AH batteries.

\section{Inspection Testing and Maintenance}

All alarms system components shall be inspected, tested, and maintained in accordance with NFPA® 72 chapter 14 .

At initial acceptance $100 \%$ of the alarm system shall be tested and shall work with all interconnected building systems. These controls shall function as designed in the design documents matrix.

Where the alarm system interacts with the fire suppressions system, these components shall be inspected, tested, and maintained by the requirements and intervals set forth in NFPA® 25 Water Based Fire Suppression Systems.

\section{Fire Protection System Analysis of Technical Area 53 Building 1}

\section{Fire Protection System}

The facility is protected throughout by two distinct automatic fire sprinkler systems with an additional wet chemical extinguishing system to protect the cooking equipment in the café. System SPW-001 covers Wings “A”, “B”, “C”. The 6 inch cast-iron fire water supply enters in the basement Room C18 where a pressure switch with a retard chamber and attached to an alarm check valve detects flow at the riser. There is also a redundant set of flow switches that divide the system by zone (e.g. wing and floor). System SPW-002 provides coverage to “D” Wing, enters Room D3 Room C18 where a pressure switch with a retard chamber and attached to an alarm check valve detects flow at the riser.

The system design density is nominally compliant with the code of record (NFPA ${ }^{\circledR}$ 13, 1980 Edition); that is, it provides $0.19 \mathrm{gpm} / \mathrm{ft}^{2}$ over $1500 \mathrm{ft}^{2}$. The current standard, NFPA ${ }^{\circledR} 13$, would require a slightly higher density $\left(0.20 \mathrm{gpm} / \mathrm{ft}^{2}\right)(4)$. The water supply has changed little through the years.

The fire sprinkler heads are standard spray upright, pendant, and extended coverage sidewall (in some offices and laboratories), $212^{\circ} \mathrm{F}$, standard response and spaced to cover $<130 \mathrm{ft}^{2} /$ head.

The “D” wing sprinkler system did not have a riser tag with flow data. After further research of available sprinkler system drawings it is believed that this portion of the building is protected using a pipe schedule system. 
Spare sprinkler cabinets were observed during the site visit as not having minimum spare sprinklers in the cabinets. These cabinets are required by NFPA ${ }^{\circledR} 13$ and should be installed with no less than 12 heads, one cabinet near each riser with each having no less than 6 spare heads would be appropriate (4). All sprinkler types in the facility should be represented with spare stock in such a cabinet (e.g. extended coverage sidewall, standard spray upright and pendant, special temperature ratings). The cabinet would normally be mounted on the wall nearest the riser. A sprinkler wrench should also be provided.

In Hallway C1, outside of Room C5, there is a duct greater than 48 in. in width with no sprinkler coverage beneath. Sprinkler coverage is required by NFPA ${ }^{\circledR} 13$ underneath any horizontal obstruction that is greater than 48 in. in width (4).

Table 7 Fire Protection Features Automatic Fire Sprinkler Systems

\begin{tabular}{|c|c|c|c|c|c|c|c|c|}
\hline Area & \multicolumn{2}{|c|}{ Suppression System Type } & $\begin{array}{l}\text { Design } \\
\mathrm{gpm} / \mathrm{ft}^{2}\end{array}$ & $\begin{array}{l}\text { Spacing } \\
\mathrm{ft}^{2} / \text { head }\end{array}$ & $\begin{array}{l}\text { System } \\
\text { Design } \\
\text { BoR } \\
\text { Req't. }\end{array}$ & $\begin{array}{l}\text { FD Hose } \\
\text { Allowance }\end{array}$ & \multicolumn{2}{|c|}{$\begin{array}{l}\text { Static - Flow - } \\
\text { Residual }\end{array}$} \\
\hline $\begin{array}{l}1,2 \\
3\end{array}$ & \multicolumn{2}{|l|}{ Wet } & $\begin{array}{l}0.19 \\
\mathrm{gpm} / \mathrm{ft}^{2} \\
1500 \mathrm{ft}^{2}\end{array}$ & $<130 \mathrm{ft}^{2}$ & $\begin{array}{l}65 \text { psi@ } \\
663 \text { gpm }\end{array}$ & 250 gpm & \multicolumn{2}{|c|}{$\begin{array}{l}\text { 75psi (S) } \\
63 \text { psi @ } \\
954 g p m\end{array}$} \\
\hline 4. & \multicolumn{3}{|l|}{ Wet } & \multicolumn{3}{|c|}{ No Design Info On File } & \multicolumn{2}{|c|}{$\begin{array}{l}\text { 70psi(S) } \\
\text { 68psi@915gpm } \\
\text { yd. 53-806 (2013) }\end{array}$} \\
\hline Area & $\begin{array}{l}\text { Std } \\
\text { Response }\end{array}$ & $\begin{array}{l}\text { Quick } \\
\text { Response }\end{array}$ & $\begin{array}{l}\text { HD } \\
\text { Activation }\end{array}$ & $\begin{array}{l}\text { UV/IR } \\
\text { Activation }\end{array}$ & $\begin{array}{l}\text { Manual } \\
\text { Actuation }\end{array}$ & $\begin{array}{l}\text { Central Stat } \\
\text { Waterflow }\end{array}$ & $\begin{array}{l}\text { ion Superv } \\
\text { Detection }\end{array}$ & $\begin{array}{r}\text { ision of: } \\
\text { Valves }\end{array}$ \\
\hline \begin{tabular}{|l|}
1. \\
2. \\
3.
\end{tabular} & All & N/A & N/A & N/A & N/A & $\begin{array}{l}\text { Pressure } \\
\text { _ \& Paddle } \\
\text { by Zone }\end{array}$ & N/A & $\begin{array}{r}\text { Yes }_{1} \\
-\end{array}$ \\
\hline 4. & All & N/A & N/A & N/A & N/A & $\begin{array}{l}\text { Pressure } \\
\text { \& Paddle }\end{array}$ & N/A & $\mathrm{Yes}_{1}$ \\
\hline
\end{tabular}




\section{by Zone}

1. Control valves are supervised; alarm valves as part of the alarm check valve and retard chamber assembly are not supervised as required.

2. Test date: September 9, 2012 and August 12, 2013

The Hydrant Flow data is provided to us by the Los Alamos County Fire Department. Every hydrant is exercised once a year with hydrant flow calculations done every two years on each hydrant. The Fire Protection Division Office believes that this hydrant flow date is not accurate for new construction or design purposes and therefore only uses this LAFD information as a way to check system health. When a new project is in the works FP-DO will conduct a test with calibrated equipment at a site nearest the point of connection.

Table 8 Sprinkler Head Location(s) and Type(s)

\begin{tabular}{|c|c|c|c|c|c|}
\hline Area & Qty. & Manufacturer & Year & Model & Type \\
\hline \multirow[t]{4}{*}{$1,2,3$} & 140 & Star & 1969 & Model D & SSU (“C” Wing Basement) \\
\hline & 30 & Reliable & 1981 & Model G & $\overline{\mathrm{SSU}}$ \\
\hline & 340 & Reliable & 1981 & Model G & $\overline{\mathrm{SSP}}$ \\
\hline & 40 & Central & 1981 & HF-17/32 & $\begin{array}{l}\text { Extended Coverage Sidewall } \\
\text { (“A” Wing Corridors) }\end{array}$ \\
\hline \multirow[t]{2}{*}{4.} & $\sim 100$ & Star & 1969 & Model D & SSU (“D” Wing Basement) \\
\hline & $\sim 100$ & Reliable & 1981 & Model G & SSP \\
\hline
\end{tabular}

Note: There are some Grinnell F950 sprinkler heads in the facility (circa 1979). These sprinkler heads are prone to unwanted activations, but none of these heads were observed near critical electronics equipment.

\section{Calculations}

For this project a hand calculation of the auditorium was completed. The calculation was completed using the new NFPA ${ }^{\circledR} 13$ and DOE requirements which are .2 gpm per square foot with an area of 1500 square feet (Ordinary group 2 demands) and a DOE required hose allowance of $500 \mathrm{gpm}$. 
A problem I had with the calculation was finding good drawings of the system. The drawings I could find were dated 1981 and had too much information on one sheet. I did my best to highlight the system and made my best guess on pipe lengths and elevation changes and fittings.

The calculation showed a system demand of 341.5gpm at 141.5 psi which is undoubtedly greater demand than the system was originally designed and is well above the available supply. The high pressures needed as a result of the hand calculation show that my guess on elevation changes, pipe lengths, and fittings were most likely wrong, resulting in the inflated pressure demand. However the site is provided with a tank and pump configuration that can serve this inflated demand.

\section{Fire Pumps}

The area that Building 1 is located in is protected by two site wide fire pumps. An electric fire booster pump, taking suction from the water storage tank, is located in the MPF-54 pump house. The fire booster pump is a PATTERSON Pump Model 8X6 MIH, single-stage horizontal fire pump (13.281-in impeller diameter), with a pump rating of 1,250 gpm @ 70 net psi at 1780 RPM. It has a nameplate net pressure of 58 psi @ 150\% rated flow (82.3 maximum BHP) when driven by an WEG Type DP electric motor rated at 150 HP @ 1785 RPM $(460$ V, 60 Hz, 3phase electric supply at $167 \mathrm{~A}$ ). The motor has a service factor $=1.15$. The electric fire pump is activated when the TA-53 water supply system pressure drops below 11 psi. The fire pump is either manual or automatic start but only manual shut-off.

A second fire water storage tank with diesel-driven fire booster pump was originally provided for TA-53 to improve the TA-53 fire water supply reliability. The tank has a capacity of 750,000gal. The pump is a Patterson Pump Model 8X6ML, single-stage horizontal fire pump (13.531-in impeller diameter) rated at 1250 gpm @ 70 net psi at 1750 RPM. The pump driver is a Clarke Model JU4H-UF58 diesel engine rated at 110 HP @ 1750 RPM, derated to 79 HP @ 1470 RPM at 7,300 ft. elevation.

It is recommended that a computer based calculation be ran on the system once better as-builds have been found or created.

Inspection Testing and Maintenance (ITM) 
Table 9 ITM

\begin{tabular}{|l|l|}
\hline Sprinklers & $\begin{array}{l}\text { At } 50 \text { years and every10 years thereafter } \\
\text { Shall be inspected for Leakage, Corrosion, } \\
\text { Physical damage, Loss of fluid in the glass } \\
\text { bulb heat responsive element, Loading, } \\
\text { Painting unless painted by the sprinkler } \\
\text { manufacturer and correct orientation annually }\end{array}$ \\
\hline Control Valves & $\begin{array}{l}\text { Shall be inspected for proper position In the } \\
\text { normal open or closed position, Sealed, locked, } \\
\text { or supervised, Accessible, Provided with } \\
\text { correct wrenches, Free from external leaks, } \\
\text { Provided with applicable identification } \\
\text { Monthly } \\
\text { Annually each valve shall be operated }\end{array}$ \\
\hline Piping & $\begin{array}{l}\text { Obstruction, internal inspection of piping shall } \\
\text { be done every } 5 \text { years } \\
\text { Piping shall be free of mechanical damage and } \\
\text { no additional external loads shall be place on } \\
\text { the piping. Monthly }\end{array}$ \\
\hline Signs & $\begin{array}{l}\text { Shall be legible to indicate what each valve } \\
\text { controls. } \\
\text { The Riser Tag should also be clear and legible. }\end{array}$ \\
\hline
\end{tabular}

The previous is just a small sampling of typical ITM activities. For a more complete list of requirements you can go NFPA ${ }^{\circledR} 25$ Standard for the Inspection, Testing, and Maintenance of Water-Based Fire Protection Systems. (5)

Fire Protection Structural Analysis of Technical Area 53 Building 1

\section{Construction}

Building 1 is an approximately 81,000 square foot building that has a fully compliant NFPA® 13 suppression system and the following construction makeup. Construction on Building 1 was completed in 1971. It consists of cast-in place concrete, concrete tee, concrete block and steel joists. The exterior walls are concrete block with significant (30-40\%) insulated spandrel glass openings. Foundation walls, tunnels, and footers are cast-in place concrete. Floor/ceiling assemblies between floors are concrete tee construction. The roof/ceiling assemblies are steel joists covered with (4 inches) lightweight concrete. If not for the unprotected steel construction, the facility would be entirely of fire resistive construction (Type I) with the unprotected steel construction in mind Building 1 is of Type II B construction. 
“A” Wing is two stories, one at grade and one above with a roughly 4' by 4' utility tunnel running around the perimeter and below grade. " $\mathrm{B}$ ” Wing is one story throughout, though the Auditorium (B105) has a projector mezzanine; there is also a utility tunnel under " $\mathrm{B}$ " Wing. "C" Wing is one story with a full basement below grade. Access to the basement is through two interior stairwells, one exterior stair, two exterior airway (ventilation only), and through a connection to the "D" Wing basement. "D” Wing is similarly a single story with a partial basement under the North-South leg. Access to the " $\mathrm{D}$ ” Wing basement is through one interior stairwell, two exterior airways (ventilation only), a freight elevator and a hoistway, and a connection to the "C" Wing basement.

\section{Occupancy Classification}

The occupancy of Building 1 is mixed with the majority of the structure being classified as business (Group B) and houses mostly office space. Building 1 does have two assembly areas a lecture hall classified as an A-3 occupancy with an occupant load of 156 and a small cafeteria that would be classified as an A-2 occupancy with an occupant load of 91. Using Table 508.4 Required Separation of Occupancies (IBC 2012) (6) the required separation between a group B and group A for a sprinklered building is 1 hour.

The height of Building 1 is 22 feet above grade with one level below grade (14') these heights do not qualify Building 1 as a high rise building. (6)

\section{IBC 2012 Construction Requirements}

Using Table 503 Allowable Building Heights and Areas (IBC 2012) (6) to assess the required construction of the Group B building. The total area of the building is 81,000 square feet with two stories above grade. The first floor has square footage of 47,680 with the second floor having a square footage of 10,345 and the basement with a square footage of 23,221. The area of the first floor exceeds the allowable limits of all construction types except Type 1 construction, which as stated earlier Building 1 is not this type. So a building area modification has to be done in accordance with Section 506 of the IBC. (6)

$$
\begin{aligned}
& A_{a}=\left\{A_{t}+\left[A_{t} X I_{f}\right]+\left[A_{t} X I_{s}\right]\right\} \\
& A_{t}=23,000 \text { Type II B } \\
& I_{f}=[F / P-.25] W / 30 \\
& F=1321 \\
& P=1768
\end{aligned}
$$

$\mathrm{W}=30$ the frontage width varies along the perimeter but all widths are over 30 feet.

$\mathrm{I}_{\mathrm{f}}=.5$ 
$I_{s}=2$ (Section 506.3 IBC states a two story building fully sprinklered gets an increase of 2)

$A_{a}=23,000+(23,000 \times$. .5) $+(23,000 \times 2)=80,500>47,680$ feet of the first floor.

All construction types could be used but Type V B is eliminated based on allowable area.

\section{Structural Fire Protection Requirements}

Due to the un-protected steel joist in the floor/ceiling assemblies this building is of Type II B construction. The requirements for this type of construction can be found in table 601 of the IBC (6). Type IIB has no fire resistance ratings that need to be achieved by the IBC. Plus with the lack of exposures to Building 1 there are no exterior wall fire resistance ratings that need to be applied.

\section{Code Compliance}

Although Building 1 was built in the 1970s it is my opinion that from a structural stand point it still meets 2012 building code and could easily have its construction type upgraded if there were ever the need.

In regards to the 1 hour separation required between the assembly areas and the business areas, it is believed that the original construction meets this requirement with the use of cinderblock walls and rated doors. However it has been an institutional issue that rated walls like these have often been breached as building components have been upgraded or decommissioned. One would have to assume this is the case for these rated separations until a proper inspection has been completed which is beyond the limits of this analysis.

\section{Fire Safety Plan for Technical Area 53 Building 1}

Procedure for Reporting Fires and Evacuation of Building

Reporting Fires

(From LANL Emergency Procedures and Protective Actions) (7)

Initial emergency reporting must be made promptly, accurately, and effectively by any on-scene observer/worker who is knowledgeable of the event. The worker must call:

- 911 for life threatening events such as a person needing medical attention or a fire,

- Workers should provide a description of the emergency, location, and protective actions taken (evacuation/sheltering).

- if applicable, response teams in the facility, and

- line/facility management and/or local Operations Center, where applicable.

\section{Building Evacuation}

(From LANL Emergency Procedures and Protective Actions) 
The purpose of evacuating a building is to remove oneself from danger such as a chemical spill, fire, suspicious package, bomb threat, or other emergency event that is within the building. It is important that all LANL workers be familiar with the evacuation procedure and posted emergency evacuation diagrams for the building that is their primary place of employment as well as other areas that they frequent.

Once a worker has received a notification to take protective actions, under no circumstances should he or she return to a hazardous area or building to perform sweeps, make notifications, or collect belongings. Building-specific emergency/facility plans may provide additional information.

If it is unsafe to go outside (e.g., due to lightning), evacuees will make a safe, secure, and responsible decision. The best course of action may be to evacuate to another building, or to personal vehicles in the parking lot.

Upon hearing the notification to evacuate, all occupants will evacuate the building immediately, if safe to do so, and perform the following with minimal delay:

1. Evacuate the building

- If accessible and safe to do so, take coats, hand bags/briefcases, and car keys in the event re-entry to the building is not allowed, or there is inclement weather.

- DO NOT carry food, drinks, or items that, if dropped, could inhibit safe egress and cause slips, trips, or falls.

- If the route is blocked by unsafe conditions, take the nearest safe path out of the building.

- DO NOT deviate from the exit route to sweep an area.

- DO NOT use the elevator.

2. Sweep while evacuating

Sweeping is the action of paying attention while evacuating. The steps for sweeping are the following:

- Conduct a visual sweep along the route between the work location and the building exit.

- Knock on office doors that are closed or locked, shout loudly to evacuate.

- If safe, open doors and shout "evacuate" in areas such as restrooms, locker rooms, conference rooms, etc., or anywhere a facility occupant could be unaware of an emergency condition.

- Pay attention to anything that may assist with the timely rescue of personnel or identify the source of the emergency event.

- Notify the AAL of any person needing assistance to evacuate.

3. Assemble at the designated Assembly Area (AA) for accountability. Accounting for all persons after emergency evacuation is essential. When gathering at the AA, workers must:

- Be aware of and give the right-of-way to responding emergency vehicles and personnel. 
- Provide the Assembly Area Leader (AAL), applicable local Operations Center, or IC with any information (e.g., smoke, pool of water, person-down, strange odor, hazardous conditions) obtained during the sweep.

- Provide information regarding any resident who is absent or missing from the AA to the AAL, applicable local Operations Center, or IC.

- Remain at the designated AA for further instructions or until the "All Clear" signal is given by the IC or designee.

- NOT re-enter the building until instructed to do so by the AAL or applicable local Operations Center (who will be instructed by the IC).

Note: Some emergency events may deteriorate rather than improve. If this is the case, the IC or building residents will determine the need to move a population from their initial AA or shelter location to a relocation center, or move uphill or upwind of the event. The AAL or applicable local Operations Center will report accountability and status of personnel back to the IC.

4. Report the event to the IC or EOC via the AAL, runner, radio, or phone call. The following should be conveyed in the report:

- Why evacuated, accountability, and changes in AA

- Observed hazards or unusual conditions

- Any known injuries

- Status of critical equipment/operations

5. Additional information from the IC will be relayed to the AAL such as all clear, etc.

6. Return to normal operations

Returning to normal operations is the point at which the IC turns the facility back over to the facility personnel (typically the FOD or designee). Facility personnel must participate in a faceto-face briefing with the IC to determine if recovery tasks must be completed. The IC or the facility personnel will then direct workers to return to the building so operations may resume. Workers must not return to the building until they have received the "All Clear" from the IC. The IC may provide the facility personnel/AAL the "All Clear” to provide to building residents.

Any worker having a permanent or temporary special need that may hinder his or her evacuation must notify his or her line manager. The line manager will assign a co-worker(s) to assist the worker during all emergency events including, but not limited to, drills and real events requiring evacuation or sheltering.

Workers assisting others should:

- Always ask someone with a disability how they can be of help before attempting any rescue technique or giving assistance.

- Assist special needs individuals out of the building using the nearest exit.

- If unable to exit the building, and if safe to do so, assist the individual to the nearest exit stairwell or safe area of refuge, and inform emergency personnel of the situation.

- Notify the AAL/IC. 
All guests, visitors, and outside personnel (including subcontract and crafts workers, maintenance workers, delivery personnel, or persons attending a meeting) conducting business in a building are responsible to ask for evacuation information or to follow a resident during an evacuation. If an emergency evacuation occurs, building residents should consider escorting visitors and ensuring visitors know they can follow the resident out of the building. 
Site Plan

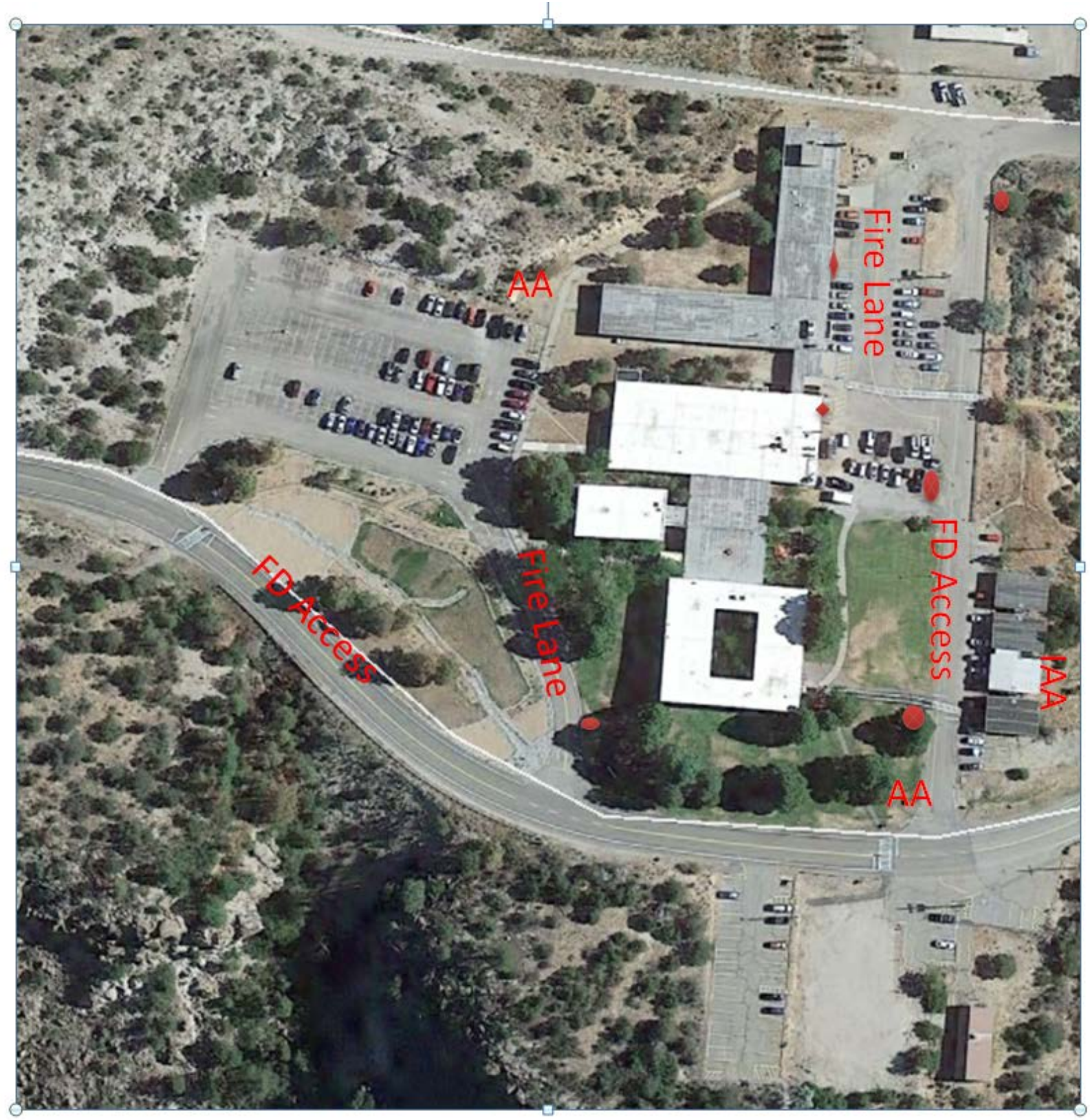

Figure 1 Site Plan

AA $=$ Assembly Area

IAA = Inclement Weather Assembly Area

= Fire Hydrant

$=\mathrm{FDC}$ 


\section{Emergency Evacuation Routes}

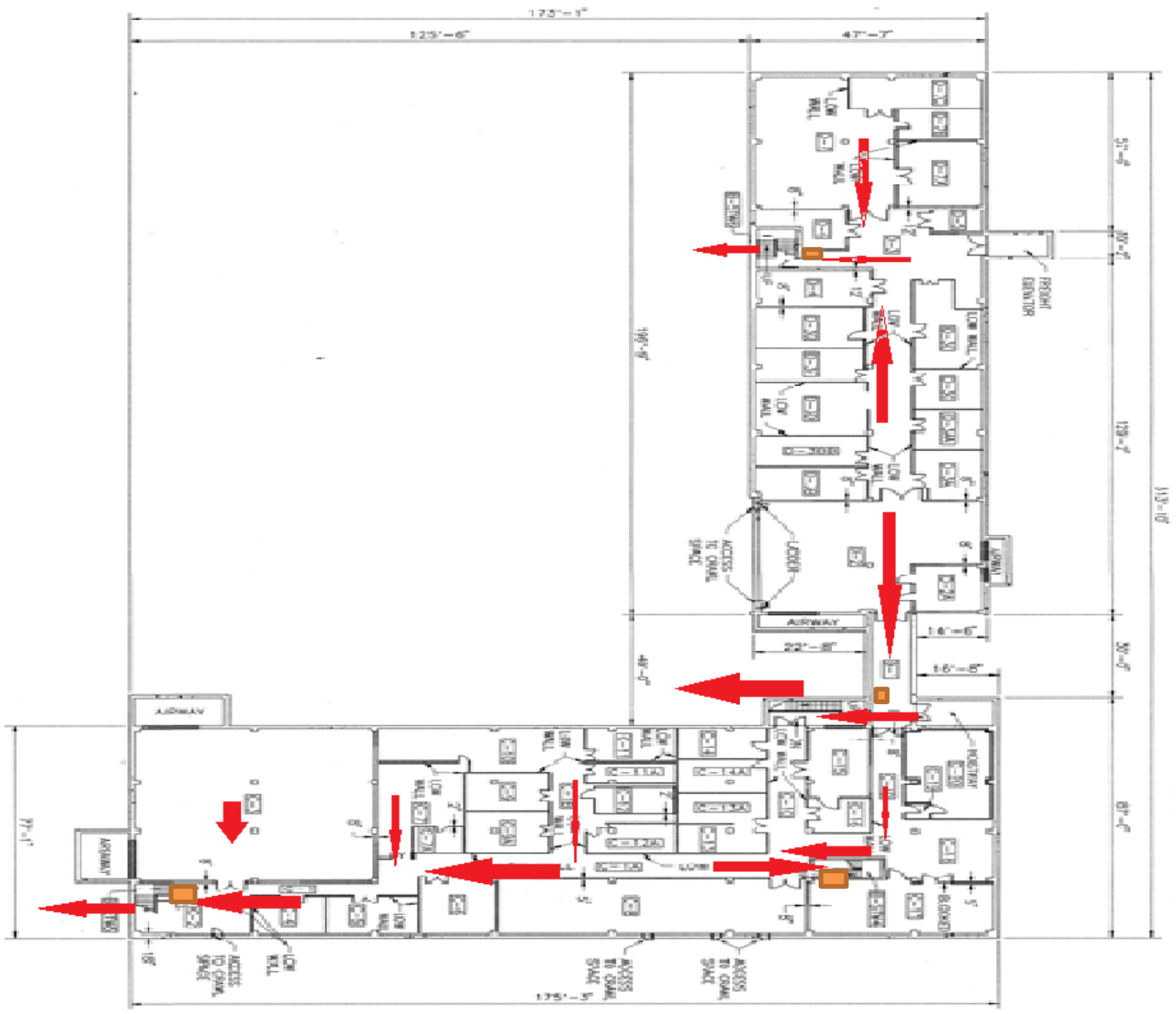

Figure 2 Basement Egress

$=$ Pull Station 


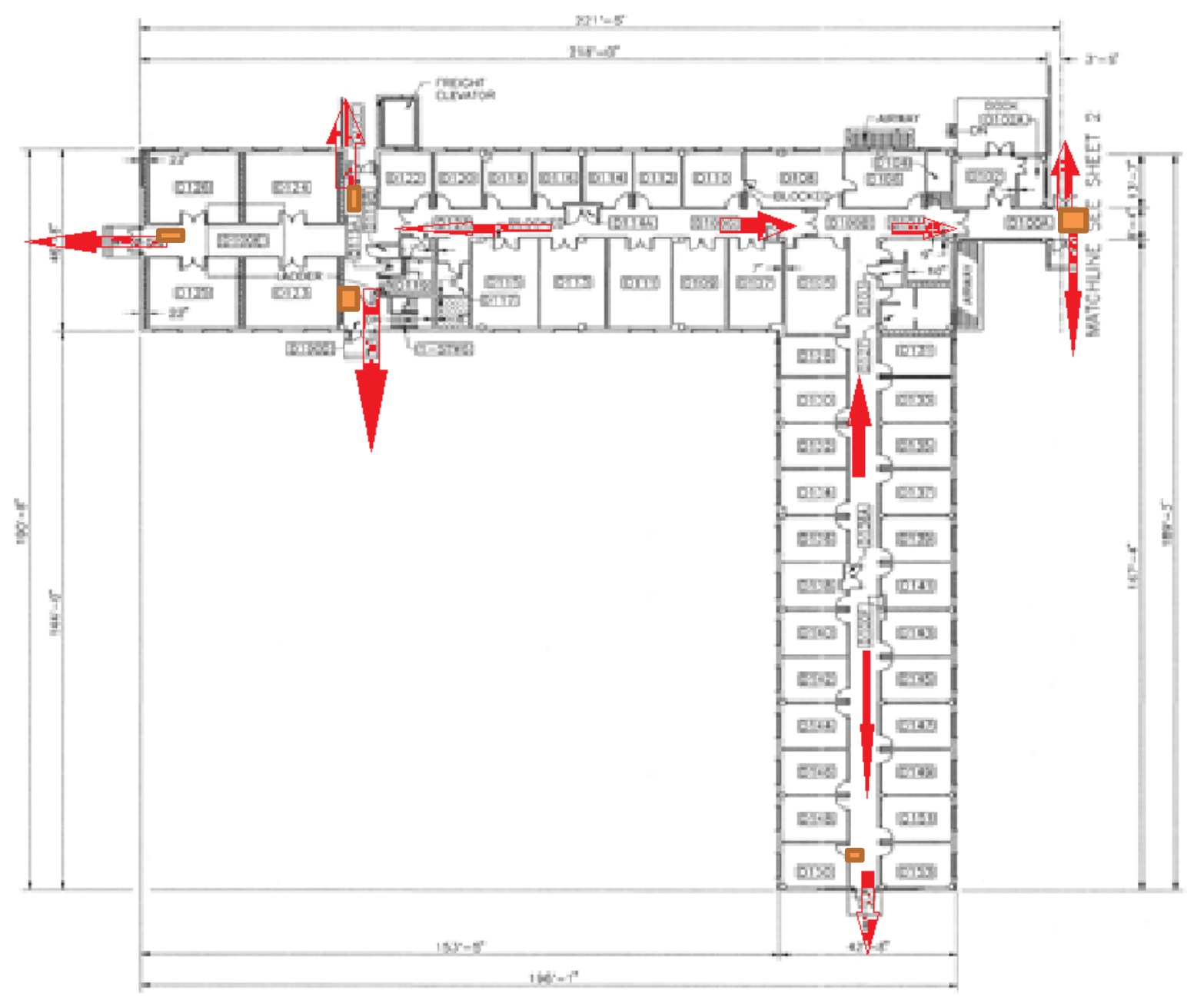

Figure 3 "D" Wing Egress 1st Floor

$=$ Pull Station 


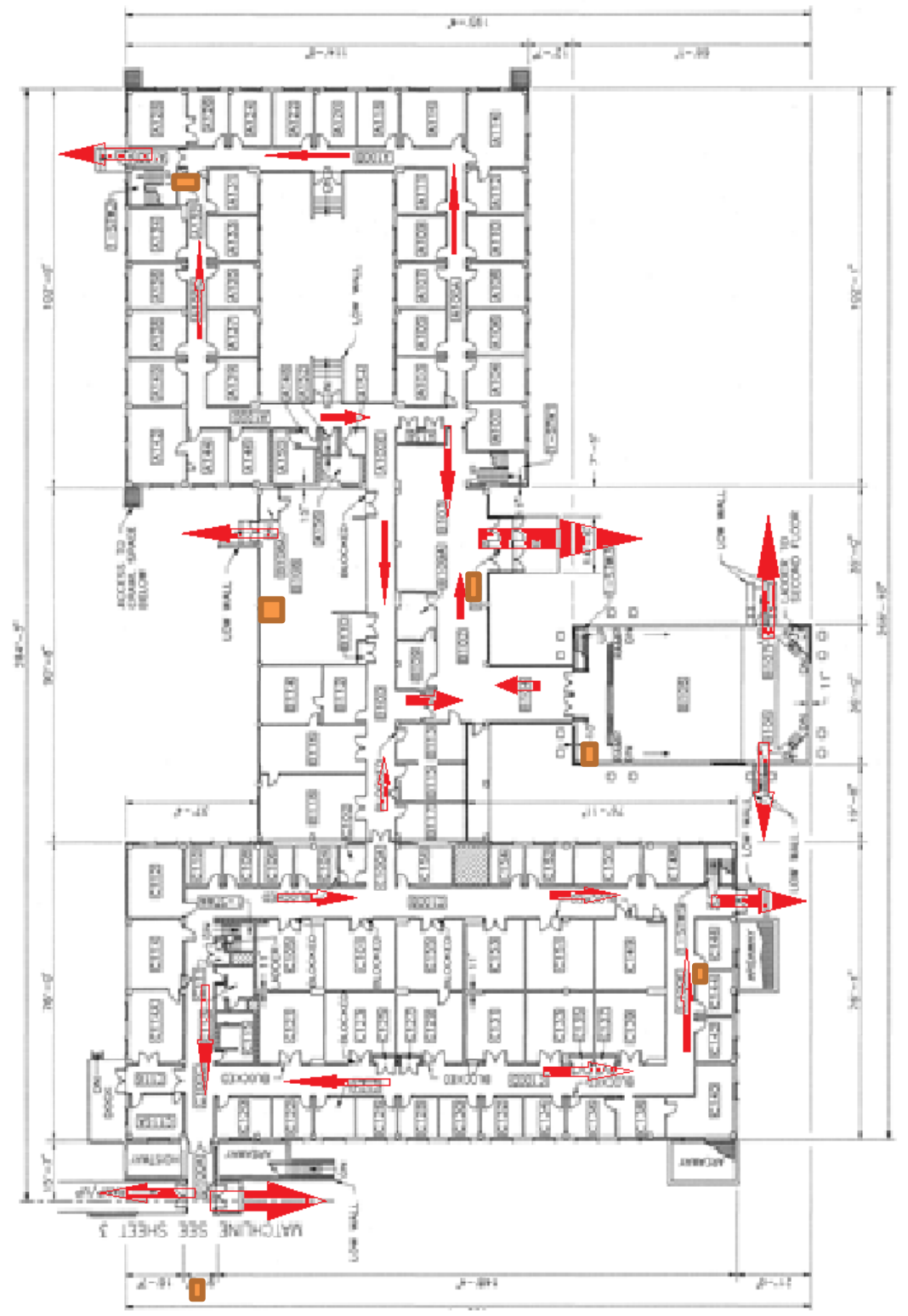

Figure 4 First Floor Egress

$=$ Pull Station 


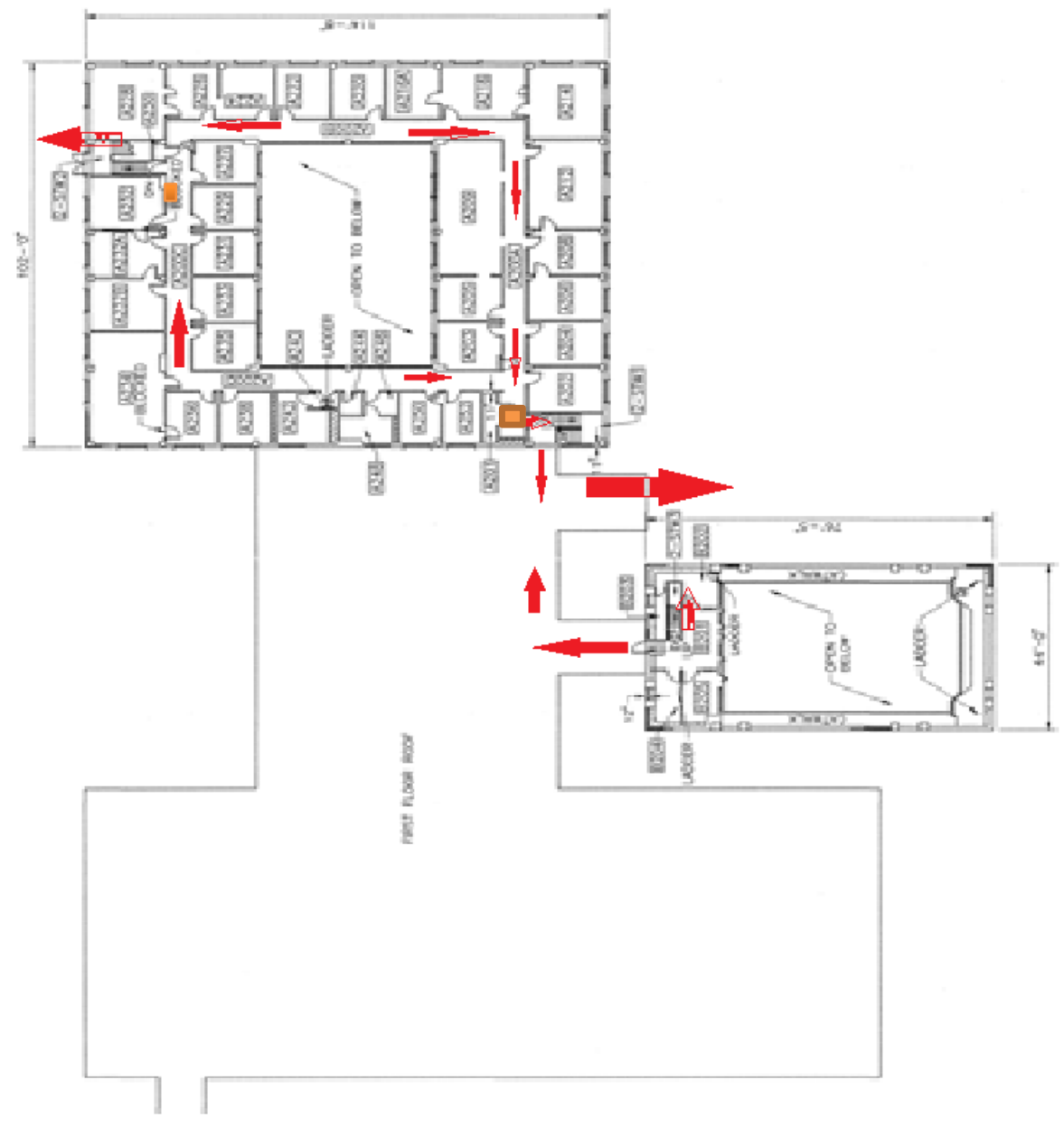

Figure 5 Second Floor Egress

$=$ Pull Station 


\section{Fire Hazards}

The fire hazards in the facility are generally consistent with business occupancies and those in physical laboratories with the possible exceptions of those outlined in this section.

Some building areas have accumulated a considerable number of combustible and flammable liquids containers with relatively small quantities of liquids. The vast majority of these containers are stored in flammable liquids cabinets. All uses of the combustible and flammable liquids appear to be incidental to the primary function of the areas located.

Because the liquids are properly stored, their use is incidental, and their quantities are relatively low, the hazard is expected to be controlled by the fire sprinkler system, as installed.

Lasers are used within the facility and do add an additional ignition hazard, however the configurations of the lasers and laser use procedures reduce these risks to an acceptable level.

The commercial kitchen is a hazard to the building and occupants as it contains deep fryer and gas fire grills and ovens. These hazards have been properly addressed with a compliant suppression system designed specifically for these hazards.

Utility hazards associated with this facility are electrical and natural gas.

Natural gas enters the facility on the eastern side, directly adjacent to Room D104 and enters the " $C$ " wing through the basement level of the C-Wing stairwell. It is metered, pressure regulated, and then dispersed to the boilers, hot water heaters, and four areas in " $\mathrm{D}$ ” Wing. The " $\mathrm{C}$ ” Wing gas line feeds the boilers, hot water heaters and areas in the " $\mathrm{C}$ ” Wing.

The facility receives power from the LANL grid at $13.2 \mathrm{kV}$. There is a large transformer in the basement, Room C10 that steps this power down to 480V (3 Phase) for distribution throughout the facility. There are small electrical control closets dispersed throughout the facility and easily accessible to the main corridors.

The large transformer in the basement could pose a significant threat to the fire safety of the building. Oil-cooled transformer fires are relatively common and occasionally catastrophic. For this reason oil-cooled transformers are seldom installed inside buildings. On the positive, the oil (PCB Contaminated) originally used for cooling has been replaced by a less flammable fluid. 


\section{Performance-Based Analysis}

The performance based guide by SFPE was used for the analysis of Building 1 . The process is as follows:

Defining Project Scope

Identifying Goals

Defining Stakeholder Objectives

Developing Performance Criteria

Developing Design Fire Scenarios

Developing Trial Designs (Not completed. Evaluating an existing Structure)

Evaluating Existing Design against Performance Criteria. (7)

\section{Defining Project Scope}

The scope of this project is to evaluate the tenability and structural response of Building 1 during likely fire scenarios. Two types of modeling software will be used for this analysis. The first model will analyze the egress system of Building 1 to help determine the available safe egress time for Building 1, with the second model analyzing the effects of fire on Building 1 structural components and the egress system.

The hope of this analysis is to show that Building 1 in its current configuration will meet the goals of the Department of Energy (DOE) with regards to life safety and structural fire resistance. If all goals are achieved for this business occupancy with the use of the aforementioned modeling software then DOE can be relatively assured that the operations housed in Building 1 for Los Alamos National Laboratory will not be greatly affected.

\section{Identifying Goals and Defining Stakeholder Objectives}

Building 1 is predominately a business occupancy with some incidental assembly occupancy space. Building 1 does not house any mission critical processes, hazardous materials, or high value equipment that require extra protection from fire that would require special analysis to evaluate the effectiveness of current fire protection features. The effect of a fire in Building 1 is 
believed to only impact personnel who currently have office space inside Building 1 , as well as some incidental lab space and meeting space.

Building 1 is divided into 4 wings and it is further believed that a fire in one wing is not likely to have an effect on all four wings. A single fire would at most damage two adjacent wings. The configuration of Building 1 in effect reduces the likelihood of a total loss fire. Using these assumptions it is reasonable to assume that wings not close to a fire would be able to be operational with limited interruption. The wings that are affected by the fire would likely have limited damage and not be a total loss.

With the previous assumptions and the configuration of Building 1 it is likely that the down time for mission operations would be limited to personnel relocations or small lab space until the damaged portions of Building 1 could be repaired barring any structural fire damage. This limits the goals of this analysis to life safety and the prevention of structural damage to Building 1 .

The life safety goal will be as found in Chapter 5 of NFPA® 101 Life Safety Code ${ }^{\circledR}$.

"5.2.2 Performance Criterion. Any occupant who is no intimate with the ignition shall not be exposed to instantaneous or cumulative untenable conditions." (1)

The goal for Structural damage is to prevent flashover conditions for the likely fire scenarios that can be found in Building 1.

The SFPE Handbook of Fire Protection Engineering states that flashover is associated with compartment temperatures of $500^{\circ} \mathrm{C}$ to $600^{\circ} \mathrm{C}(8)$.

\section{Developing Performance Criteria}

The performance criteria for preventing structural damage is preventing temperatures from reaching $600^{\circ} \mathrm{C}$. At these temperatures the light weight concrete used in the construction of Building 1 loses roughly about $50 \%$ of its strength (8). Likewise the steel joists used in Building 1 also lose $50 \%$ of their strength at around $600^{\circ} \mathrm{C}(8)$.

The performance criteria for Life Safety will be based on occupant's ability to find their way to an exit. The limit for this has been determined for a large enclosure where the occupants may not be familiar with the building at a visibility of at least 13 meters (8). 
Table 2-4.2 Allowable Smoke Densities and Visibility That Permits Safe Escape

\begin{tabular}{lcc}
\hline $\begin{array}{l}\text { Degree of Famillarity } \\
\text { with Inside Bullding }\end{array}$ & $\begin{array}{c}\text { Smoke Density } \\
\text { (extlinction coefliclent) }\end{array}$ & VIslbillty \\
\hline Untamlllar & $0.151 / \mathrm{m}$ & $13 \mathrm{~m}$ \\
Famillar & $0.51 / \mathrm{m}$ & $4 \mathrm{~m}$ \\
\hline
\end{tabular}

Figure 6 Table 2-4.2 from SFPE Handbook Third Edition

A quick internet search of average height of males in the United States showed several sites that indicate that height to be 5 feet 9 inches. With this height in mind a 6 foot height or 2 meters above the finished floor seems like a reasonable distance at which to hold the 13 meter visibility distance.

Building 1's construction and current configuration will be found acceptable if during all of the likely fire scenarios modeled, the visibility within the egress system stays at or above 13 meters at a height of 2 meters above the finished floor for the required amount of time needed for safe egress as determined by the egress model and if flashover conditions are never attained during the fire event.

\section{Developing Design Fire Scenarios}

A survey of approximately 10 websites for the most common causes of fire in business occupancies resulted in the following list.

Table 10 Common Causes for Business Fires

\begin{tabular}{|l|l|}
\hline \multicolumn{1}{|c|}{ Cause } & \multicolumn{1}{c|}{ Number of times found in search } \\
\hline Open Flames & 1 \\
\hline Electrical & 5 \\
\hline Cooking & 1 \\
\hline Spontaneous Ignition & 1 \\
\hline Flammable and Combustible Materials & 1 \\
\hline Human Error & 3 \\
\hline Arson & 5 \\
\hline Smoking & 2 \\
\hline Hot Work & 1 \\
\hline
\end{tabular}

Open flames does not seem like a likely cause for a fire in Building 1 due to the restriction of the use of candles by the laboratory. One might assume that because Building 1 houses some lab space that open flames might be a factor, however Building 1's labs our electronics labs with no need for open flames plus most of the labs in Building 1 are no longer routinely used. 
Electrical fires were one of the most mentioned and seem like a likely cause for ignition in Building 1. One of the design fires will incorporate this cause into its scenario.

Cooking as a cause did not have huge support from the websites visited, but Building 1 does have a small commercial kitchen and although the hazards within the cafeteria are properly addressed a kitchen fire is not out of the realm of possibility. For this reason a scenario will be developed with cooking as the cause of ignition.

Spontaneous ignition such as oily rags not properly disposed of is not a likely fire scenario for Building 1 and will not be evaluated. This type of fire lends itself more to an industrial occupancy as opposed to the office space that is Building 1.

Flammable and combustible materials are a plausible fire cause for Building 1 and will be a part of a design fire scenario.

Human error is a plausible fire cause for Building 1 and will be a part of a design fire scenario.

Arson was one of the most popular causes of fire in businesses, however Building 1 is located behind a guarded perimeter where access is only available by way of badge access or security guard. There is no business competition that would drive arson for hire. The likelihood of a disgruntled employee starting a fire is less due to the access restrictions. For these reasons arson will not be evaluated in a design fire scenario.

Smoking as a cause seems like a plausible fire cause but due to it being heavily restricted and enforced on laboratory property it most likely is less of an issue than in other areas.

Hot work does seem as though it would have a high likelihood as a cause for fire in Building 1, but due to the age of the building and its components it is likely that some refurbishment may need to be done in the mechanical areas of the basement resulting in hot work. Hot work will be a component of a design fire scenario.

\section{Design Fires}

Because the assumption is that a fire in one wing of Building 1 will not involve all of the wings of Building 1. One design fire for each wing and one for the basement were developed using the common causes of fire for businesses discussed earlier. Another assumption made was that all fires happen in occupied areas, therefore it is assumed that notification is made by pull station almost immediately upon the onset of the fire.

\section{Basement Fire}

The design fire that was developed for the basement is based on inspection and the potential for such a scenario to happen. In the basement of "C" wing by the west stairway there is a small room created with low walls approximately 7 feet high. Within this space a 3 foot high stack of flattened corrugated cardboard was found. Also above this space is duct work for the HVAC system for Building 1. 
The scenario developed is that due to the age of the building and nature of the basement being a mechanical area an upgrade to the duct work is needed in the area defined above. This work will require some hot work and while procedures and inspections of the area are required before work begins human error gets involved and not all the hot work precautions are followed which can lead to the ignition of the 3 foot high stack of corrugated cardboard.

The location of this fire will challenge the egress system from the basement as well as have the potential to challenge the egress from the first floor. Additional assumptions for this scenario are that the normally closed door at the top of the stairs is open throughout the duration of the fire making this a true worst case incident.

Wing “D” Fire

The wing " $D$ " fire scenario involves the use of flammable liquids in a laboratory setting. This fire will have a liter of ethanol pool fire. This is the likely scenario that a wash bottle of ethanol with an unsecured lid is knocked over on a lab bench and the contents come in contact with hot equipment in the area igniting the pool of ethanol. This fire will be located in an area that will challenge a major intersection in the Wing " $\mathrm{D}$ " egress system and will assume a worst case of the doors to the fire room being open and staying open throughout the fire.

Wing "C" Fire

The wing "C" fire scenario involves the careless placement of a winter coat in close proximity to a space heater. This fire will represent the more human error but this time in an office setting. This fire will be located in an area that will challenge an intersection in the Wing "C" egress system and will assume a worst case of the doors to the fire room being open and staying open throughout the fire.

Wing "B" Fire

The wing " $\mathrm{B}$ " fire will be a kitchen fire located in the cafeteria. This scenario encompasses the largest hazard associated with Wing " $\mathrm{B}$ ". This fire will have both the sprinkler system operational and the wet chemical suppression system operational to show if the hazards are properly addressed. The fire will be a deep fat fryer fire.

\section{Wing A/B Fire}

The Wing "A/B" fire will be a wastebasket fire in an office setting. The office will be located on the first floor near the east exit and east stairwell. Again all doors will be open to represent the worst case conditions. A fire in this area has the potential to completely render half the egress system for Wing “A/B”.

This fire will represent an overloaded electrical outlet located next to a small recycle waste paper basket. 


\section{Analysis}

\section{Models}

FDS is the fire and smoke modeling software that will be used for the following analysis. FDS was developed at the National Institute of Standards and Technology (NIST) (9). "FDS simulates fire scenarios using computational fluid dynamics (CFD) optimized for low-speed, thermally driven flow" (9). For this analysis PyroSim was used as an interface with FDS to build the models and fire scenarios. PyroSim is a graphical user interface for FDS (9). This interface provides immediate input feedback and ensures that the FDS input file used is correct (9).

PyroSim was used to build and run the fire scenarios described above. This software allowed quick feedback on the developed scenario to make sure that the model was set up correctly based on the inputs through PyroSim. This function was very helpful in identifying areas within the model that needed attention.

Pathfinder was used for the calculation of total amount of time it takes all of the occupants of Building 1 to exit the building, also known as the required safe egress time. "Pathfinder is an agent passed egress and human movement simulator" (10) . Pathfinder was very helpful in showing visually what the previous egress calculations showed. Pathfinder shows a visual representation of the egress process during an egress event based on the imported parameters, both human and building.

\section{Egress Model}

A Pathfinder model was developed for Building 1 using drawing files. Each floor was drawn per its floor arrangement with all egress components built to connect the floors and exterior exits from Building 1. The Pathfinder model will show a visual representation of occupants before and during the building evacuation event. The only parameters were that occupants were to use the nearest available exit and were to start the exit process immediately. After the total time for all the occupants to exit had been calculated the pre-movement time discussed earlier was added to the model's time to make the total required safe egress time (RSET). This time will determine the length of time needed to run each fire scenario.

As stated before the likely occupant load for Building 1 with the lecture hall full is 1703 occupants. This was the number of occupants placed in the Pathfinder model with the aforementioned parameters. The Pathfinder model showed a total egress time of 144.3 seconds or roughly 2.5 minutes. The pre-movement time stated earlier as worst case was 3 minutes, when the 3 minute pre-movement time is added to the model's 2.5 minute required egress time the total RSET for Building 1 is 5.5 minutes. This 5.5 minutes will be the bounding time each of the fire scenarios will be evaluated against to determine if there is enough available safe egress time (ASET). 
Brett Noakes

June 2015

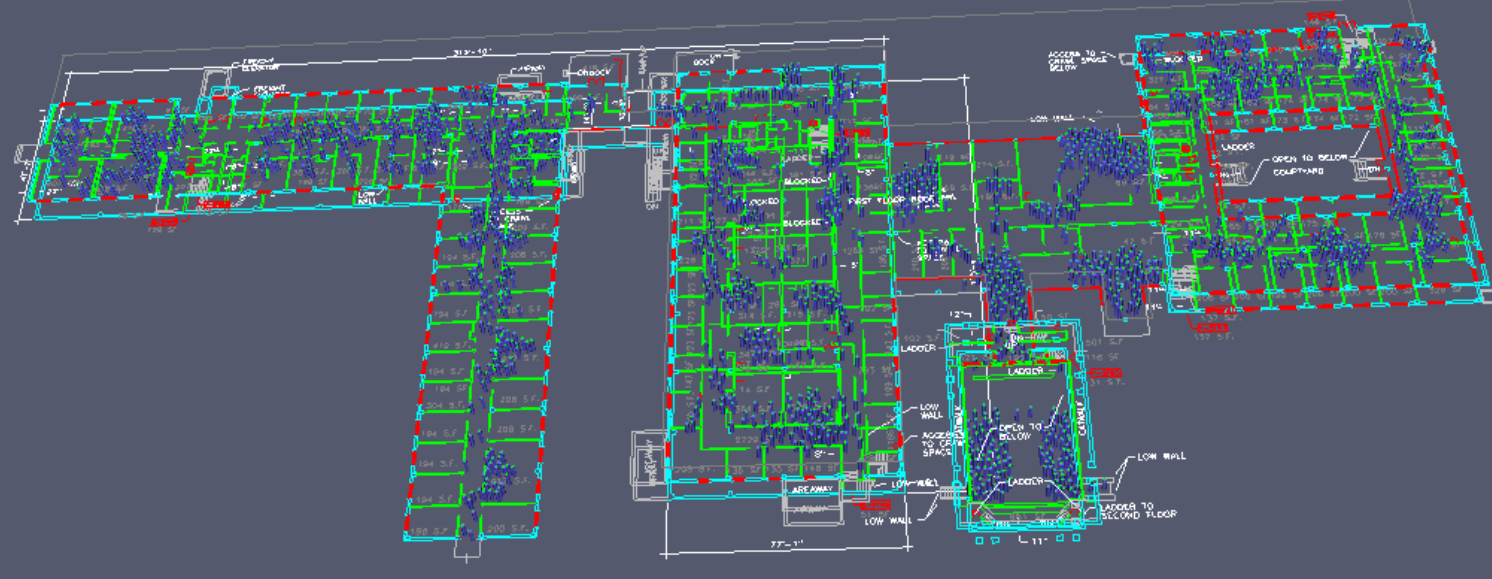

Figure 7 Pathfinder model at the beginning of egress simulation. 
Figure 8 Screen shot of Pathfinder model showing all three levels of Building 1.

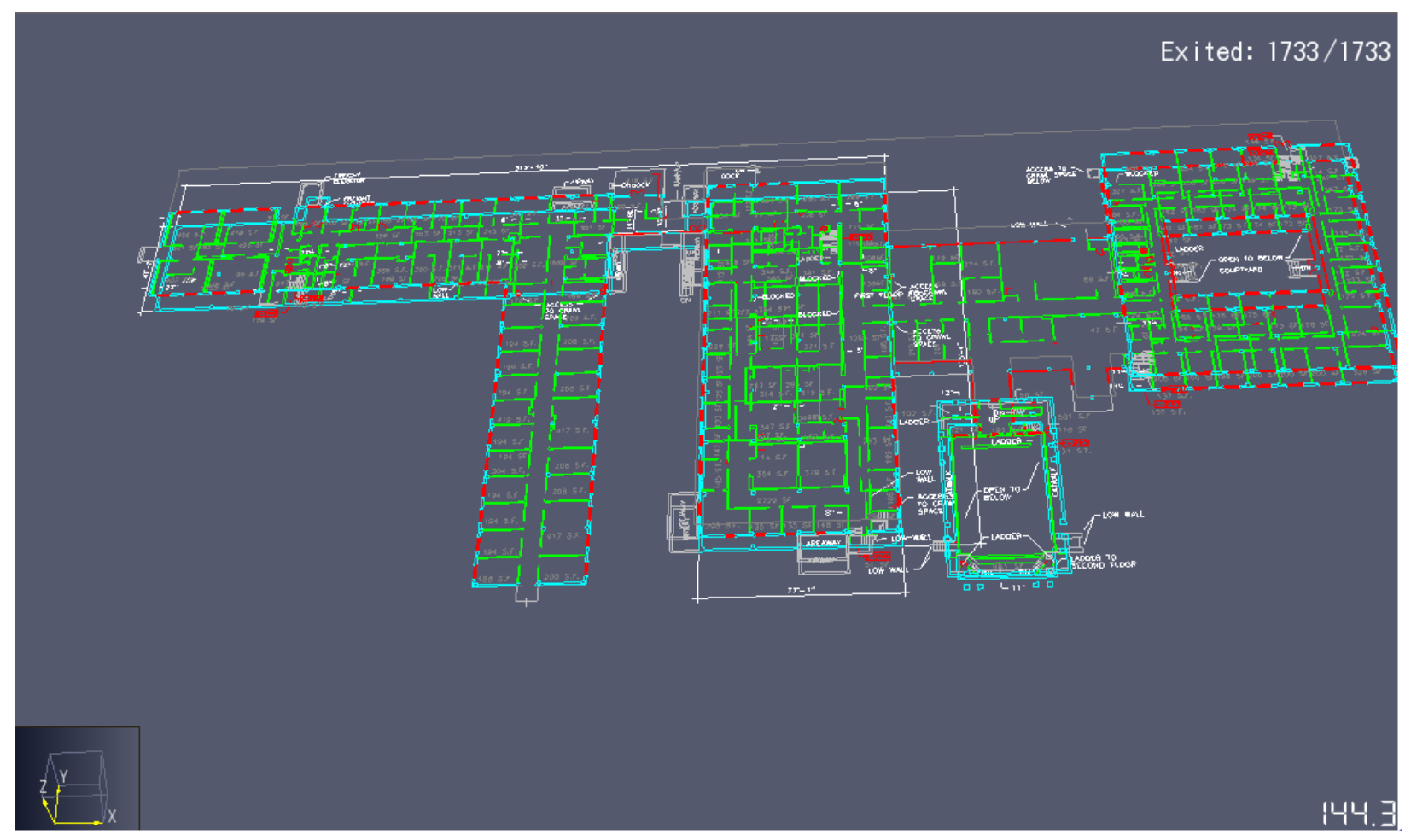

Figure 9 Pathfinder model showing all occupants have exited.

\section{Fire Analysis}

\section{Basement Fire Scenario}

The FDS model was built using PyroSim software with imported floor plans. The general layout of the fire area was constructed using the imported floor plan. All model meshes were set at .5 meters cubed. The use of smaller meshes was not feasible as using them made two computers crash.

\section{Model parameters:}

Room heights for this scenario where set at 14 feet for the basement area and 10 feet for the first floor corridor. Only the corridor for the first floor was constructed while the basement was constructed as a large open area aside from the room of origin. The majority of the basement area is partitioned with low walls; because of this construction, the smoke movement is assumed to accumulate undeterred like an open room.

The fire parameters for this model were developed using information found in the SFPA Handbook. The fuel package for this model will be a stack of corrugated cardboard boxes. The 
fuel package for this fire was at a height of 1 meter or about three feet in height; however the only data that could be found in the SFPA Handbook was for whole pallets or large stacks of like materials, for this reason some assumptions were made based on the data that was found in the SFPA Handbook.

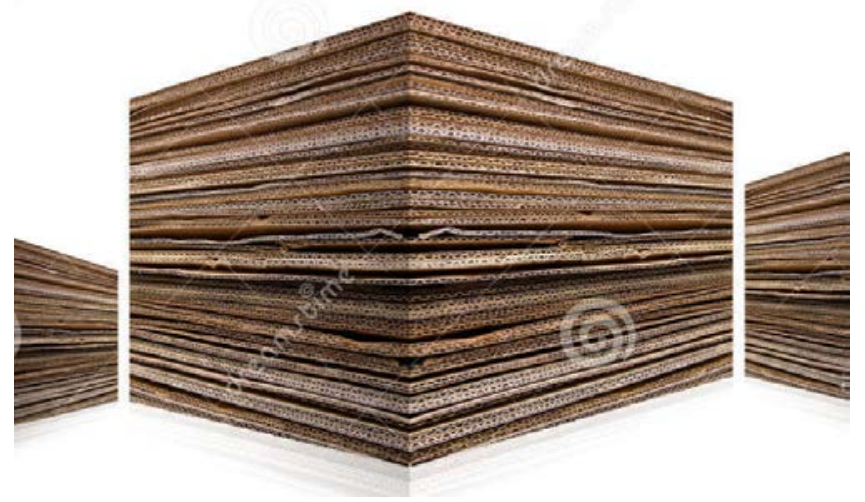

Figure 10 Photo of Similar Fuel Package from Dreamstime.com

SFPE Data:

\begin{tabular}{|c|c|c|c|c|}
\hline Test & Commodity & $\begin{array}{l}\text { Storage } \\
\text { Helght } \\
\text { (m) }\end{array}$ & $\begin{array}{c}\text { Peak } \\
\text { HRR } \\
(\mathrm{kW} \cdot \mathrm{m}-2)\end{array}$ & $\begin{array}{l}\text { Time of } \\
\text { Peak } \\
\text { (s) }\end{array}$ \\
\hline SP-4 & PS Jars in compartmented CB cartons & 4.11 & 16,600 & 439 \\
\hline SP-13 & PS foam meat trays, wrapped in PVC film, in CB cartons & 4.88 & 10,900 & 103 \\
\hline SP-23 & PS foam meat trays, wrapped in paper, in CB cartons & 4.90 & 11,700 & 113 \\
\hline SP-30h & PS toy parts in CB cartons & 4.48 & 5,210 & 120 \\
\hline SP-35 & PS foam insulation & 4.21 & 26,000 & 373 \\
\hline SP-44 & PS tubs in CB cartons & 4.17 & 6,440 & 447 \\
\hline SP-15 & PE bottles in compartmented $\mathrm{CB}$ cartons & 4.20 & 5,330 & 434 \\
\hline SP-22 & $\mathrm{PE}$ trash barrels in $\mathrm{CB}$ cartons & 4.51 & 28,900 & 578 \\
\hline $\mathrm{SP}-43$ & PE bottles in CB cartons & 4.41 & 4,810 & 190 \\
\hline SP-6 & PVC bottles in compartmented CB cartons & 4.63 & 8,510 & 488 \\
\hline SP-19 & PP tubs in compartmented $\mathrm{CB}$ cartons & 4.26 & 5,870 & 314 \\
\hline$S P-41$ & Compartmented CB cartons, empty & 4.51 & 2,470 & 144 \\
\hline RS-2 & 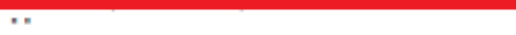 & 2.95 & 1,490 & 89 \\
\hline RS-3 & $\cdots$ & 2.95 & 1,680 & 180 \\
\hline RS -4 & $\cdots$ & 4.47 & 2,520 & 120 \\
\hline RS-5 & . & 4.47 & 2,250 & 240 \\
\hline RS-6 & $\cdots$ & 5.99 & 3,260 & 210 \\
\hline RS-7 & PS cups in compartmented CB cartons & 2.90 & 4,420 & 95 \\
\hline RS- 8 & $\cdots$ & 2.90 & 4,420 & 100 \\
\hline RS-9 & $\cdots$ & 2.90 & 4,420 & 120 \\
\hline RS- 10 & $\cdots$ & 4.42 & 6,580 & 100 \\
\hline RS- 11 & $\cdots$ & 5.94 & 8,030 & 148 \\
\hline
\end{tabular}

$\mathrm{CB}$, cardboard; $\mathrm{PE}$, polyethylene; $\mathrm{PP}$, polypropylene; PS, polystyrene; PU, polyurethane

Figure 11 Table 3-1.5 HRR Values of Palletized and Rack Storage Commodities Tested at FMRC for SFPE Handbook Third Edition

The data shows a peak Heat Release Rate (HRR) of 2,470 kw/m² for a 4.5 meter high stack of empty cardboard. The fuel package in this scenario is 1 meter as found, so dividing the peak 
HRR by four reduces the HRR to $617 \mathrm{kw} / \mathrm{m}^{2}$ which is what was used in the model. It is understood that a linear relationship between height and HRR does not exist but it is safe to assume that less fuel will produce a smaller peak HRR.

The next step was to find a HRR curve that for a similar type of fuel. One was found in Figure 3.1.42 of the SFPE Handbook Fourth edition. Using the SCEA std, Curve which had a peak of about the same $2400 \mathrm{~kW}$ all that was needed was to adjust the curve to the time constraints set by the scenario. The SCEA curve reached its peak at 600 seconds however its HRR was at 0 at the 500 second mark so the model started basically at the 500 second mark.

Table 11 Model HRR Inputs for Fire Growth

\begin{tabular}{|c|c|}
\hline Time (seconds) & Fraction of Peak HRR \\
\hline 25 & $10 \%$ \\
\hline 50 & $20 \%$ \\
\hline 100 & $100 \%$ \\
\hline 150 & $70 \%$ \\
\hline 200 & $50 \%$ \\
\hline 250 & $20 \%$ \\
\hline 300 & $10 \%$ \\
\hline
\end{tabular}

The room of origin is protected by two $212^{\circ} \mathrm{F}\left(100^{\circ} \mathrm{C}\right)$ sprinkler heads. These were placed as appropriate in the model.

The use of the model is to show the tenability of the area and the temperature of the room of origin so slice files were used to see the effects of the fire on the area. One temperature slice file was used in the middle of the room of origin to see if the $600^{\circ} \mathrm{C}$ threshold was exceeded. Two visual slice files were used to evaluate the distance one would expect to be able to see during the fire event for the duration of the RSET time of 5.5 minutes. These were placed 6 feet above the floor on both the basement level and the first floor.

The figure below shows the highest temperatures attained in the room were at $270^{\circ} \mathrm{C}$, well below the 600 degree threshold. The highest temperatures were achieved during the peak HRR. 


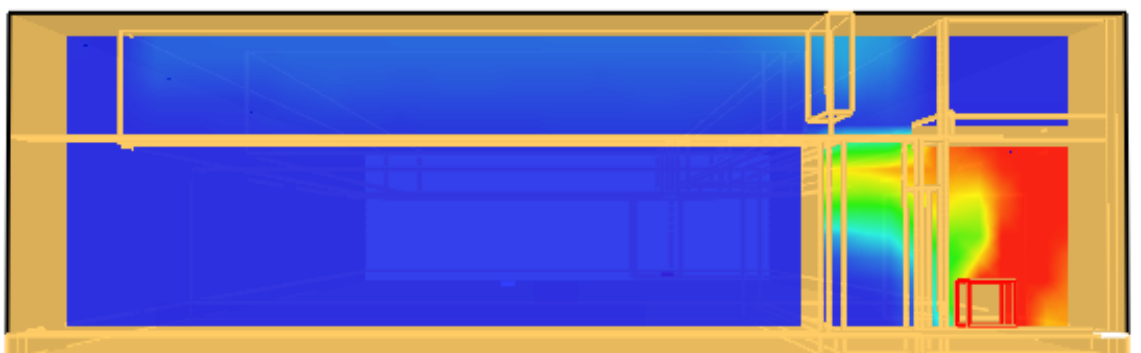

\section{Figure 12 Highest Temperatures for Basement Scenario}

The output files for this model show a sprinkler activation time of 54 seconds for the first sprinkler and 60 a second activation time for the second sprinkler in the room.

The visual distance one could be expected to see is demonstrated in the following figures. As one can see the basement did not meet the criteria of maintaining the 13 meters of visual distance as the visual distance of the basement dropped below 13 meters at around 240 seconds. The first floor corridor however never dropped below 15 meters throughout the analysis.

It could be argued that it is not likely for guests to be in the basement area of Building 1 and therefore the criteria of a 4 meter visual distance could be the threshold to consider. If this criterion were applied the basement level would have passed this analysis. For the purposes of this report it was determined that the basement level fire did not meet the performance criteria set by the stake holders and therefore additional steps need to be taken to remedy this scenario. Those steps would be to remove the fuel package from the basement to limit the fuel load in this area. 


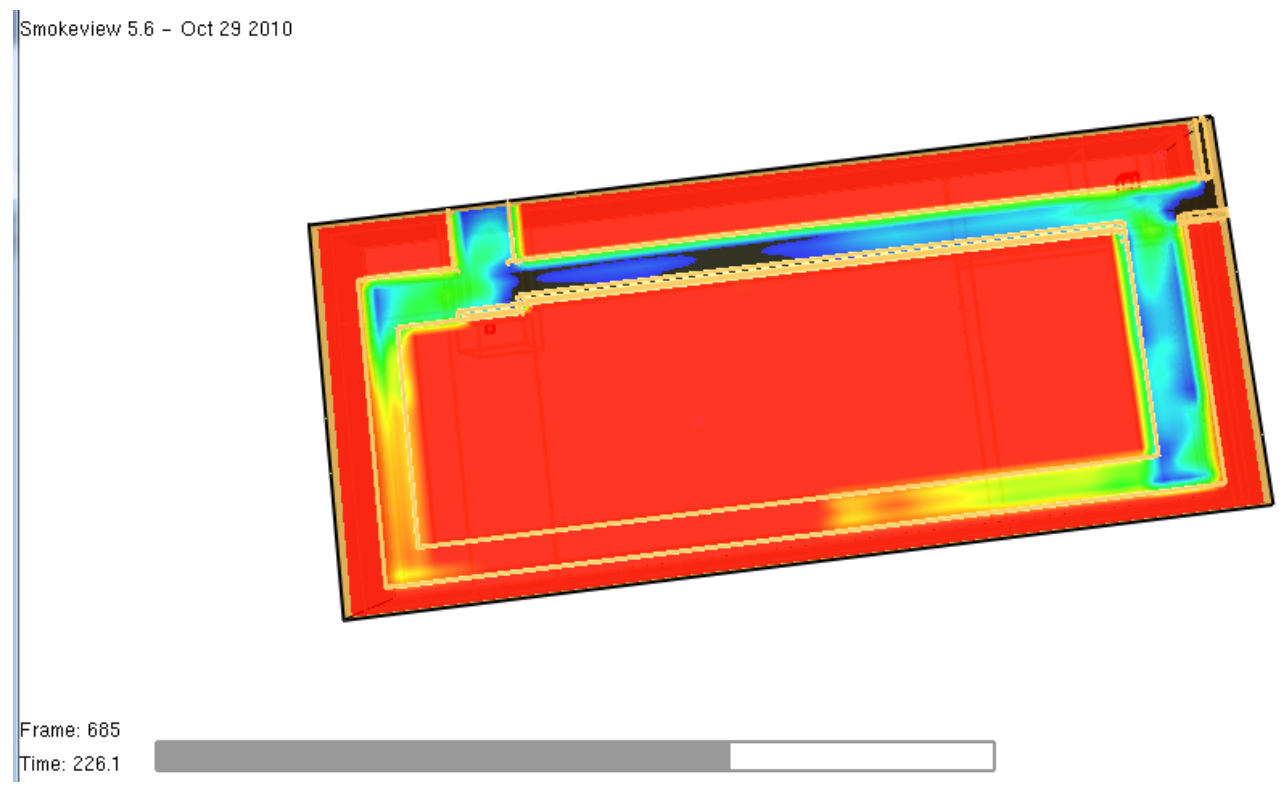

Figure 14 First Floor Visual Distance at 6 feet 


\section{Wing "D" Fire Scenario}

The FDS model was built using PyroSim software with imported floor plans. The general layout of the fire area was constructed using the imported floor plan.

\section{Model Parameters:}

Room heights for this scenario where set at 9 feet for the whole area. Only the corridor for the first floor was constructed and the room of origin. As stated in the scenario doors to the room are open throughout the fire.

The fire parameters where developed using a series of calculations found in the SFPE Handbook on flammable liquid spill fires.

First estimate the size of the spill.

$$
\begin{gathered}
A_{s}=\left(1.4 m^{2} / L\right) \mathrm{V} \\
\mathrm{V}=1 \mathrm{~L} \\
\mathrm{~A}_{\mathrm{s}}=1.4 \mathrm{~m}^{2}
\end{gathered}
$$

Second estimate the maximum possible fire size.

$$
\begin{gathered}
A=1.55 * A_{s} \\
A_{s}=1.4 \\
A=2.17 m^{2}
\end{gathered}
$$

Third calculate the heat release rate of Ethanol.

$$
\dot{Q}=\dot{m} * * \mathrm{~A}^{*} \Delta \mathrm{hc}
$$

$\dot{m} "=.022 \mathrm{~kg} / \mathrm{m}^{2} \mathrm{~s}$ form page $3-38$ of the SFPE Handbook (8) for Diameters of greater that .6m but less than $3.0 \mathrm{~m}$

$$
\begin{gathered}
\mathrm{D}=1 \\
\mathrm{~A}=2.17 \mathrm{~m}^{2}
\end{gathered}
$$

$\Delta \mathrm{hc}=26.8 \mathrm{MJ} / \mathrm{kg}$ from table 3-1.21 in the SFPE Handbook (8) for Ethanol

$$
\dot{Q}=1.27 \mathrm{MW}
$$

Fourth calculate the total burn time of the fire. 


$$
\begin{gathered}
\mathrm{t}_{\mathrm{b}}=\left(\mathrm{V}^{*} \rho\right) /\left(\dot{m^{*} * \mathrm{~A}}\right) \\
\mathrm{V}=1 \mathrm{~L}\left(1 \mathrm{~L}=.001 \mathrm{~m}^{3}\right)
\end{gathered}
$$

$\rho=794 \mathrm{~kg} / \mathrm{m}^{3}$ from table 3-1.21 in the SFPE Handbook (8) for Ethanol

$$
\begin{gathered}
\mathrm{A}=2.17 \mathrm{~m}^{2} \\
\mathrm{t}_{\mathrm{b}}=17 \text { seconds total burn time }
\end{gathered}
$$

From the above calculations the fire designed in the PyroSim has a peak HRR of $1270 \mathrm{kw} / \mathrm{m}^{2}$. It is also assumed that once ignited the pool fire will be at peak HRR for the duration of the fire with no ramp up. The fire will burn for 17 seconds and then extinguish once the fuel is consumed.

The room of origin is protected by six $100^{\circ} \mathrm{C}$ heads that were placed in the model appropriately. The room selected in the structure is located at the intersection of the two main corridors for Wing “D”.

The use of the model is to show the tenability of the area and the temperature of the room of origin so slice files were used to see the effects of the fire on the area. One temperature slice file was used in the middle of the room of origin to see if the $600^{\circ} \mathrm{C}$ threshold was exceeded. One visual slice file was used to evaluate the distance one would expect to be able to see during the fire event for the duration of the RSET time of 5.5 minutes, it was placed 6 feet above the floor. The rendering seen below shows that the highest temperature in the room was $111^{\circ} \mathrm{C}$ far below the $600^{\circ} \mathrm{C}$ threshold. 


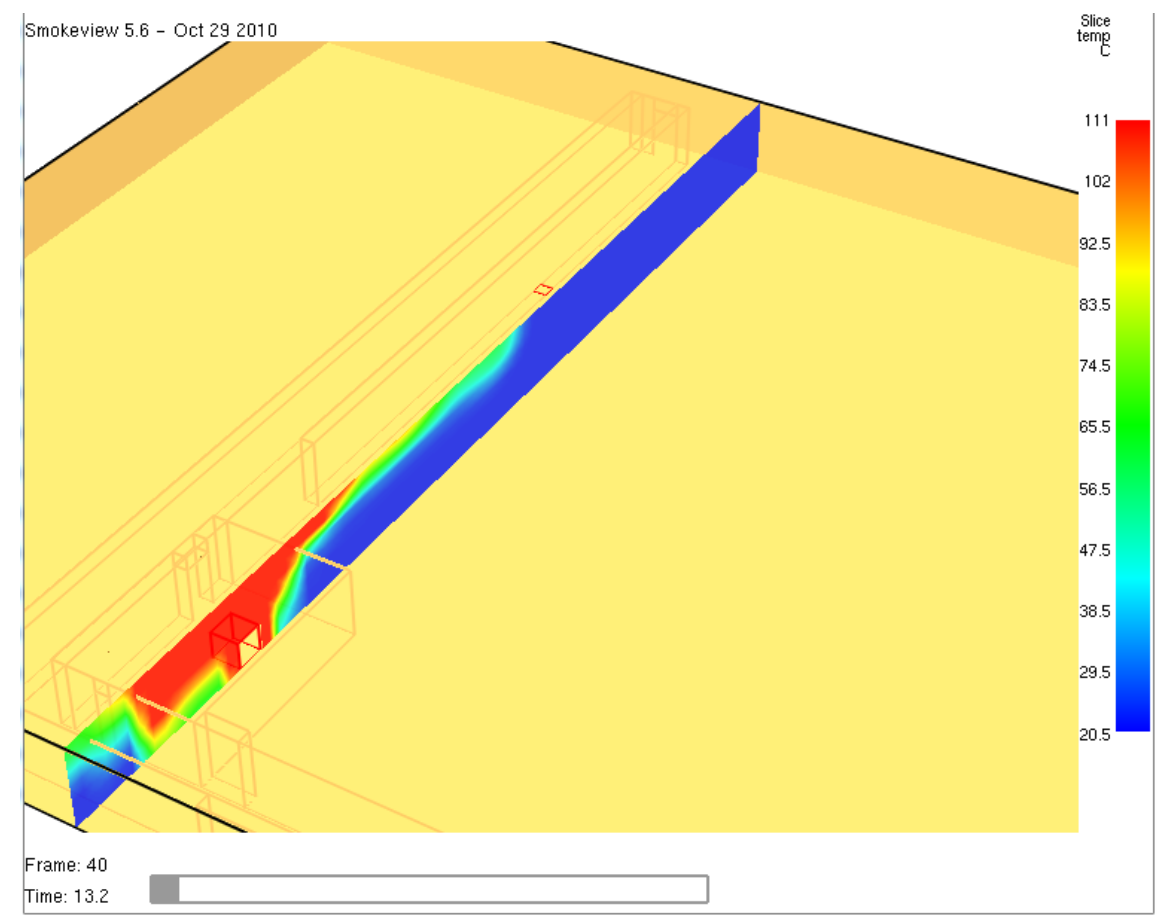

Figure 15 Temperature Slice for the Wind D fire

The rendering below shows that the visibility at 6 feet above the finished floor was only limited to 22.5 meters which is above the 13 meter threshold. 


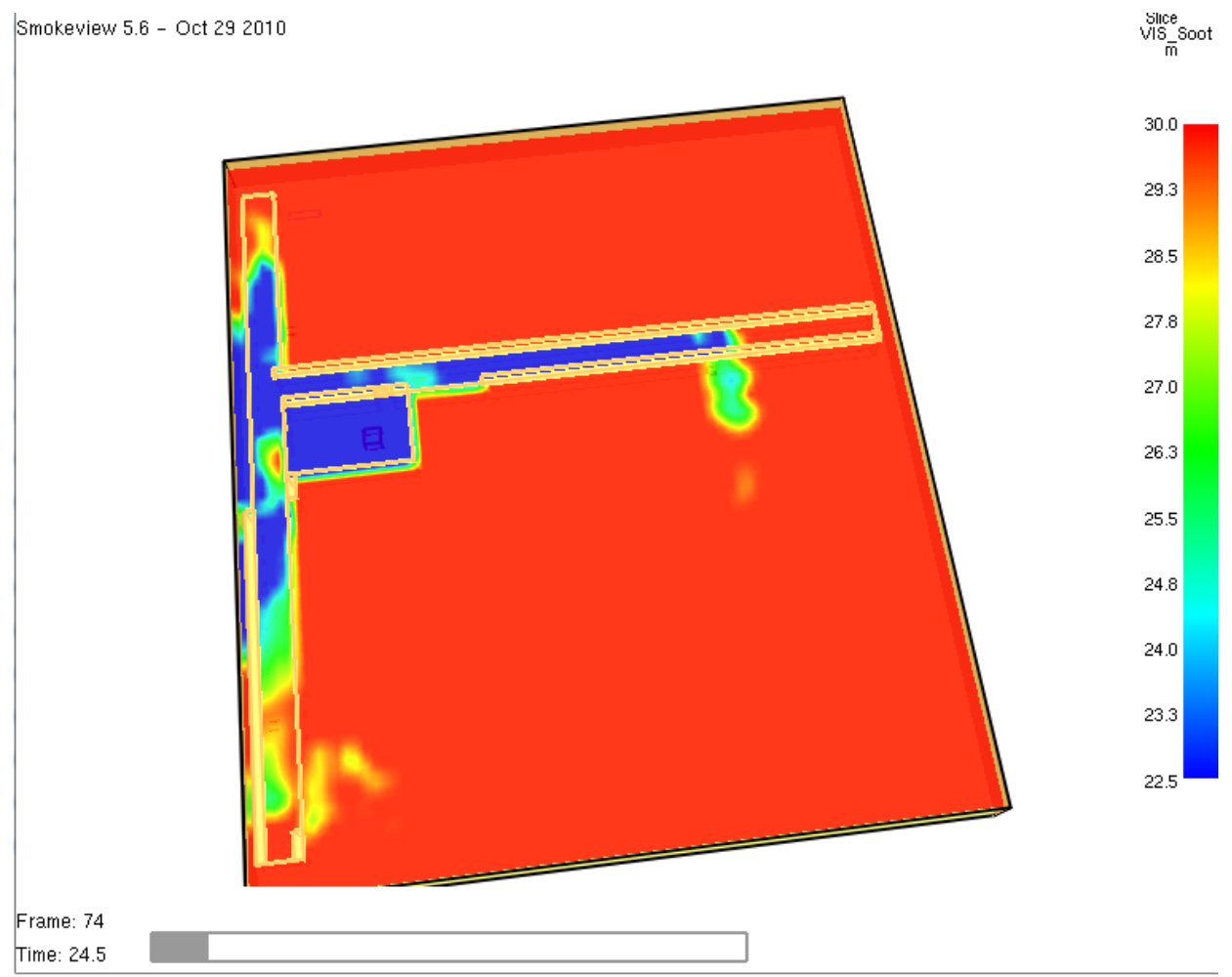

Figure 16 Visual Slice of the D Wing Fire at 6 Feet

The output files of the model show the first sprinkler discharge was 2 seconds into the event ultimately all sprinklers in the room activated.

The model shows that for this type of fire scenario Building 1's current configuration is acceptable.

\section{Wing "C" Fire Scenario}

The FDS model was built using PyroSim software with imported floor plans. The general layout of the fire area was constructed using the imported floor plan.

\section{Model Parameters}

Room heights for this scenario were set at 9 feet for the whole area. Only the corridor for the first floor was constructed and the room of origin. As stated in the scenario doors to the room are open throughout the fire.

The HRR curve that was used for this model simulated two jackets that have ignited by a nearby space heater is an office located in Wing "C". The office like the previous scenario is located at a major corridor junction in Wing “C”. 


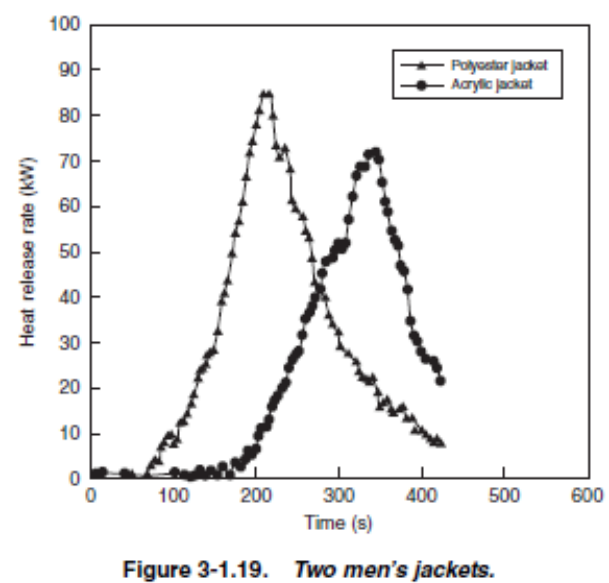

Figure 17 HRR Curve of Two men's Jackets from SFPE Handbook Third Edition The curve modeled was for the Polyester Jackets to show a worst case scenario. Below is the data that was input in the model to control the fire growth.

Table 12 HRR Inputs for the Wing C Fire

\begin{tabular}{|c|c|}
\hline Time (seconds) & Fraction of Peak HRR \\
\hline 0 & $0 \%$ \\
\hline 100 & $10 \%$ \\
\hline 175 & $75 \%$ \\
\hline 200 & $100 \%$ \\
\hline 250 & $60 \%$ \\
\hline 300 & $40 \%$ \\
\hline 350 & $10 \%$ \\
\hline
\end{tabular}

The rendering below shows that the room temperature of the Wing " $\mathrm{C}$ ” fire only reached a temperature of $85^{\circ} \mathrm{C}$ again far below the $600^{\circ} \mathrm{C}$ threshold. The model output files show sprinkler activation at 173 seconds. Only one of the two sprinkler heads located in the room activated. 


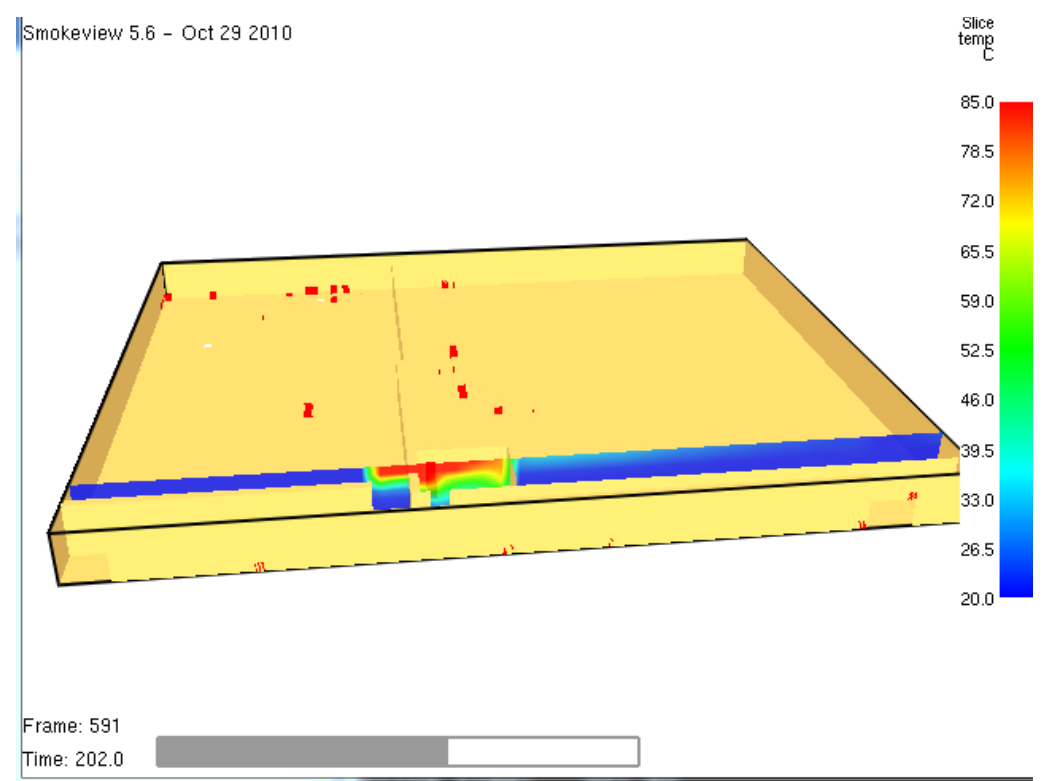

Figure 18 Temperature Slice of the Wing C Fire

The rendering below shows the visibility at 6 feet above the floor. As shown the visibility drops to 11.5 meters which is below the threshold set for this analysis. The argument can be made that if the 13 meter requirement is not maintained that it would cause persons unfamiliar with the building to turn and go another way. The way the egress system is set up in Building 1 it would allow individuals safe egress away or around the high concentration of smoke for the area located at the end of the corridor.

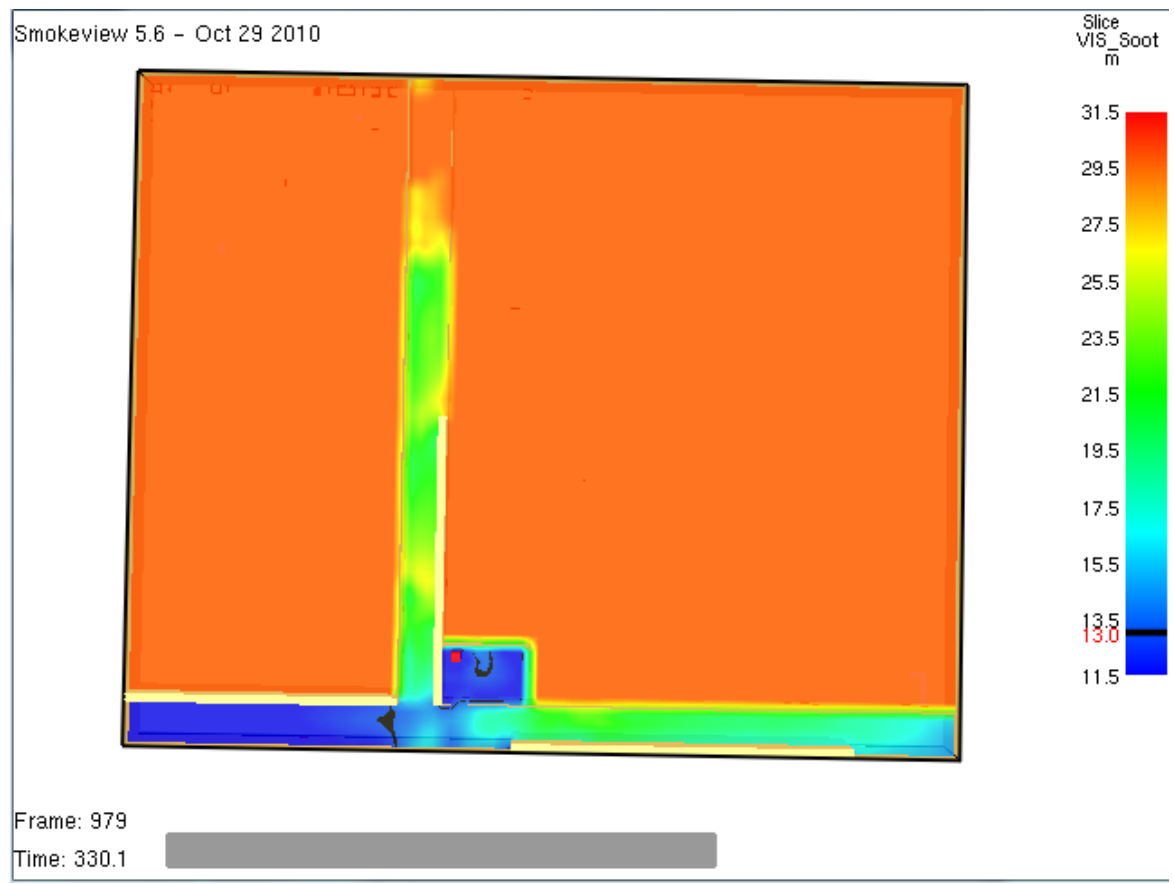

Figure 19 Visual Slice of the Wing C Fire at 6 feet. 
For the purposes of the analysis based on the limited experience of the evaluator with this modeling software this scenario should have additional modeling completed to further eliminate any errors that may have reduced the visibility.

\section{Wing "B" Fire Scenario}

The FDS model was built using PyroSim software with imported floor plans. The general layout of the fire area was constructed using the imported floor plan.

\section{Model Parameters}

Room heights for this scenario where set at 9 feet for the whole area. Only the corridor for the first floor was constructed and the room of origin and the main entrance area. As stated in the scenario doors to the room are open throughout the fire.

Online research was conducted to find appropriate data to import into the model for the design fire. During this research a draft paper was found by W.K Chow and Xiaomin Ni of China titled Experimental Evaluation of Performance of Open Kitchen Fire Suppression Systems (11). The report explains a series of experiments using a $25 \mathrm{~cm}$ pan with cooking oil heated electrically to its autoignition temperature. In some tests the oil was allowed to free burn and in others the effect of extinguishment were evaluated. One such experiment showed the effect of a dry chemical extinguishing agent being applied to the cooking oil fire. Below is the graph of those tests.

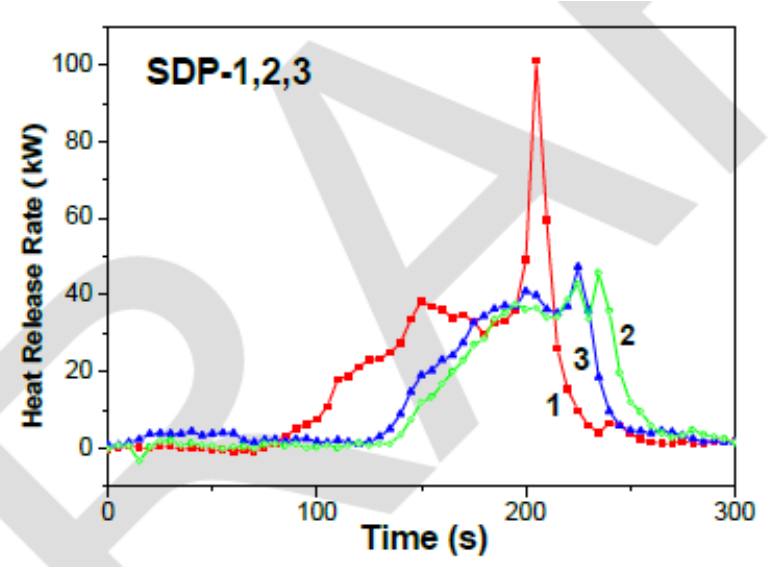

Fig. 13. Heat release rate measured for tests SDP-1 to SDP-3.

\section{Figure 20 Screen Shot of the HRR Curves Measured During the Experiments with Dry Powder Extinguishment (11)}

The report stated that after the initial extinguisher discharge there was a brief flare up and rise in the HRR after the discharge of the extinguishing agent but then the fire quickly extinguished (11). The SDP-1 curve is the one used to design the fire for this scenario. 
The SDP-1 test shows a peak HRR of $100 \mathrm{~kW}$ for a $25 \mathrm{~cm}$ pan. The fryer that is located in the kitchen of Wing “B” is approximately 14 ” X 14" (35.5 cm X 35.5cm) and has a larger surface area than the pan used in the experiments noted in the report. The surface area of the experimental pan was calculated to be $491 \mathrm{~cm}^{2}$, while the surface area of the fryer is $1260 \mathrm{~cm}^{2}$ roughly 2.5 times larger. Using the equation $\dot{Q}=\dot{m} \dot{m}^{*} \mathrm{~A} * \Delta$ hc with all other things being equal the only change between the experiment and the scenario application are the surface areas of the oil. For this reason the average HRR of $33.2 \mathrm{~kW}$ was multiplied by 2.5 to arrive at a new HRR for the scenario of $83 \mathrm{~kW}$. After the discharge of the extinguisher in the experiment the HRR rose to 100 $\mathrm{kW}$ or $300 \%$ increase before extinguishment. For this reason the $83 \mathrm{~kW}$ was multiplied by three to arrive at a new peak HRR of $249 \mathrm{~kW}$.

The curves with the adjustment of increased surface area include the extinguishment by way of dry chemical which is similar to the extinguishment installed in the hood of kitchen of Wing "B". By using this curve I am also modeling the application of the installed extinguishment system. The model will however have the installed sprinklers for the area around the hood system.

The table below shows the inputs in the model for the fire in the Wing " $\mathrm{B}$ " café.

Table 13 HRR Inputs for the Wing B Fire

\begin{tabular}{|c|c|}
\hline Time (seconds) & Fraction of Peak HRR \\
\hline 10 & $10 \%$ \\
\hline 100 & $20 \%$ \\
\hline 150 & $40 \%$ \\
\hline 175 & $30 \%$ \\
\hline 200 & $100 \%$ \\
\hline 220 & $10 \%$ \\
\hline 300 & $0 \%$ \\
\hline
\end{tabular}

The rendering below shows that the room temperature of the Wing " $\mathrm{B}$ " fire only reached a temperature of $55^{\circ} \mathrm{C}$ again far below the $600^{\circ} \mathrm{C}$ threshold. The model output files show sprinkler activation at 198 seconds. Only one sprinkler in the room activated. 


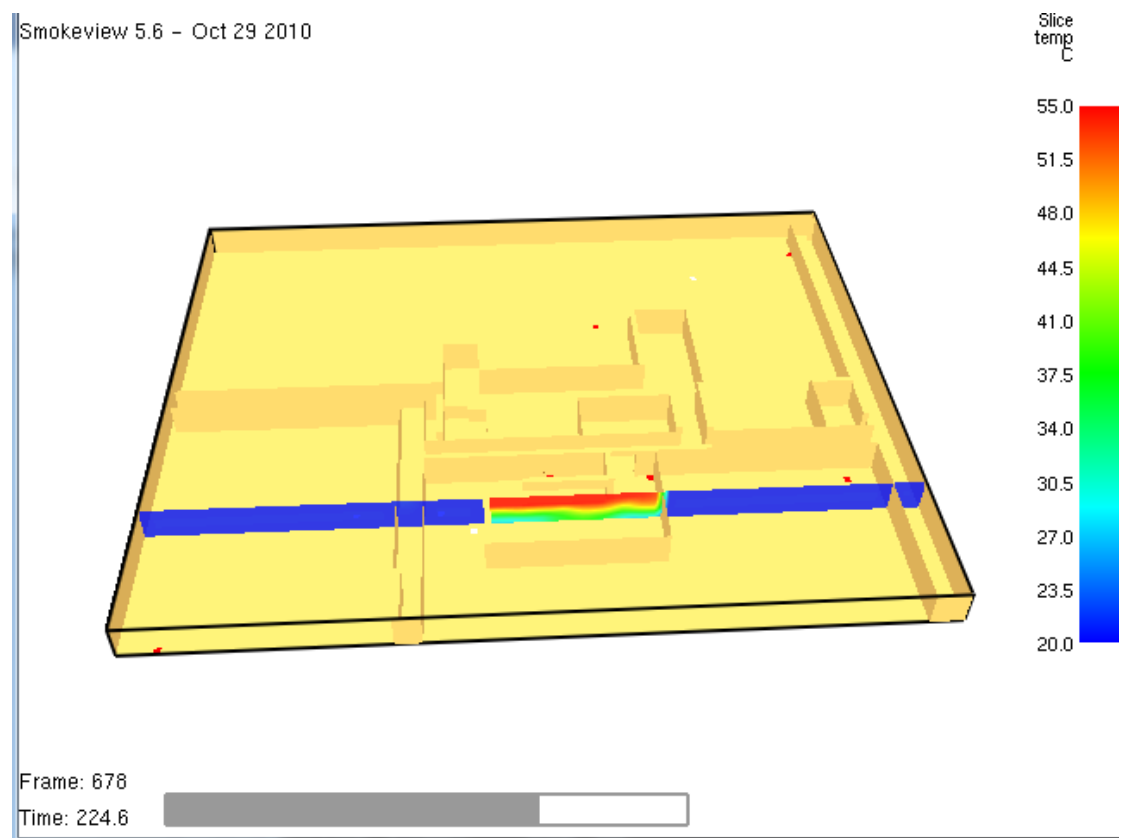

Figure 21 Temperature Slice File for Wing B fire

The rendering below shows the visibility at 6 feet above the floor. As shown the visibility drops to 15 meters which is above the threshold set for this analysis and therefore this scenario is found to be properly addressed with Building 1's current configuration.

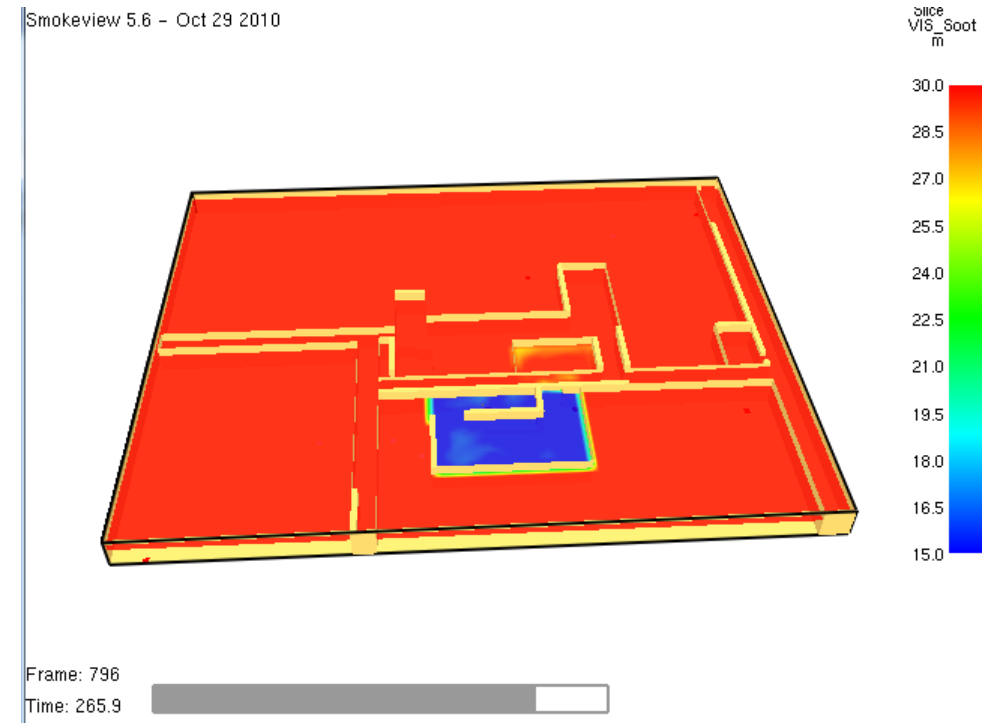

Figure 22 Visual Slice at 6 feet for Wing B Fire 


\section{Wing "A/B" Fire Scenario}

The FDS model was built using PyroSim software with imported floor plans. The general layout of the fire area was constructed using the imported floor plan.

\section{Model Parameters}

Room heights for this scenario where set at 9 feet for the whole area. Only the corridor for the first floor was constructed and the room of origin and the main entrance area. The stairwell to the second floor of Wing " $\mathrm{A}$ ” was included as well as the second floor corridors to evaluate the visibility at the 6 foot levels on both floors. As stated in the scenario doors to the room are open throughout the fire.

The HRR curve was used for this model to simulate a trash fire that was ignited by an overloaded electrical outlet in the reception area of the main entrance of Wings " $B$ ” and " $A$ ". The purpose of this fire was to see how a likely fire scenario at a junction of two adjacent wings would affect occupants on two floors as well as in the area of the auditorium.

The below HRR curve from the SFPE Handbook was used for the design of the fire for this scenario. The curve input into the model is the Three Sacks curve that has a peak of $350 \mathrm{~kW}$ at 75 seconds. This was the peak HRR used during this scenario. 


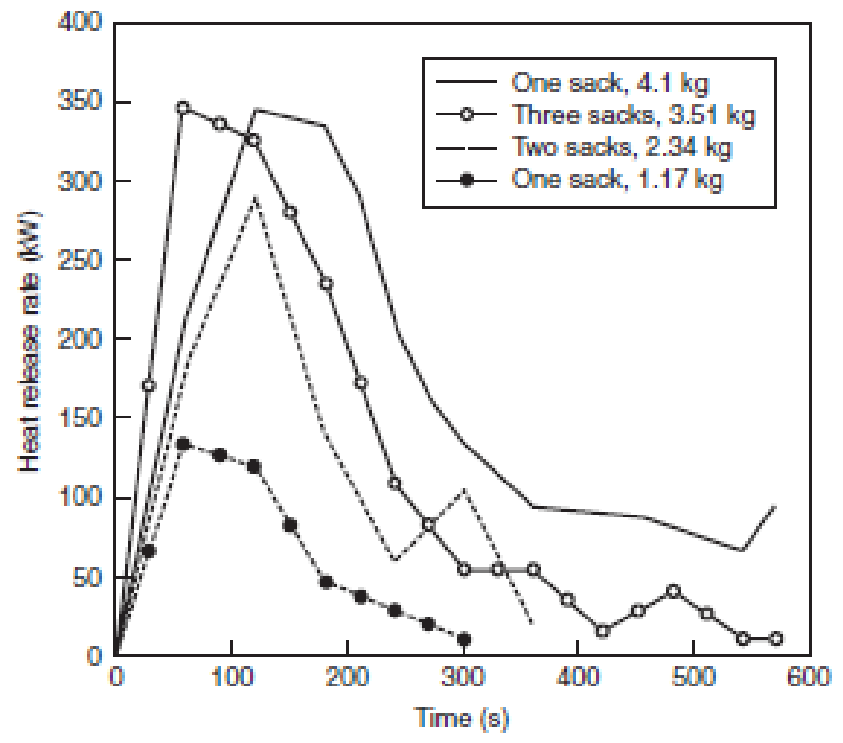

Figure 3-1.49. Trash bags.

Figure 23 HRR Curve for Trash Bags from SFPE Handbook Third Edition.

Below is the model inputs used to build the fire growth for this scenario.

Table 14 HRR Inputs for Wing A/B Fire

\begin{tabular}{|c|c|}
\hline Time (seconds) & Fraction of Peak HRR \\
\hline 0 & $0 \%$ \\
\hline 25 & $20 \%$ \\
\hline 50 & $70 \%$ \\
\hline 100 & $100 \%$ \\
\hline 125 & $90 \%$ \\
\hline 150 & $75 \%$ \\
\hline 200 & $50 \%$ \\
\hline 250 & $30 \%$ \\
\hline 300 & $10 \%$ \\
\hline
\end{tabular}

The rendering below shows that the room temperature of the Wing “ $\mathrm{A} / \mathrm{B}$ ” fire only reached a temperature of $120^{\circ} \mathrm{C}$ again far below the $600^{\circ} \mathrm{C}$ threshold. The model output files show sprinkler activation at 56 seconds. Only two sprinklers activated during this scenario fire model. 


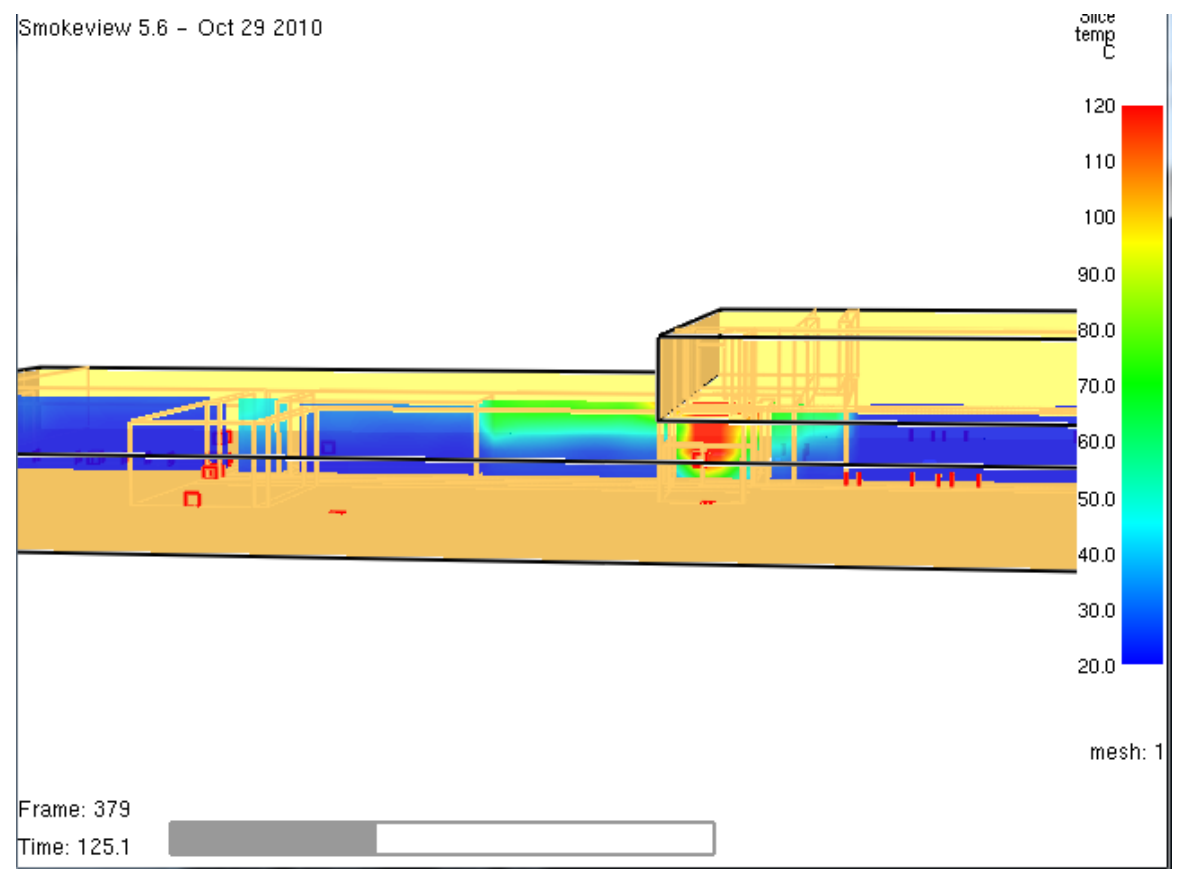

Figure 24 Temperature Slice for the Wing A/B Fire

The rendering below shows the visibility at 6 feet above the floor for the first floor. As shown the visibility drops to 11 meters which is below the threshold set for this analysis and therefore this scenario is found to be improperly addressed with Building 1's current configuration.

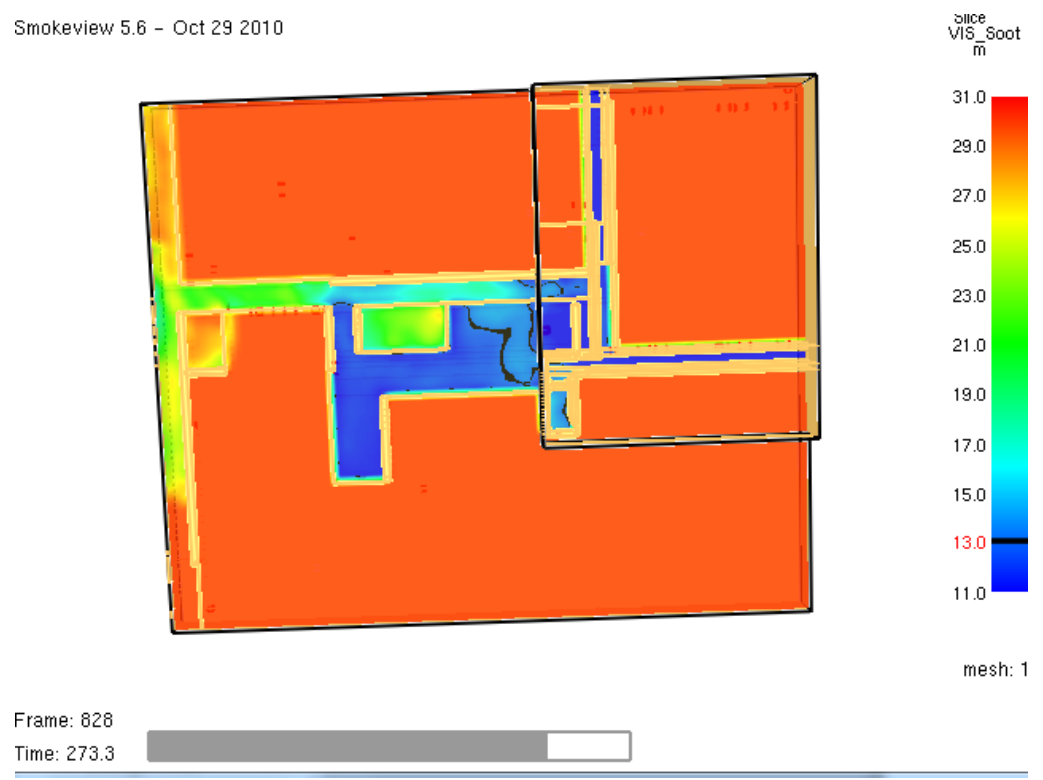

Figure 25 Visual Slice at 6 Feet for the First Floor of wing A/B 
The rendering below shows the visibility at 6 feet above the floor for the second floor of Wing "A". As shown the visibility drops to 11.5 meters which is below the threshold set for this analysis and therefore this scenario is found to be improperly addressed with Building 1's current configuration.

Smokeview 5.6 - Oct 292010

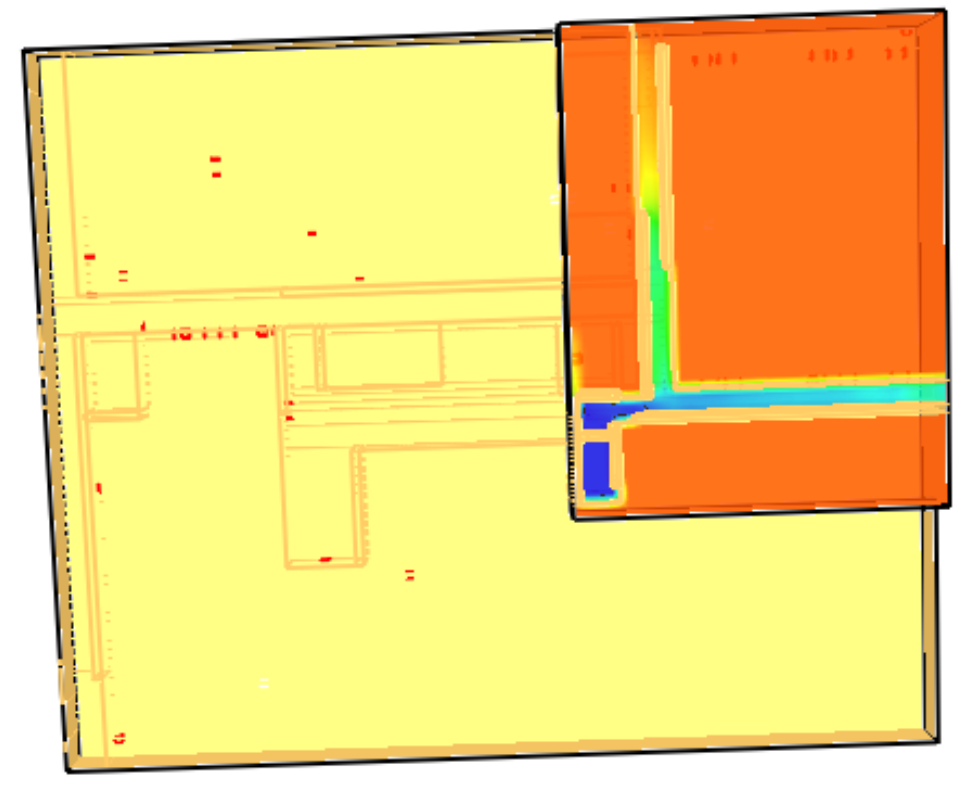

Frame: 620

Time: 204.6

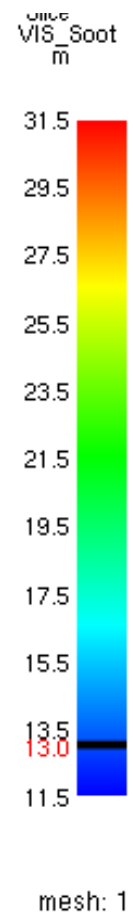

mesh: 1

Figure 26 Visual Slice at 6 Feet for the Second Floor of Wing A

The visibility for this scenario is still well above the threshold for those occupants that are familiar with the building but this scenario is in the area where Building 1 is most likely to have guests. In fact guests are instructed to report to the very reception area in this scenario. For this reason combustibles in this area should be kept to a minimum. Again this scenario is using a worst case scenario of three bags of trash which could be argued the likelihood of which is small but if janitorial services are not available the three bags of trash could happen. More modeling could be done by a more experienced evaluator to better create the area for this scenario. The more simple solution could be to remove the reception area from this area or add more restrictive administrative controls. 


\section{Conclusion}

This analysis of Building 1 has shown that the 1971 vintage building does meet current building codes. This analysis also used modern fire modeling techniques to model likely fire scenarios for each wing to see if Building 1's current configuration could perform to the stated criteria. The models showed that Building 1's current configuration is acceptable on the basis of structural fire protection as temperatures during the fire models stayed well below flashpoint which was one part of the criteria. The models also showed, however, that the smoke visibility levels could not be maintained to the more restrictive unfamiliar occupant distance of 13 meters. In a few of the models the visual distance dropped below the criteria; however all models would have passed the less restrictive familiar occupant distance of 4 meters. Additional modeling could be completed by a more experienced evaluator to determine the relevancy of this analysis. 


\section{References}

1. National Fire Protection Association. NFPA 101 Life Safety Code. Quincy, Massachusetts : National Fire Protection Association, 2012. 101.

2. -. Fire Protection Handbook 20th Edition. Quincy, Massachusetts : National Fire Protection Association, 2008.

3. -. National Fire Alarm and Signaling Code. Quincy, Massachusetts : National Fire Protection Association, 2013. NFPA 72.

4. - NFPA 13 Standard for the Installation of Sprinkler Systems. Quincy, Massachusetts : National Fire Protection Association, 2010. NFPA 13.

5. - NFPA 25 Standard for the Inspection, Testing, and Maintenance of Water-Based Fire Protection Systems. Quincy, Massachusetts : National Fire Protection Association, 2010. NFPA 25.

6. International Code Council. International Building Code. Country Club Hills, IL : International Code Council, 2012.

7. Los Alamos National Laboratory. LANL Emergency Procedures and Protective Actions. Los Alamos : LANL, 2014. No: P1201-4. R2.

8. Society of Fire Protection Engineers. SFPE Engineering Guide to Performance-Based Fire Protection Analysis and Design of Buildings. Quincy, Massachusetts : National Fire Protection Association, 2000.

9. Society of Fire Protection Engineers . THE SFPE Handbook of Fire Protection Engineering Fourth Edition. Quincy, Massachusetts : National Fire Protection Association, 2008. 4.

10. Thunderhead Engineering . PyroSim 2015 Manual. PyroSim. [Online] Thunder head Engineering, 2015. [Cited: May 5, 2015.] https://www.thunderheadeng.com/wpcontent/uploads/dlm_uploads/2014/02/PyroSimManual.pdf.

11. Thundrhead Engineering. Pathfinder User Manual. Pathfinder Resources. [Online] Thunderhead Engineering, 2014. [Cited: May 5, 2015.] http://www.thunderheadeng.com/wpcontent/uploads/downloads/2014/10/users_guide.pdf.

12. Ni, W.K. Chow and Xiaomin. Experimental Evaluation on Performance of Open Kitche Fire Duppresion Systems. Hong Kong, China : Fire Safety Science-Draft Proceedings of the Eleventh International Symposium, 2014. 


\section{Drawings}

(A complete drawing set could not be found) 


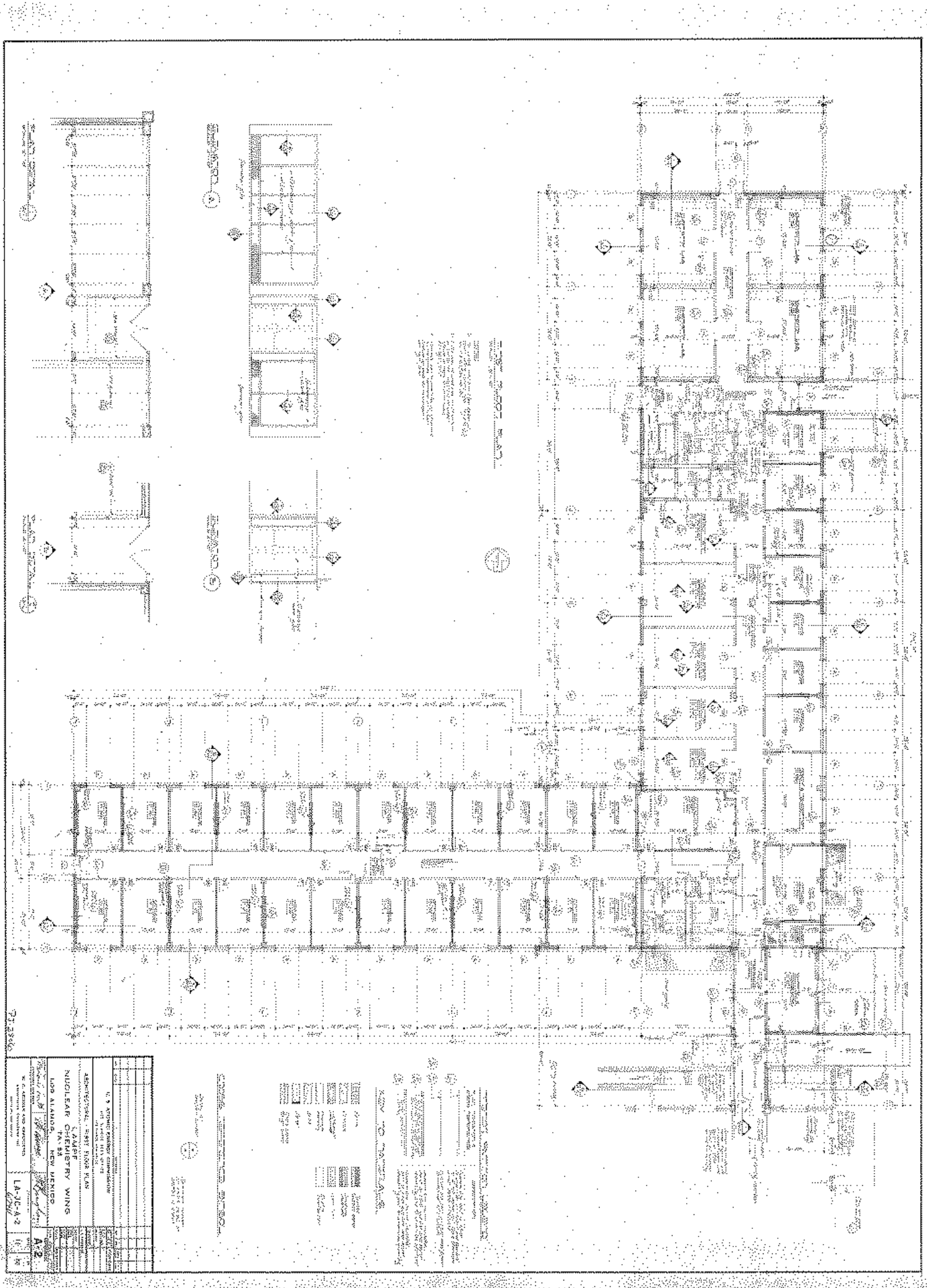




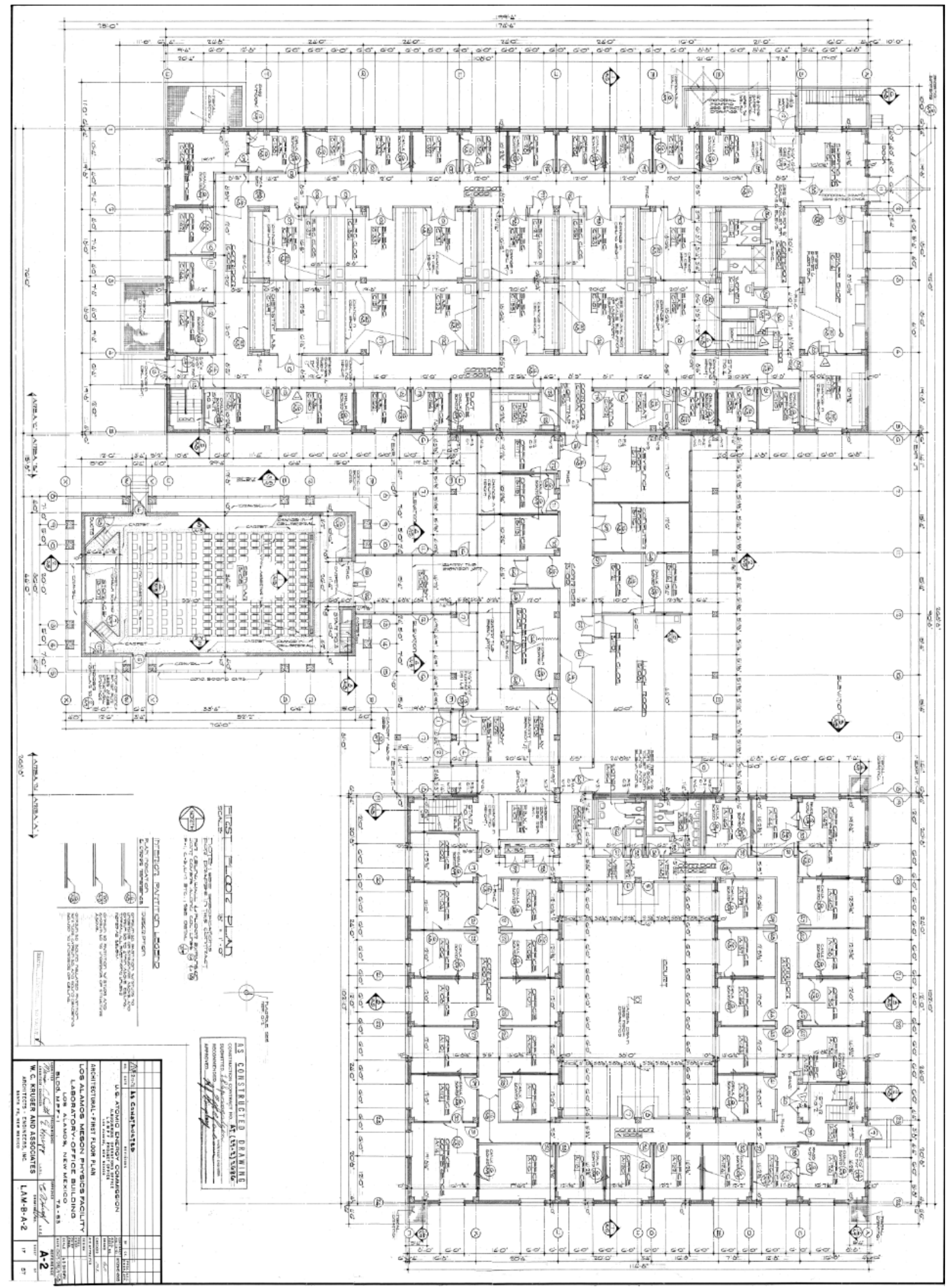




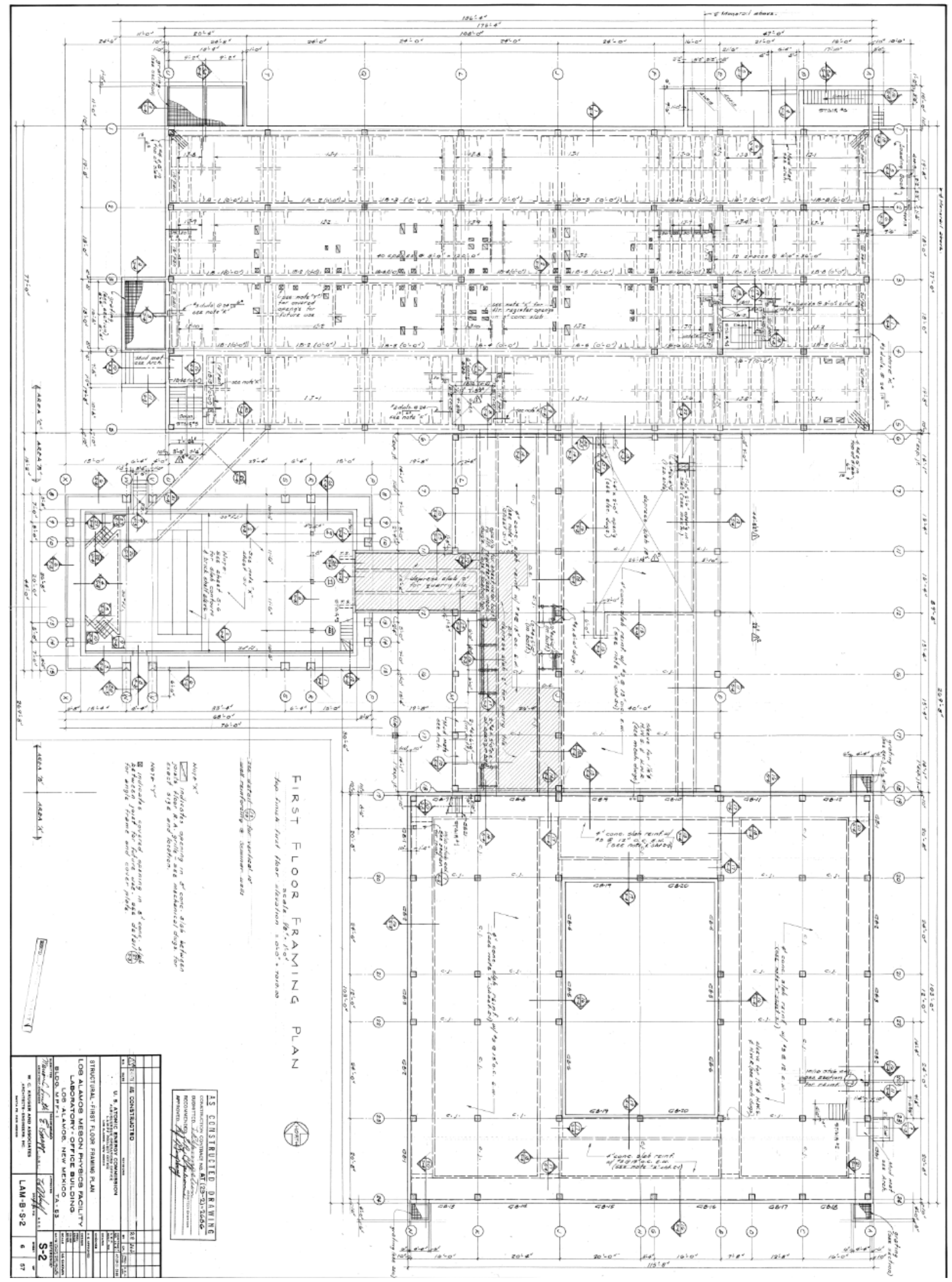




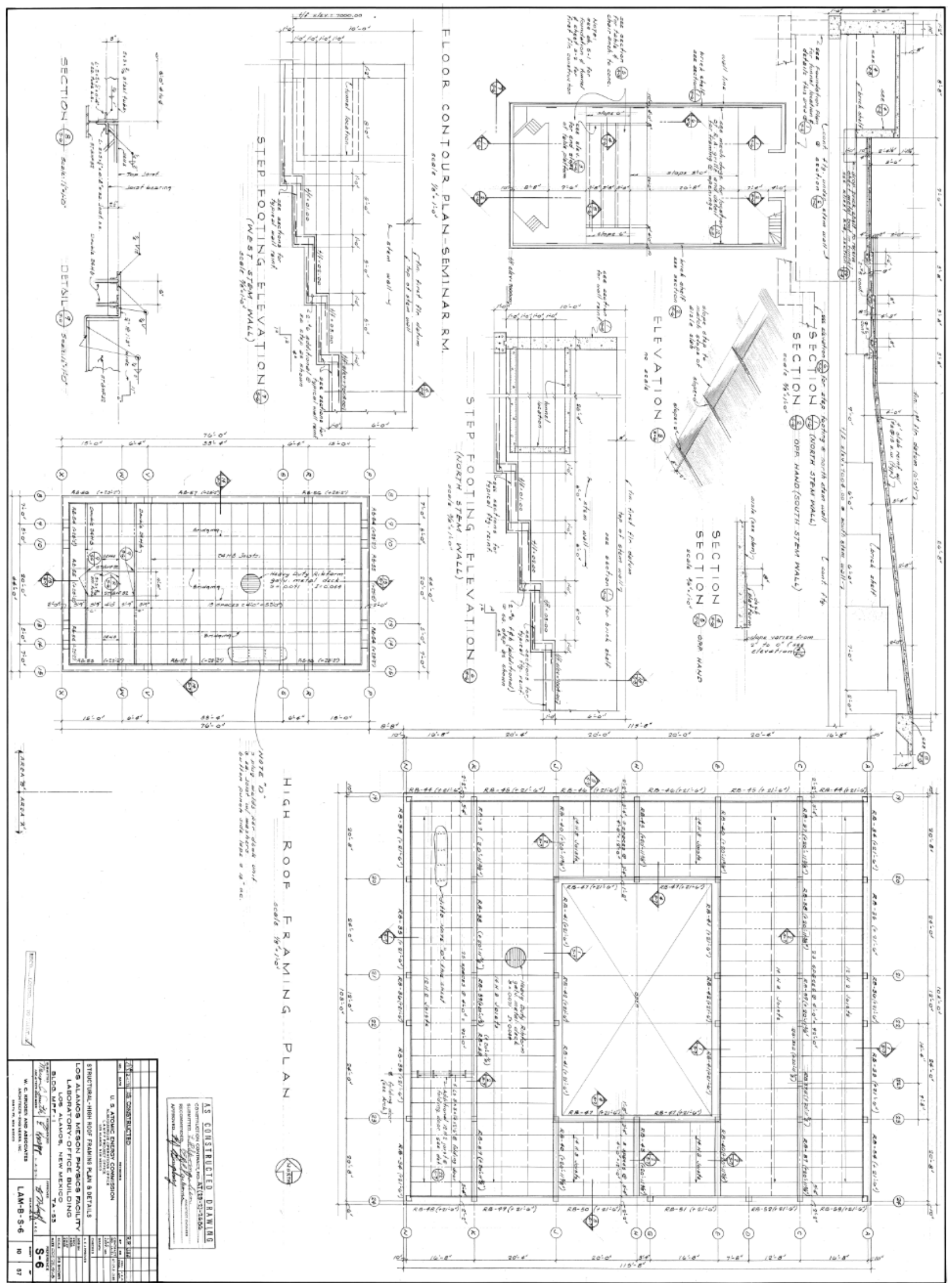




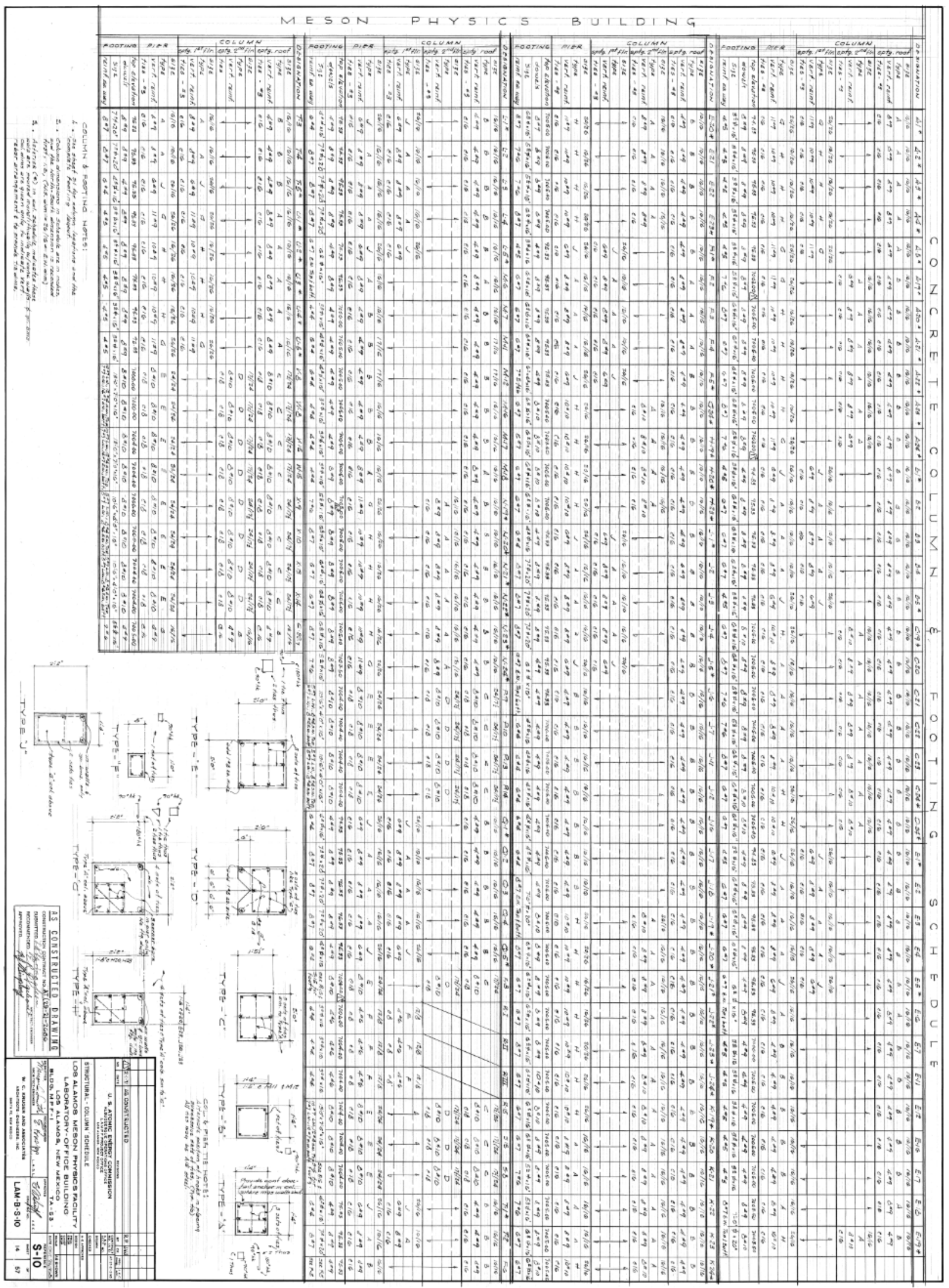




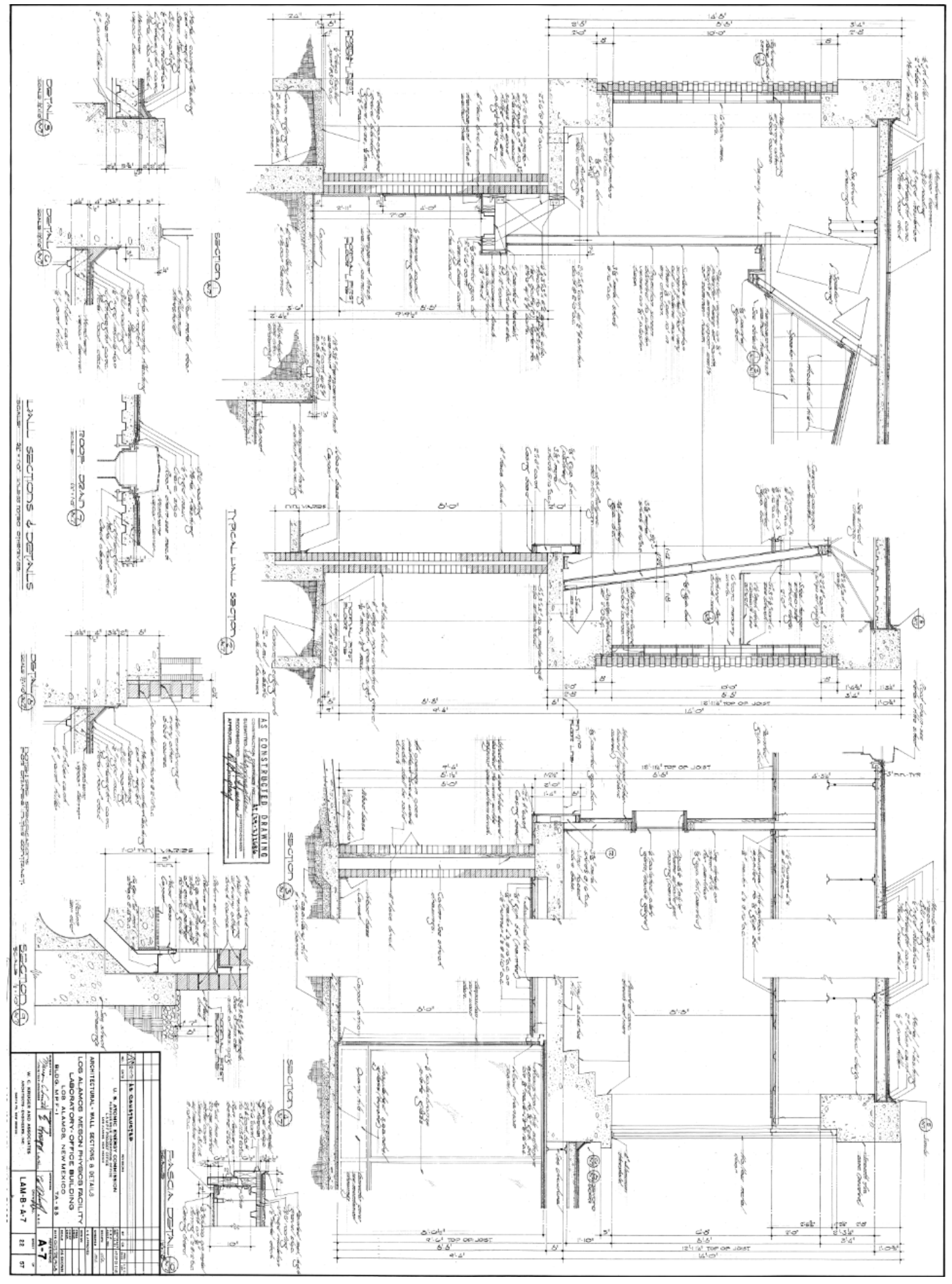




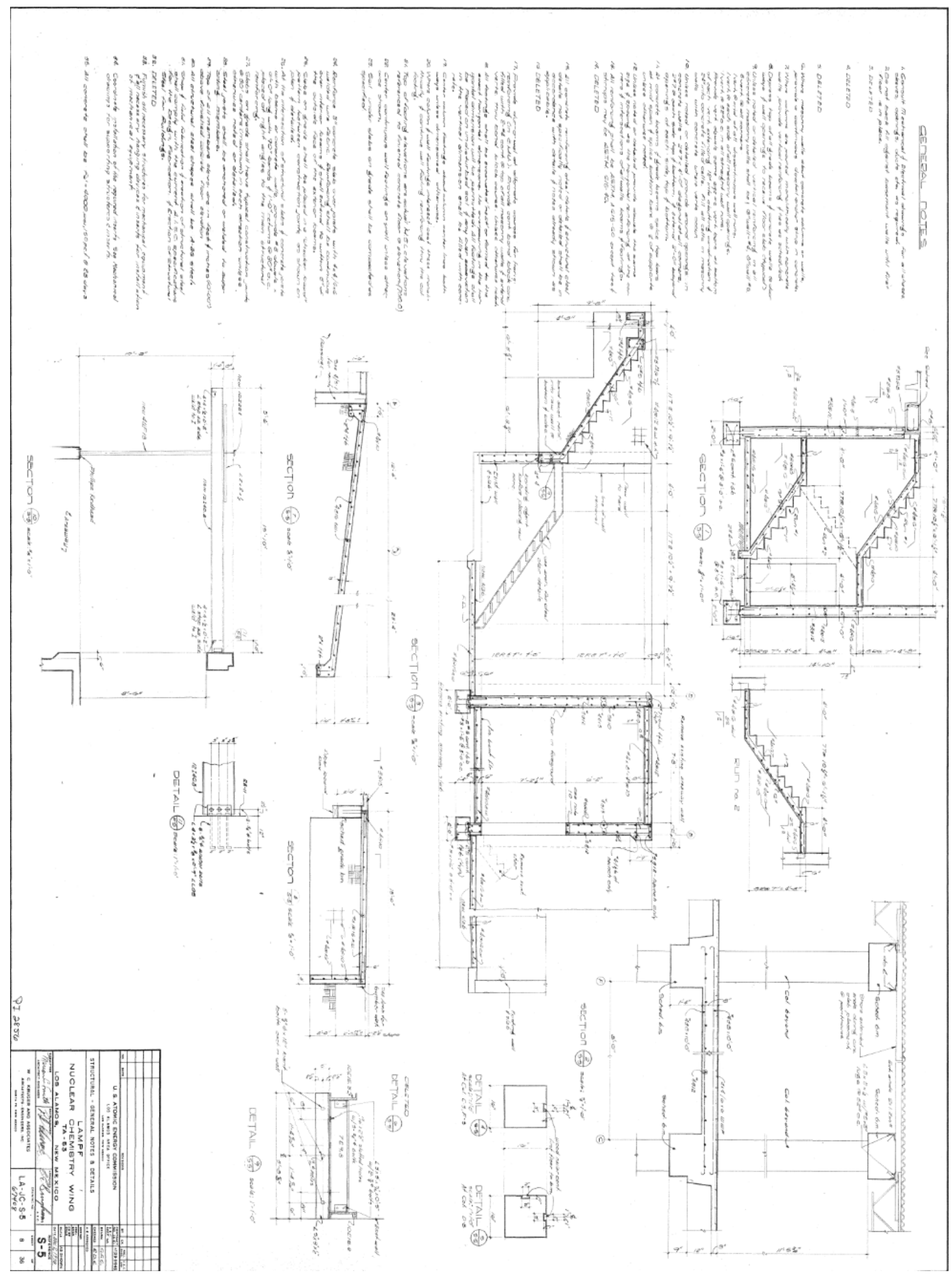




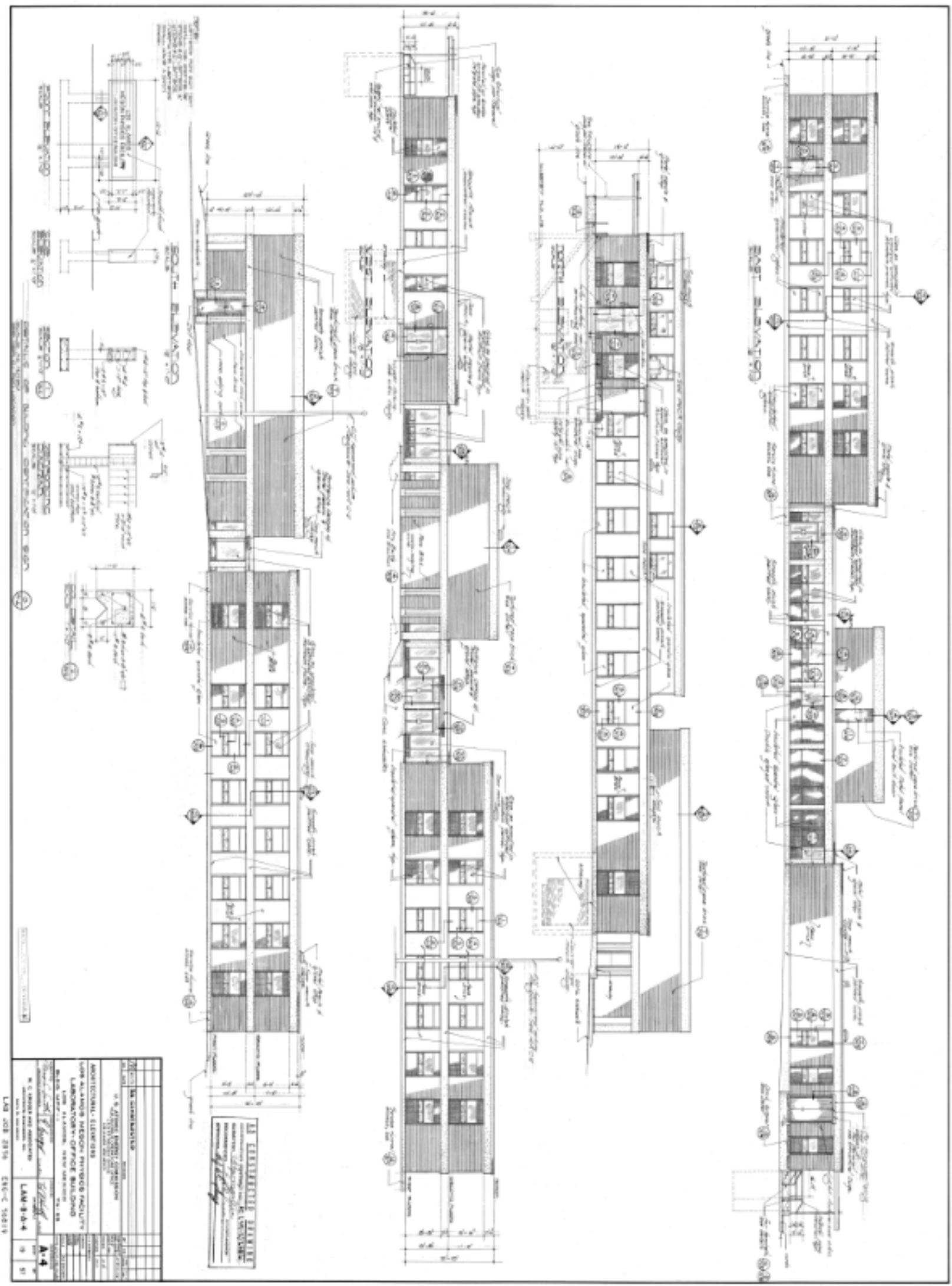


Brett Noakes

June 2015

Suppression System Drawings 


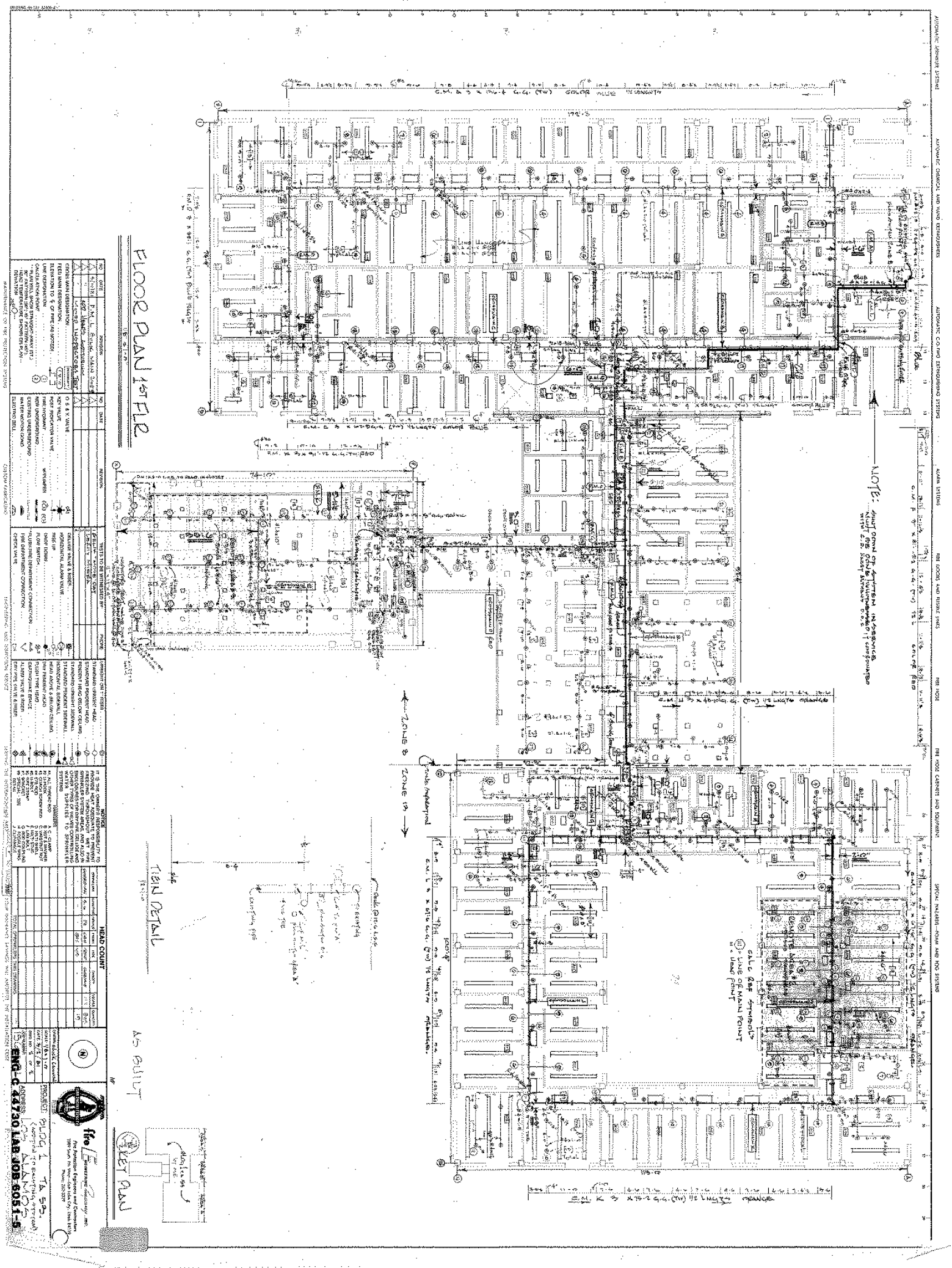




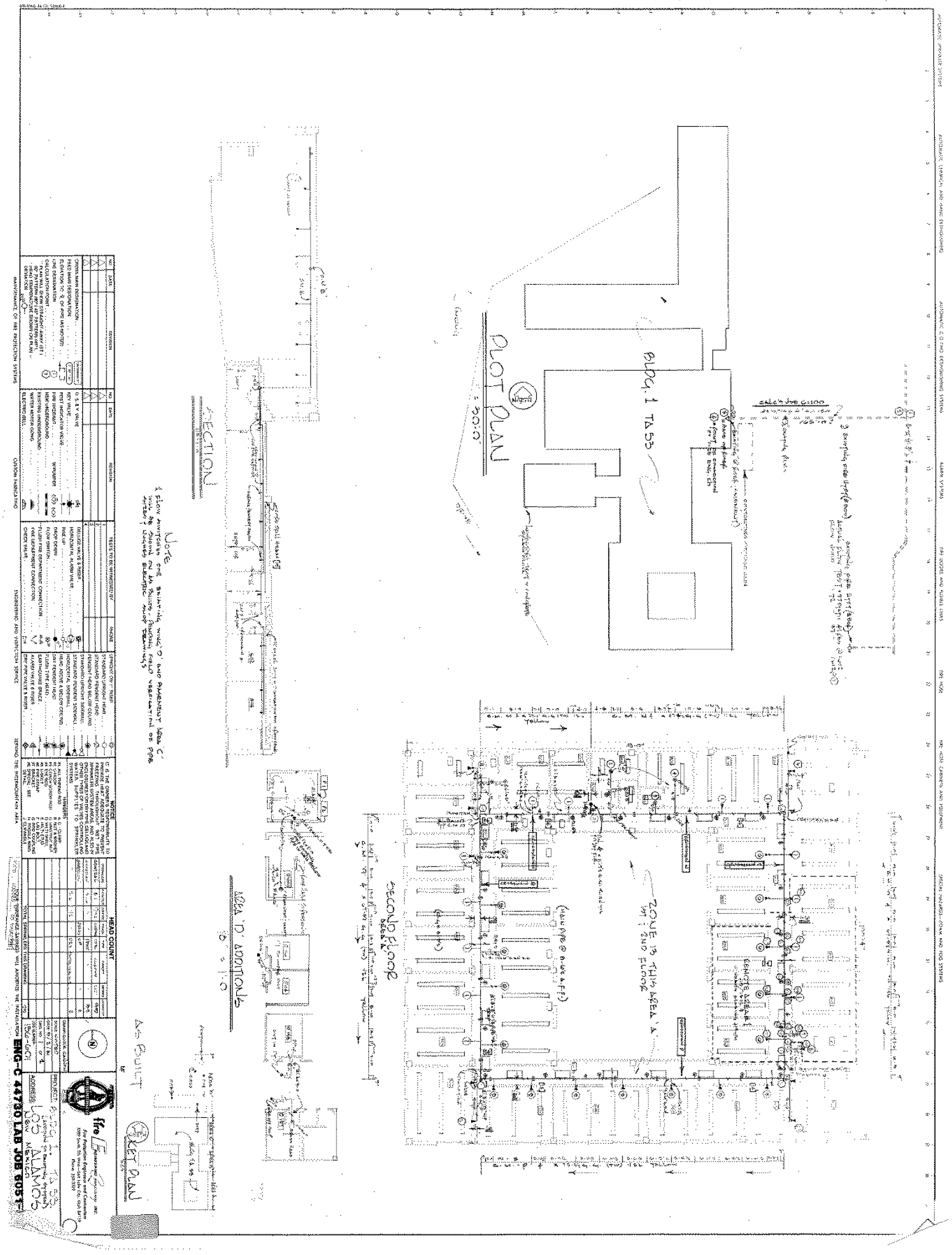




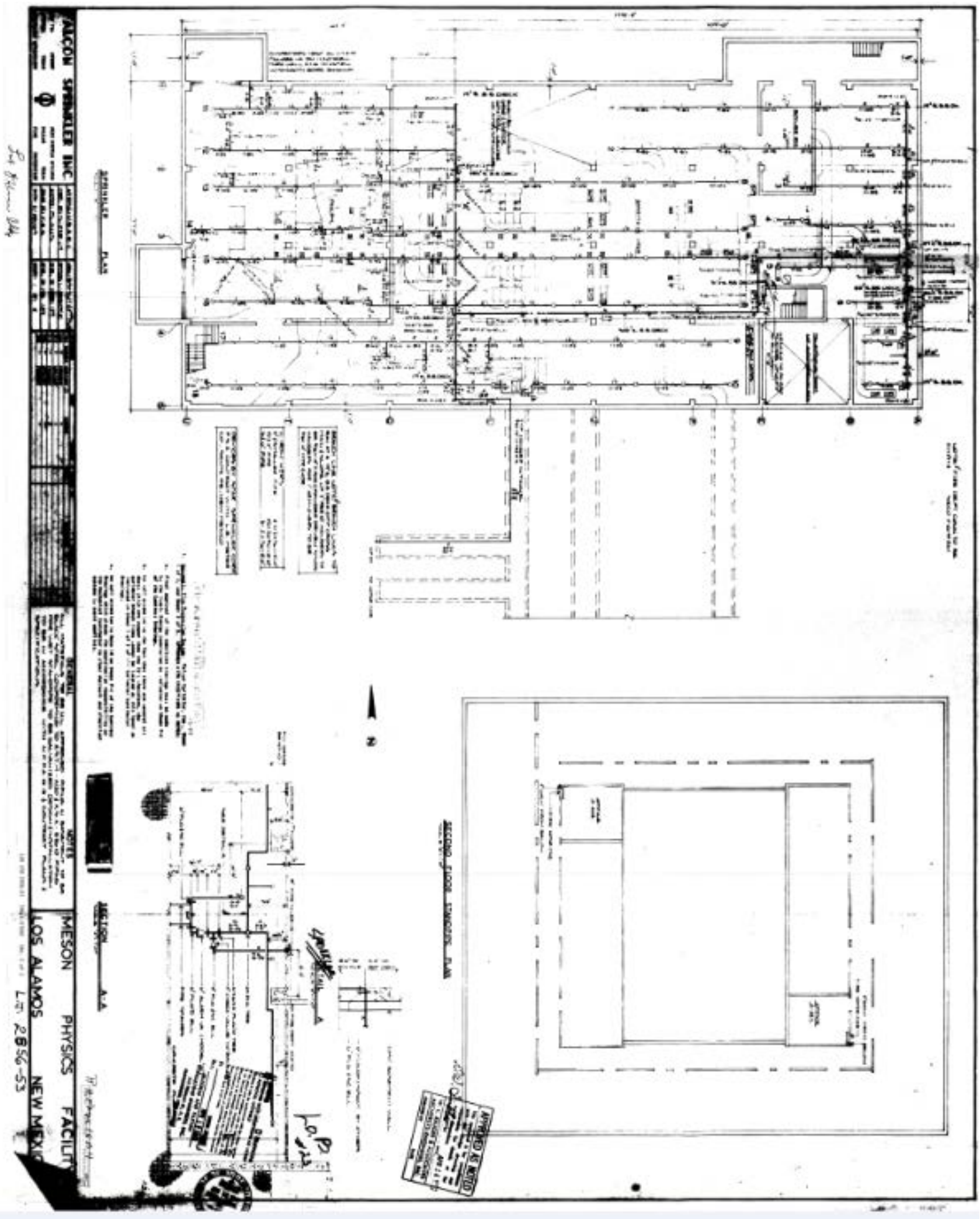




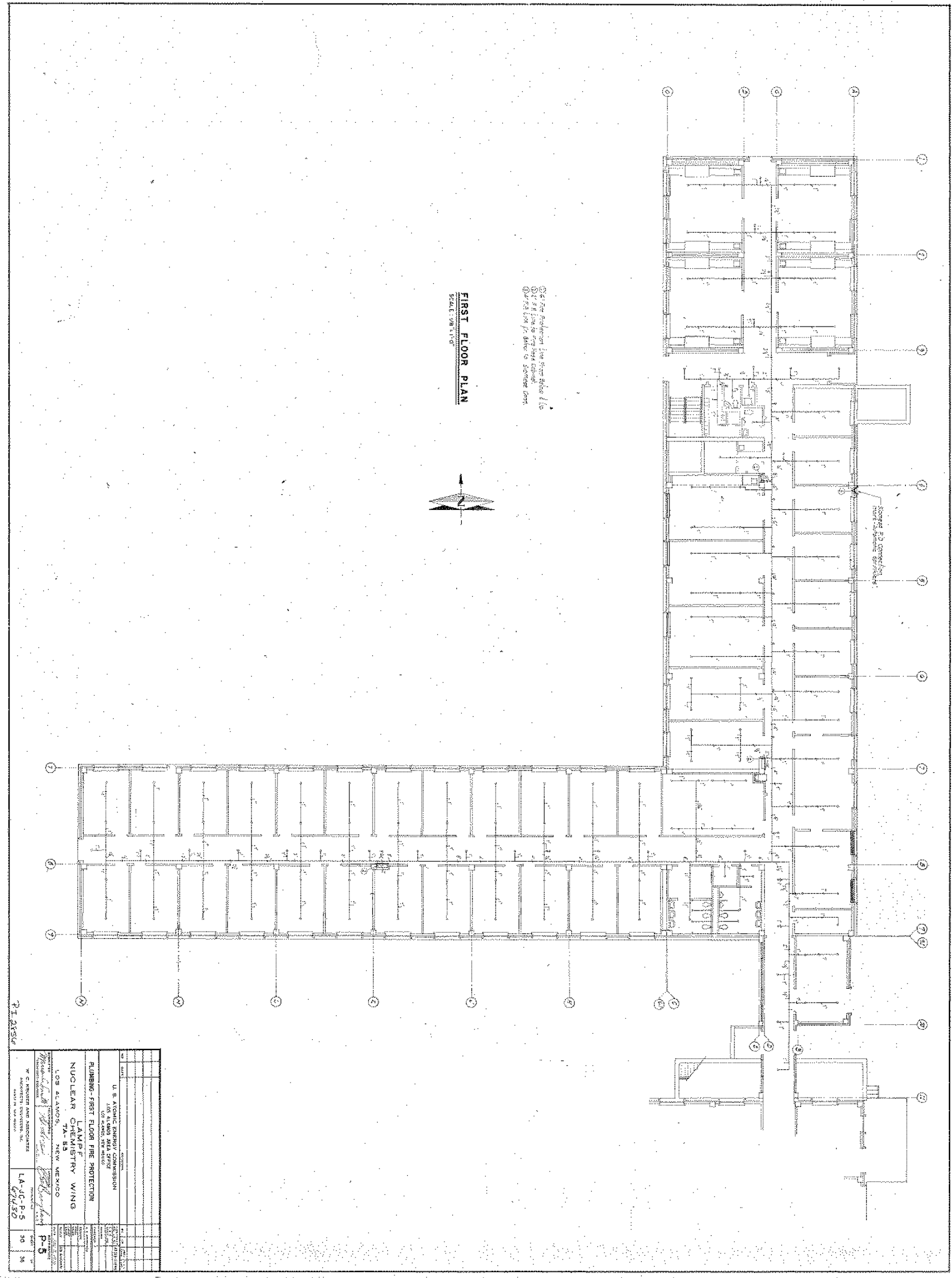




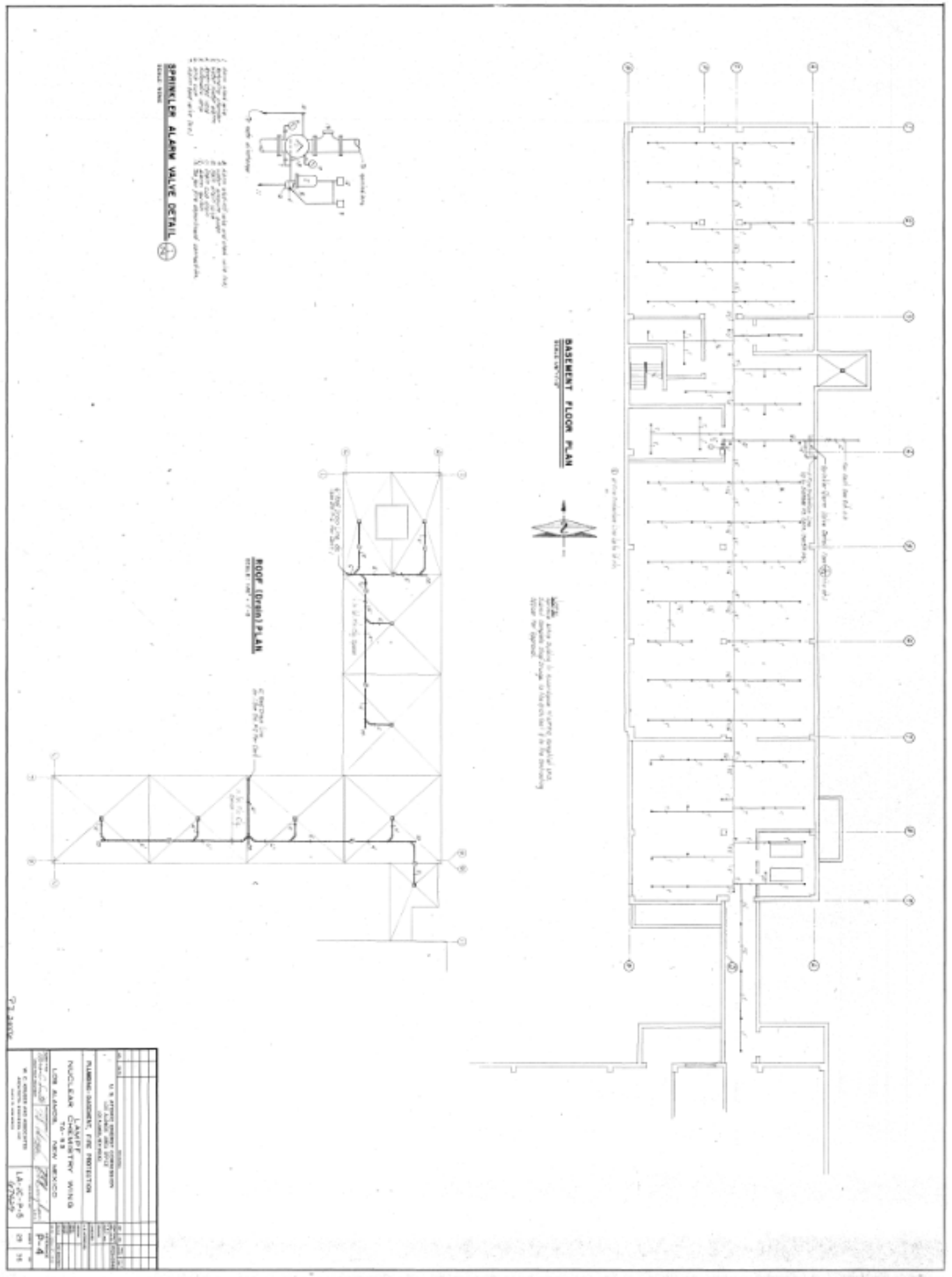


Brett Noakes June 2015

Fire Alarm Drawings 


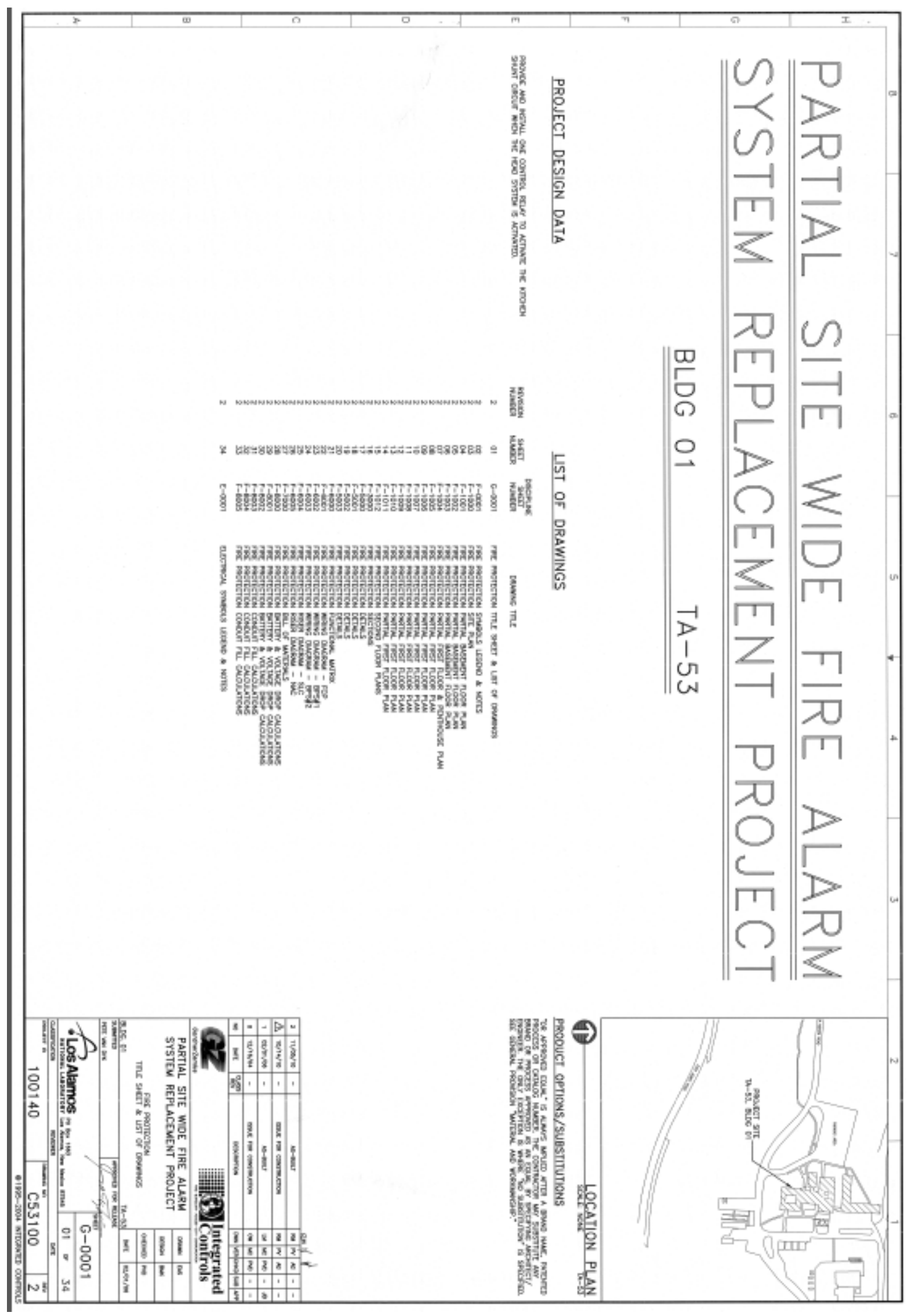



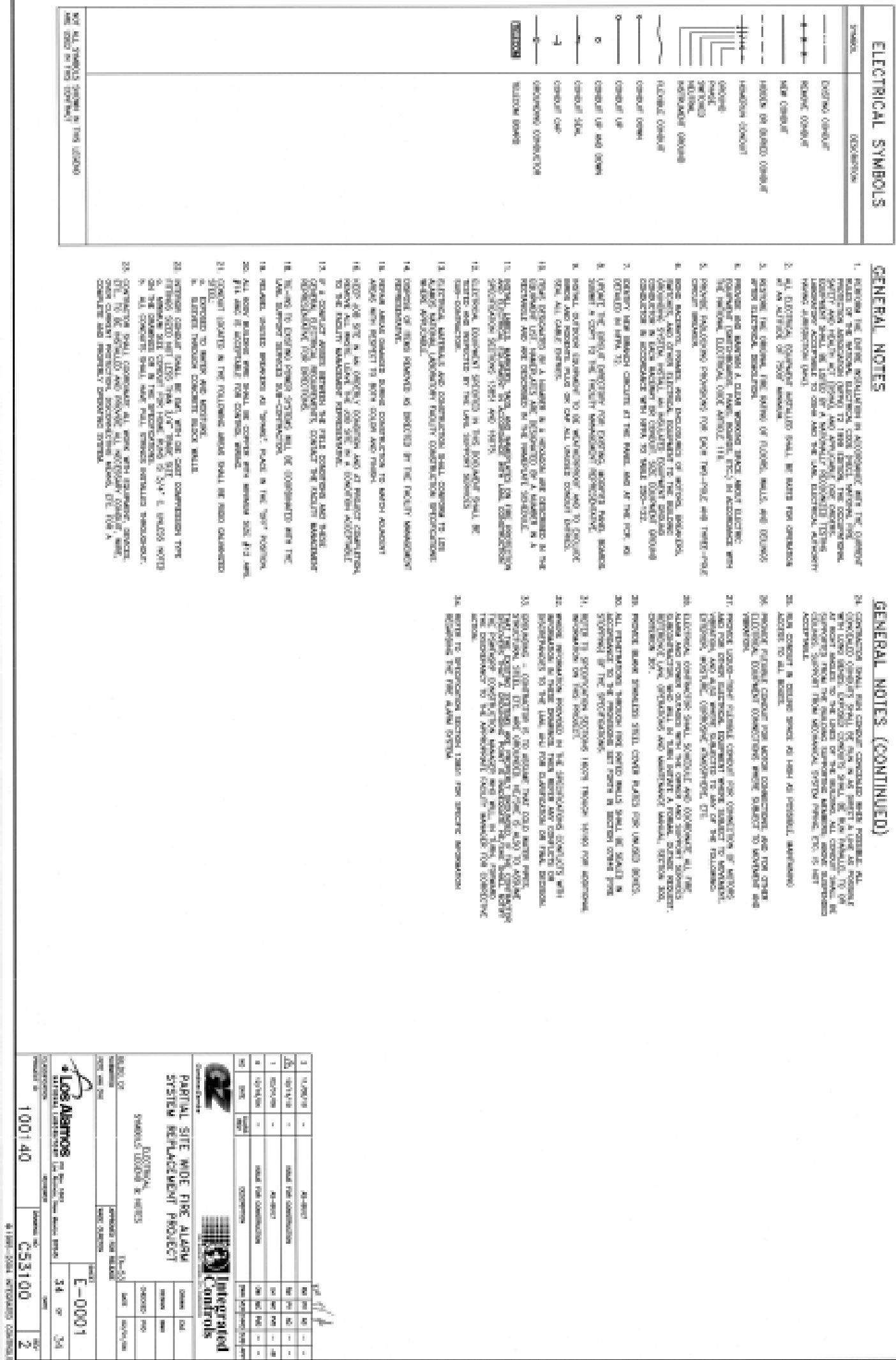

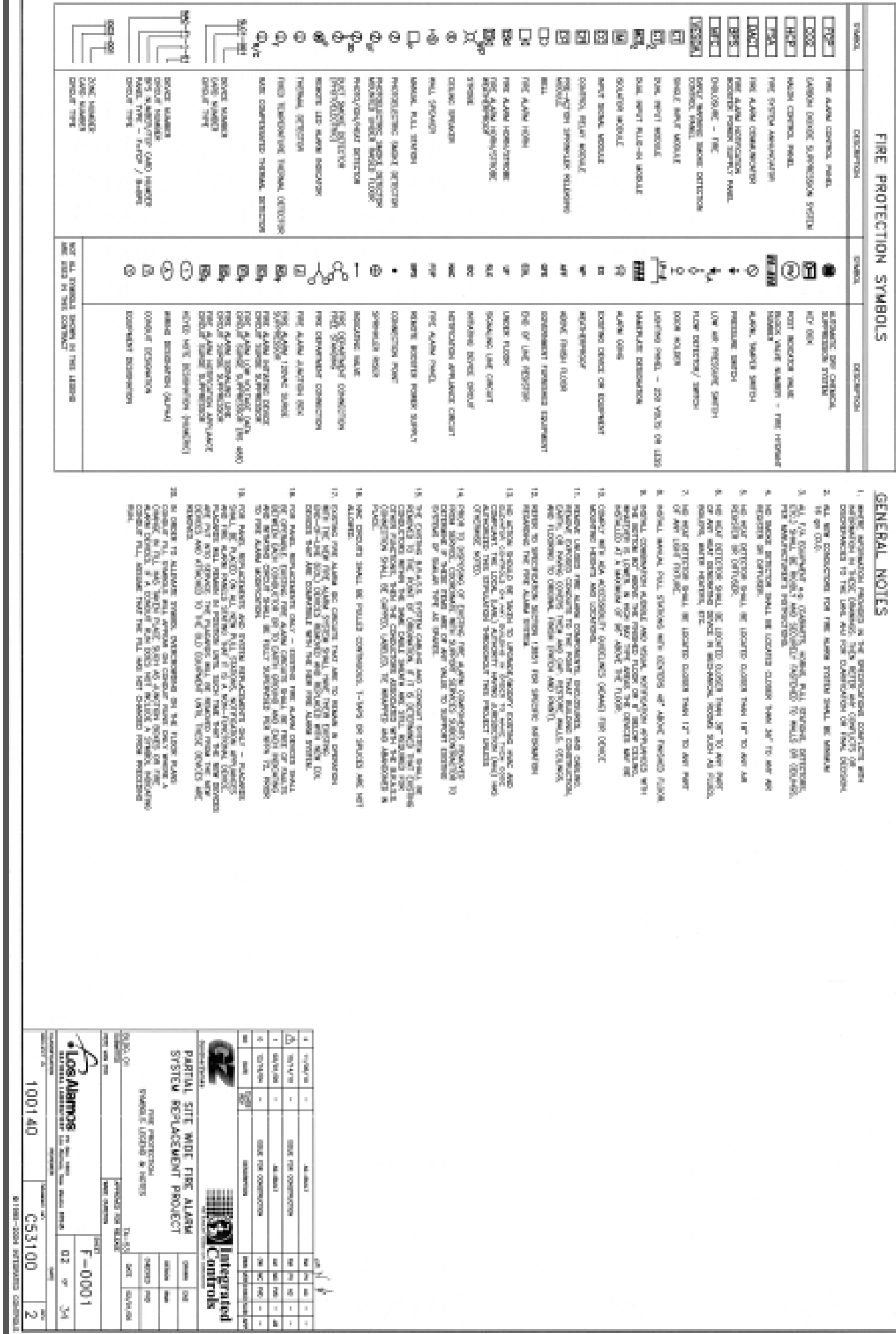
Brett Noakes

June 2015

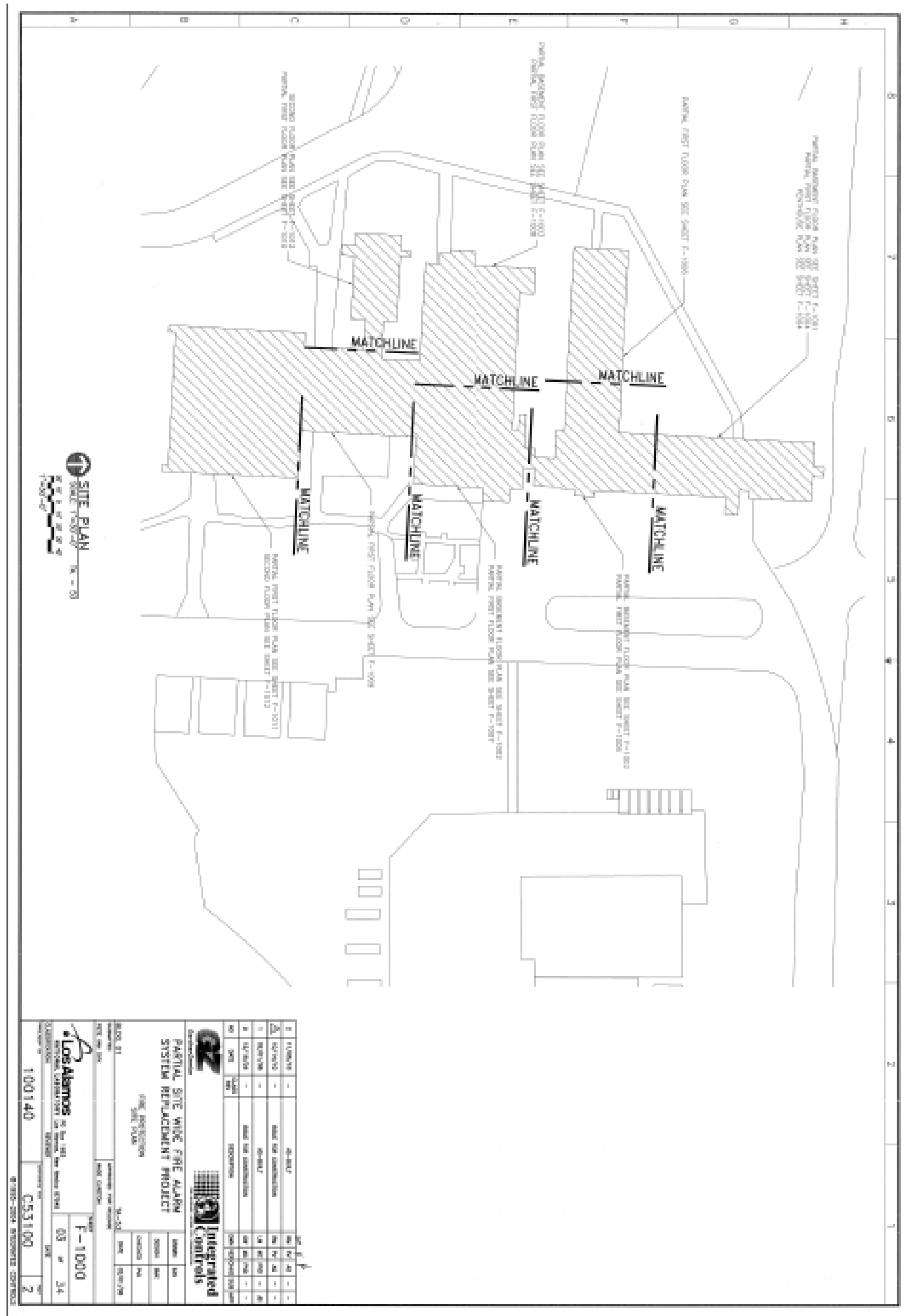




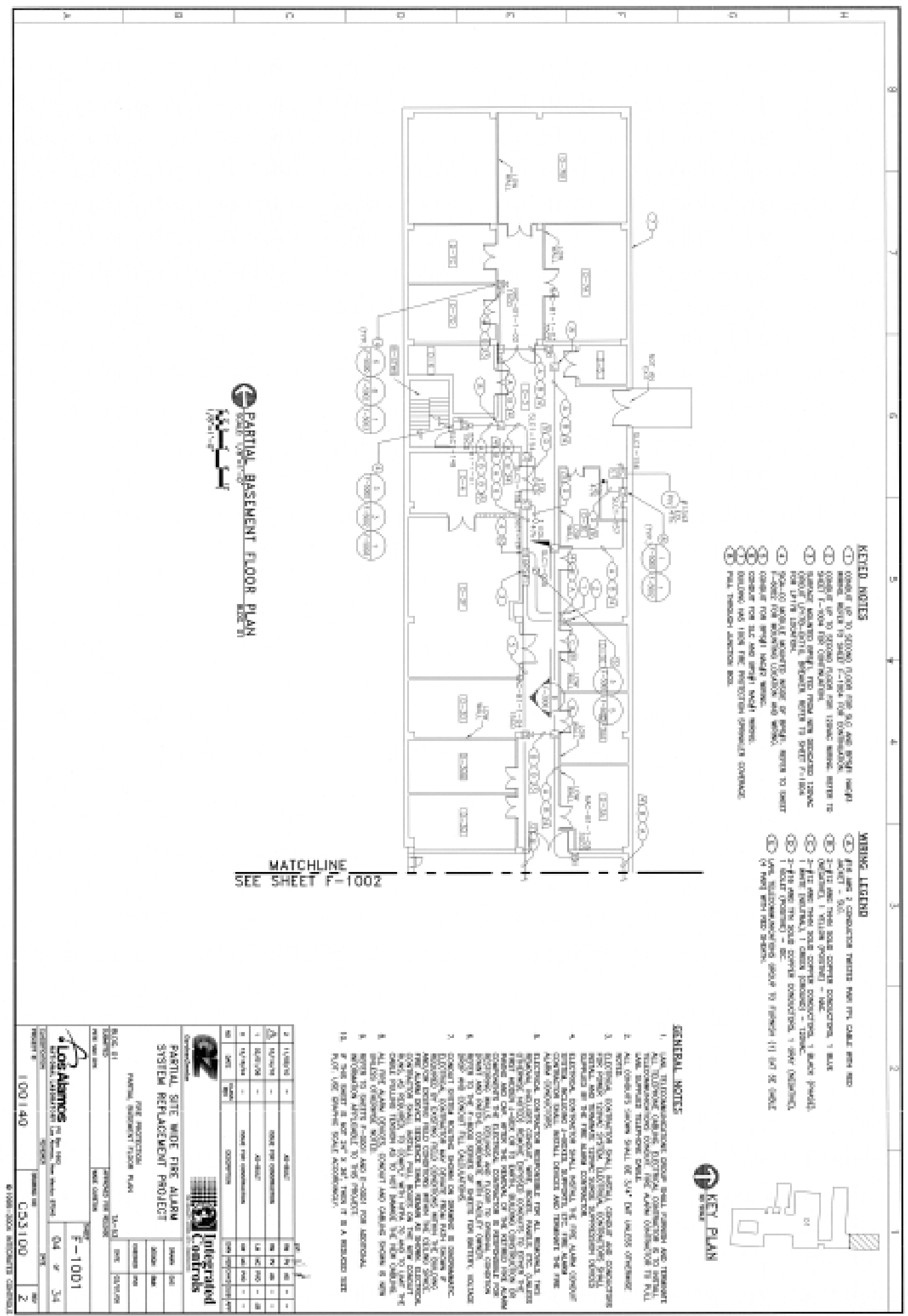




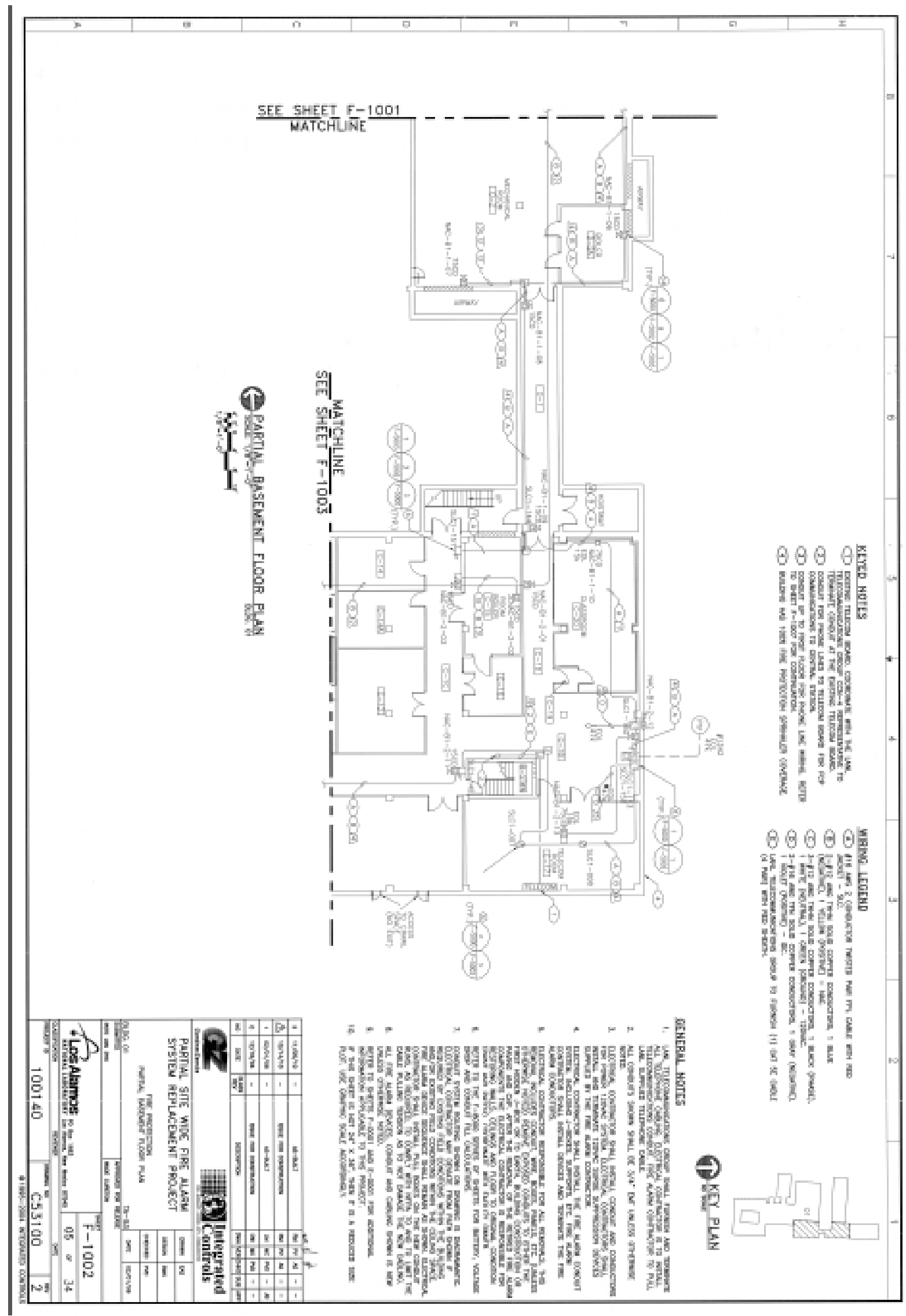




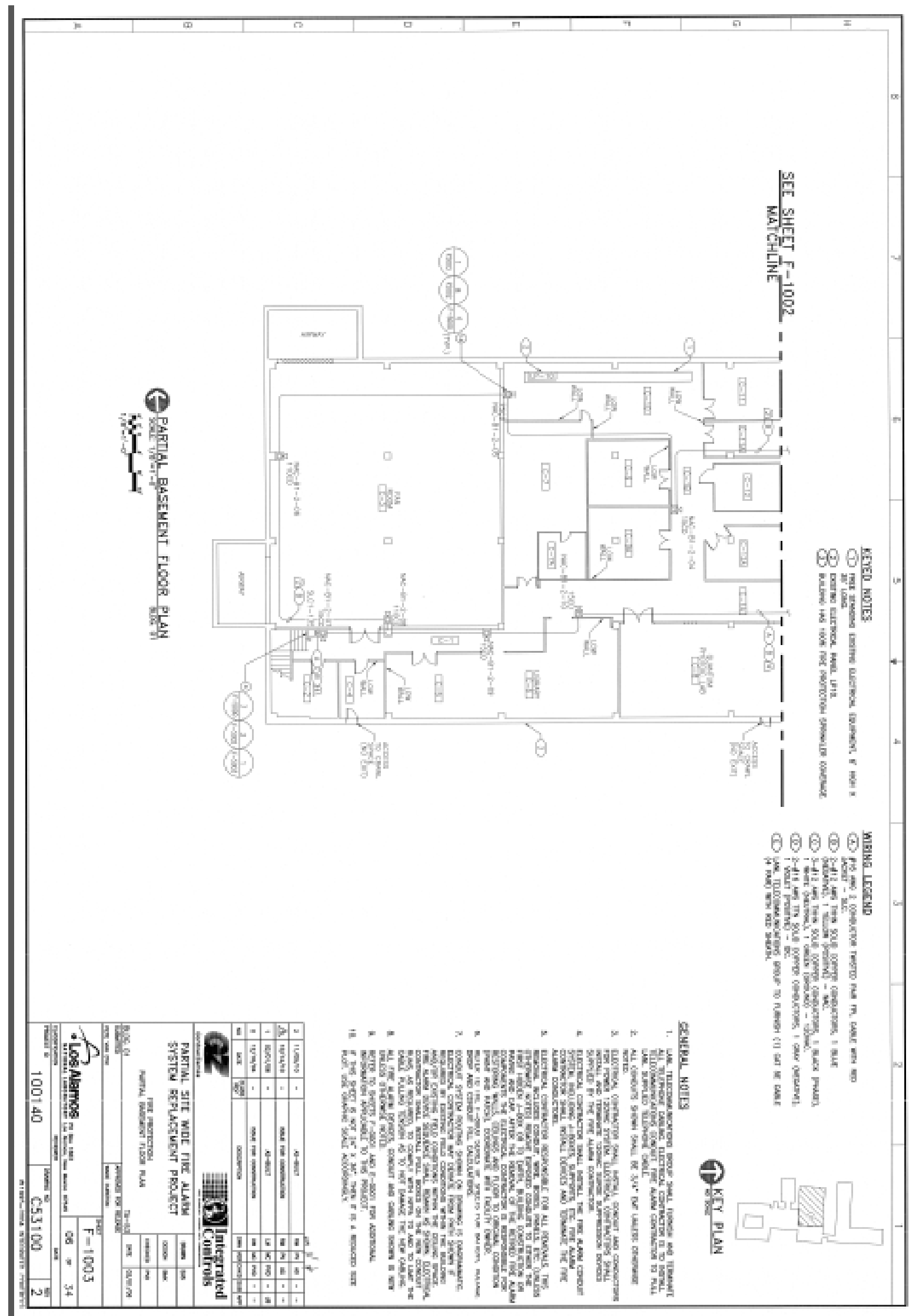




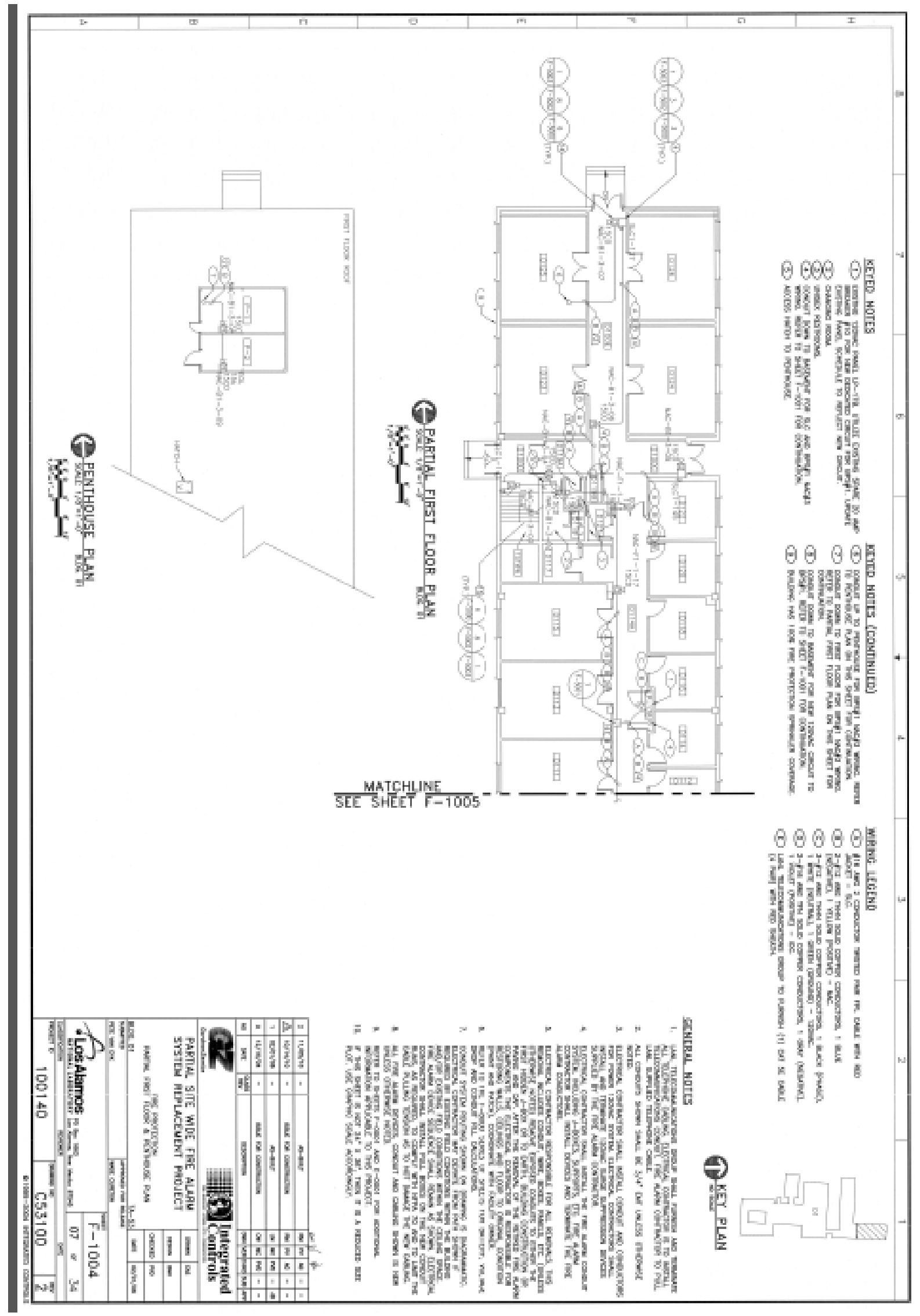




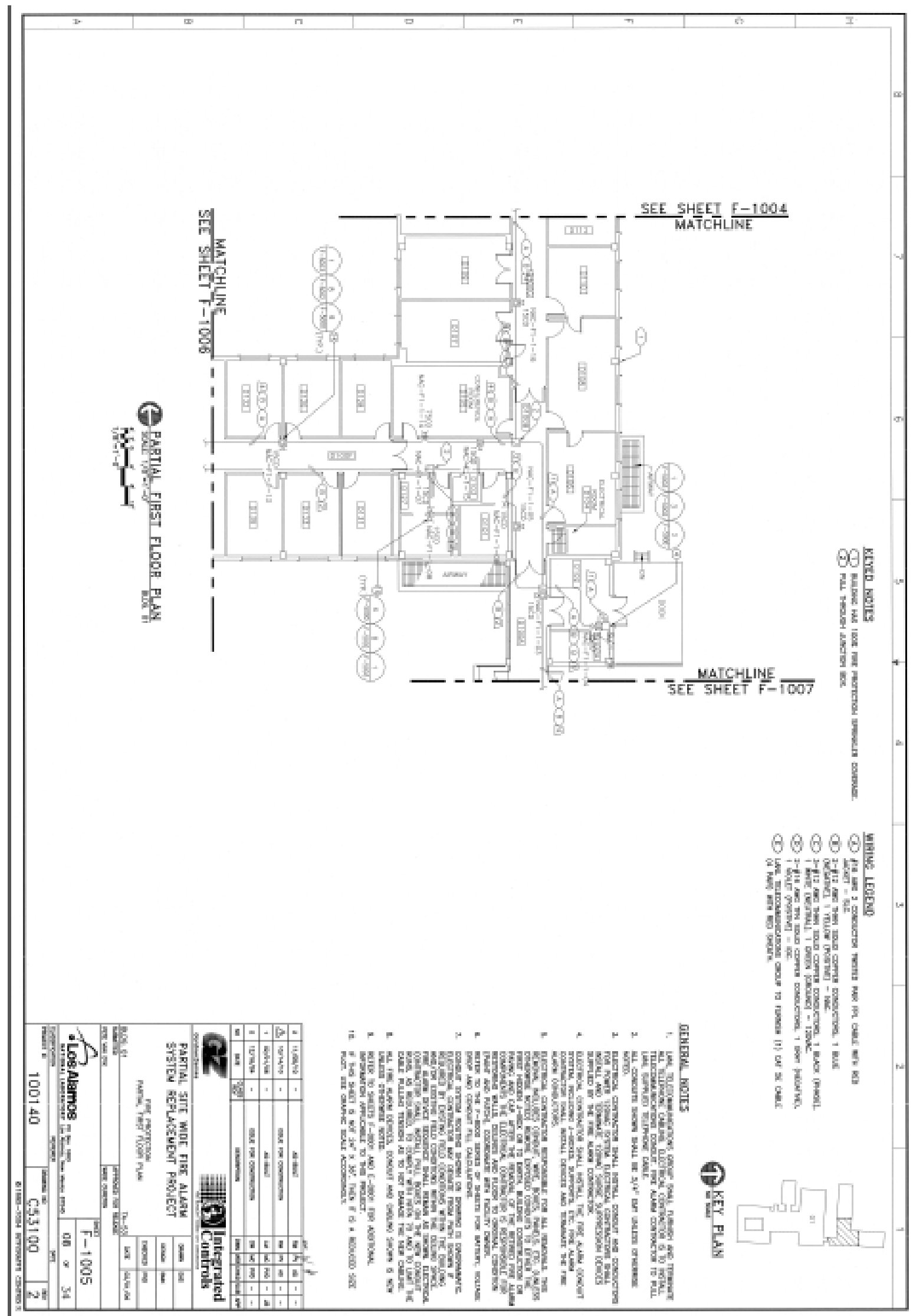




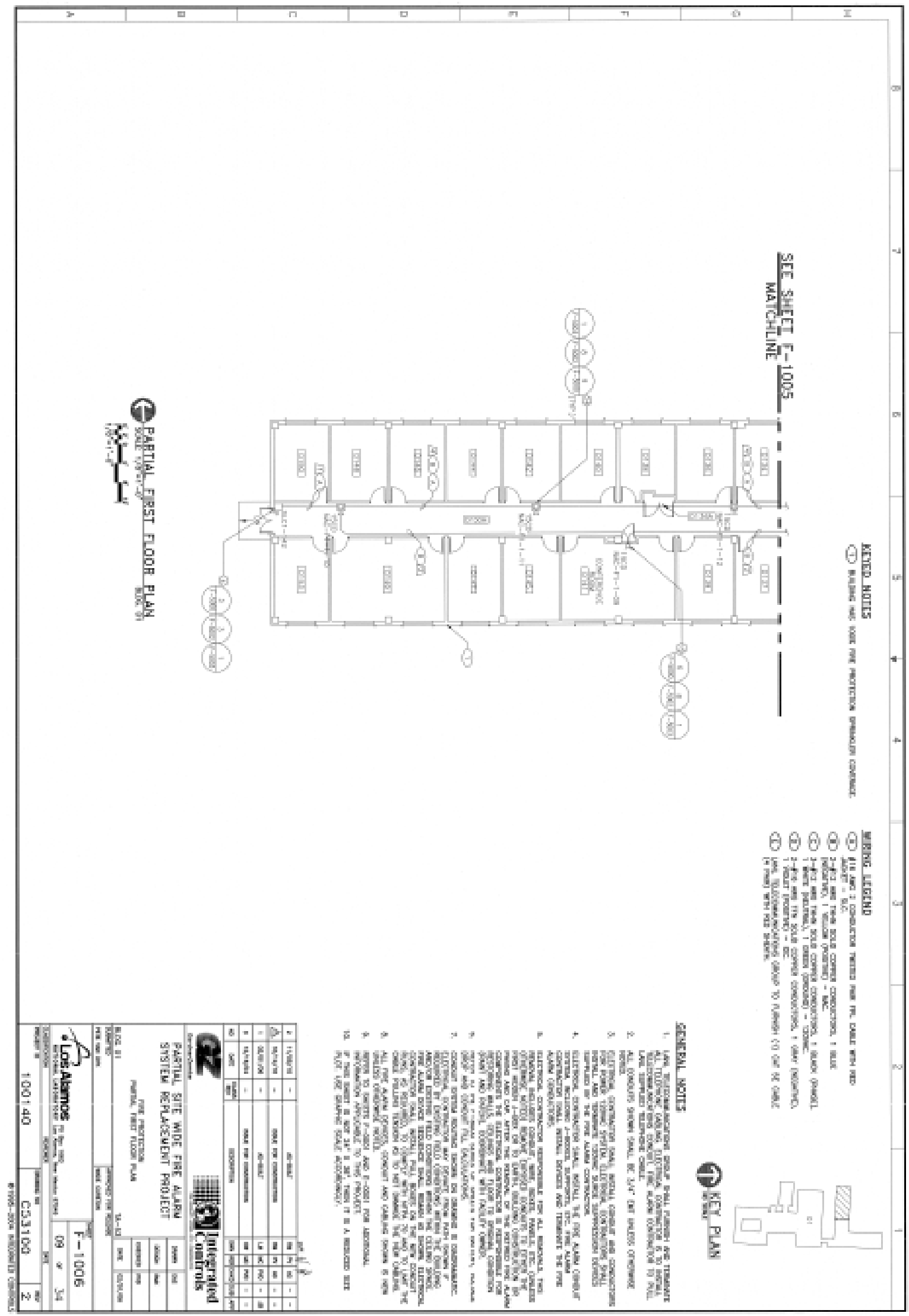




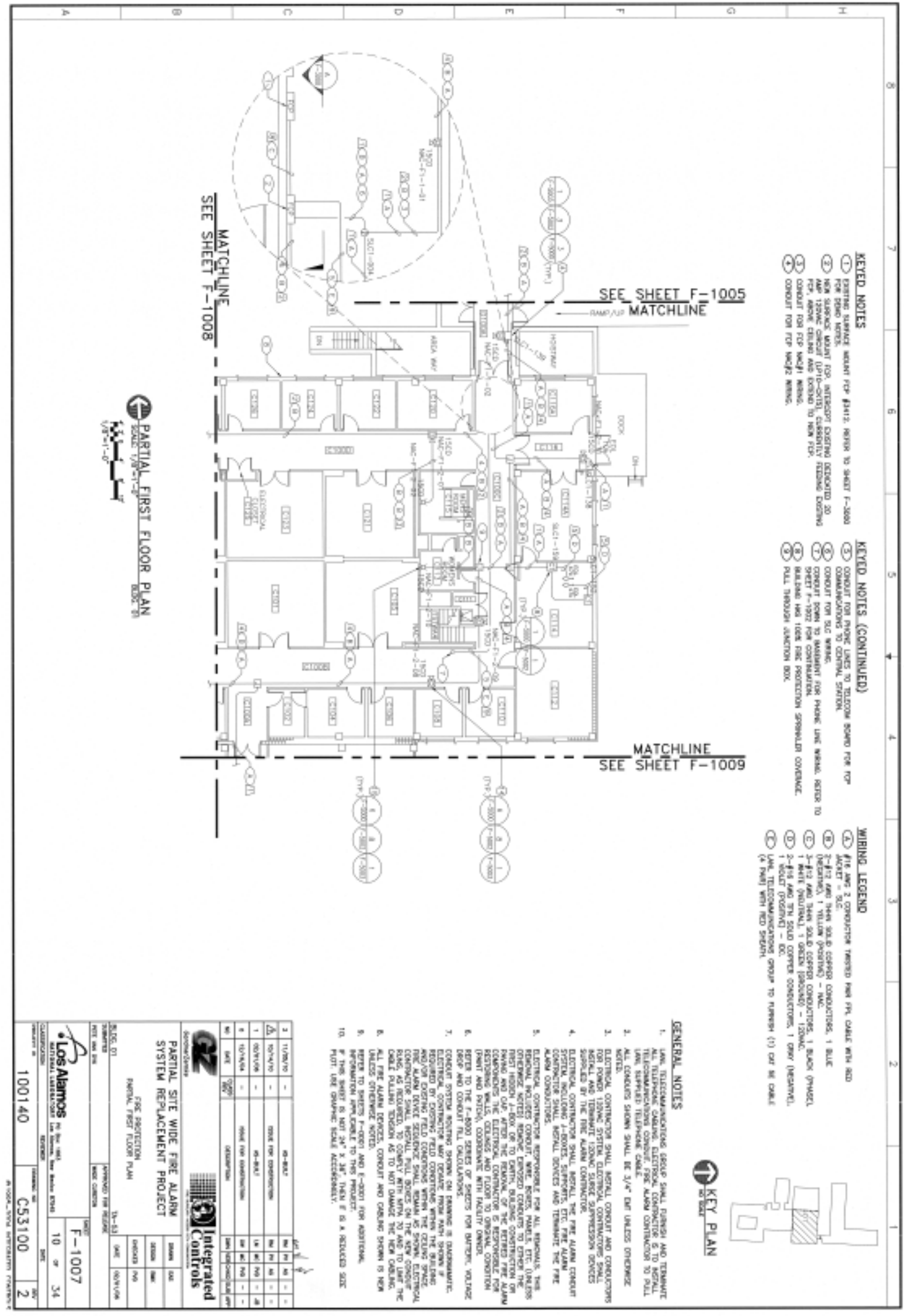




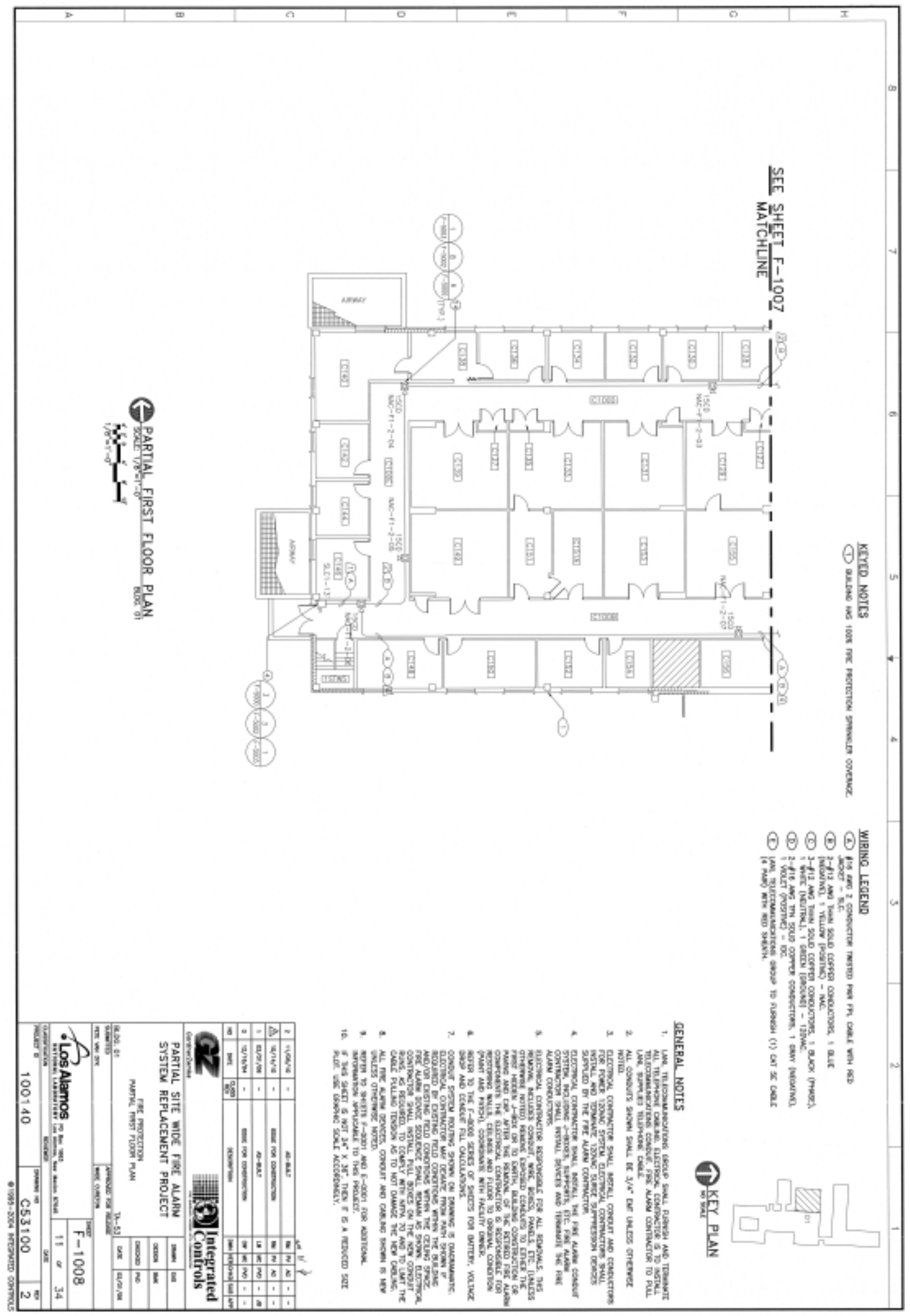




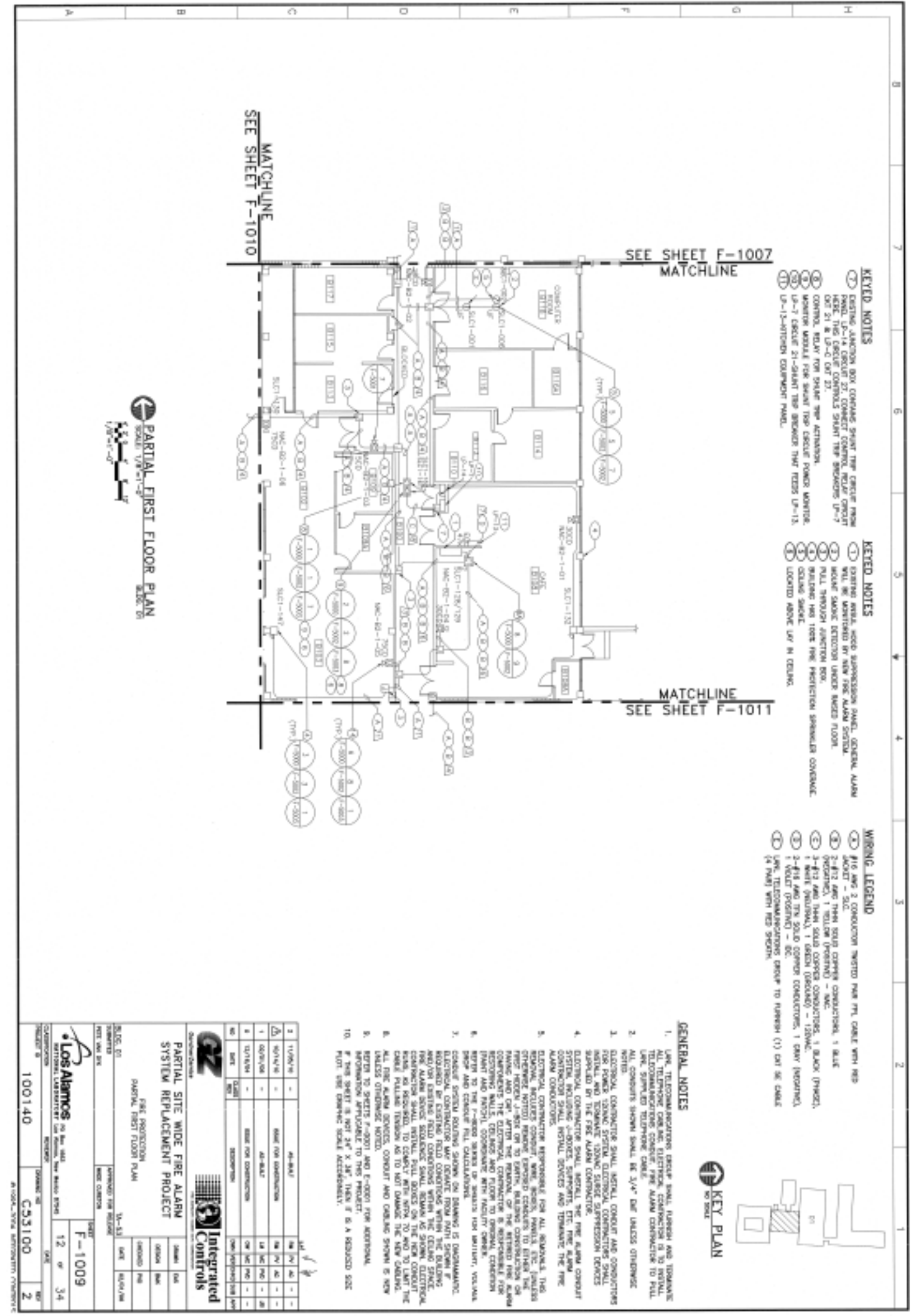




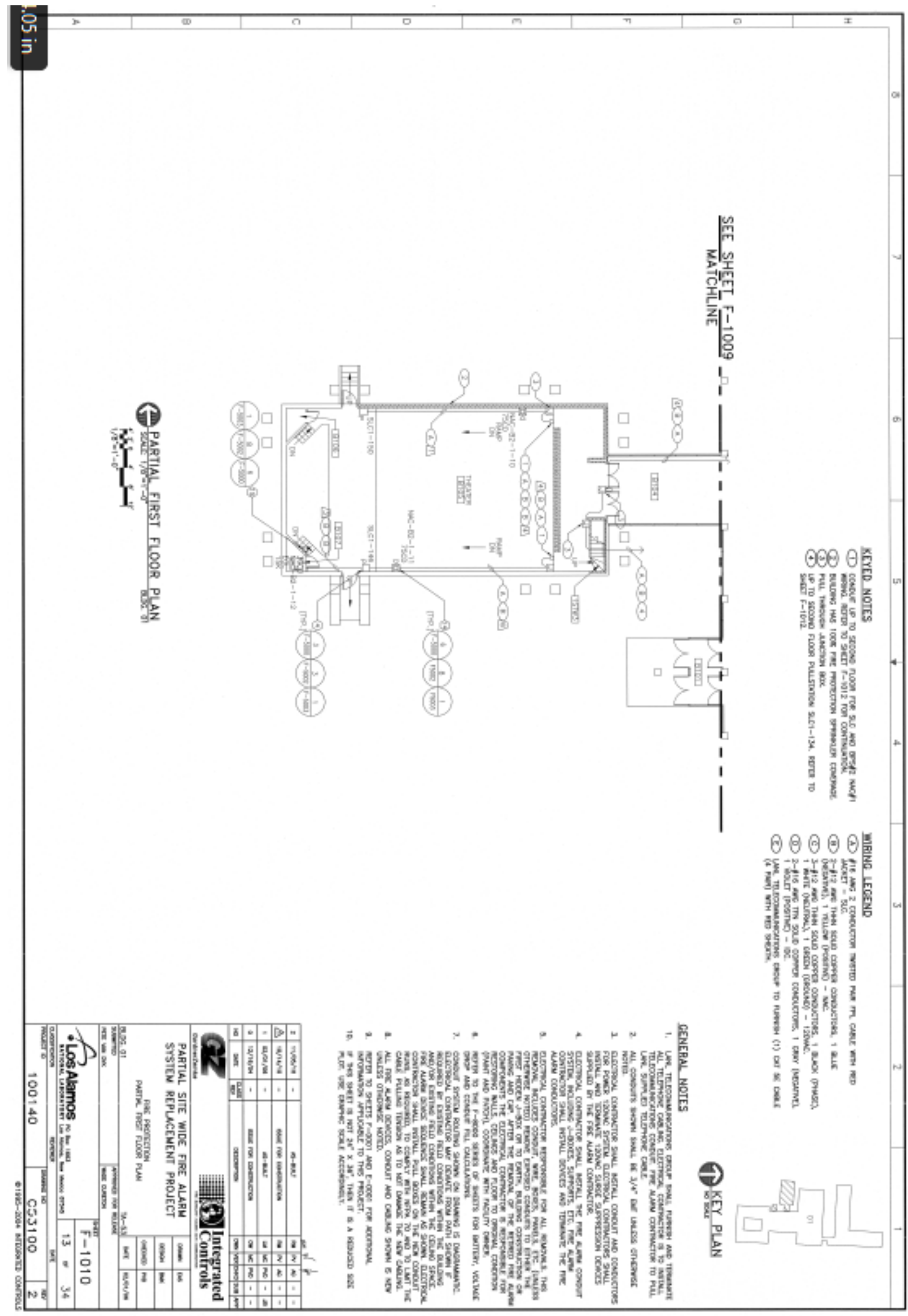




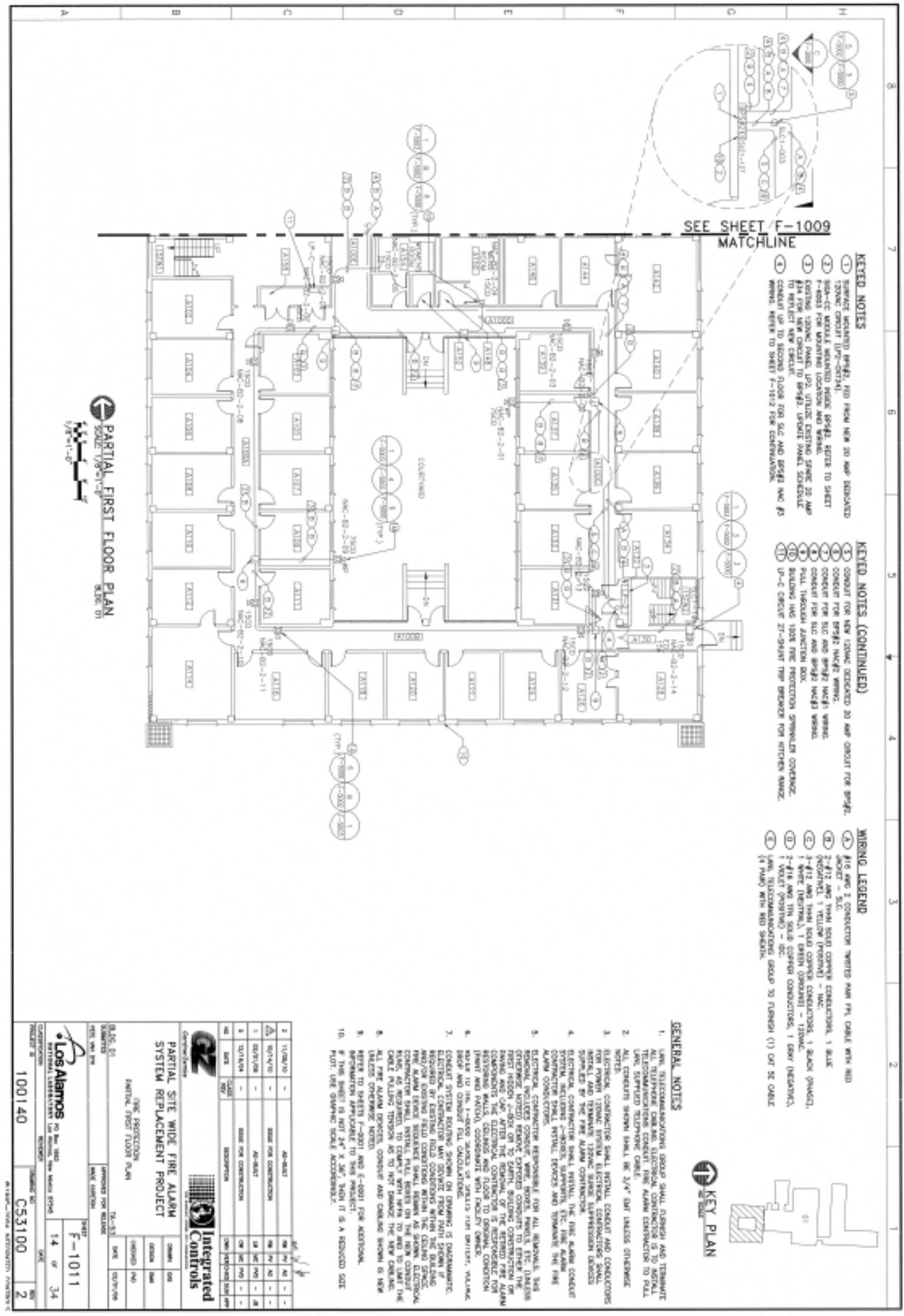




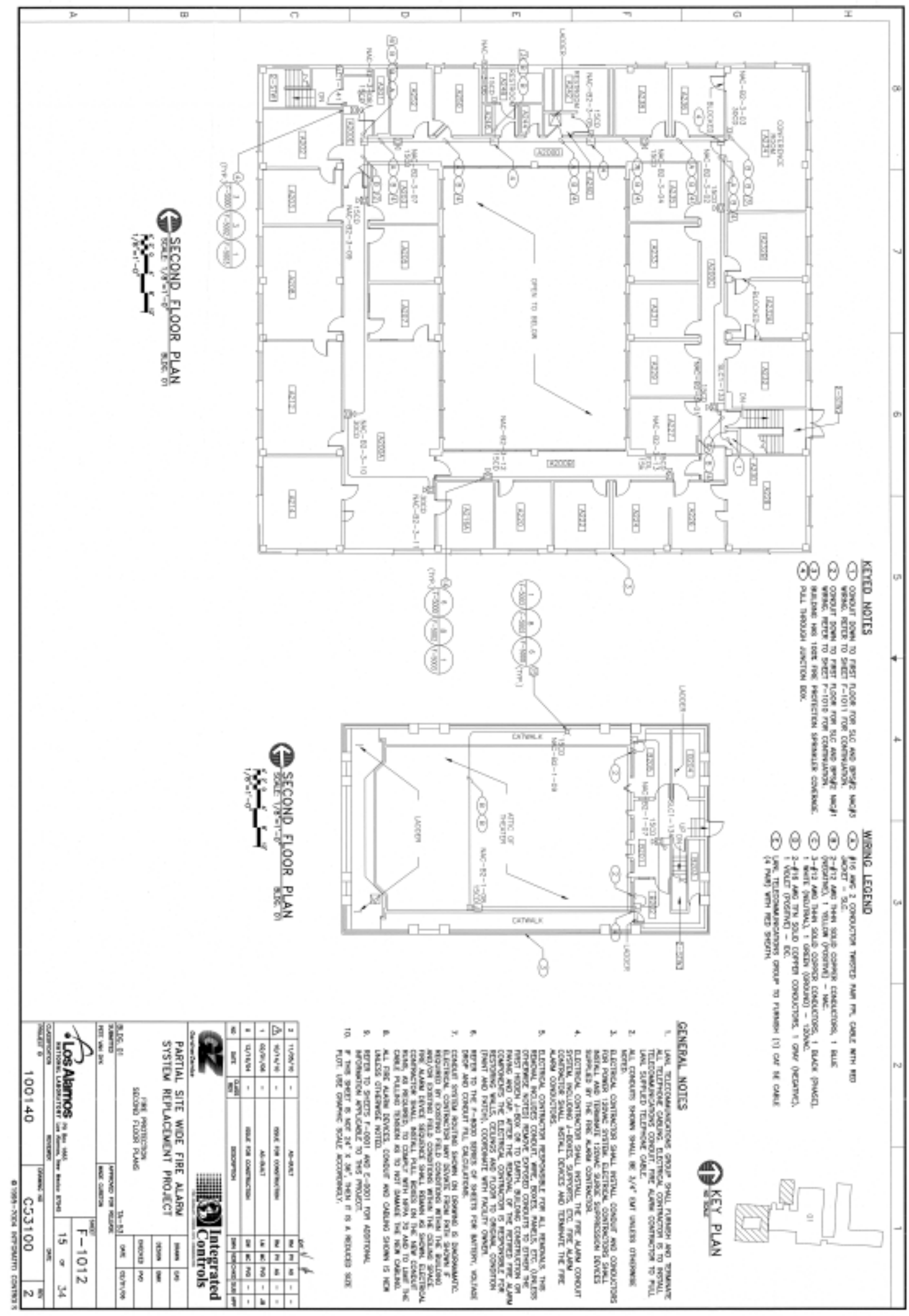




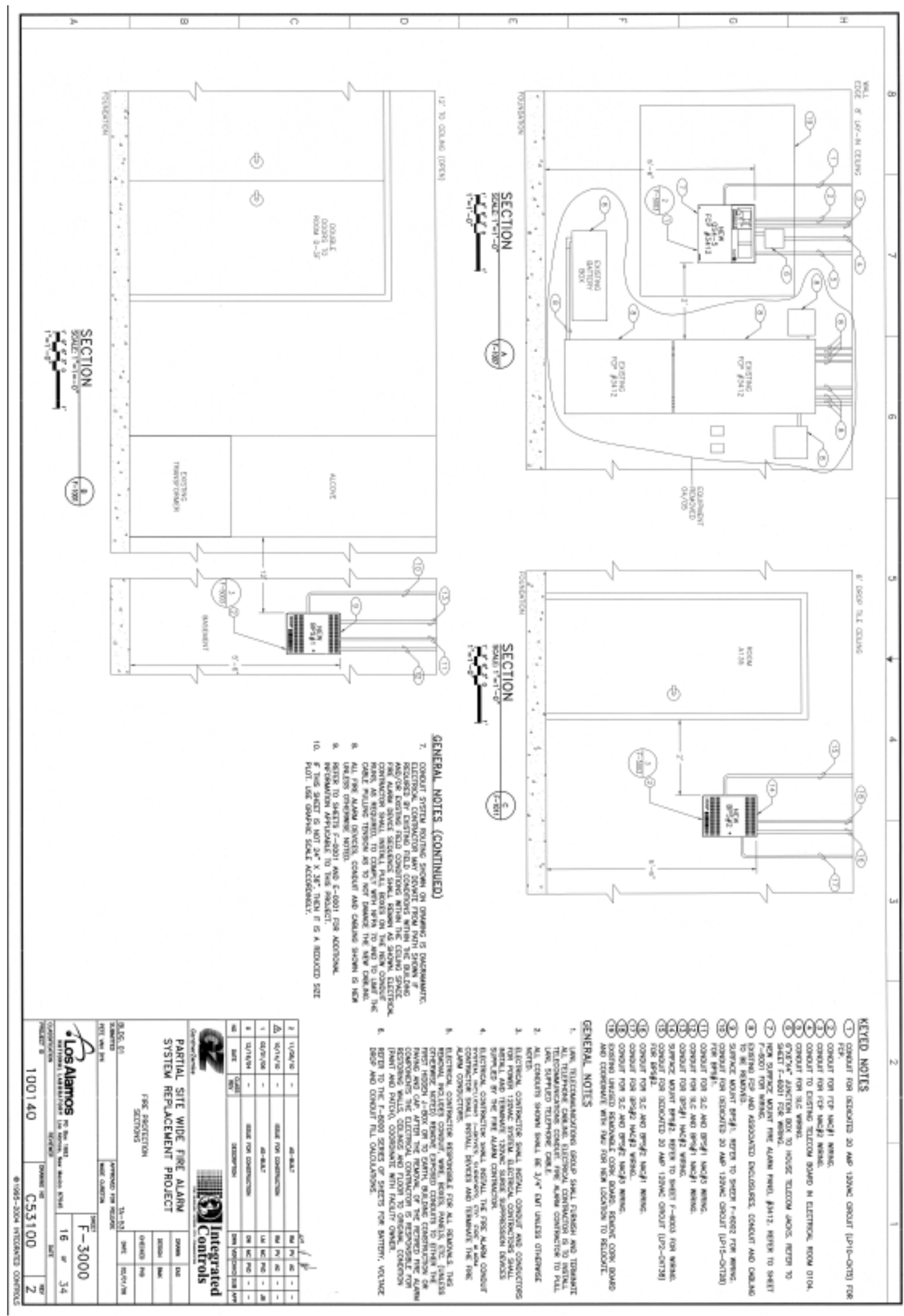




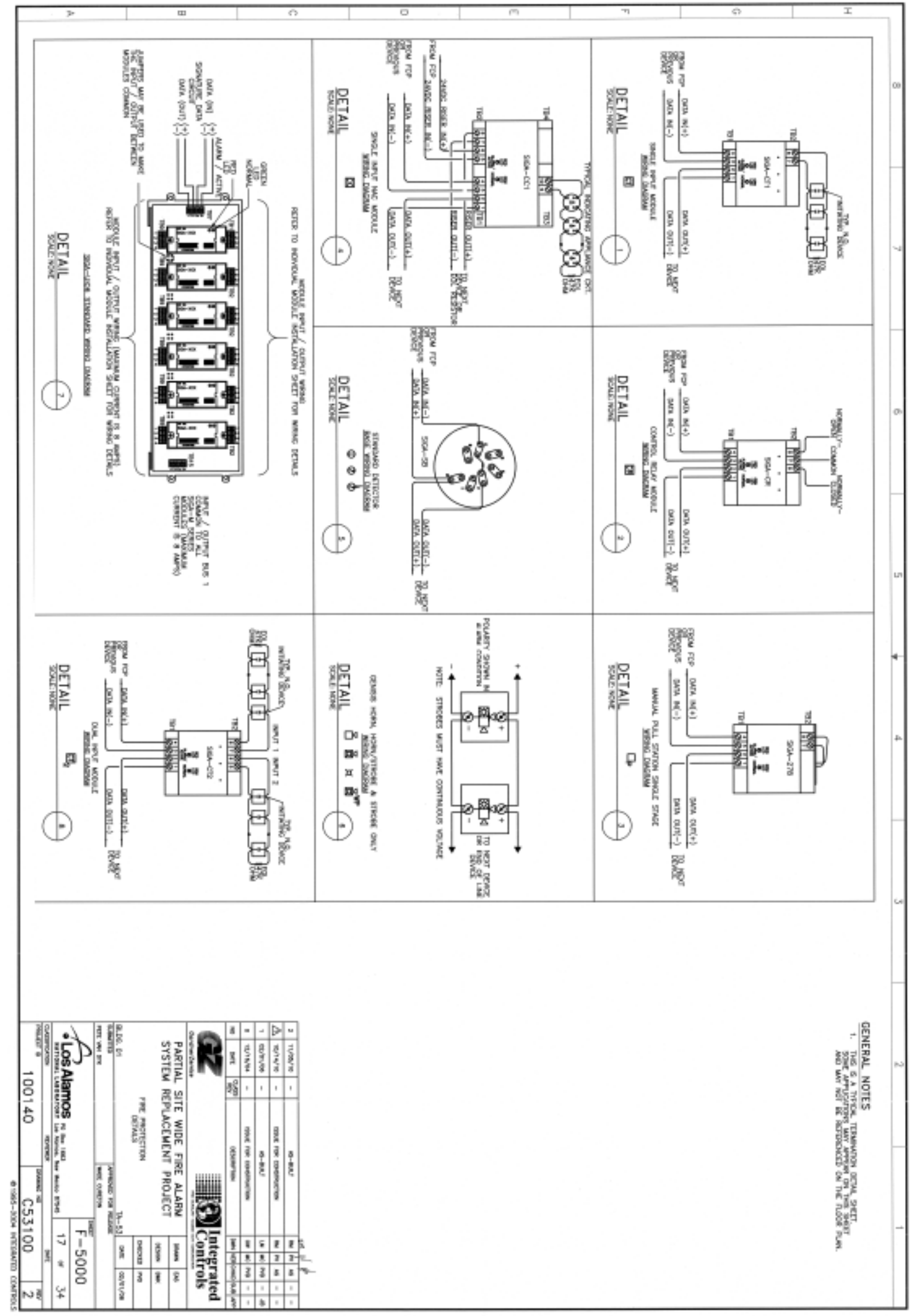




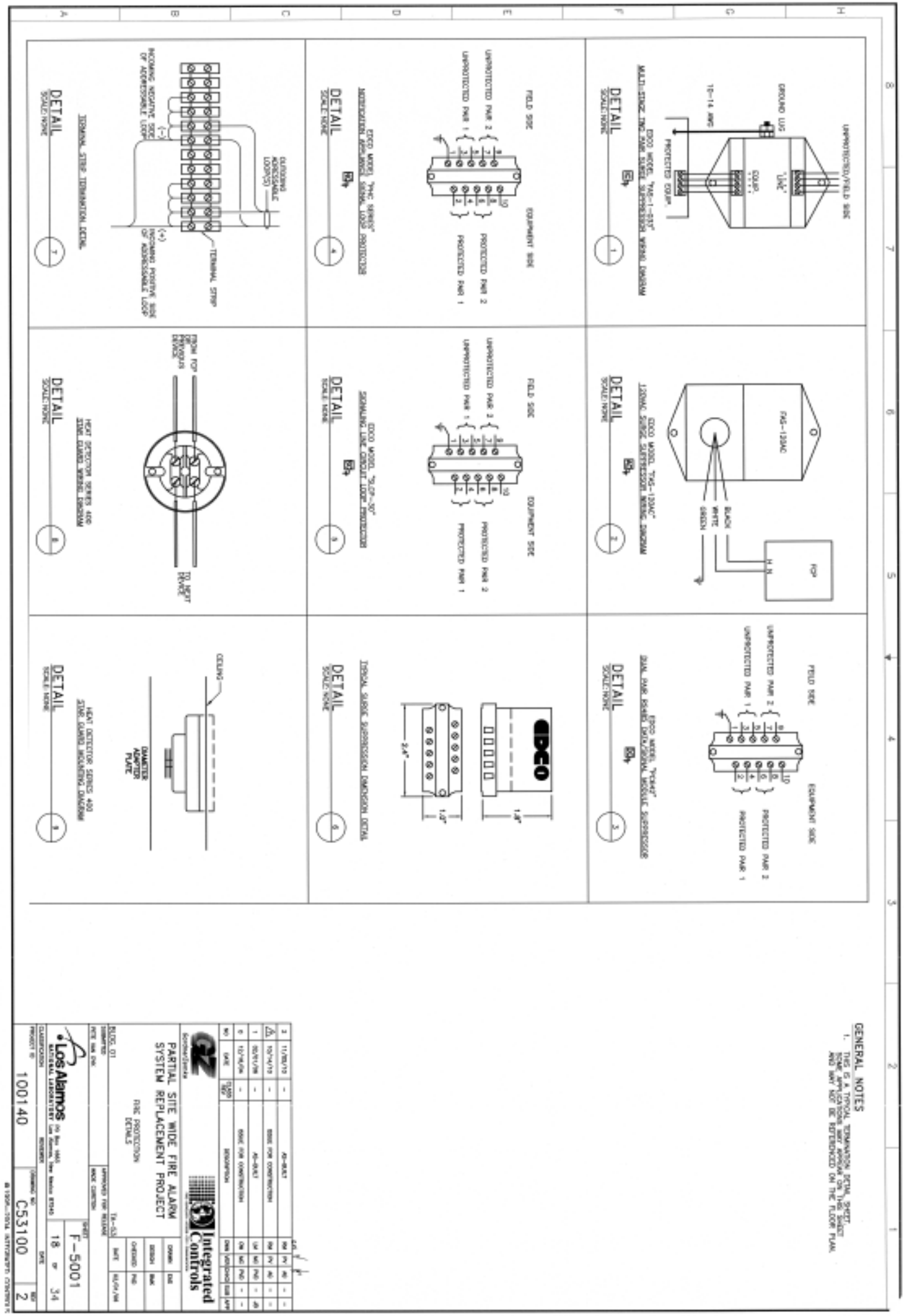




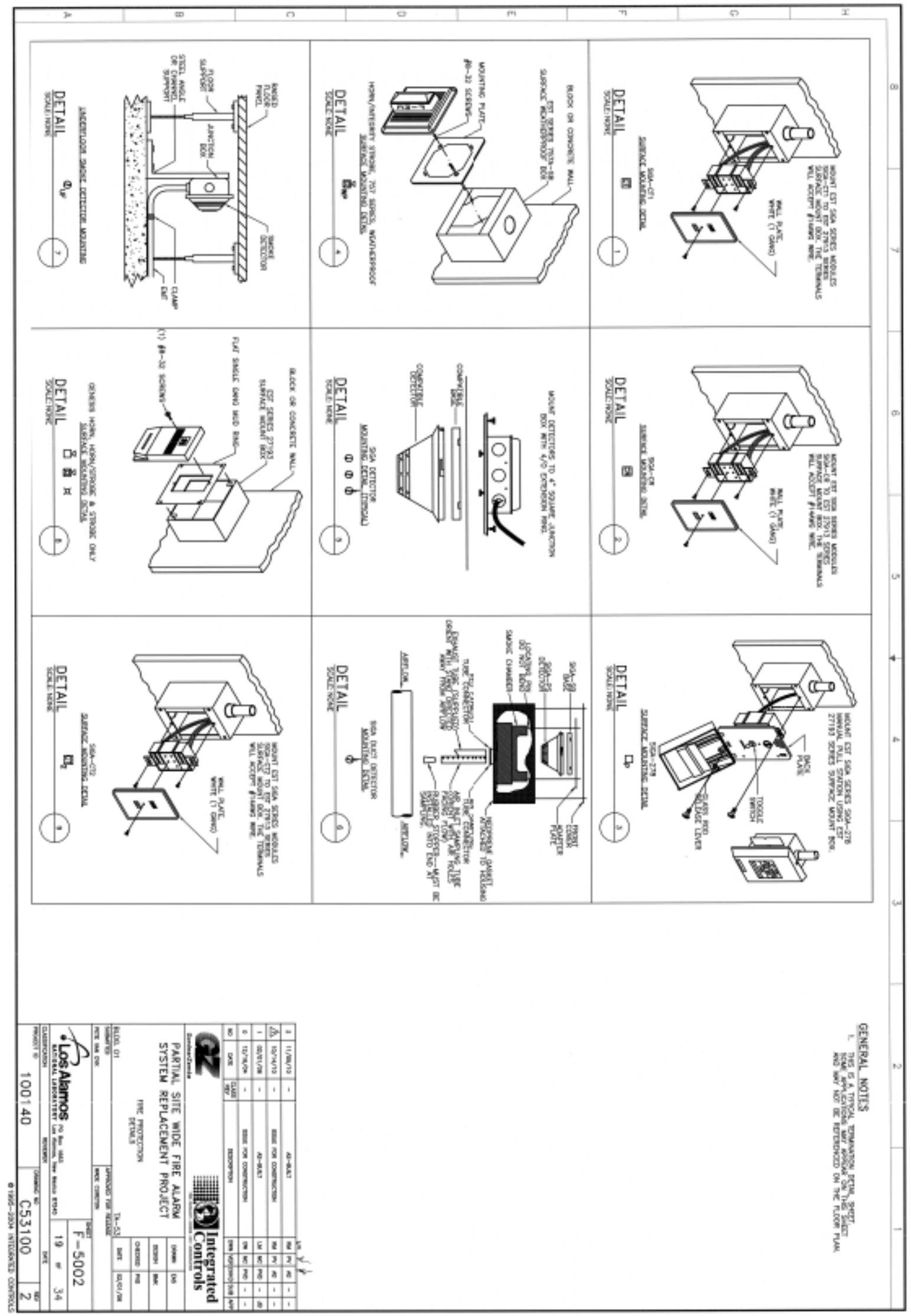




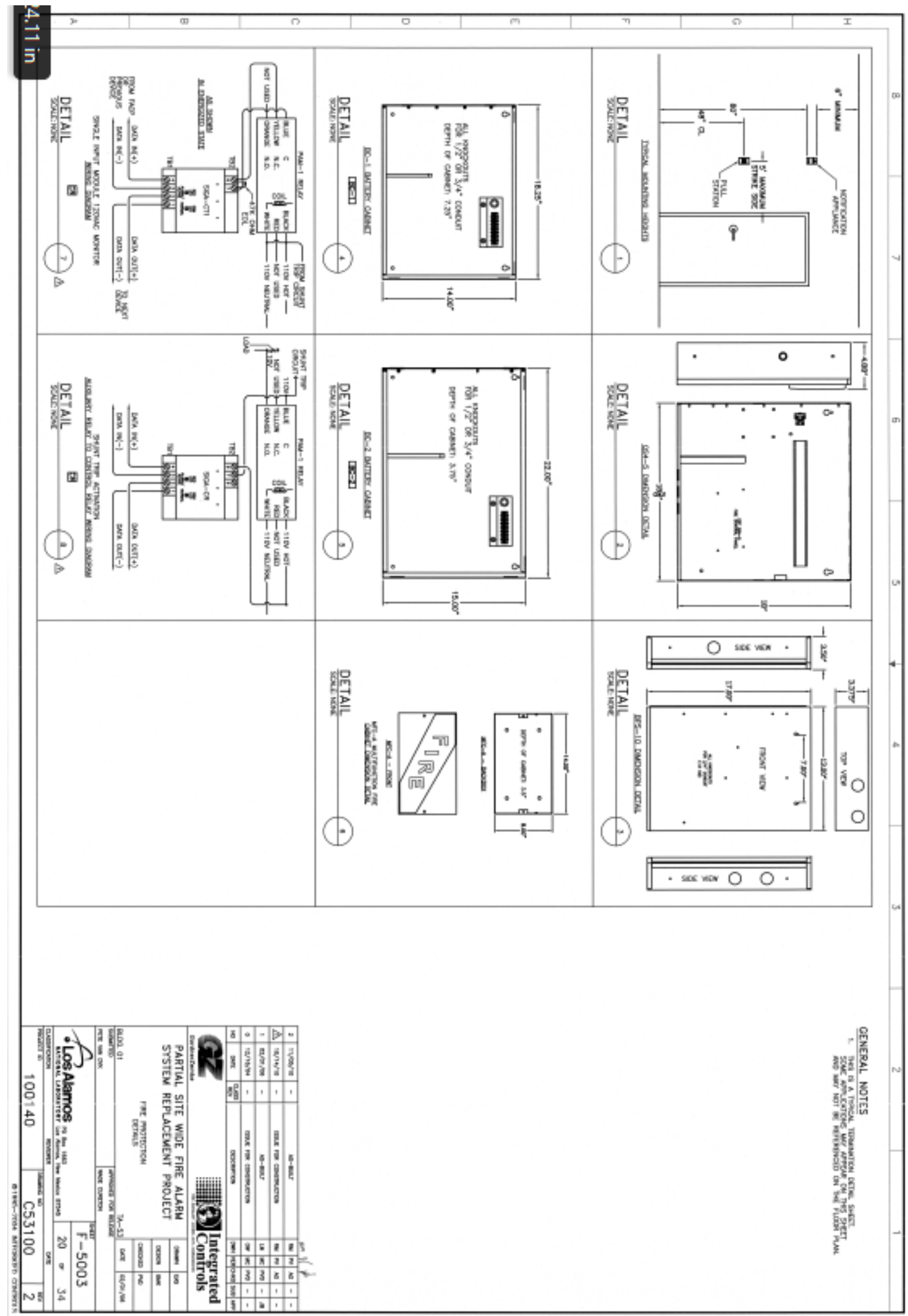


Brett Noakes

June 2015

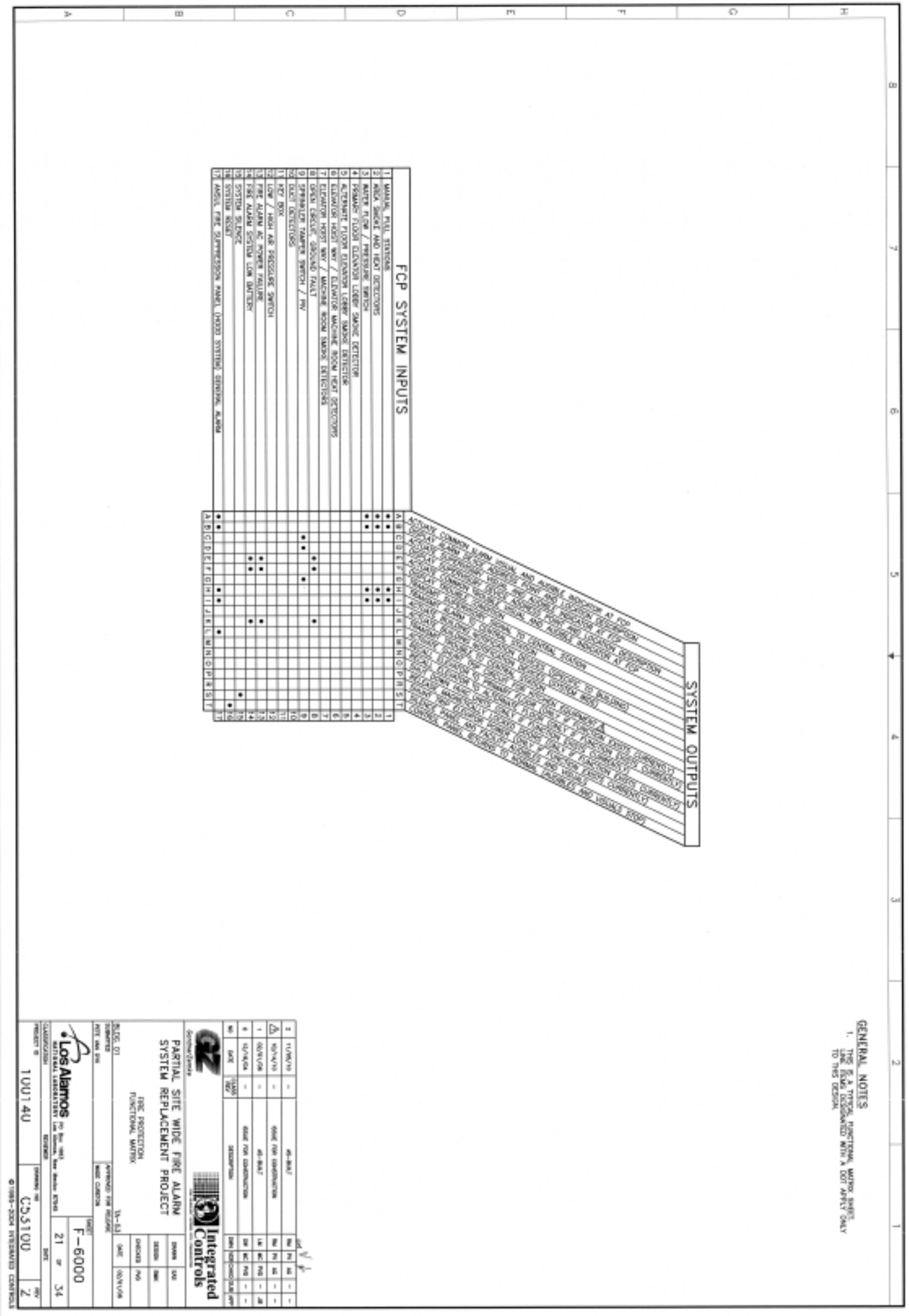




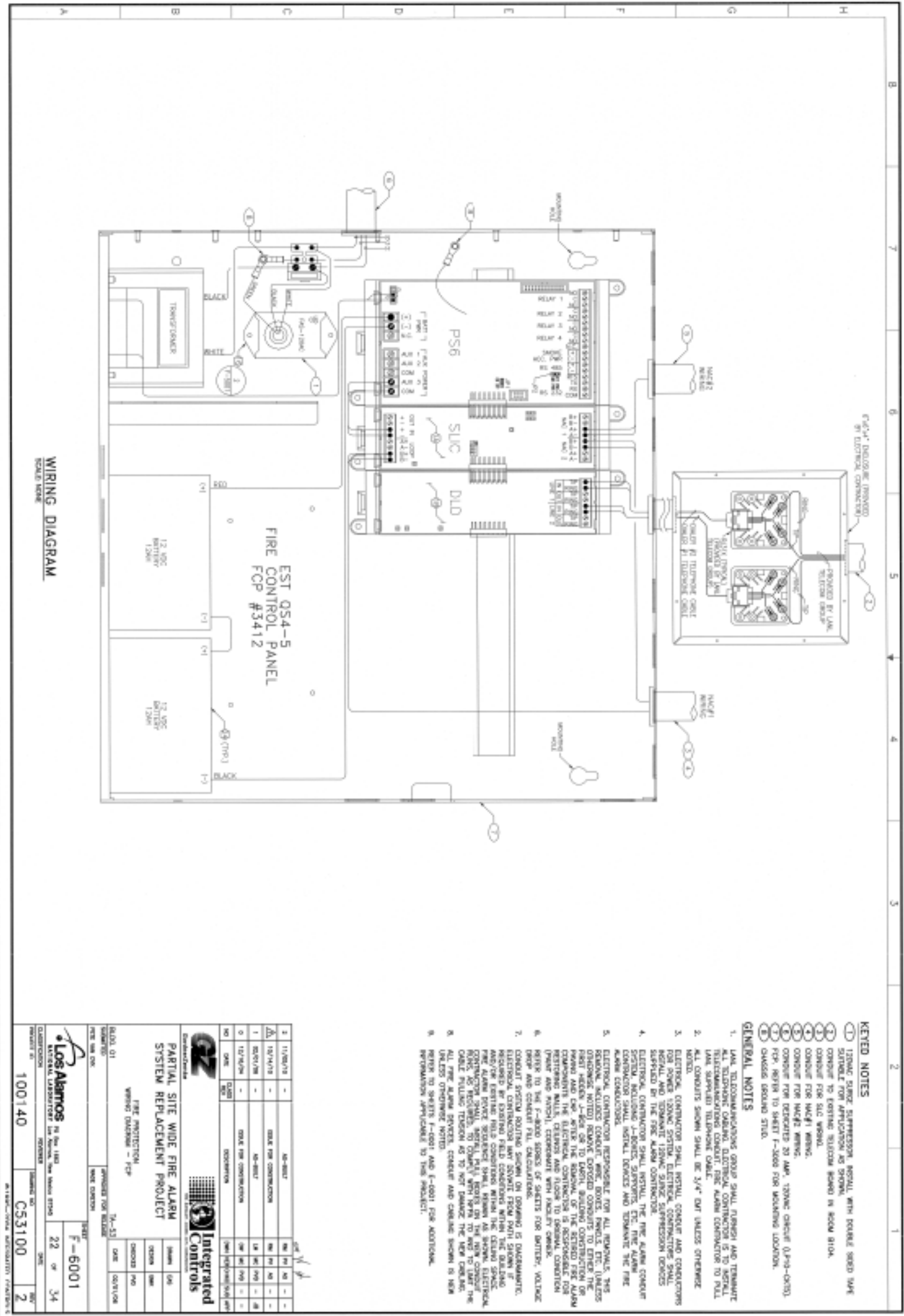




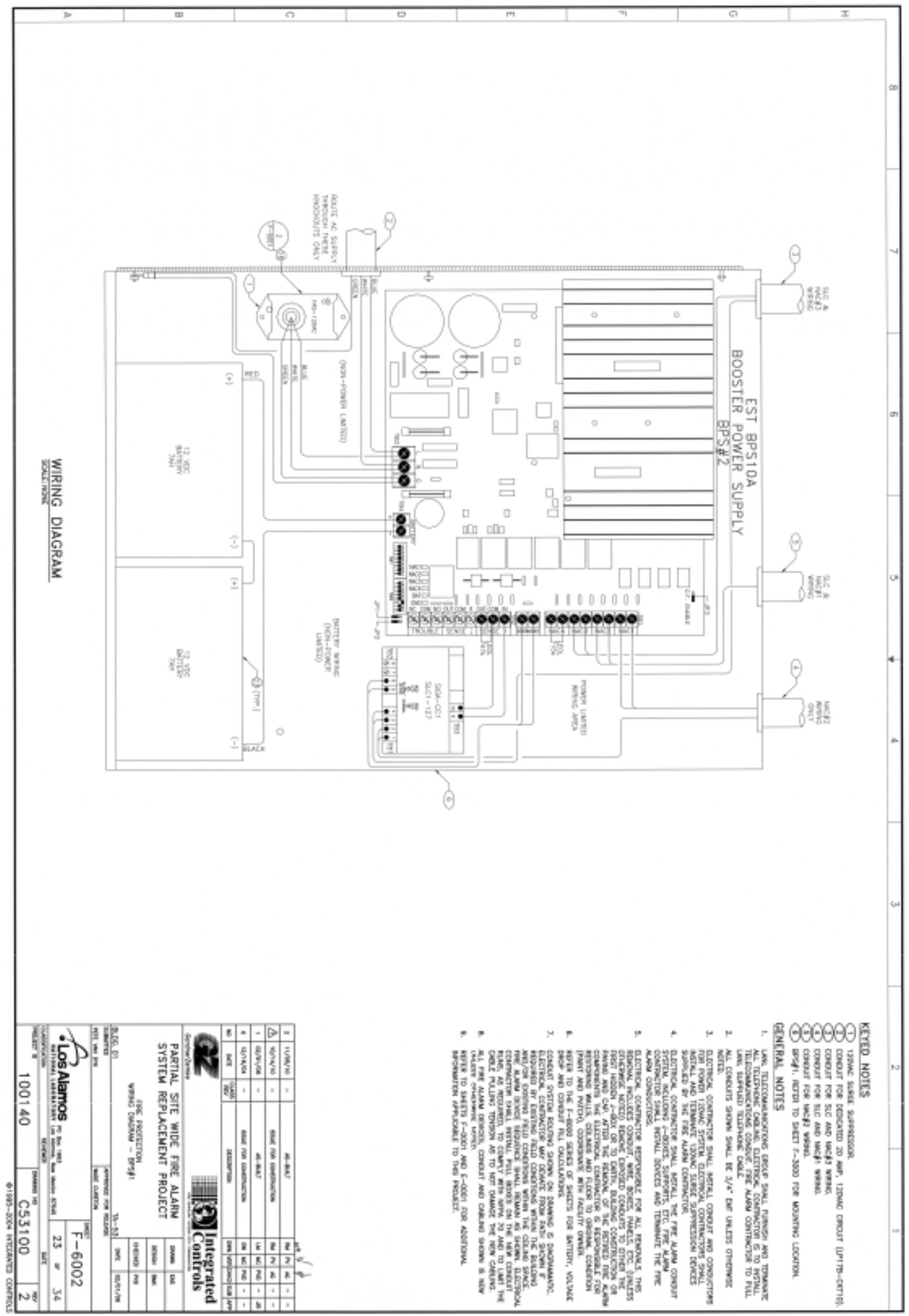



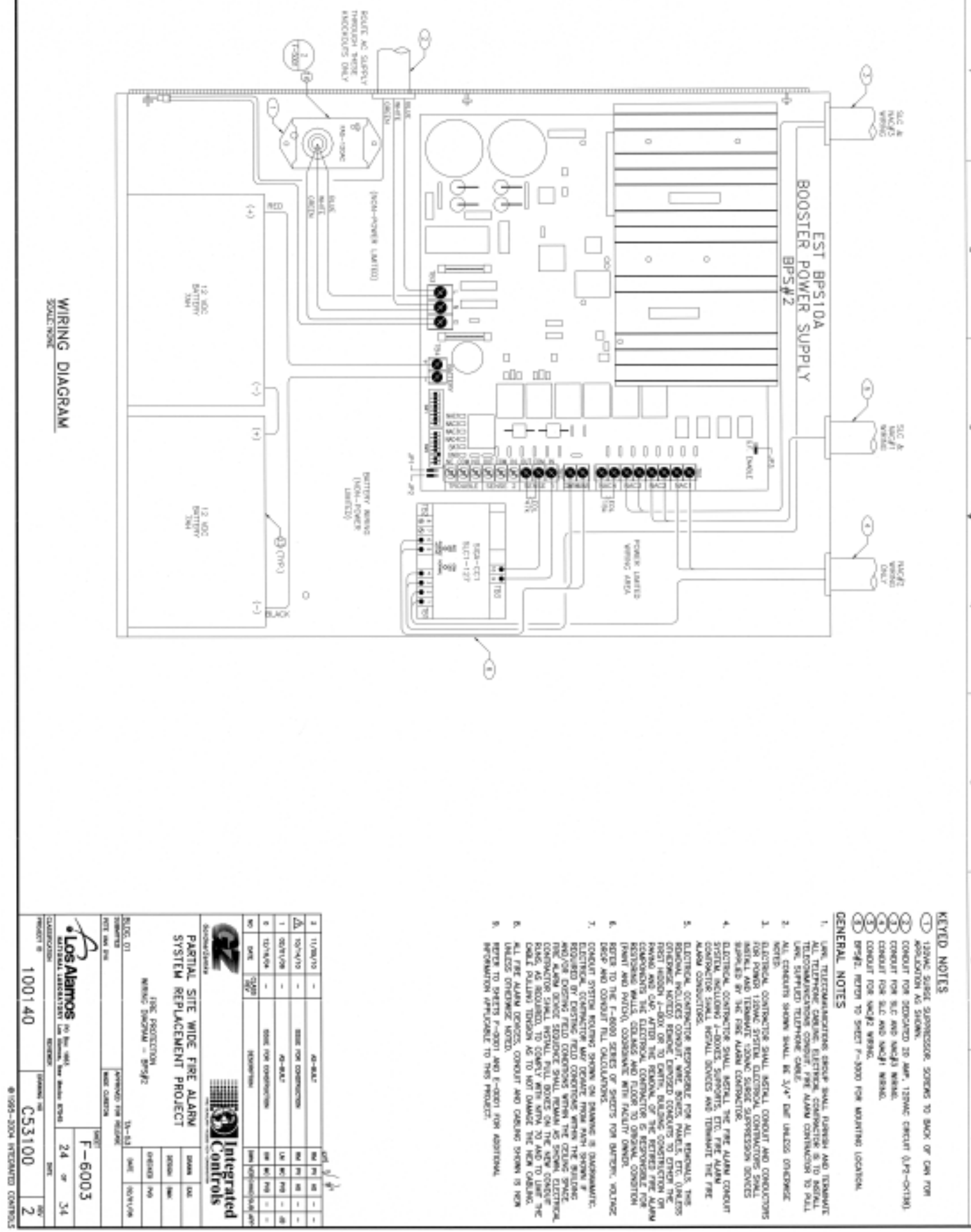


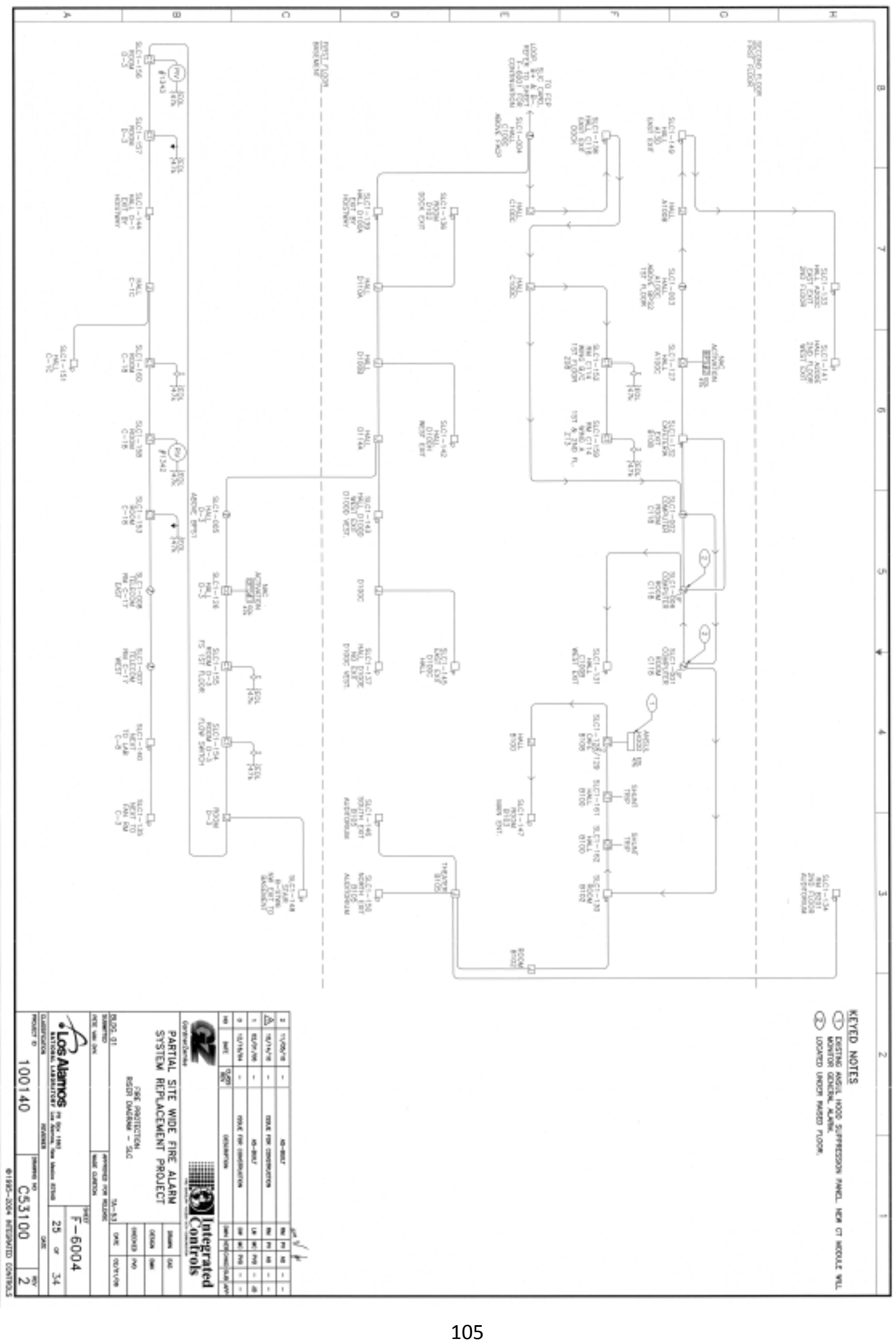




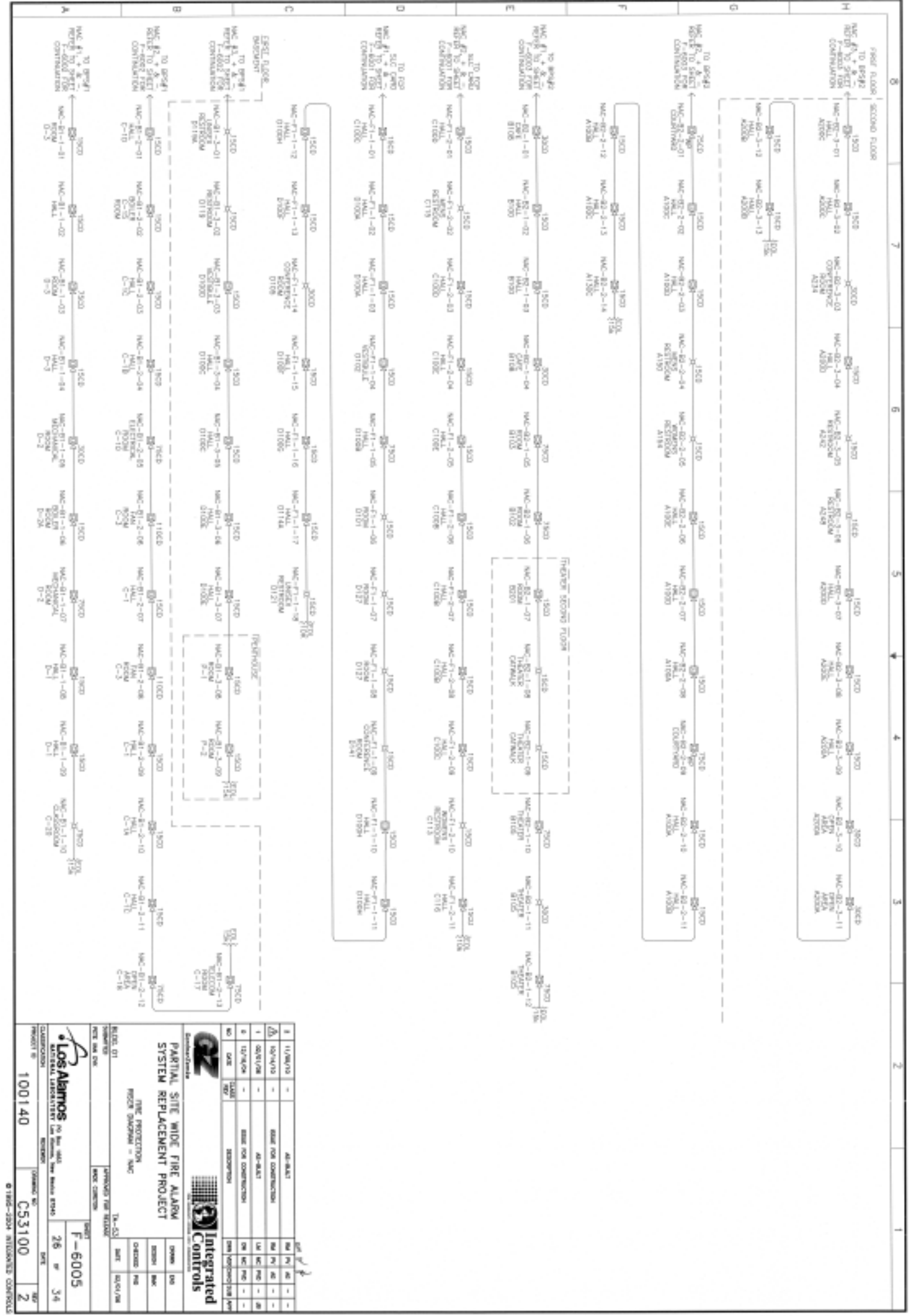




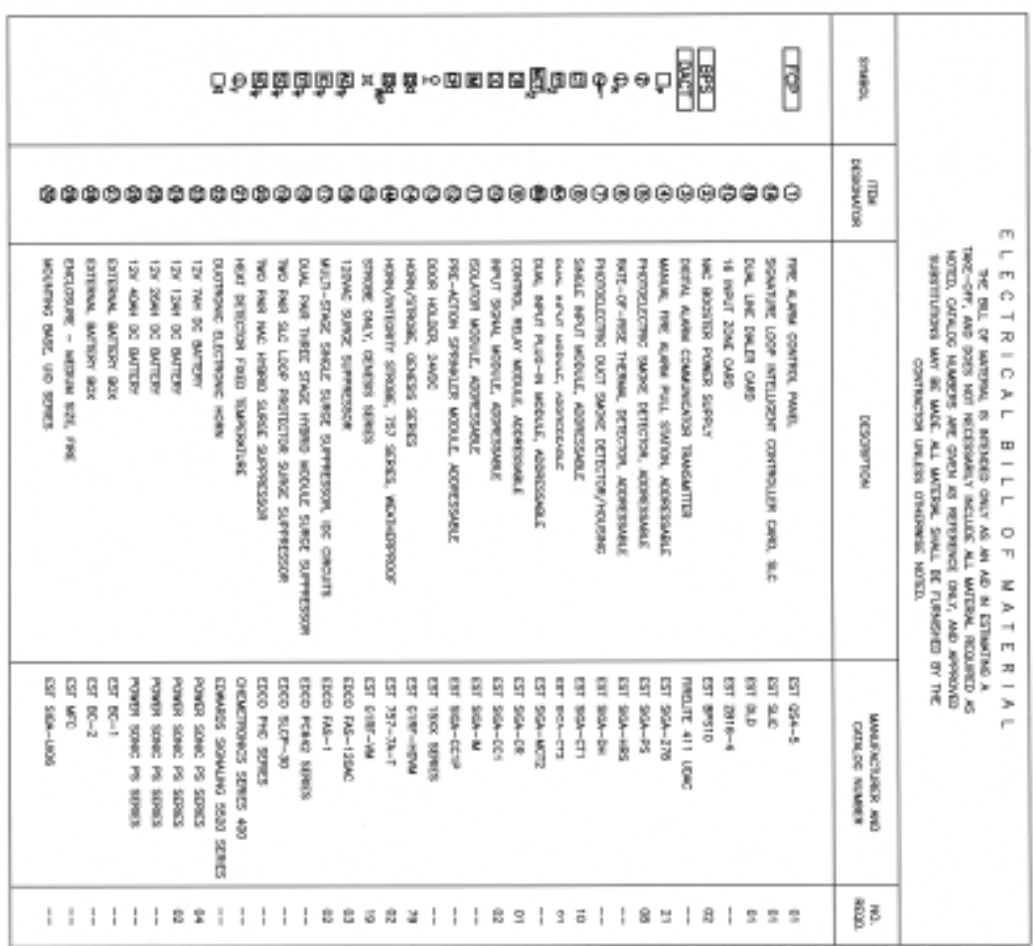

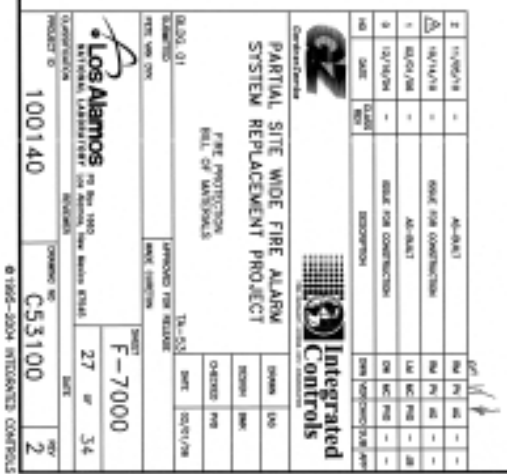




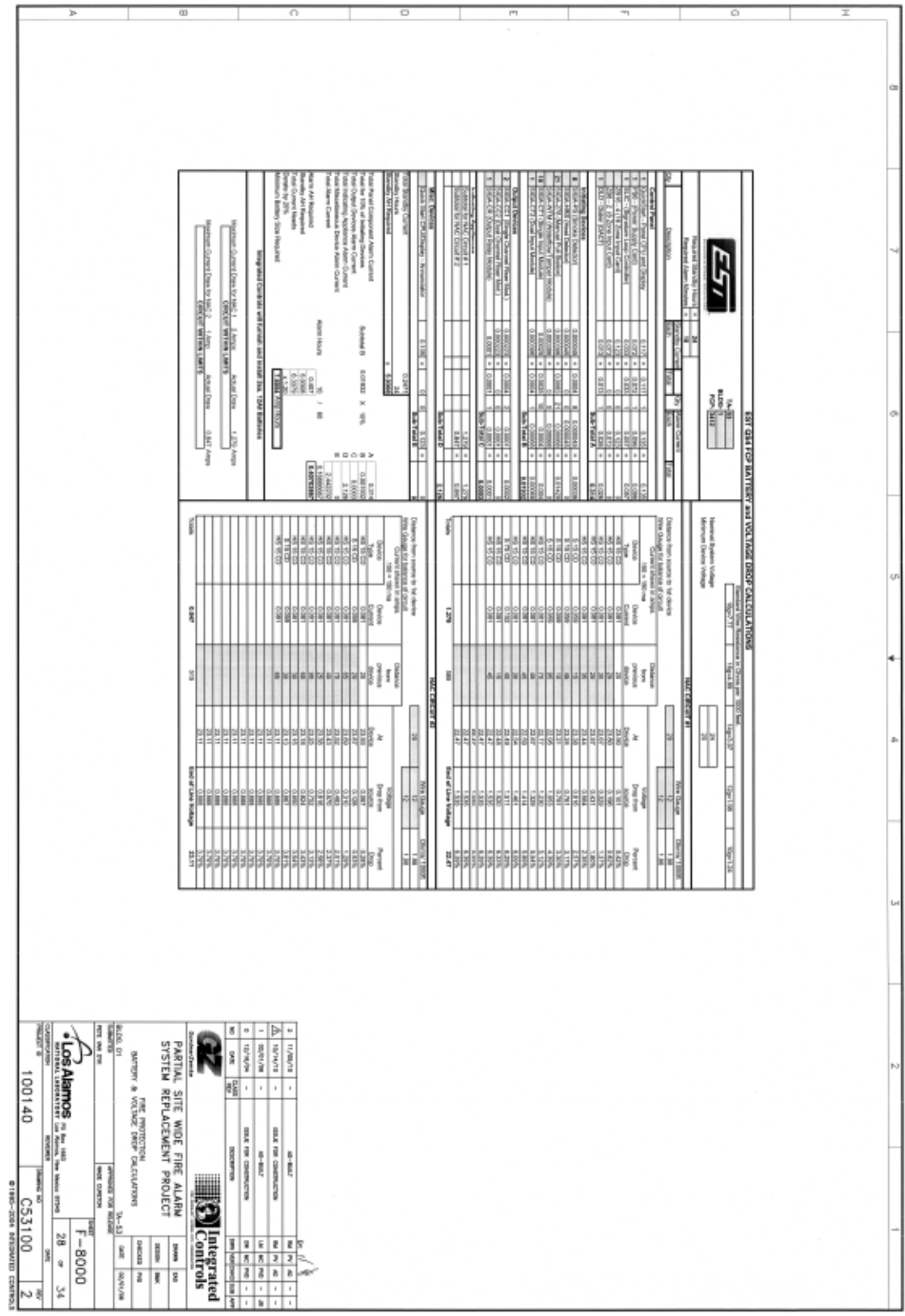




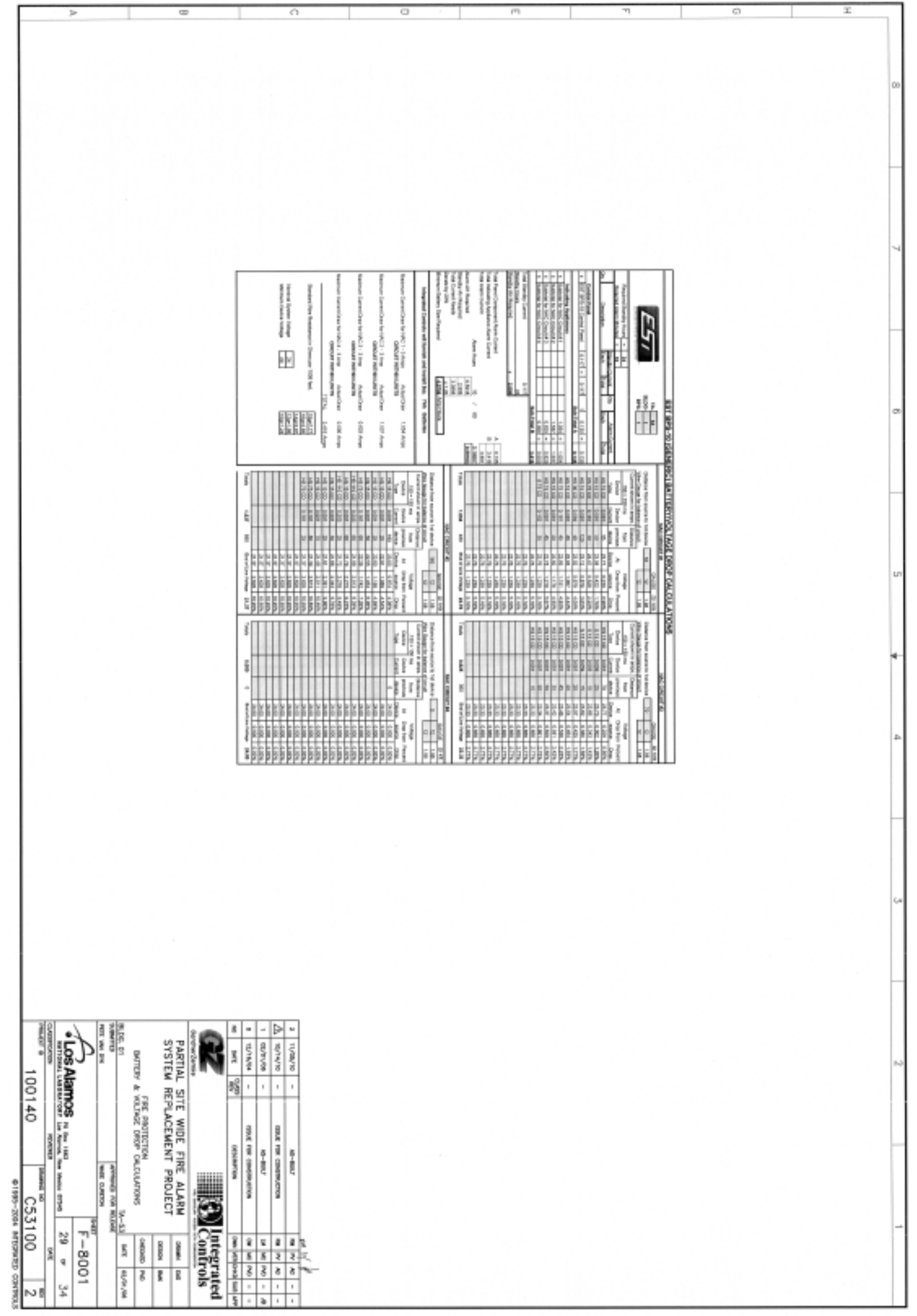




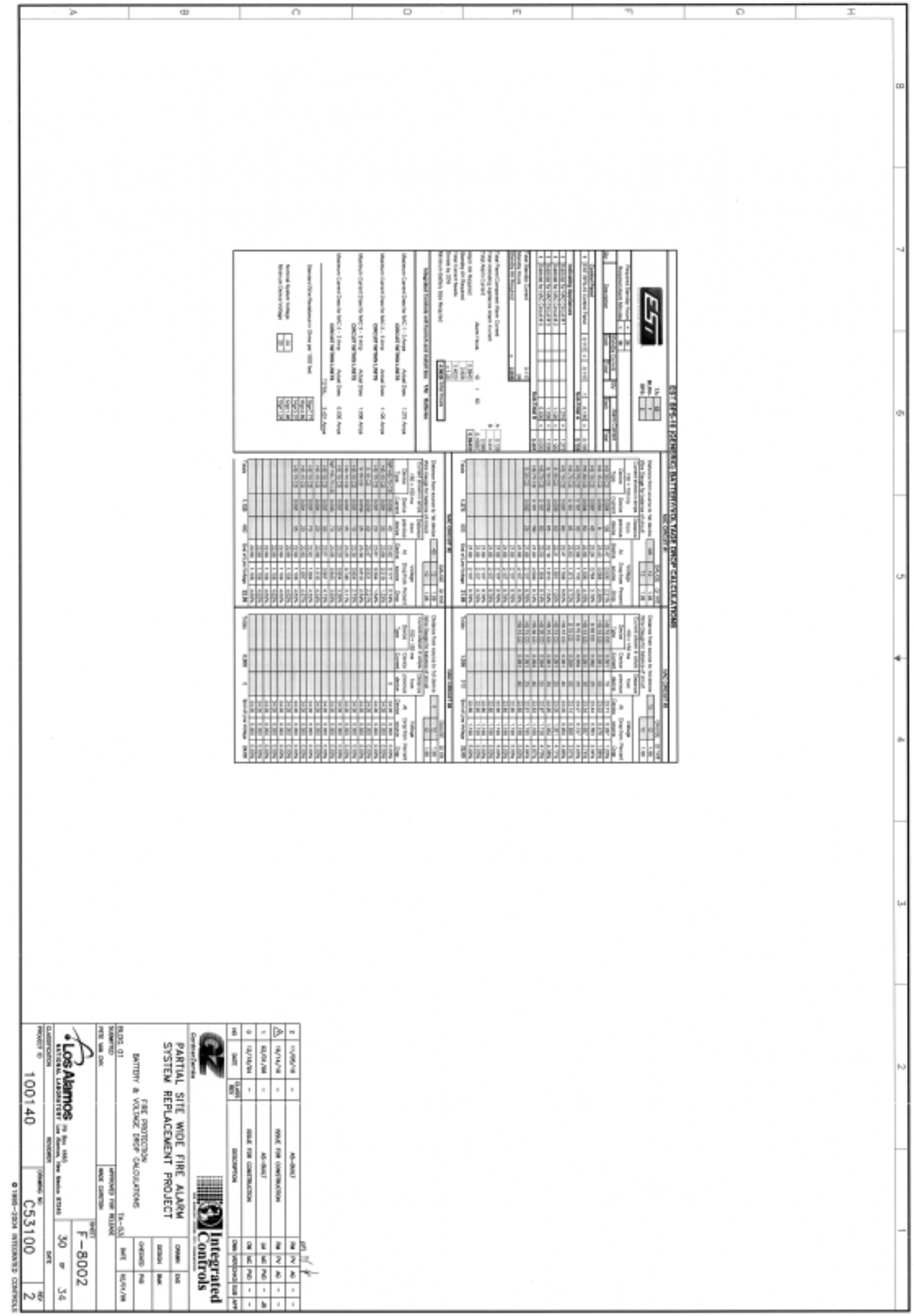




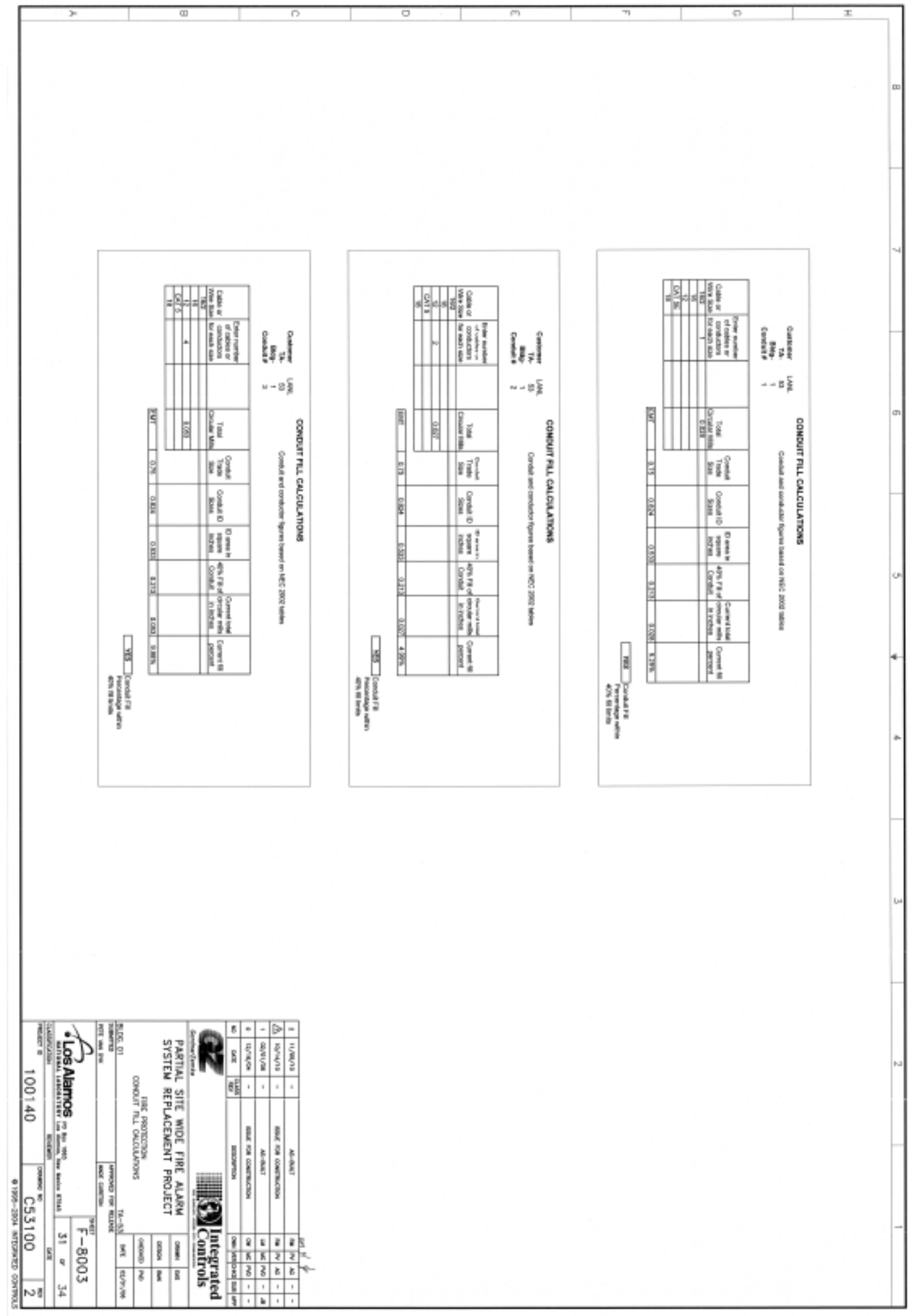




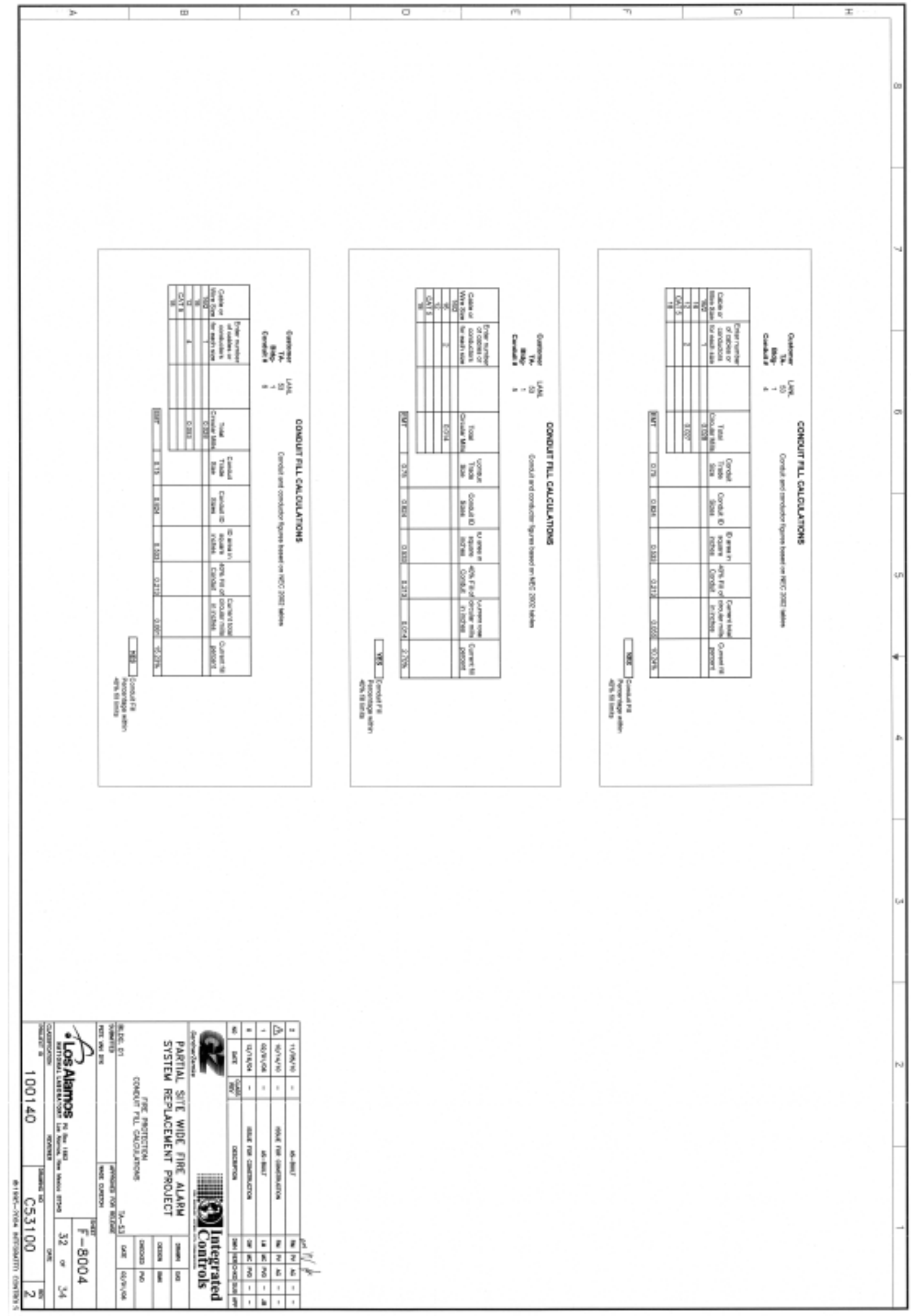




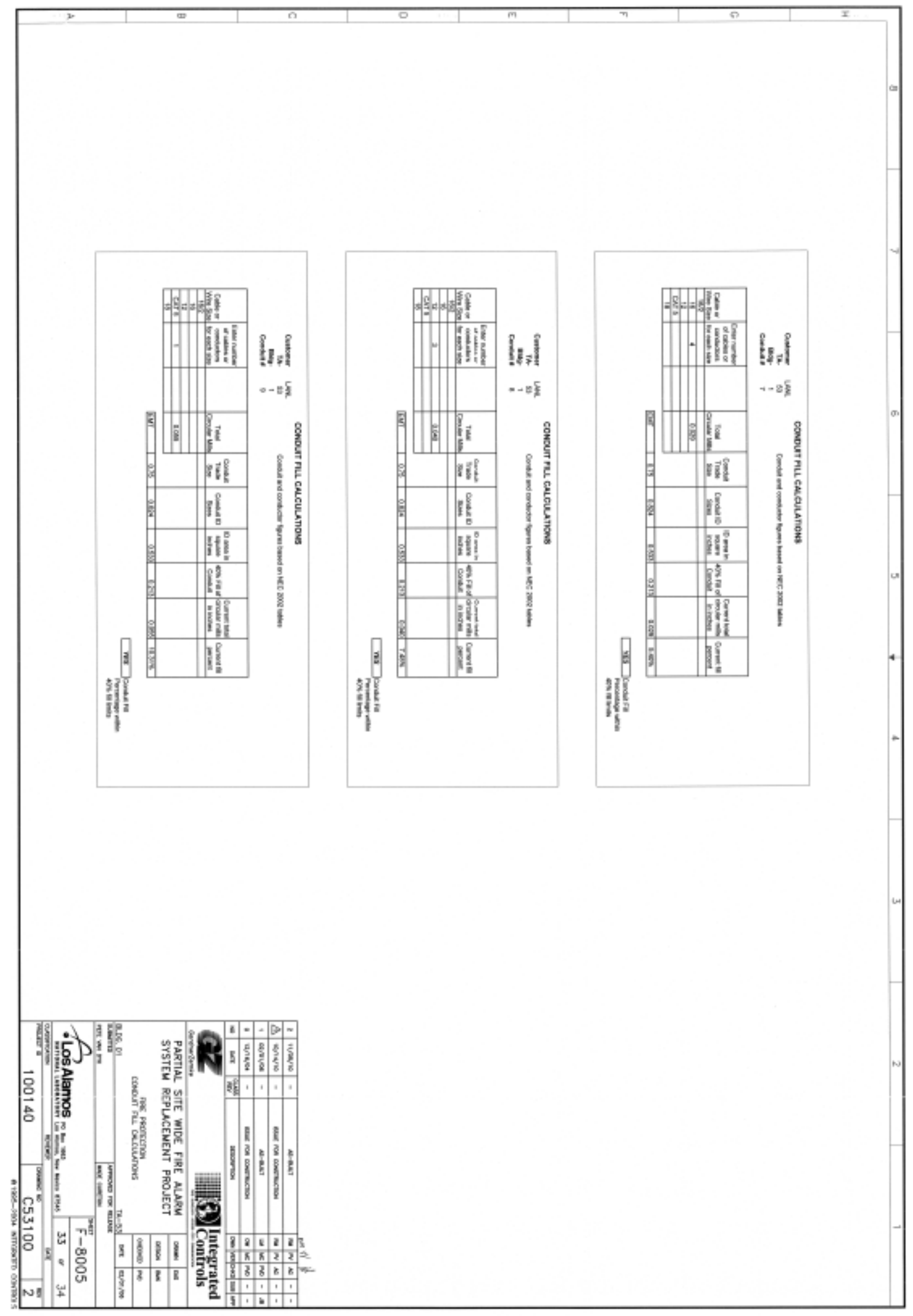


Brett Noakes June 2015

\section{DETACT Models}




\section{Smoke Detectors}

DETACT.XLS: Estimate of the response time of ceiling mounted fire detectors

\begin{tabular}{|r|c|l|r|r|l|}
\hline \multicolumn{1}{|l|}{ INPUT PARAMETERS } & CALCULATED PARAMETERS \\
\hline Calculation reset & 1 & 0 or 1 & $\mathrm{R} / \mathrm{H}$ & 3.8148 & - \\
\hline Ceiling height $(\mathrm{H})$ & 2.7 & $\mathrm{~m}$ & $\mathrm{~W} / \mathrm{H}$ & 3.3704 & - \\
\hline Room width $(\mathrm{W})$ & 9.1 & $\mathrm{~m}$ & Temperature factor & 0.1229 & - \\
\hline Radial distance $(\mathrm{R})$ & 10.3 & $\mathrm{~m}$ & Velocity factor & 0.1734 & - \\
\hline Ambient temperature (To) & 20 & $\mathrm{C}$ & Calculation time $(\mathrm{t})$ & 101 & $\mathrm{~s}$ \\
\hline Actuation temperature (Ta) & 27.2 & $\mathrm{C}$ & Fire HRR $(\mathrm{Q})$ & 479.45 & $\mathrm{~kW}$ \\
\hline Rate of rise rating (ROR) & 0 & $\mathrm{C} / \mathrm{min}$ & Gas temperature $(\mathrm{Tg})$ & 44.299 & $\mathrm{C}$ \\
\hline Response time index (RTI) & 1 & $(\mathrm{~m}-\mathrm{s}) 1 / 2$ & Gas velocity $(\mathrm{Ug})$ & 0.9747 & $\mathrm{~m} / \mathrm{s}$ \\
\hline Fire growth power $(\mathrm{n})$ & 2 & - & ROR at detector & 19.278 & $\mathrm{C} / \mathrm{min}$ \\
\hline Fire growth coefficient (k) & 0.047 & $\mathrm{~kW} / \mathrm{s}^{\wedge} \mathrm{n}$ & Detector temp $(\mathrm{Td})$ & 44.294 & $\mathrm{C}$ \\
\hline Fire location factor (kLF) & 1 & - & Detection trigger & 61 & 100 \\
\hline
\end{tabular}

\begin{tabular}{|r|c|}
\hline Representative t2 coeff. & $k$ \\
\hline Slow & 0.003 \\
\hline Medium & 0.012 \\
\hline Fast & 0.047 \\
\hline Ultrafast & 0.400 \\
\hline
\end{tabular}

\begin{tabular}{|r|c|c|l|}
\hline CALCULATION RESULTS & FT & ROR & \\
\hline Transport lag time (t) & 46 & 46 & $\mathrm{~s}$ \\
\hline Detection time (td) & 41 & 2 & $\mathrm{~s}$ \\
\hline HRR at detection (Qd) & 79 & 0 & $\mathrm{~kW}$ \\
\hline HRR w/transport lag (Q|+d) & 358 & 109 & $\mathrm{~kW}$ \\
\hline
\end{tabular}

< Press PgDn key for additional results >

Sprinklers

DETACT.XLS: Estimate of the response time of ceiling mounted fire detectors Sprinkler

\begin{tabular}{|c|c|c|c|c|c|}
\hline \multicolumn{3}{|l|}{ INPUT PARAMETERS } & \multicolumn{3}{|l|}{ CALCULATED PARAMETERS } \\
\hline Calculation reset & 1 & 0 or 1 & $\mathrm{R} / \mathrm{H}$ & 1.8889 & - \\
\hline Ceiling height $(\mathrm{H})$ & 2.7 & $\mathrm{~m}$ & $\mathrm{~W} / \mathrm{H}$ & 1.5556 & - \\
\hline Room width (W) & 4.2 & $\mathrm{~m}$ & Temperature factor & 0.225 & - \\
\hline Radial distance $(\mathrm{R})$ & 5.1 & $\mathrm{~m}$ & Velocity factor & 0.2244 & 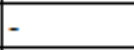 \\
\hline Ambient temperature (To) & 20 & C & Calculation time $(\mathrm{t})$ & 501 & s \\
\hline Actuation temperature $(\mathrm{Ta})$ & 100 & $\mathrm{C}$ & Fire HRR $(\mathrm{Q})$ & 3012 & $\mathrm{~kW}$ \\
\hline Rate of rise rating (ROR) & 0 & $\mathrm{C} / \mathrm{min}$ & Gas temperature $(\mathrm{Tg})$ & 171.48 & $\mathrm{C}$ \\
\hline Response time index (RTI) & 100 & $(m-s) 1 / 2$ & Gas velocity (Ug) & 2.3272 & $\mathrm{~m} / \mathrm{s}$ \\
\hline Fire growth power (n) & 2 & - & ROR at detector & 24.122 & $\mathrm{C} / \mathrm{min}$ \\
\hline Fire growth coefficient $(\mathrm{k})$ & 0.012 & $\mathrm{~kW} / \mathrm{s}^{\wedge} \mathrm{n}$ & Detector temp (Td) & 145.53 & $\mathrm{C}$ \\
\hline Fire location factor (kLF) & 1 & - & Detection trigger & 119 & 500 \\
\hline
\end{tabular}

\begin{tabular}{|r|c|}
\hline Representative t2 coeff. & $k$ \\
\hline Slow & 0.003 \\
\hline Medium & 0.012 \\
\hline Fast & 0.047 \\
\hline Ultrafast & 0.400 \\
\hline
\end{tabular}

\begin{tabular}{|r|c|c|l|}
\hline CALCULATION RESULTS & FT & ROR & \\
\hline Transport lag time (t) & 31 & 31 & $\mathrm{~s}$ \\
\hline Detection time (td) & 383 & 2 & $\mathrm{~s}$ \\
\hline HRR at detection (Qd) & 1760 & 0 & $\mathrm{~kW}$ \\
\hline HRR w/transport lag (Q|+d) & 2059 & 13 & $\mathrm{~kW}$ \\
\hline
\end{tabular}

< Press PgDn key for additional results > 
Brett Noakes

June 2015

Alarm Device Cut Sheets 


\section{Integrity Synchronized Temporal Horn-Strobe Installation Sheet}

\begin{tabular}{|c|c|c|}
\hline \multicolumn{3}{|l|}{ Description } \\
\hline \multicolumn{3}{|c|}{$\begin{array}{l}\text { The Integrity Synchronized Temporal Horn-Strobe is a fire } \\
\text { alarm notification appliance designed for indoor or outdoor } \\
\text { walls and ceilings. (The } 15 \text { cd strobe is for indoor use only.) } \\
\text { For model numbers, see Table 1; for accessories see Table } 2\end{array}$} \\
\hline & & \\
\hline Description & Numbers & \\
\hline 15 cd horn-strobe, red [1] & $\begin{array}{l}\text { 757-5A-T } \\
\text { XLS757-5A- }\end{array}$ & $\begin{array}{l}\text { INT-5AT } \\
\text { 2452THS-15-R }\end{array}$ \\
\hline 15 cd horn-strobe, white [1] & $\begin{array}{l}\text { 757-5A-TW } \\
\text { XLS757-5A-TW }\end{array}$ & $\begin{array}{l}\text { INT-5ATW } \\
\text { 2452THS-15-W }\end{array}$ \\
\hline 30 cd horn-strobe, red & $\begin{array}{l}\text { 757-3A-T } \\
\text { XLS757-3A-T }\end{array}$ & $\begin{array}{l}\text { INT-3AT } \\
\text { 2452THS-30-R }\end{array}$ \\
\hline 30 od horn-strobe, while & $\begin{array}{l}\text { 757-3A-TW } \\
\text { XLS757-3A-TW }\end{array}$ & $\begin{array}{l}\text { INT-3ATW } \\
\text { 2452THS-30-W }\end{array}$ \\
\hline 75 of hom-strobe, red [2] & $\begin{array}{l}\text { 757-4A-T } \\
\text { XLS757-4A-T }\end{array}$ & $\begin{array}{l}\text { INT-4AT } \\
\text { 2452THS-75-R }\end{array}$ \\
\hline 75 od horn-strobe, white [z] & $\begin{array}{l}\text { 757-4A-TW } \\
\text { XLS757-4A-TW }\end{array}$ & $\begin{array}{l}\text { INT-4ATW } \\
\text { 2452THS-75-W }\end{array}$ \\
\hline $15 / 75 \mathrm{~cd}$ hom-strobe, red & $\begin{array}{l}\text { 757-7A-T } \\
\text { XLS757-7A-T }\end{array}$ & $\begin{array}{l}\text { INT-7AT } \\
\text { 2452THS-15/75-R }\end{array}$ \\
\hline $15 / 75$ cd horn-strobe, white & $\begin{array}{l}\text { 757-7A-TW } \\
\text { XLS757-7A-TW }\end{array}$ & $\begin{array}{l}\text { INT-7ATW } \\
\text { 2452THS-15/75-W }\end{array}$ \\
\hline 110 od horn-strobe, red & $\begin{array}{l}\text { 757-BA-T } \\
\text { XLS757-8A-T }\end{array}$ & $\begin{array}{l}\text { INT-BAT } \\
\text { 2452THS-110-R }\end{array}$ \\
\hline 110 cd horn-strobe, white & $\begin{array}{l}\text { 757-BA-TW } \\
\text { XLS757-8A-TW }\end{array}$ & $\begin{array}{l}\text { INT-8ATW } \\
\text { 2452THS-110-W }\end{array}$ \\
\hline $\begin{array}{l}\text { [1] For indoor use only } \\
\text { [2] Not ULC Listed }\end{array}$ & & \\
\hline Description & Numbers & \\
\hline Surface box, red, indoor & $\begin{array}{l}\text { 757A-SB } \\
\text { XLS757A-SB }\end{array}$ & $\begin{array}{l}\text { INT-SB } \\
\text { 2459-SMB-R }\end{array}$ \\
\hline Surface box, white, indoor & $\begin{array}{l}\text { 757A-SBW } \\
\text { XLS757A-SBW }\end{array}$ & $\begin{array}{l}\text { INT-SBW } \\
\text { 2459-SMB-W }\end{array}$ \\
\hline $\begin{array}{l}\text { Weatherproof box, red, } \\
\text { outdoor }\end{array}$ & $\begin{array}{l}\text { 757A-WB } \\
\text { XLS757A-WB }\end{array}$ & $\begin{array}{l}\text { INT-WB } \\
\text { 2459-WPB-R }\end{array}$ \\
\hline $\begin{array}{l}\text { Weatherproof box, white, } \\
\text { outdoor }\end{array}$ & $\begin{array}{l}\text { 757A-WBW } \\
\text { XLS757A-WBW }\end{array}$ & $\begin{array}{l}\text { INT-WBW } \\
\text { 2459-WPB-W }\end{array}$ \\
\hline $\begin{array}{l}\text { Bidirectional mounting frame, } \\
\text { red, indoor }\end{array}$ & $\begin{array}{l}\text { 757A-BDF } \\
\text { XLS757A-BDF }\end{array}$ & $\begin{array}{l}\text { INT-BDF } \\
2459-3 D F \cdot R\end{array}$ \\
\hline $\begin{array}{l}\text { Bidirectional mounting frame, } \\
\text { white, indoor }\end{array}$ & $\begin{array}{l}\text { 757A-BDFW } \\
\text { XLS757A-BDFW }\end{array}$ & $\begin{array}{l}\text { INT-BDFW } \\
\text { 2459-BDF-W }\end{array}$ \\
\hline
\end{tabular}

The strobe operates on any existing two-wire signal circuit. There are jumpers for selecting either a temporal or steady tone, and high or low volume. See Figure 4 for the jumper locations.

The strobe features an enhanced synchronization circuit to comply with the latest requirements of UL 1971 Signaling Devices for the Hearing Impaired and CAN/ULC-S526 Visible Signal Devices for Fire Alarm Systems, Including Accessories. Synchronized operation requires a separately installed synchronization control module. See Table 3 for a list of compatible synchronization modules.

Table 3: Compatible synchronized models

Description Numbers

Auto-Sync Output Module SIGA-CC1S SIGA.MCC1S

Genesis Signal Master - $\quad$ ADTG1M-RM MG1M-RM

XLSG1M-RM EG1M-RM

$\begin{array}{ll}\text { G1M-RM } & \text { ZG1N-RM } \\ \text { BPS-6(10)A } & \text { APS-6(10)A }\end{array}$

Installation

WARNING: Electrocution hazard. To avoid personal injury or death from electrocution, remove all sources of power and allow stored energy to discharge before installing or removing equipment

Notes

- Electrical supervision requires the wire run to be broken at each terminal. Do not loop the signaling circuit field wires around the terminals.

- To ensure flash synchronization, do not install this enhanced strobe (identified by a red cd rating on the front of the unit) in the same field of view as older models (identified by a black od rating on the front of the unit).

Install this product in accordance with applicable requirements in the latest editions of NFPA 72, National Fire Alarm and Signaling Code, and CSA C22.1 the Canadian Electrical Code, Part 1, Section 32, CAN/ULC-S524 Installation of Fire Alarm Systems and in accordance with the local authority having jurisdiction. 
GE

Security
Notification Appliances

\section{Overview}

The Genesis line of signals are among the smallest, most compact oudible-visible emergency signaling devices in the world. About the size of a deck of playing cards, these devices are designed to blend with any decor:

Thanks to potented breakthrough technology, GE Security Genesis strobes do not require bulky specular reflectors and lenses. Insteod. an exclusive covity design conditions light to produce a highly controlled distribution pattern. Significant development efforts em. ploying this new technology hove given rise to a new benchmark in strobe performance - Fulliight technology.

Fulltight strobe technology produces a smooth light distribution pattern without the spikes and voids charocteristic of specular reflectors. This ensures the entire coveroge oreo receives consistent illumination from the strobe flash. As a result, Genesis strobes with Fullight technology go well beyond the minimum UL-required ' $T$ ' pattern, significantly exceeding UL-1971 and ULC-\$526 light distribution requirements.

Genesis strobes and horn-strobes offer 15 to 110 condela output, which is selectable with a conveniently-located switch on the side of the device. Models are also available that offer fixed $15 / 75 \mathrm{~cd}$ output. The condela output setting remains cleorly visible even ofter final instaliation, yet it stays locked in ploce to prevent unauthorized tompering

Genesis signals feoture textured housings in architecturally neutrol white or traditional fire red. An ingenious iconogrophic symbol indicates the purpose of the device. This uriversal symbol is code-compliant and is exsily recognized by all buiding occupants regardless of what language they speak. Models with "FIRE" markings are also aualuble.

\section{Standard Features}

- Unique low-profile design

- The most compoct UL-1971/ULC-S526 listed strobe available

- Ultra-slim - protrudes less than one inch

- Attractive appearance

- No visible mounting screvs

- Four field-configurable options in one device

- Select $15,30,75$, or 110 cd strobe output

- Select high Idefoult or low dB horn output

- Select temporal (default) or steody hom output

- Select public mode flash rate (defoult) or private mode temporal flash

\section{- Ficed $15 / 75 \mathrm{~cd}$ model available}

- Easy to instal

- Fits stondard 1-gang electricol boxes - no trim plate needec - Optional trim plate accommodates oversized openings

- Pre-cssembled with captive hardware

- \#12 AWG terminols - ideal for long runs or existing wiring

- Unparalleled performance

- Industry's most even light distribution

- Meets tough synchronizing standards for strobes

- Single microprocessor controls both horn and strobe

- Low current drow minimizes system overhead

- Independent horn control over a single pair of wires

- Highiy reguloted in-rush current

- Multiple frequency tone improves sound penetrotion

- Industry's first temporal strobe output

\section{Field Configurable Horns and Strobes} Genesis Series

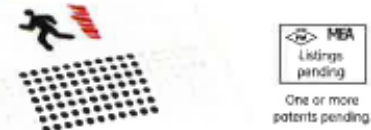

75 Not to be used for installation Shet 85001.0573 lassue 8 
Installation

Genesis horns and strobes mount to any standard one-gang surfoce or flush electrical box. Matching optional trim plates are used to cover oversized openings and can accommodote one-gang. two-gang, four-inch square, or octagonal bowes, and European 100 mm square.

All Genesis signals come pre-assembled
with captive mounting screws for easy in-
stollation. Two tobs at the top of the signal
unlock the cover to reveol the mounting
hardware. The shallow depth of Genesis
devices leoves ample room behind the
signal for extro wiring. Once instolled with
the cover in ploce, no mounting screws are
visible.

\section{Wiring}

Field wiring terminals accommodate \#18 to \#12 AWG $10.75 \mathrm{~mm}^{2}$ to $2.5 \mathrm{~mm}^{2}$ ) wiring. Horns, strobes, and combinotion horn-strobes ore interconnected with a single poir of wires as shown below

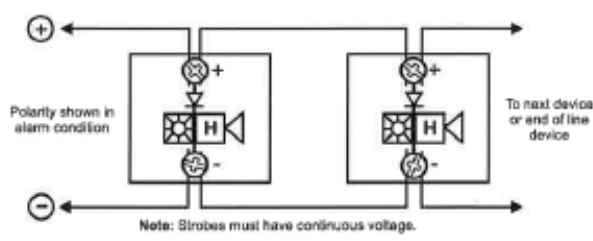

ured for use with coded systems by cutting a jumper on the circuit boord. This results in o steady output that can be turned on and off (coded) as the system applies and removes power to the signol circuit. A Genesis Signal Moster is required when horn-strobe models are configured for coded systems. Non-temporal, horn-only models sound a steady tone.

Genesis strobes and horn-strobes are shipped from the factory ready for use as UL 1971 compliant signols for public mode operation. These signols may be configured for temporal flash by cutting a jumper on the circuit boord. This battery-saving feoture is intended for private mode signaling only.

Genesis strobes and horn-strobes may be set for $15,30,75$, or 110 candela output The output setting is changed by simply opening the device and sliding the switch to the desired setting. The device does not hove to be removed to change the output setting. The setting remains visible through a small window on the side of the device after the cover is closed.

Horns and horn-strobes are factory set for high dB output. Low dB output may be selected by cutting a jumper an the circuit board. This reduces the output by obout $5 \mathrm{~dB}$.
WAARIING: These devices wil not coperate without electricol power. As fires frequently

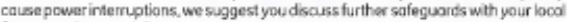
fire protection specialist.

These visual signal appliances' flach intensity may not be odequete to olert or woken occuports in the protected area. Researchindicates thot the intensity of strobenseeded that strobes in slooging rooms be 110 cod minimum. 


\section{Security}

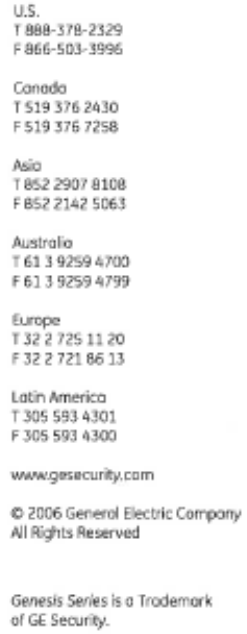

Ordering Information

\begin{tabular}{|c|c|c|c|}
\hline \multicolumn{2}{|c|}{ Cotalog Number } & \multirow[b]{2}{*}{ Description } & \multirow{2}{*}{$\begin{array}{l}\text { Ship Wt. } \\
\text { lbs }(\mathrm{kg})\end{array}$} \\
\hline $\begin{array}{l}\text { White } \\
\text { Finish }\end{array}$ & $\begin{array}{l}\text { Red } \\
\text { Finish }\end{array}$ & & \\
\hline G1-HDMM & $\begin{array}{l}\text { G1R- } \\
\text { HOWM }\end{array}$ & $\begin{array}{l}\text { Genes is Horn-Strobe [selectable } 15,30,75 \text {, or } 110 \text { ed output, } \\
\text { selectable high/low d8 output) }\end{array}$ & \multirow{10}{*}{$\begin{array}{c}0.25 \\
10.11\end{array}$} \\
\hline G1-VM & G1R-VM & Genesis Strobe (selectable $15,30,75$, of 110 cd output & \\
\hline G1-HD & G1R-HD & Genesis Temporal Horn Iselectable high/low dB outputl & \\
\hline G1-P & G1R-P & $\begin{array}{l}\text { Genesis Steody Horn } \\
\text { inot compotible with Genesis Signol Master) }\end{array}$ & \\
\hline $\begin{array}{l}\text { G1F: } \\
\text { HDVM }\end{array}$ & $\begin{array}{l}\text { G1RF- } \\
\text { HDVM }\end{array}$ & $\begin{array}{l}\text { Genesis Horn-Strobe Iselectoble } 15,30,75 \text {, or } 110 \text { cd output, } \\
\text { selectoble high/low dB output - with "FIRE" morking }\end{array}$ & \\
\hline G1F-VM & G1AF-VM & $\begin{array}{l}\text { Genesis Strobe iselectoble } 15,30,75 \text {, or } 110 \text { cd output) } \\
\text { - with "FIRE' marking }\end{array}$ & \\
\hline G1F-HD & G1RF-HO & $\begin{array}{l}\text { Genesis Temporal Horn (selectobie high/low dB outputl } \\
\text { - with FIRE' marking }\end{array}$ & \\
\hline G1F-P & G1RF-P & $\begin{array}{l}\text { Genesis Steody Horn with "FIRE" marking } \\
\text { (not compatible with Genesis Signal Masterf }\end{array}$ & \\
\hline $\begin{array}{l}\text { G1F- } \\
\text { HDV1575 }\end{array}$ & $\begin{array}{l}\text { G1RF- } \\
\text { HDV1575 }\end{array}$ & $\begin{array}{l}15 / 75 \mathrm{~cd} \text { temporal horn-strobe, hillo dB-24V } \\
\text { - with "FIRE" marking (see note 1) }\end{array}$ & \\
\hline $\begin{array}{l}\text { G1F- } \\
\text { V1575 }\end{array}$ & $\begin{array}{l}\text { G1RF- } \\
\text { V1575 }\end{array}$ & $15 / 75 \mathrm{~cd}$ strobe - with "FIRE" marking lsee note 1 ) & \\
\hline
\end{tabular}

\begin{tabular}{|c|c|c|c|}
\hline \multicolumn{4}{|c|}{ Mounting Accessories } \\
\hline G1T & G1RT & Genesis Trim Plote Ifor two-gang or 4 "squore boxes\} & 0.15 [0.7] \\
\hline G1T-FIRE & $\begin{array}{l}\text { G1RT- } \\
\text { FIRE }\end{array}$ & $\begin{array}{l}\text { Genesis Trim Plote ifor two-gang or } 4^{\prime \prime} \text { squore boxest } \\
\text { with "FlRE" morkings }\end{array}$ & 0.1510 .7 \\
\hline $27193-16$ & 27193-11 & One-gang surface mount box & $1|0.4|$ \\
\hline
\end{tabular}

Synchronization Modules

\begin{tabular}{|c|c|c|}
\hline G1M & Genesis Signal Moster - Snap-on Mount & \\
\hline G1M-RM & Genesis Signal Moster - Remote Mount (1-gang) & .21 \\
\hline SIGA-CC1S & Intelligent Synchronizotion Output Module (2-gang) & $0.5(0.23)$ \\
\hline SIGA-MCC1S & Inteligent Synchronizotion Output Module (Plug in UIOI & 0.1810 .000 \\
\hline
\end{tabular}

Note 1: These 15/75 cd models provide fixed output and are not multi-candelo devices. The $15 \mathrm{~cd}$ cutput component complies with UL1971, while the 75 ed output component complies with UL 1638 .

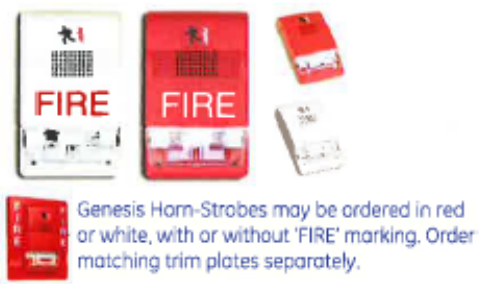


Figure 2: Typical one-circuit wiring diagram

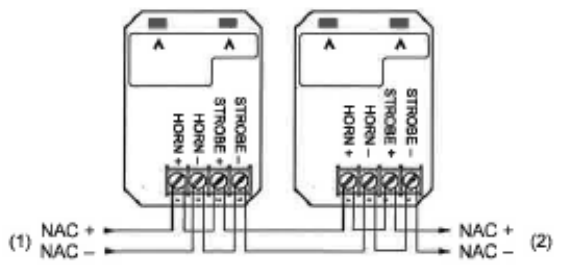

Polarity is shown in the active state.

(1) From ULULC Listed fire alarm control panel signal circuit

(2) To next device or end of line resistor for Class B. Return to control panel for Class A connection.

Figure 3: Typical two-circuit wiring diagram

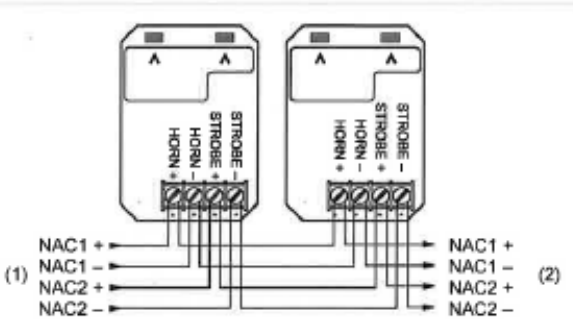

Polarity is shown in the active state.

(1) From ULULC Listed fire alarm control panes signal circuit.

(2) To next device or end of line resistor for Class B. Retum to control panel for Class A connection.

Mounting the electrical box

Figure 1 shows mounting details for:

- Standard box. When using a 4 in. square box, use an extension ring for additional wiring space, if needed. If using a double-gang electrical box that is $2-1 / 2$ in $(64 \mathrm{~mm})$ deep, locate the condut only at the rear of the box.

- Weatherproof box. Peel off the adhesive backing from the gasket and adhere to the box.

- Surface mount box

\section{Selecting the volume and tone}

The horn has a jumper for selecting a high or low volume output level. The default is high volume. To set the output to low volume, remove the output jumper from the circuit board on the rear of the unit. See Figure 4 below.

The horn has a jumper for selecting either a temporal or steady tone. The default is temporal tone. To set the output to steady tone, remove the tone jumper from the circuit board on the rear of the unit.

Tip: Save the jumper by sliding it onto a single pin.
Figure 4: Jumper setup and terminal block

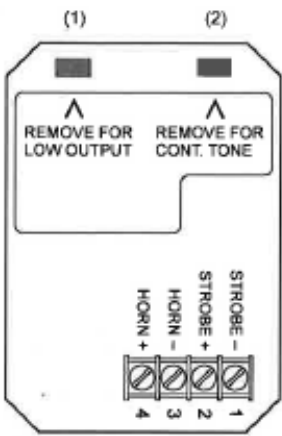

\begin{tabular}{lll}
\hline Item & In & Out \\
\hline (1) & High output & Low output \\
(2) & Temporal tone & $\begin{array}{l}\text { Steady (continuous) } \\
\text { tone }\end{array}$ \\
\hline
\end{tabular}

\section{Maintenance}

Note: Do not change the factory-applied finishes

This unit is shipped from the factory as an assembled unit it contains no user-serviceable parts and should not be disassembled.

Perform a visual inspection and an operational test twice a year or as directed by the local authority having jurisdiction.

\section{Specifications}

\begin{tabular}{|c|c|}
\hline Operating voltage & 16 to 33 VDC, 16 to 33 VFWR \\
\hline Strobe operaling current & See Table 4 \\
\hline Horn operating current & See Table 5 \\
\hline Sound output & See Table 6 and Table 7 \\
\hline Light output & See Table 10 \\
\hline Horn temporal paitern & $\begin{array}{l}0.5 \mathrm{~s} \text { on, } 0.5 \mathrm{~s} \text { off, } 0.5 \mathrm{~s} \text { on, } 0.5 \mathrm{~s} \text { off, } 0.5 \mathrm{~s} \\
\text { on, } 1.5 \mathrm{~s} \text { off, repeat cycle }\end{array}$ \\
\hline Wire size & 12 to 18 AWG (0.75 to $2.50 \mathrm{~mm}^{2}$ ) \\
\hline $\begin{array}{l}\text { Compatible electrical } \\
\text { boxes }\end{array}$ & $\begin{array}{l}\text { 2-1/2 in. (64 mm) deep double-gang, } \\
4 \text { in. square box 2-1/8 in. ( } 54 \mathrm{~mm} \text { ) deep, } \\
\text { Surface or bidirectional mounting box per } \\
\text { Table } 2\end{array}$ \\
\hline \multicolumn{2}{|l|}{ Operating temperature } \\
\hline Indoor & 32 to $120^{\circ} \mathrm{F}$ (0 to $\left.49^{\circ} \mathrm{C}\right)$ \\
\hline UL outdoor & -35 to $150^{\circ} \mathrm{F}\left(-37\right.$ to $\left.66^{\circ} \mathrm{C}\right)$ \\
\hline ULC outdoor & -40 to $150^{\circ} \mathrm{F}\left(-40\right.$ to $\left.66^{\circ} \mathrm{C}\right)$ \\
\hline \multicolumn{2}{|l|}{ Relative humidity } \\
\hline Indoor & 93\% noncondensing \\
\hline Outdoor & $98 \%$ noncondensing \\
\hline
\end{tabular}


Brett Noakes

June 2015

Regulatory information

\begin{tabular}{|c|c|}
\hline Manufacturer & $\begin{array}{l}\text { Edwards, A Division of UTC Fire \& Security } \\
\text { Americas Corporation, inc. } \\
\text { 8985 Town Center Parkway, Bradenton, FL } \\
\text { 34202, USA }\end{array}$ \\
\hline $\begin{array}{l}\text { Year of } \\
\text { manufacture }\end{array}$ & $\begin{array}{l}\text { The first two digits of the date code (located on } \\
\text { the product identification label) are the year of } \\
\text { manufacture. }\end{array}$ \\
\hline UL rating & Regulated 24 DC, regulated 24 FWR [1] \\
\hline $\begin{array}{l}\text { Enwironmental } \\
\text { class }\end{array}$ & Indoor, outdoor \\
\hline Synchronization & $\begin{array}{l}\text { Meets UL } 1971 \text { requirements. Maximum allowed } \\
\text { resistance between any two devices is } 20 \Omega \text {. } \\
\text { Refer to specifications for the synchronization } \\
\text { control module, this strobe, and the control panel } \\
\text { to determine allowed wire resistance. }\end{array}$ \\
\hline \multirow[t]{2}{*}{$\begin{array}{l}\text { North American } \\
\text { standards }\end{array}$} & $\begin{array}{l}\text { Meets: CAN/ULC-S525-07, CAN/ULC -S526-07, } \\
\text { UL 464, UL } 1638 \text { and UL } 1971\end{array}$ \\
\hline & Follow: NFPA 72 and CAN/ULC.S524 \\
\hline FCC compliance & $\begin{array}{l}\text { This equipment has been tested and found to } \\
\text { comply with the limits for a Class A digital device, } \\
\text { pursuant to Part } 15 \text { of the FCC rules and } \\
\text { regulations. }\end{array}$ \\
\hline
\end{tabular}

Contact information

For contact information, see www.utcfireandsecurity.com. 


\section{Overview}

The Control Relay Module and the Polarity Reversal Relay Module are port of the Signature Series system. They are intelligent anolog addressable devices available in either plug-in (UIO) versians, on standard l-gang mount versions.

The SIGA-CR/MCR Control Relay Module provides a Form "C" dry relay contoct to control externol appliances such os door closers fans, dampers etc. This device does not provide supervision of the stote of the relay contoct. Instead, the on-boord microprocessor ensures thot the reloy is in the proper ON/OFF state. Upon command from the loop controller, the SIGA-CR/MCR relay activates the normally open or normally-closed cantact.

The SIGA-CRR/MCRR Polority Reversal Reloy Module provides Form " $\mathrm{C}$ " dry relay contoct to power ond activate a series of SIGA. $A B A G$ Audible Sounder Boses. Upon command from the Signoture loop controller, the SIGA-CRR reverses the polarity of its $24 \mathrm{Vdc}$ output, thus octivating all Sounder Boses on the dato loop

Standard-mount versions (SIGA-CR and SIGA-CRR) are installed to standard North American 1-gang electrical boxes, making them ideal for locations where only one module is required. Separate $1 / 0$ and data loop connectians ore made to each module.

Plug-in UIO versions (SIGA-MCR and SIGA-MCRR) ore part of the UIO family of plug-in Signature Series modules. They function identically to the standard mount versions, but take odvantage of the modulor flexibility and eosy installation that characterizes all

UIO modules. Two- and six-module UIO motherboards are availoble. All wiring connections are mode to terminal blocks on the motherboard, UIO assemblies may be mounted in GE Security enclosures.
Standard Features

- Provides one no/nc contoct (SIGA-CR/MCR)

Form ' $C$ ' dry relay contact can be used to contral external appliances such us door clasers, fans, dampers etc.

- Allows group operotion of sounder bases The SIGA-CRR/MCRR reverses the polority of its $24 \mathrm{Vdc}$ output. thus activating all Sounder Boses on the data loop.

- Plug-in (UIO) or standard 1-gang mount

UiO vers ons allow quick installation where multiple modules are required. The 1-gang mount version is ideal for remote locotions that require o single module.

- Automatic device mapping

Signoture modules tronsmit information to the loop controller regarding their circuit locations with respect to other Signature devices on the wire loop.

- Electronic addressing

Programmable addresses are downloaded from the loop controller, a PC, or the SIGA-PRO Signature Program/Service Took there are no switches or dials to set.

- Intelligent device with microprocessor All decisions are mode at the module to allow lower communica. tion speed with substantially improved control ponel response time and less sensitivity to line noise and loop wiring properties: twisted or shielded wire is not required.

- Ground fault detection by address

Detects ground foults right down to the device level.

\section{Control Relay Modules}

SIGA-CR, SIGA-MCR, SIGA-CRR, SIGA-MCRR

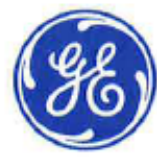

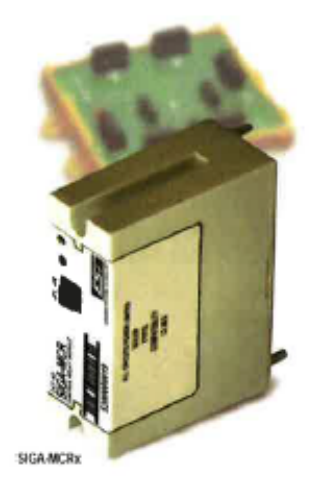

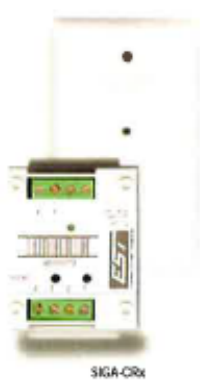

MEA

(U.

(드)

Dota Sheet 85001-0239 issue ? 
Typical Wiring

Modules will accept \#18 AWG $\left[0.75 \mathrm{~mm}^{2}\right\}$, \#16 $\left[1.0 \mathrm{~mm}^{2}\right)$, \#14 AWG $\left(1.50 \mathrm{~mm}^{2}\right)$ and \#12 AWG $\left.12.5 \mathrm{~mm} \gamma\right\}$ wire sizes.

Note: Sizes \#16 AWG $\left(1.0 \mathrm{~mm}^{2}\right)$ and \#18 AWG $\left(0.75 \mathrm{~mm}^{2}\right)$ are preferred for ease of installation. See Signature Loop Controller catalog sheet for detciled wiring requirement specifications.

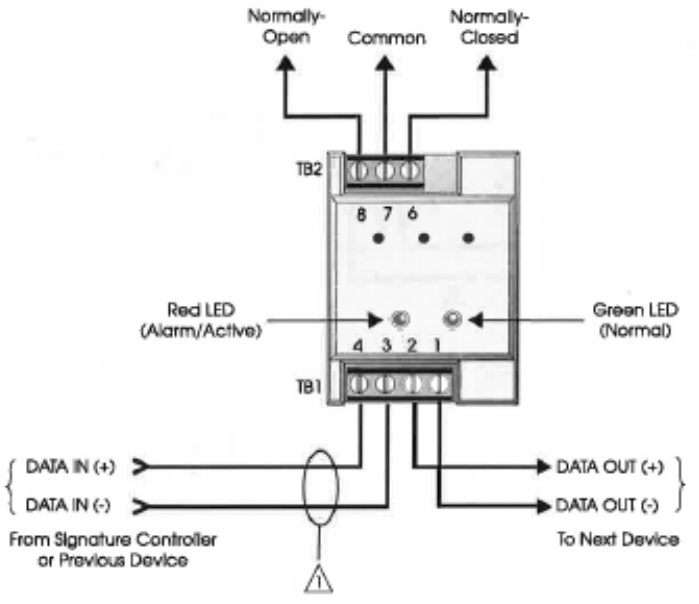

SIGA-CR Control Relay

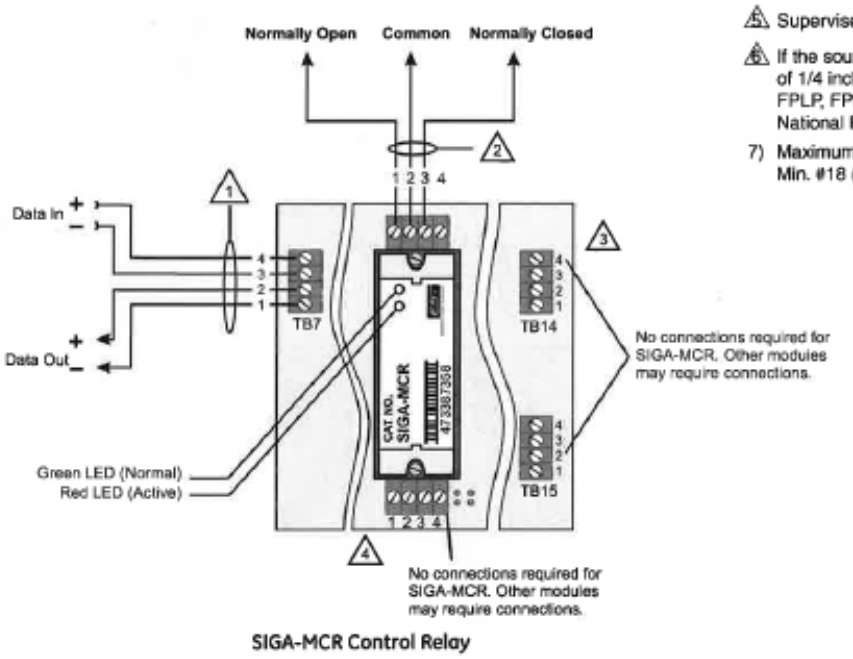

Notes

A. Reter to Signature Loop Controller Installation Sheet or wiring specifications.

2. NFPA 72 requires that the SIGA-CR/SIGA-MCR be installed in the same room as the device it is control. ling. This requirement may not apply in all markets. Check with your local AHJ for details.

A. The SIGA-UIOER and the SIGA-UIO2R do not come with TB14.

4. The SIGA-UIO6 does not come with TB8 through

anpower-limited, maintain a space 作 Er an equivalent in accordance with the Electrical Code.

\#12 AWG (2.5mm²) wire. $018\left(0.75 \mathrm{~mm}^{2}\right)$. 
Brett Noakes June 2015

\begin{tabular}{|c|c|c|c|c|}
\hline Catalog Number & SIGA-CR & SIGA-MCR & SIGA-CRR & \$IGA-MCRRR \\
\hline Description & \multicolumn{2}{|c|}{ Control Fielay } & \multicolumn{2}{|c|}{ Polarity Reversal Relay } \\
\hline Type Code & \multicolumn{2}{|c|}{ Personality Code B IFoctory Set) } & \multicolumn{2}{|c|}{ Personality Code 8 (Foctory Set] } \\
\hline Address Requirements & \multicolumn{4}{|c|}{ Uses 1 Module Address } \\
\hline Operating Current & \multicolumn{4}{|c|}{ Standby $=100 \mu \mathrm{A}$ Activated $=100 \mu \mathrm{A}$} \\
\hline Operating Voltoge & \multicolumn{4}{|c|}{15.2 to $19.95 \mathrm{Vdc}$ l19 Vde nominall } \\
\hline Relay Type and Rating & \multicolumn{4}{|c|}{ Form ' $C$ ' 24 VDC $=2$ amps (pilot duty) 120 Voc $=0.5$ amps 220 Voc $($ non $-U L$ ) $=0.5 \mathrm{amps}$} \\
\hline Mounting & $\begin{array}{c}\text { North Arnerican } 26 / 5 \text { inch } \\
(64 \mathrm{~mm}) \text { deep } 1 \text {-gang boxes } \\
\text { and } 11 / 2 \text { inch } 138 \mathrm{~mm}) \text { deep } \\
4 \text { inch square boxes with } \\
1 \text {-gang cowers and SIGA-MP } \\
\text { mounting plates }\end{array}$ & $\begin{array}{l}\text { Plugs into U1O2R, UIO6R or } \\
\text { U1O6 Motherboords }\end{array}$ & $\begin{array}{l}\text { North American } 21 / 2 \text { inch } \\
(64 \mathrm{~mm}) \text { deep } 1 \text {-gang boxes } \\
\text { and } 11 / 2 \text { inch }(38 \mathrm{~mm}) \text { deep } \\
4 \text { inch square bokes with } \\
1 \text {-gong covers and SIGA-MP } \\
\text { mounting plates }\end{array}$ & $\begin{array}{l}\text { Plugs into UIO2R, UIO6R or } \\
\text { UIO6 Motherboards }\end{array}$ \\
\hline Construction \&. Finish & \multicolumn{4}{|c|}{ High Impact Engineering Polymer } \\
\hline $\begin{array}{l}\text { Storage and Operating } \\
\text { Environment }\end{array}$ & \multicolumn{4}{|c|}{$\begin{array}{l}\left.\text { Operating Temperature } 32^{\circ} \mathrm{F} \text { to } 120^{\circ} \mathrm{F} 10^{\circ} \mathrm{C} \text { to } 49^{\circ} \mathrm{C}\right) \\
\text { Storoge Temperature: }-4^{\circ} \mathrm{F} \text { to } 140^{\circ} \mathrm{F}\left(-20^{\circ} \mathrm{C} \text { to } 60^{\circ} \mathrm{Cl} \text { Humidity: } 0 \text { to } 93 \% \text { RH }\right.\end{array}$} \\
\hline LED Operation & \multicolumn{4}{|c|}{ On-board Green LED - Floshes when poiled On-bcard Red LED - Flashes when in alarm/octive } \\
\hline Compotibility & \multicolumn{4}{|c|}{ Use With: Signeture Locp Controller } \\
\hline Agency Listings & \multicolumn{4}{|c|}{ UL, ULC, CSFM, MEA } \\
\hline
\end{tabular}

\section{Ordering Information}

\begin{tabular}{|c|c|c|}
\hline Catalog Number & Description & Ship Weight - lbs (kg) \\
\hline SIGA-CR & Control Relay Module (Stondard Mount) - UL/ULC Listed & $0.4[0.15]$ \\
\hline SIGA-MCR & Control Reloy Module (UIO Mount) - UL Listed & $0.18(0.08)$ \\
\hline SIGA-CRR & Polarity Reversal Reloy Module (Standard Mount) - ULUULC Listed & $0.4[0.15$ \\
\hline SIGA-MCRR & Polarity Reversal Relay Module [UlO Mount] - UL Listed & $0.18(0.08)$ \\
\hline \multicolumn{3}{|l|}{ Related Equipment } \\
\hline $27193-11$ & Surfoce Mount Box - Red, 1-gang & 10.61 \\
\hline 27193.16 & Surfoce Mount Box - White, 1-gong & $1|0.6|$ \\
\hline SIGA-UIOZR & Universal input-Output Module Boord w/Piser inputs - Two Module Positions & $0.32[0.15]$ \\
\hline SIGA-UIOGR & Universol Input-Output Module Boord w/Riser Inputs - Six Modula Positions & $0.62(0.28)$ \\
\hline SIGA-UIO6 & Universal Input-Output Module Boord - Six Motule Positions & 0.56 (0.25) \\
\hline SIGA-ABAG & Audible (Sounder) Detector Base & $0.310 .15\}$ \\
\hline \multicolumn{3}{|l|}{ Accessories } \\
\hline MFC-A & Mult function Fire Cobinet - Red, supports Signature Module Mounting Plates & $7.013 .1]$ \\
\hline SIGA-MP1 & Signature Module Mounting Plate, 1 footprint & $1.510 .70 \mathrm{H}$ \\
\hline SIGA-MP2 & Signature Module Mounting Plote, 1/2 footprint & 0.510 .231 \\
\hline SIGA-MP2L & Signature Module Mounting Plote, 1/2 extended footprint & $1.02(0.46)$ \\
\hline
\end{tabular}




\section{Overview}

SIGA-CC1/MCC1 Single Input Signal Modules and SIGA-CC2/MCC2 Dual input Signal Modules ore part of GE Securitys Signature Series system. They are intelligent analog addressable devices used for connecting. upon command from the loop controller, supervised Class B signol or telephone circuits to their respective power inputs. The power inputs may be polarized $24 \mathrm{Vdc}$ to operate audible and visible signal appliances or 25 and 70 VRMS to operate audio evocuotion speokers and firefighter's telephones.

The actual operation of the SIGA-CC1/MCC1 and SIGA-CC2/MCC2 is determined by the "personality code" selected by the installer. It is downloaded to the module from the Signature loop controller during system configuration.

The SIGA-CC1 and SIGA-CC2 mount to stondord North American two-gang electrical bokes, making them ideol for locotions where only one module is required. Seporote I/O and dato loop connections are mode to each module.

The SIGA-MCC1 and SIGA-MCC2 are port of the UIO family of plug-in Signature Series modules. They function identically to the SIGA-CC1 and SIGA-CC2, but take odvantage of the modular flexibility and easy installation that characterize oll UIO modules. Two- and six-module UIO motherboards are avalable. These can accommodate individual risers for each on-board module, or risers that are shared by any combination of its UIO modules. All wiring connections are mode to terminal blocks on the motherboard. UIO assemblies may be mounted in GE Security enclosures.

\section{Standard Features}

\section{- Single and Dual input (riser) select}

Use for connecting supervised $24 \mathrm{Vdc}$ Audible/Visible signal circuits, or 25 and 70 VRMS Audio Evocuation and Telephone circuits to their power inputs.

- Ring-tone generator

When configured for telephone circuits, the SIGA-CC1 generates its own ring-tone signol eliminoting the need for a separate ringtone circuit.

- Plug-in (UIO) or standard 2-gang mount

UIO versions cllow quick installation where multiple modules are required. The 2-gang mount version is ideal for remote locations that require a single module.

\section{- Automatic device mapping}

Signature modules transmit information to the loop controller regarding their circuit locations with respect to other Signature devices on the wire loop.

\section{- Electronic addressing}

Programmable addresses are downlooded from the loop con troller, a PC, or the SIGA-PRO Signoture Progrom/Service Tool

there are no switches or dials to set.

\section{- Intelligent device with microprocessor}

All decisions are made at the module to ollow lower communication speed with substantially improved control ponel response time and less sensitivity to line noise and loop wiring properties: twisted or shielded wire is not required.

- Ground fault detection by address Detects ground fou'ts right down to the device level.

\section{Signal Modules SIGA-CC1, SIGA-MCC1, SIGA-CC2 \& SIGA-MCC2}
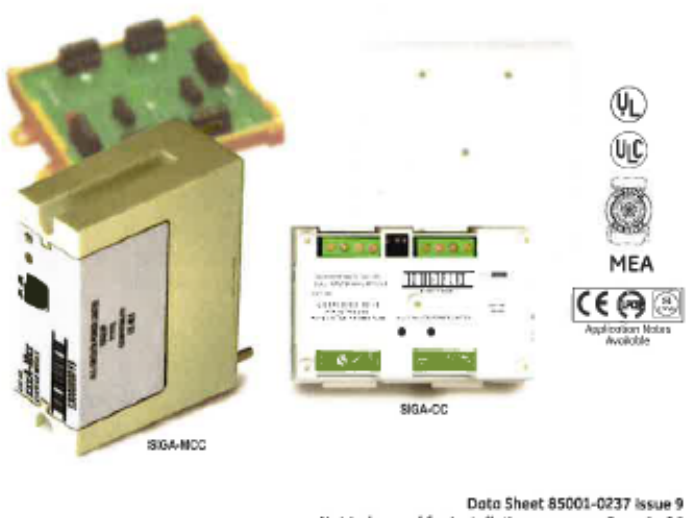

Not to be used for instollotion pusposes. Poge 1 of 6 
Typical Wiring (SIGA-CC2/MCC2)

Modules will accept \#18 AWG $\left.10.75 \mathrm{~mm}^{2}\right]$. \#16 (1.0mm²), \#14 AWG $\left[1.50 \mathrm{~mm}^{2}\right)$ and \#12 AWG $\left(2.5 \mathrm{~mm}^{2}\right)$ wire sizes.

Note: Sizes \#16 AWG [1.0mm 7 ] and \#18 AWG $10.75 \mathrm{~mm}^{7}$ ) are preferred for ease of installotion. See Signature Loop Controller cotalog sheet for detaled wiring requirement specifications.
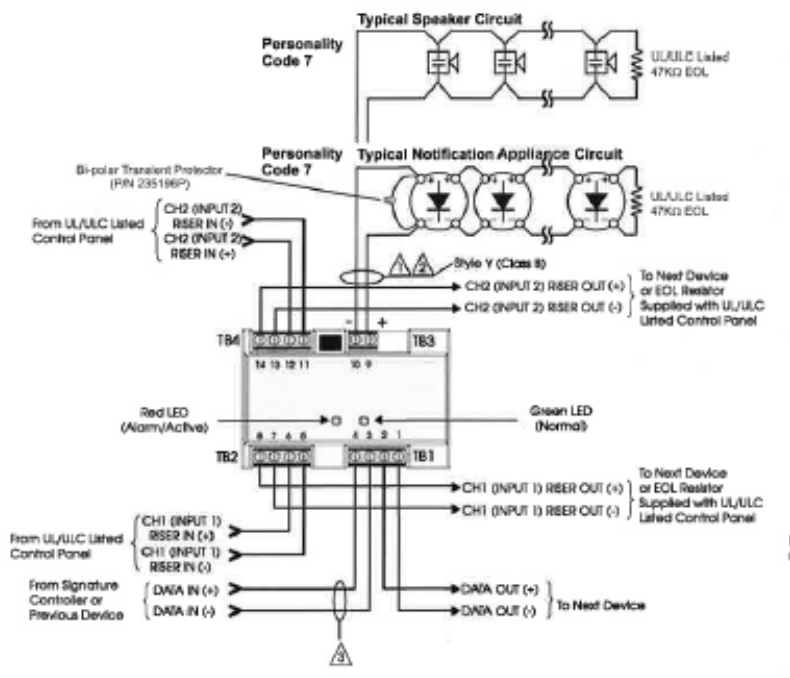

SIGA-CC2

Notes

A For maximum wire resistance and maximum wire distances, refer to IOMC Manual (P/N 270144).

(2) Maximum \#12 AWG (2.5mm²) wire. Min. $\# 18\left(0.75 \mathrm{~mm}^{2}\right)$.

A. Feter to Signature Loop Controller Installation Sheet for wiring specifications.

4. These modules will NOT support two-wire smoke detectors.

A. All wiring power limited and supervised. If the input source is non-power limiled, then maintain spacing of $1 / 4$ inch or
use FPL. FPLP, FPLA or equivalent in accordance with NEC.

A. The SIGA-UIO6 does not come with TB8 through TB13.

$\triangle$ Supervised and power-limited.

1. Supervised and power-limited when connected to a powerlimited source. If the source is nonpower-limited, maintain lod sol a space of $1 / 4$ inch from power-limited wining or use $\mathrm{FPL}$. tional Electrical Code.

A. The input for this riser is cornmon to all modules.

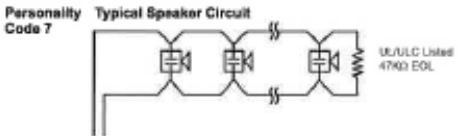

Personalizy Typical Notification Applianoe Cireull
Code 7

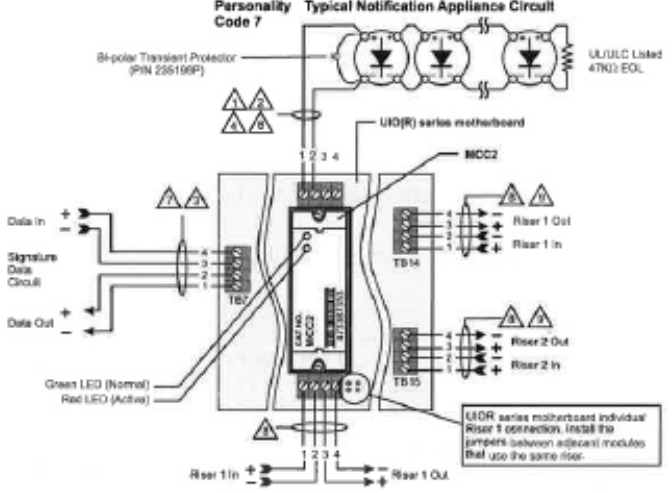

SIGA-MCC2

\begin{tabular}{ccc}
\multicolumn{3}{c}{ Maximum Output Lood } \\
\hline $24 \mathrm{Vdc}$ & $25 \mathrm{~V}$ & $70 \mathrm{~V}$ \\
\hline Signais & Audio & Audio \\
\hline $2 \mathrm{~A}$ & $50 \mathrm{~W}$ & $35 \mathrm{~W}$ \\
\hline
\end{tabular}


Brett Noakes

June 2015

Śignature Series Overview

The Signature Series intelligent anolog-addressoble system from $\mathrm{GE}$ Security is an entire family of multi-sensor detectors and mounting bases, multiple-function input and output modules, network and non-network control panels, and user-friendly maintenance and service tools. Anaiog information from equipment connected to Signature devices is gathered and converted into digital signals. An onboord microprocessor in each Signoture device measures and analyzes the signol and decides whether or not to input on alarm. The microprocessor in each Signature device provides four oddi. tional benefits - Self-diagnostics and History Log. Automatic Device Mapping, Stond-alone Operation and Fost, Stoble Communication.

Self-diagnostics and History Log - Eoch Signature Series device constantly runs self-checks to provide important maintenance information. The results of the self-check are cutcmatically updated and permonently stored in its non-volatile memory. This informotion s accessible for review any time ct the control panel, PC, or using the SIGA-PRO Signature Program/Service Tool. The information stored in device memory includes:

- Device sericl number, address, and type

- Time and date of last alarm IEST3 V 2 only.

- Most recent trouble code logged by the detector -32 possible trouble codes may be used to diognose faults.
Automatic Device Mapping -The Signature Dato Controller $[S D C$ learns where each device's serial number oddress is insta led relative to other devices on the circuit. The SDC keeps o mop of al Signoture Series devices connected to it. The Signature Series Doto Entry Program olso uses the mapping feature. With interoctive menus and graphic support, the wired circuits between eoch device can be exarnined. Layout ar "as-buit" drawing information showing branch wiring (T-taps), device types and their address ore stored on disk for printing hard copy. This takes the mystery out of the instol lation. The preparation of as-built drawings is fast and efficient.

Device mopping allows the Signoture Dato Controller to discover: - Unexpected additional device addresses

- Missing device addresses

- Changes to the wiring in the circuit.

Most Signature modules use a personality code selected by the installer to determine their actual function. Personality codes are downlooded from the SDC during system configuration and are ind coted during device mopping. 
Typical Wiring

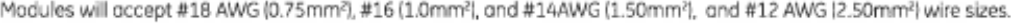

Note: Sizes \#16 AWG $\left.\mid 1.0 \mathrm{~mm}^{7}\right)$ and \#18 AWG $\left[0.75 \mathrm{~mm}^{2}\right]$ are preferred for ease of instailation. See Signature Loop Controller cotalog sheet for detailed wiring requirement specifications,

Initiating islovel Device Circuit Wire Specifications

\begin{tabular}{|c|c|c|}
\hline Maximum Allowable Wire Resistance & \multicolumn{2}{|c|}{50 ohrns ( 25 ohms per wire) per Circuit } \\
\hline Maximum Allowoble Wire Capocitance & & \\
\hline \multirow[t]{5}{*}{ For Design Reference: } & Wire Șize & Maximum Distance to EOLR \\
\hline & $\# 18$ AWG $10.75 \mathrm{~mm}^{2}$ & \multirow{4}{*}{$4,000 \mathrm{ft} 11.219 \mathrm{ml}$} \\
\hline & $\# 16$ AWG $\left(1.00 \mathrm{~mm}^{2}\right)$ & \\
\hline & \#14 AWG (1.50 $\left.\mathrm{mm}^{2}\right)$ & \\
\hline & \#12 AWG $\left(1.50 \mathrm{~mm}^{2}\right)$ & \\
\hline
\end{tabular}
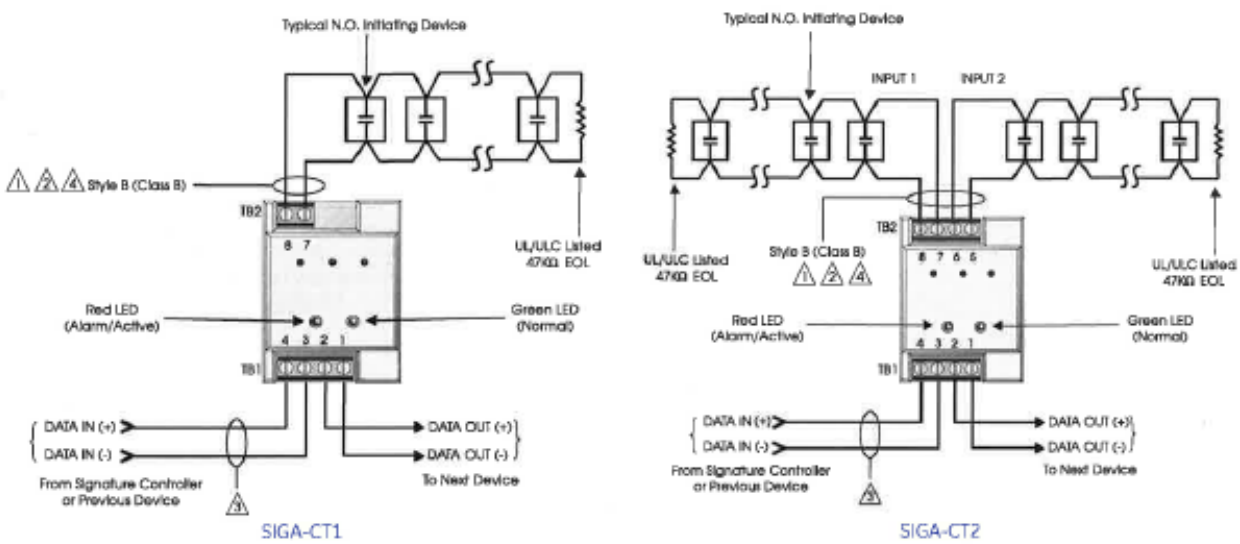

NOTES

A Mokimum 25 Ohm resistance per wire.

A. Maximum \#12 AWG $12.5 \mathrm{~mm}^{2}$ / wire: Minimum \#18 AWG $0.75 \mathrm{mmal}$

S. Fiffer to Signoture controler installation shoet for wiring specifications

$\triangle$ Maximum 10 Vdc 350 $1 \mathrm{\mu A}$

(5) The SIGA-UIOtr and the SIGA-UIO2R to not carne with TE14.

6 All wiring is gupervised and power-imited

7 These modules will not support 2-wire smoke detectors.

\section{Warnings \& Cautions}

This module will not operate without electrical power. As fires frequently couse power interruption, we suggest you discuss further sofeguards with your local fire protection speciolist.

\section{Compatibility}

The Signature Series modules are compatible only with GE Security's Signature Loop Controller.

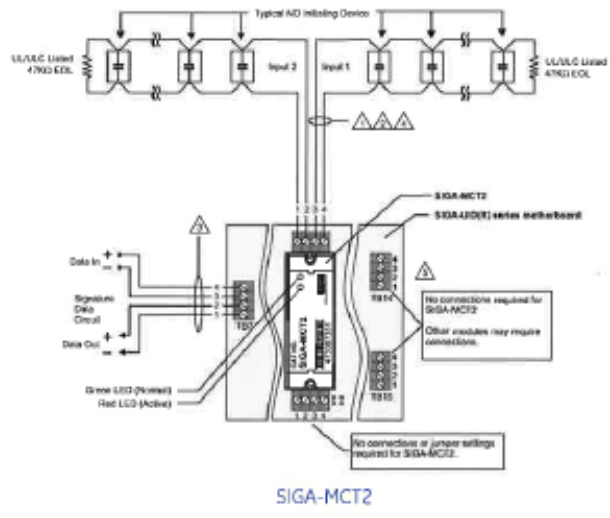




\section{EST \\ Lite satety Gommunications}

\section{Manual Pull Stations \\ SIGA-270, SIGA-270P, SIGA-278}

\section{Overview}

The SIGA-270 and SIGA-278 series Manual Pul Stations are part of EST's Signature Series system. The SIGA-270 Fire Alarm Manual Pul Stations feature our very familiar teardrop shape. They are made from die-cast zinc and finished with red epoxy powdercoat paint complemented by aluminum colored stripes and mark. ings. With positive pul-lever operation, one pull on the station handle breaks the glass rod and turns in a positive alarm, ensuring protection plus fool-proof operation. Presignal models (SIGA-270P) are equipped with a general alarm (GA) keyswitch for applications where two stage operation is roquired. The up-front highly visible glass rod discourages tampering, but is not required for proper operation.

EST's double action single stage SIGA-278 station is a contemporary style manual station made from durable red colored lexan. To initiate an alarm, first lift the upcer door marked "LIFT THEN PULL HANDLF", then pull the alam handle.

\section{Standard Features}

Note: Scme foatures deschbed here may not be supported by al control sys. terms. Check your cantrol penel's instalation and Coeration Guide for detals.

- Traditional familiar appearance

SIGA-270 models feature our famliar teardrop design with simple positive pull action and sturdy die-cast motal body

- One stage (GA), two stage (pre-signal), and double action models

SIGA-270 models are avalable for one or two stage alarm systerns. The single stage double action SIGA-278 fatures a rugged Lexan housing with keyed reset mechanism.

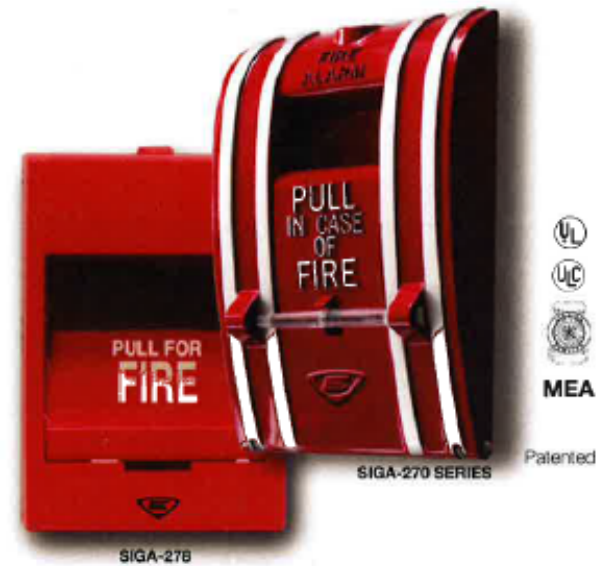

- Break glass operation

An up-front visible glass rod on the SIGA-270 discourages tampering.

- Intelligent device with integral microprocessor All decisions are made at the station allowing lower communication speed while substantially improving control pane response time. Less sensitive to line noise and loop wining properties; twisted or shialded wire is not required.

- ADA Compliant

Meets ADA requirements for manual puli stations.

- Electronic Addressing with Non-volatile memory Permanently stores programmable address, serial number. type of device, and job number. Automatically updates historic information including hours of cperation, last maintenance date, number of alarms and troubles, and time and date of last alarm.

- Automatic device mapping

Each station transmits wiring information to the loop controller regarding its location with respect to other devices on the circuit.

- Stand-alone operation

The station inputs an alarm even if the loop controller's poling interrogation stops.

- Diagnostic LEDs

Status LEDs; flashing GREEN shows normal polling; flashing RED shows alarm state.

- Designed for high ambient temperature operation instal in ambient temperatures up to $120^{\circ} \mathrm{F}\left(49^{\circ} \mathrm{C}\right)$. 
Installation

Single-stage Signature Series fire alarm manual pull stations mount to North American 21/2 inch (64 mm) deep 1-gang boxes.

Two stage presignal (270P) models require $11 / 2$ inch $(38 \mathrm{~mm})$ deep 4 -inch square boxes with 1-gang, 1/2-inch raised covers. Openings must be angular. Rounded openings are not acceptable. Recommended box: Steel City Model 52-C-13; in Canada, use lberville Model Cl. $52-\mathrm{C}-49-1 / 2$.

All models include terminals are suited for \#12 to \#18 AWG $\left(2.5 \mathrm{~mm}^{2}\right.$ to $\left.0.75 \mathrm{~mm}^{2}\right)$ wire size. Edwards recommends that these fire alarm stations be installed according to latest recogrized edition of national and local fire alarm codes.

Electronic Addressing: The bop controller electronicaly addresses each manual station, saving valuable time during system commissioning. Setting complicated switches or dials is not required. Each station has its own unique serial number stored in its on-board memory. The loop controller identifies each device on the loop and assigns a "soft" address to each serial number. If desired, the stations can be addressed using the SIGA-PRO Signature ProgramVService Tool.

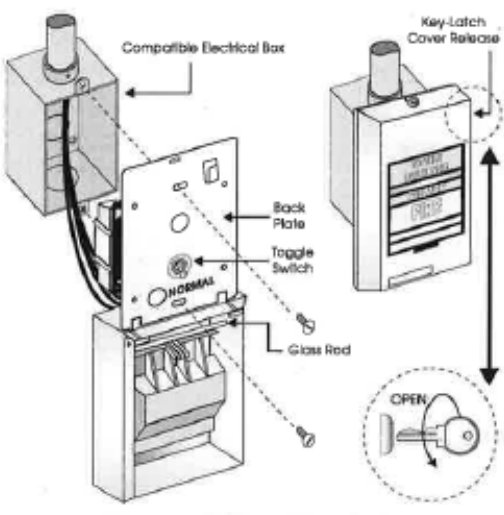

Figure 1. SIGA-278 installation

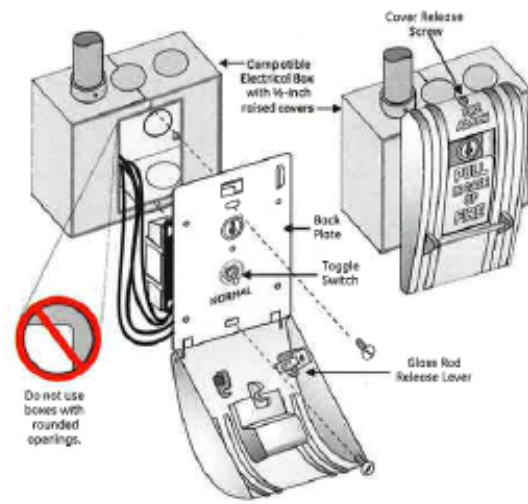

Figure 3. SIGA-27OP, SIGC-270PB installation

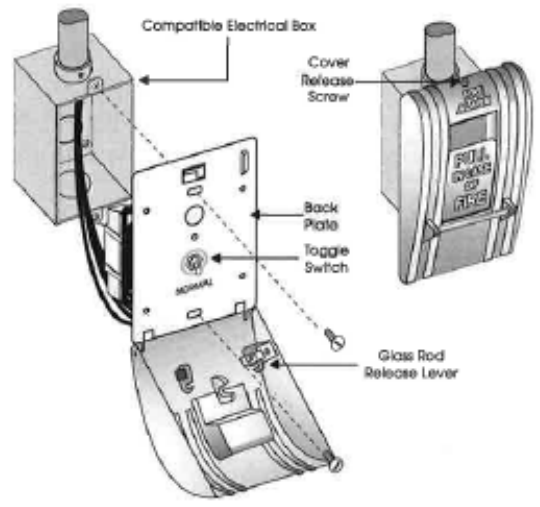

Figure 2. SIGA-270, SIGC-270F, SIGC-270B installation 


\section{EST}

Part of GE

Security

\section{QS4 Multi-loop Intelligent/ Conventional Life Safety Control Panel}

Features

- One to four Signature loops - each with a capacity of 250 Intelligent devices - PLUS up to 48 conventional circuits

- Compatible with two-and four-wire smoke detectors

- Combines the Signature intelligent releasing module with Signature multisensor detectors for reliable suppression

- Failsafe mode ensures uncompromised reliability

- Class A (Style 7) or Class B (Style 4) wiring options

- Capacity for eight remote annunciators

- Four built-in system reloys

- Optional dual line dialer supports Contact ID and $4 / 2$ formats

- Three methods of programming:QuickStart "auto-learn," front panel and personal computer (PC)

- Supports optional barcode scanner for direct device data entry

- Two optional banks of 30 front panel switches with dual LEDs

- Up to 20 adjustable pre-alarm settings for Signature smoke detectors

- Red or grey cabinets in two sizes for surface or semi-flush mounting

- Large 14-line (224 charocter) backlit LCD display

- Four password levels, plus priority access keyswitch

- Message routing by event type or by individual message

- Alarm sensitivity by time of day or manual selection

- 1,000 event history buffer, plus alarm history counter

- 6 amp Power Supply, 4.75 amps available for external use

- ULC-\$527-99compliant

- Compare utility identifies system changes and simplifies testing

\section{Description}

EST's QS4 QuickStart life safety control panel provides conventional ond ntelligent addressoble circuits in a single inteligent control pone. Designed for easy setup and simple installation, QuickStort lives up to its namein every respect QSe's exclusive Quickstart outo-learntunction,

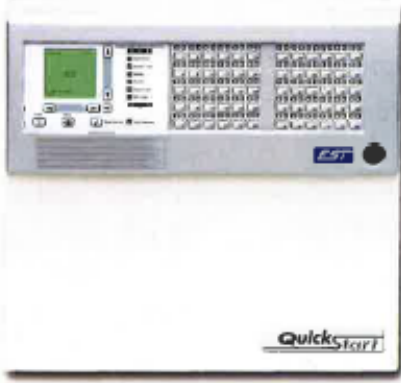

(4L)

MEA

programming or from a PC, makes short work of systern setup. Devices come on-line in no time os well, thanks to QS4's built-in barcode scanner port. A simple pass of the optional sconner is all it takes to store device informotion in the QuickStort dotobose. The sconner con aiso be used for quick and eosy text entry when ossembling custom messoges.

QS4's setup routine is deceptively simple, considering this system's robust features and broad copacity. Supporting up to 1,000 intelligern detectors and modules, Q54 takes full advantage of EST's exclusive Signoture Series technology, which provides electronic addressing. automotic devicemopping, whironmentalcompensotion, ond true multisensordetection.

As a hybrid system, QS4 combines Signoture Series support olang with up to 48 conventional Class B or a combination of 40 Class A and Closs Binitioting circuits. Compotiblewith either two- or four-wire detectors, these circuits olso provide built-in support for EST's EC family of conventionol detectors.

QuickStart's design leaves plenty of room for system expansion. Option cords snop onto OS4's eosily-occessible DIN mounting rcils Thesecords include o dialer, auxiliory reloys and additional system capocity The QSt a QSt also supports as many as eight remote onnunciotors and up to 60 front panelswitches with dualteos or system contro ond disploy.

QSA is as simple to operote as it is to set up. Its large 14-ine bocklit $L C O$ display provides easy-to-understond detoils concerning up to 1.000 system events, while bright system stotus LEDs and lorge, toctile control buttons present the user with a clean, crystal clear interfoce. Four possword levels limit control and information retrievol to outhorized personnel. A priority access keyswitch gives Level 2 occess, without a possward, to manogement and emergency personnel. B985 TOWN CENTER PARKWAY, BRADENTON, FL 34202 PHONE: B89-378-2329. FAX: $866-5034209$ CANADA SALES: OWEN SOUNO, ON519-376-2430, FAX519-376-728 INTERNLTIONAL SALES: 001) $905-270-1711$; FAX 10011)905-270-955

Not to be used for installation purposena. Poish 2 of 5 


\section{CPU / LCD Display}

The QS4 front panel display provides 14 lines by 16 characters of text detoling event, device, diognostic, and progromming in ormation. large backlit LCD screen is easy to reod and always provides at-aglance indicotion of the systern's state of operation. The CPU/Display Unit houses the CPU cord and mounting spoce for two optional LEOI Switchcords.

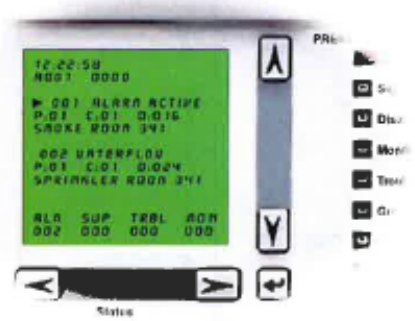

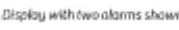

Specifications

\begin{tabular}{|l|l}
\hline Operating & Temperature: $32-120^{\circ} \mathrm{F}\left(0-49^{\circ} \mathrm{C}\right)$
\end{tabular}

environment Humidity: $93 \% \mathrm{RH}$, non-condensing

\begin{tabular}{l|l} 
Current & Standby: 117 mA when connected to PS6;
\end{tabular}

requirements $105 \mathrm{~mA}$ when connected as remote annunciator

Alarm: $\quad 135 \mathrm{~mA}$ when connected to PS6; $123 \mathrm{~mA}$ when connected as a remote annunciator

Failsafe Mode

If the CPU loses communication with other circuit cards, the power supply card continues to monitor the system for any alorm events. If on the power supply activates all alarm outputs and instructs the dialer to transmit a default alarm messoge to themanitoring stotion.

\section{Remote Annunciator Dimensions}

\begin{tabular}{|c|c|c|c|}
\hline Model & Height & Width & Depth \\
\hline QSA-1-S & $7.6(19.46 \mathrm{~cm})$ & $14.25^{\prime}(36.20 \mathrm{~cm})$ & $2.8^{\prime}(7.3 \mathrm{~cm})$ \\
\hline QSA.1.F (rough in) & $6.56^{\circ}(16.66 \mathrm{~cm})$ & $13.25^{\prime \prime}(33.66 \mathrm{~cm})$ & $2.1^{*}[5.33 \mathrm{~cm}]$ \\
\hline OSA-1.F (finished) & $7.8^{\circ}[19.81 \mathrm{~cm}]$ & $14.42(36.63 \mathrm{~cm})$ & $1.38^{\circ}(3.49 \mathrm{~cm})$ \\
\hline OSA.2.S & $7,6^{*}[19.46 \mathrm{cml}$ & $18.5 \sigma^{\circ}(47.14 \mathrm{~cm})$ & $2.8^{\circ}(7.3 \mathrm{~cm})$ \\
\hline OSA-2-F (rough in) & $6.56^{\circ}(16.66 \mathrm{~cm})$ & $17.56^{\prime}(44.60 \mathrm{~cm})$ & $2.1^{*}(5.33 \mathrm{~cm})$ \\
\hline OSA-2-F (finished) & $7.8^{\circ}[19.81 \mathrm{~cm}]$ & $18.75 \cdot(47.63 \mathrm{~cm})$ & $1.3 \mathrm{~g}^{\circ}(3.49 \mathrm{~cm})$ \\
\hline
\end{tabular}

\section{CabinetDimensions}
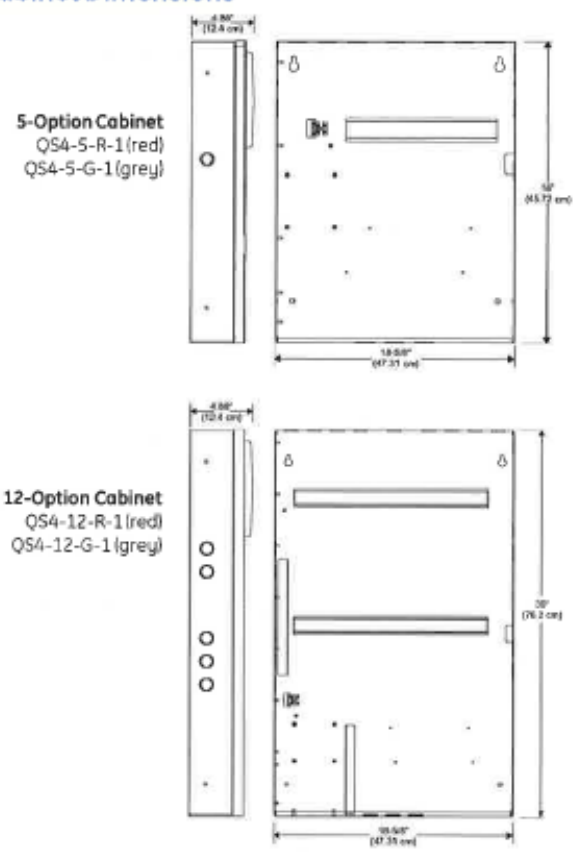

\section{Cabinet Mounting}

12 and 5-Option Cabinets

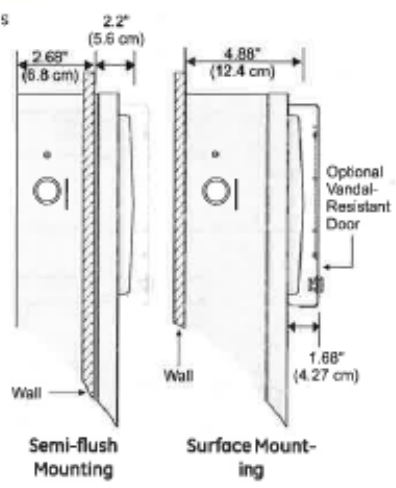

Semi-flush mounting requires an optional trim ring, which odds $3^{*}$ to all sides of the panel. 


\section{Standard Components \\ and Option Cards}

All QS4 panels come standard with a CPU/Disploy Unit, and a PS6 Power Supply isee ordering information for detailst.

QuickStart option cords provide a wide range of features and extro system copocity. Thanks to the convenient Quick-Lok mounting system, option cords snap onto the OIN mounting rails easily and securely. Wallboxes are available in two sizes with room for either five or 12 singlespoce option cards. Both sizes of wallbox feature eosily-occessible mounting rails and plenty of room for cobling

eption cord cobinet wet optioncarts and

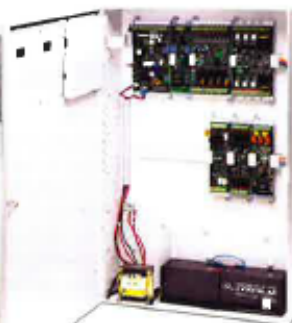

\section{Power Supply Card}

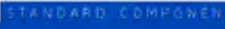

The PS6 provides primary de power to all the circuit cards installed in the cabinet. There are four $24 \mathrm{Vdc}$ power output circuits - three for powering auxiliory applications, and one for powering four-wire smoke detectors - and a charging circuit for stondby botteries. The PS6 olso provides common olarm, supervisony and trouble relays, os well as a fourth relay that is user programmable.
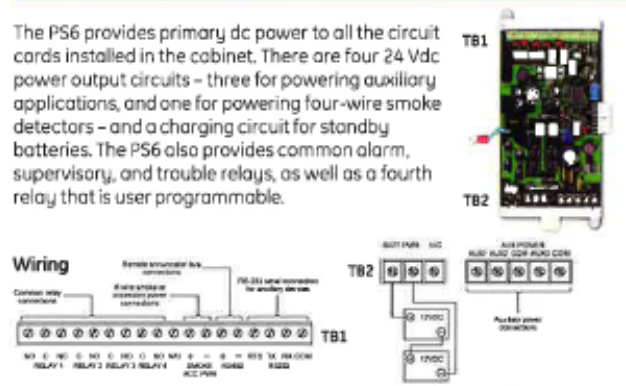

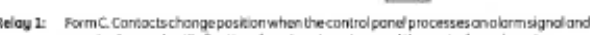

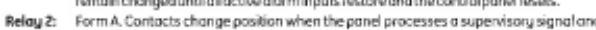

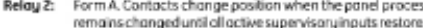

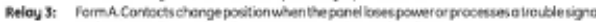

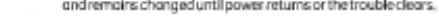

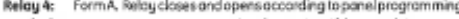
Smoke/Accessory Power: Lumper setting determines if the 24 Wdeis constont or resettrobio

\begin{tabular}{|c|c|}
\hline Main supply circuit & $\begin{array}{l}\text { AC input: } 115 \text { or } 230 \text { Vac, } 50 / 60 \text { Hertz } \\
\text { DC input: } 24 \text { Vde batteries }\end{array}$ \\
\hline Battery charging circuit & $\begin{array}{l}\text { Charge current: } 2 \text { amps } \\
\text { Charge capacity: } 40 \text { amp hours (UL) } \\
\qquad 30 \text { amp hours (ULC) }\end{array}$ \\
\hline $\begin{array}{l}\text { Smoke/Accessory } \\
\text { power output circuit }\end{array}$ & $\begin{array}{l}\text { Voltage: } 24 \mathrm{Vdc} \text {, reguiated } \\
\text { Current: } 250 \mathrm{~mA} \\
\text { Wire size: } 12 \text { to } 18 \text { AWG } 10.75 \text { to } 2.5 \mathrm{~mm}^{2} \text { ) }\end{array}$ \\
\hline $\begin{array}{l}\text { Auxiliary power } \\
\text { output circuits }\end{array}$ & $\begin{array}{l}\text { Quantity: } 3 \\
\text { Voltage: } 24 \text { vdc full wave rectified } \\
\text { Current: } 1.5 \text { amps each }\end{array}$ \\
\hline Common alarm relay & $\begin{array}{l}\text { Style: Form C } \\
\text { Contact rating: } 1 \text { amp } \\
\text { Wire size: } 12 \text { to } 18 \text { AWG }\left(0.75 \text { to } 2.5 \mathrm{~mm}^{2}\right)\end{array}$ \\
\hline $\begin{array}{l}\text { Trouble, Supervisory } \\
\text { and programmable } \\
\text { relays }\end{array}$ & $\begin{array}{l}\text { Style: Form A (N/O) } \\
\text { Contact rating: } 1 \mathrm{amp} \\
\text { Wire size: } 12 \text { to } 18 \text { AWG }\left(0.75 \text { to } 2.5 \mathrm{~mm}^{2}\right)\end{array}$ \\
\hline Operating environment & $\begin{array}{l}\text { Temperature: } 32-120^{\circ} \mathrm{F}\left(0-49^{\circ} \mathrm{C}\right) \\
\text { Humidity: } 93 \% \mathrm{RH} \text {, non-condensing }\end{array}$ \\
\hline Current requirements & $\begin{array}{l}\text { Stand by current: } 72 \mathrm{~mA} \\
\text { Alarm current: } 96 \mathrm{~mA}\end{array}$ \\
\hline
\end{tabular}

\section{Signature Loop intelligent Controller}

The SLIC provides one Closs A or Class B dato circuitilooplfor connecting Signoture Series detectors ond modules The SULC olso provides tivo programmable Closs A or Class B notification appliancecircuits!NACs! for connecting polarized 24 Vde notification appliances such os horns and strobes. Both the QS4-5 and the QS4-12 support one to four Stics.
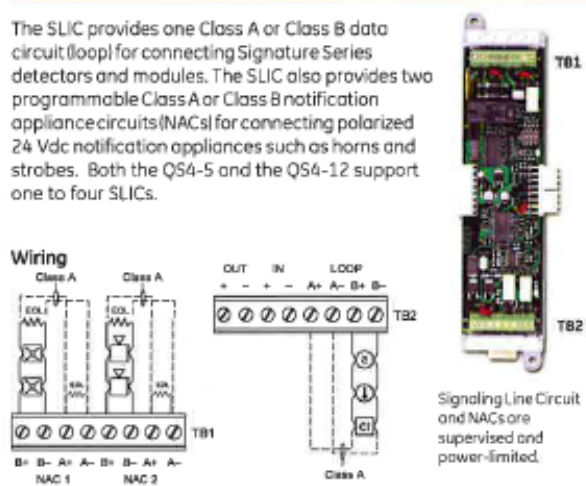


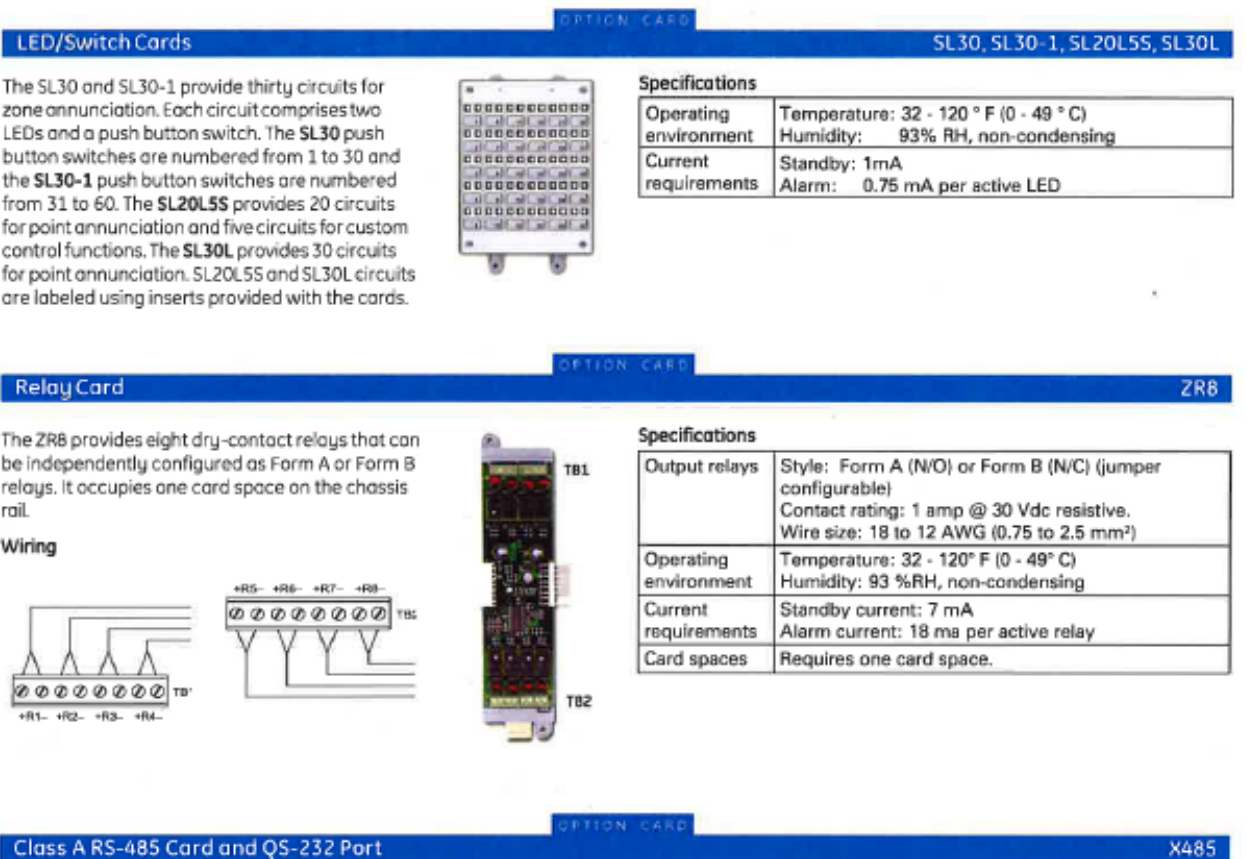

The NT-A, which includes the X485/RS$485 \mathrm{card}$ and QS-232/UART port, provides one Class A serial remote annunciator bus forconnecting remoteonnunciator ponels. Control panels require the Xa85 card ond UART port which olso serves os loptop or printer port The X4B5 occupies one card space on the chassis rail. The UART port plugs into the panelCPU.

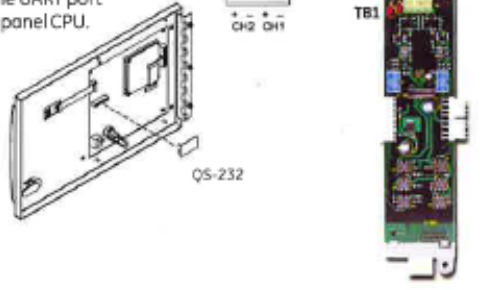

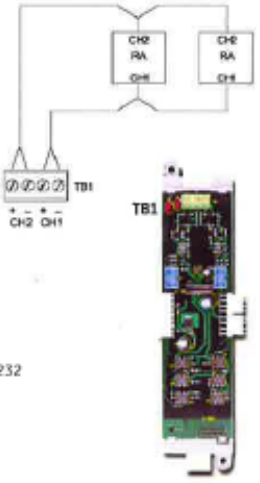

Specificotions

\begin{tabular}{|l|l|}
\hline Wire size & $\begin{array}{l}12 \text { to } 18 \text { AWG }\left(0.75 \text { to } 2.5 \mathrm{~mm}^{2}\right) \\
\text { twisted pair (6 twists per foot minimum) }\end{array}$ \\
\hline Circuit resistance & $100 \mathrm{Ohms}$ \\
\hline Circuit capacitance & $0.4 \mu \mathrm{F}$ \\
\hline Operating envirenment & $\begin{array}{l}\text { Temperature: } 32-120^{\circ} \mathrm{F}\left(0-49^{\circ} \mathrm{C}\right) \\
\text { Humidity: } 93 \% \mathrm{RH} \text {, noncondensing }\end{array}$ \\
\hline Current requirements & $\begin{array}{l}\text { Standby: } 75 \mathrm{~mA} \\
\text { Alarm: } 75 \mathrm{~mA}\end{array}$ \\
\hline Card Spaces & Requires one space for the NT-A \\
\hline
\end{tabular}




\section{Overview}

The Signature Series Model SIGA-PS Intelligent Photoelectric Smoke Detector gathers analog informotion from its smoke sensing element and converts it into digitol signals. The detector's on-bocrd microprocessor measures ond analyzes these signals. It compares the information to historical readings and time patterns to make an alorm decision. Digital filters remove signal potterns that are not typical of fires. Unwonted olarms are virtually eliminated.

The microprocessor in each detector provides four odditional benefits - Self-diognostics and History Log. Automotic Device Mopping. Stand-olone Operation and Fast, Stable Communication.

Self-diagnostics and History Log - Eoch Signature Series detector constantly runs self-checks to provide important maintenance information. The results of the self-check are automatically updated and permanently stored in the detector's non-volatile memory

Automatic Device Mapping - The loop controller learns where eoch device's serial number oddress is installed relative to other devices on the circuit. The mapping feoture provides supervision of eoch device's installed location to prevent a detector from being reinstalled lafter cleaning etc.l in a different location from where it was originally.

Stand-alone Operation - A decentralized alarm decision by the detector is guaranteed. On-boord intelligence permits the detector to operate in stand-alone mode. If loop controller CPU communica. tions foil for more than four seconds, all devices on that circuit go into stand-olone mode. The circuit octs like a conventional alorm receiving circuit.
Fast Stable Communication - On-board intelligence means less information needs to be sent between the detector and the loop controller, Other than regulor supervisory polling response, the detector only needs to communicate with the loop controller when it has something new to report.

\section{Standard Features}

- Integral microprocessor

- Non-volatile memory

- Automatic mopping device

- Electronic oddressing

- Environmentol compensation

- Intelligent detector

- Wide $0.67 \%$ to $3.77 \% / \mathrm{ft}$. sensitivity range

- Twenty pre-alorm sersitivity values, set in $5 \%$ increments

- Identification of dirty or defective detectors

- Automatic day/night sensitivity adjustment

- Twin RED/GREEN status LEDs

- Stondard, relay, foult isolator, and audible mounting boses

- Designed and manufoctured to ISO 9001 stondards

Intelligent Photoelectric Smoke Detector SIGA-PS 
Application

Although photoelectric detectors have o wide range of fire sensing capabilities they are best suited for detecting slow, smoldering fires. The table below shows six standard test fires used to rate the sensitivity of smoke and heat detectors. The table indicates that no single sensing element is suited for all test fires.

GE Security recommends that this detector be installed according to latest recognized edition of national and local fire alarm codes.

\begin{tabular}{llllll} 
Test Fire & SIGA-IS lon & SIGA-PS Photo & $\begin{array}{l}\text { SIGA-HRS and SIGA- } \\
\text { HFF Rote-of-Rise/ } \\
\text { Fixed Temp. }\end{array}$ & $\begin{array}{l}\text { SIGA-PHS } \\
\text { Photo Heat 3D }\end{array}$ & $\begin{array}{l}\text { SIGA-IPHS } \\
\text { lon/Photo/Heat 4D }\end{array}$ \\
\hline Open Wood & optimum & Unsuitable & optimum & very suitable & optimum \\
\hline Wood Pyrolysis & suitable & optimum & unsuitable & optimum & optimum \\
\hline Smouldering Cotton & very suitoble & optimum & unsuitoble & optimum & optimum \\
\hline Poly Urethane Foom & very suitoble & very suitable & suitable & very suitable & optimum \\
\hline n-Heptane & optimum & very suitoble & very suitable & optimum & optimum \\
\hline Liquid Fire without Smoke & unsuitable & unsuitable & optimum & very suitable & very suitoble \\
\hline
\end{tabular}

\section{Typical Wiring}

The detector mounting bases occept \#18 AWG $\left.10.75 \mathrm{~mm}^{2}\right)$, \#16 $\left(1.0 \mathrm{~mm} 2\right.$ ). \#14 AWG $\left.11.5 \mathrm{~mm}^{2}\right)$, ond \#12 AWG (2.5mm² wire sizes. Note: Sizes \#16 AWG (1.0mm?) and \#18 AWG $\left(0.75 \mathrm{~mm}^{2}\right)$ are preferred for ease of installation. See Signature Loop Controller catalog sheet for detoiled wiring requirement specifications.

Standard Detector Base, SIGA-SB, SIGA-SB4

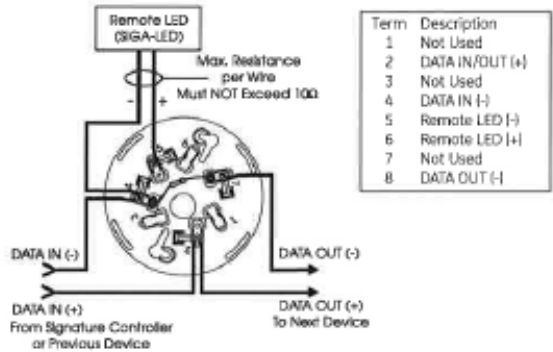

Isolator Detector Base, SIGA-IB, SIGA-IBA

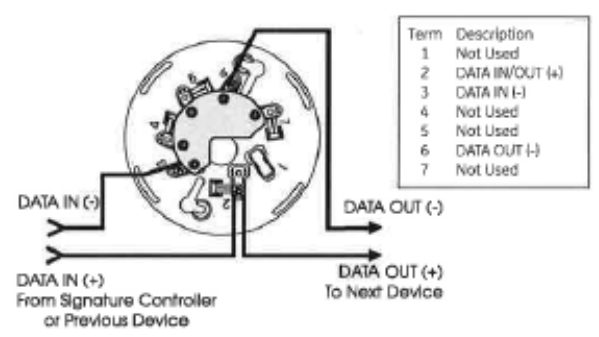

Relay Detector Base, SIGA-RB, SIGA-RBA
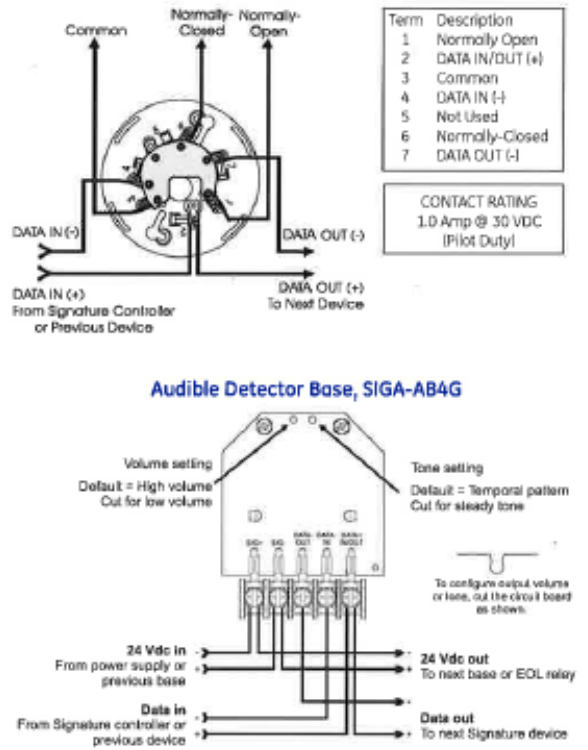


\section{Overview}

The SIGA-CT1 Single Input Module and SIGA-CT2/SIGA-MCT2 Duol Input Modules are intelligent analog oddressable devices used to connect one or two Class 8 normaly-open Alarm, Supervisory, or Monitor type dry contoct Initiating Device Circuits IIDC).

The actual function of these modules is determined by the "personality code' selected by the installer. This code is downlooded to the module from the Signature loop controller during system configuration.

The input modules gother anolog information from the initiating devices connected to them and convert it into digital signals. The module's on-board microprocessor analyzes the signal and decides whether or nat to input on alarm.

The SIGA-CT1 and SIGA-CT2 mount to standard North American 1-gang electrical boxes, making them ideol for locotions where only one module is recuired. Separate $\mathrm{I} / \mathrm{O}$ and data loop connections are made to eoch module.

The SIGA-MCT2 is port of the UIO family of plug-in Signature Series modules. It functions identically to the SIGA-CT2, but takes odvantoge of the madular flexibility and easy installation that characterizes all UIO modules. Twa- and six-madule UIO motherboards are ovoilable. All wiring connections are mode to terminal blocks on the motherboard. UIO assemblies may be mounted in GE Security enclosures.

\section{Standard Features}

Multiple applications

Including Alarm, Alarm with deloyed latching (retord) for woterflow applications, Supervisory, and Monitor. The installer selects one of four "personality codes" to be downlooded to the module through the loop controller

- Plug-in (UIO) or standard 1-gang mount

UIO versions allow quick instollation where multiple modules are required. The 1-gang mount version is ideol for remote locations that require a singie module.

\section{- Automatic device mapping}

Signoture modules tronsmit information to the loop controller regarding their circuit locations with respect to other Signature devices on the wire loop.

Programmable addresses are downloaded from the loop controller, o PC, or the SIGA.PRO Signature Progrom/Service Tool. There ore no switches or dials to set.

- Non-volatile memory

Permonentily stores serial number, type of device, and job number.

\section{- Stand-alone operation}

The module mokes decisions and inputs an alarm from initiating devices connected to it even if the loop controller's polling interrogation stops. (Function avalobility dependent upon control pane ()

- Ground fault detection by address

Detects ground foults right down to the device level.
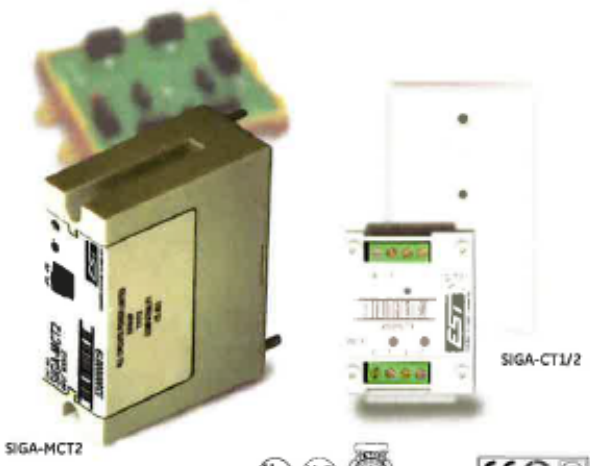

(15) (ULC) (3) MEA CEN (8)
Input Modules

SIGA-CT1, SIGA-CT2 \& SIGA-MCT2 
Brett Noakes June 2015

\section{Floor Plans with Exits}




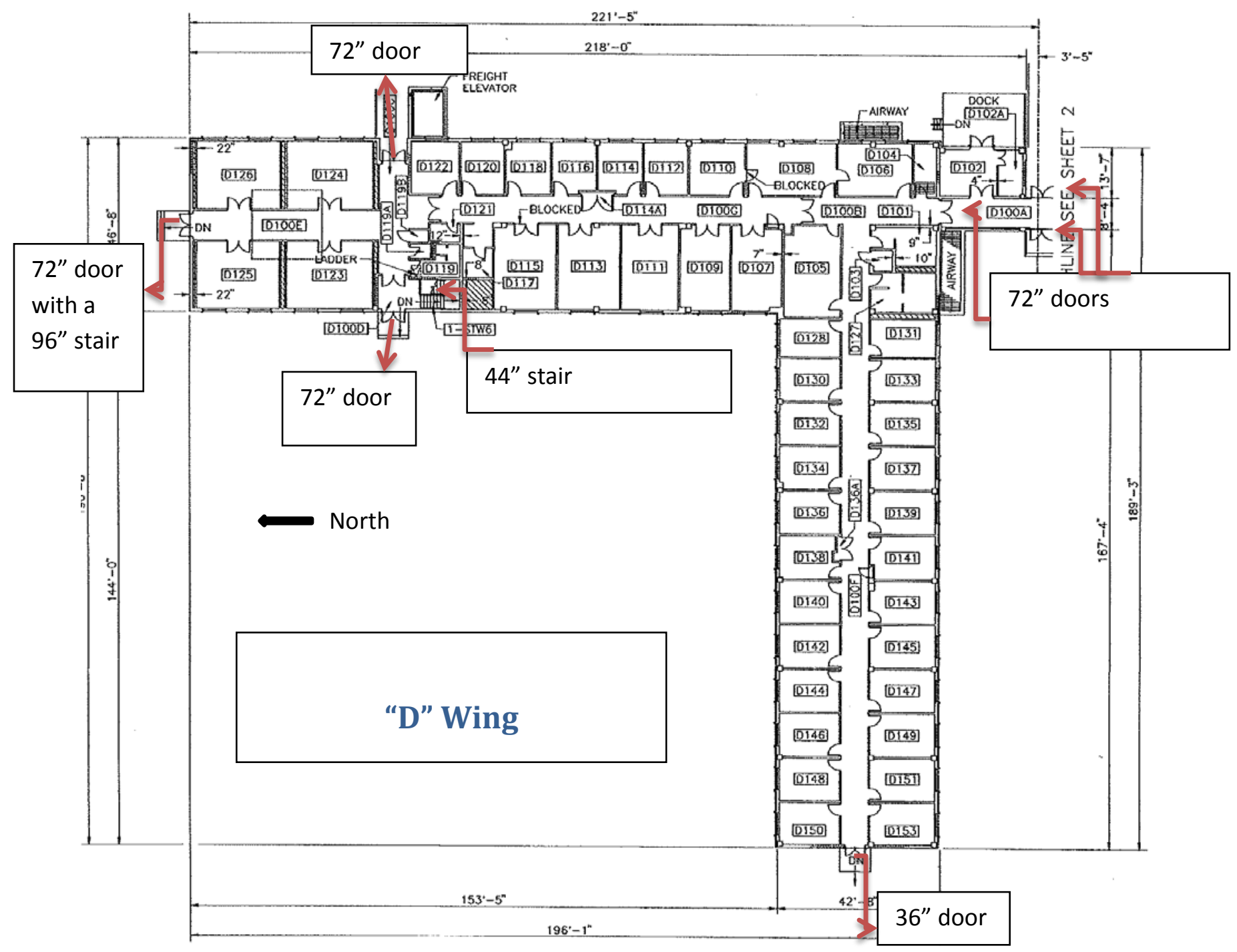

FIRST FLOOR PLAN 


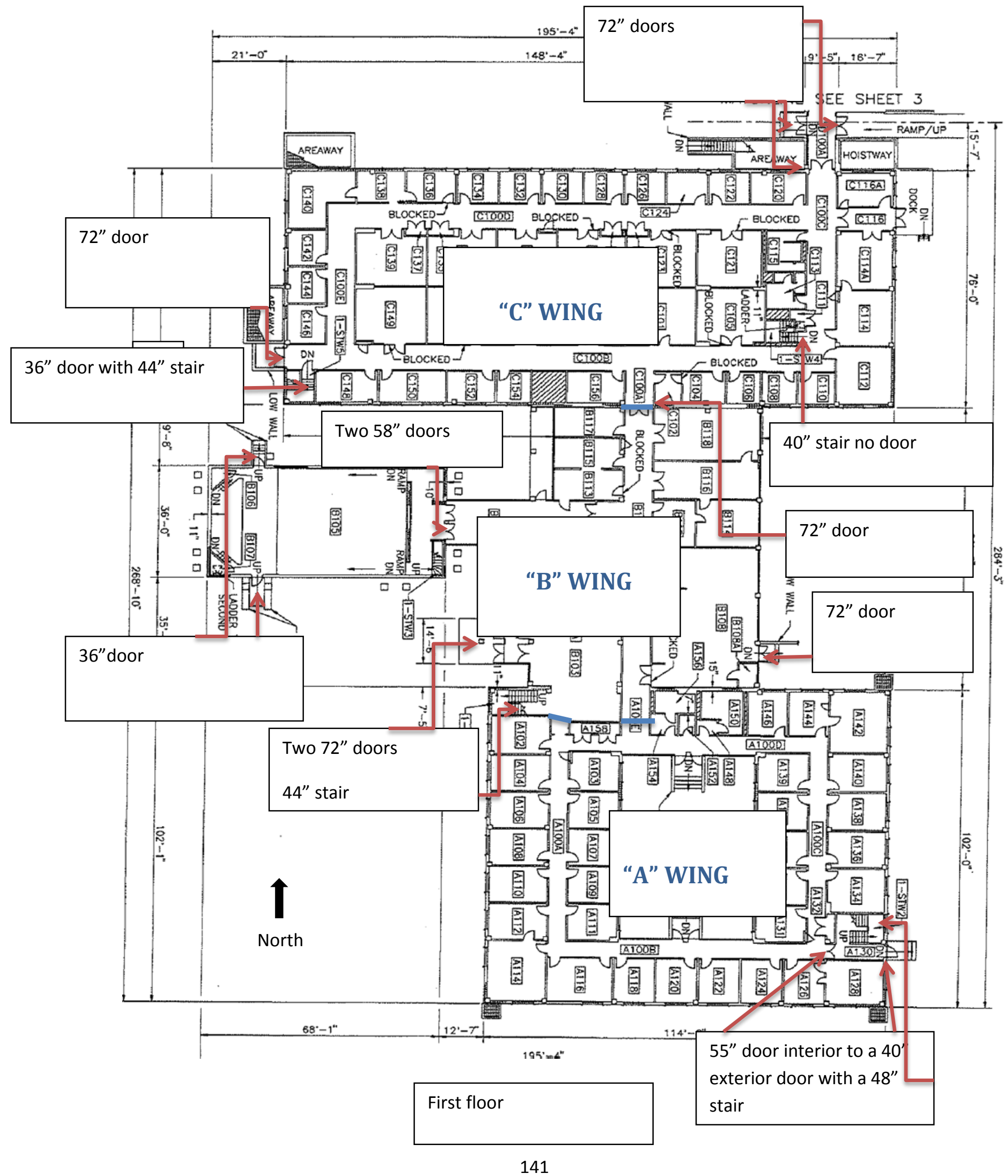


Brett Noakes

June 2015

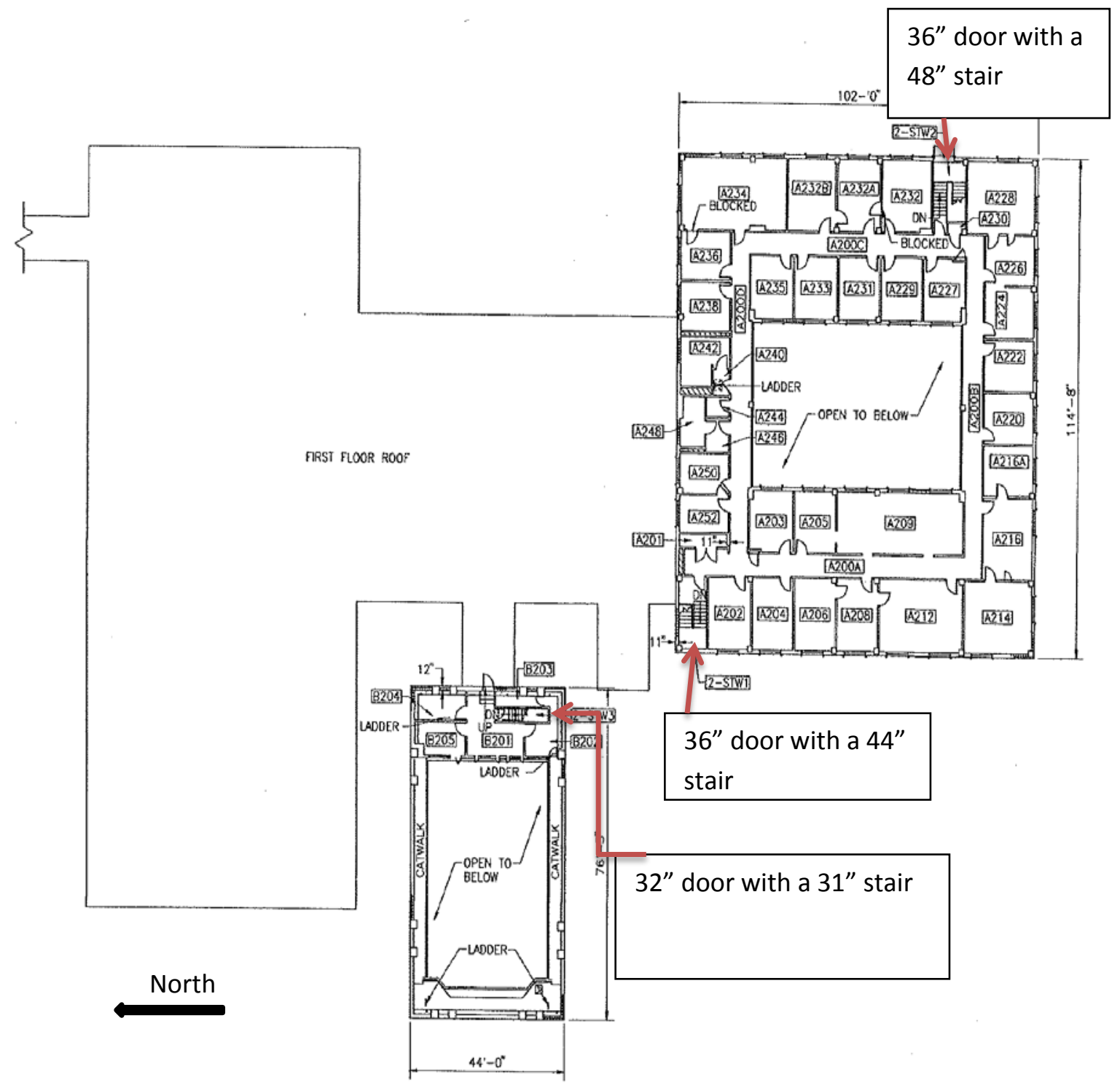

SECOND FLOOR PLAN

SCAE: $1 / 16^{\circ}=11-0^{\circ}$ 


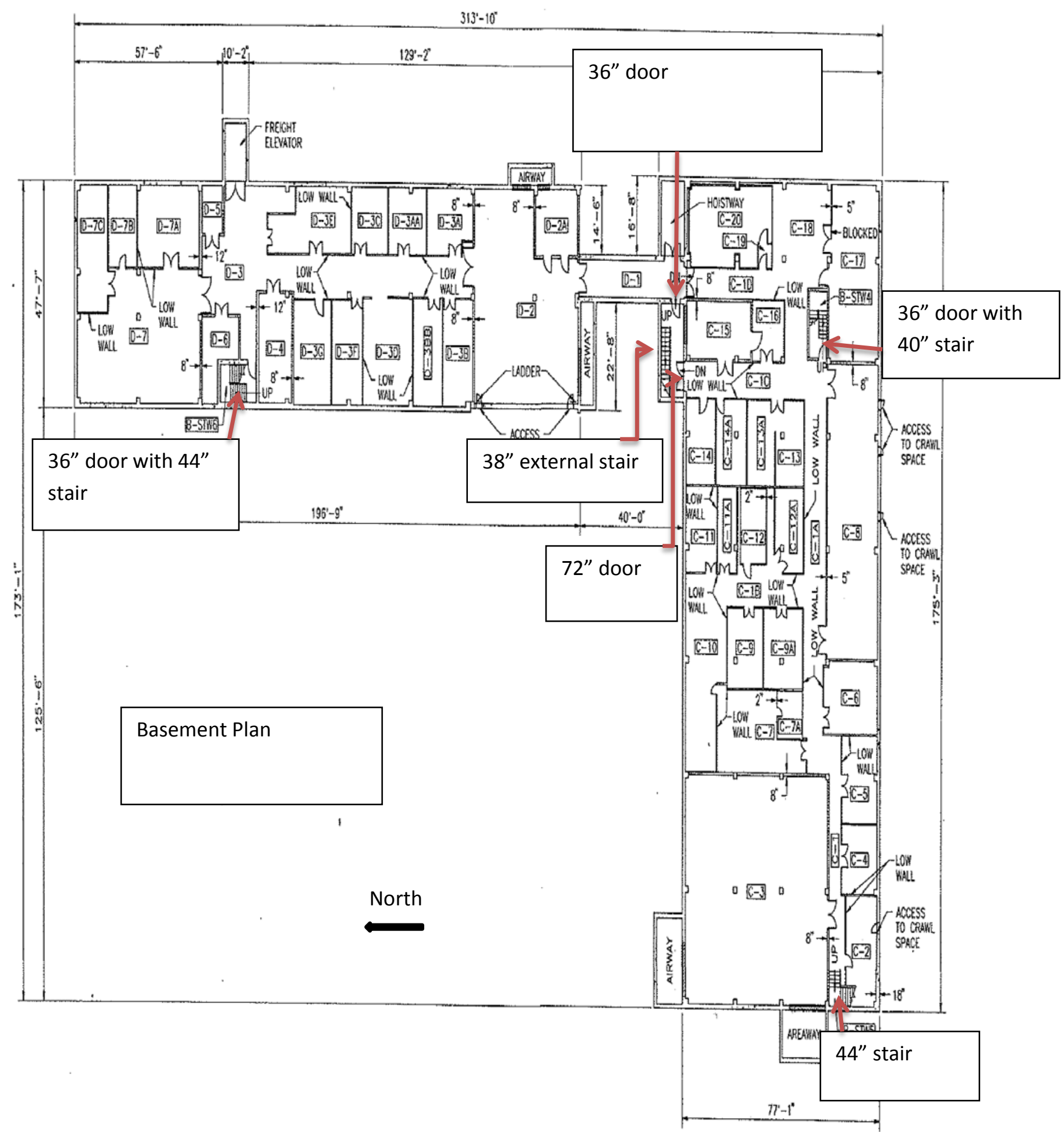




\section{Occupancy Identification Maps}



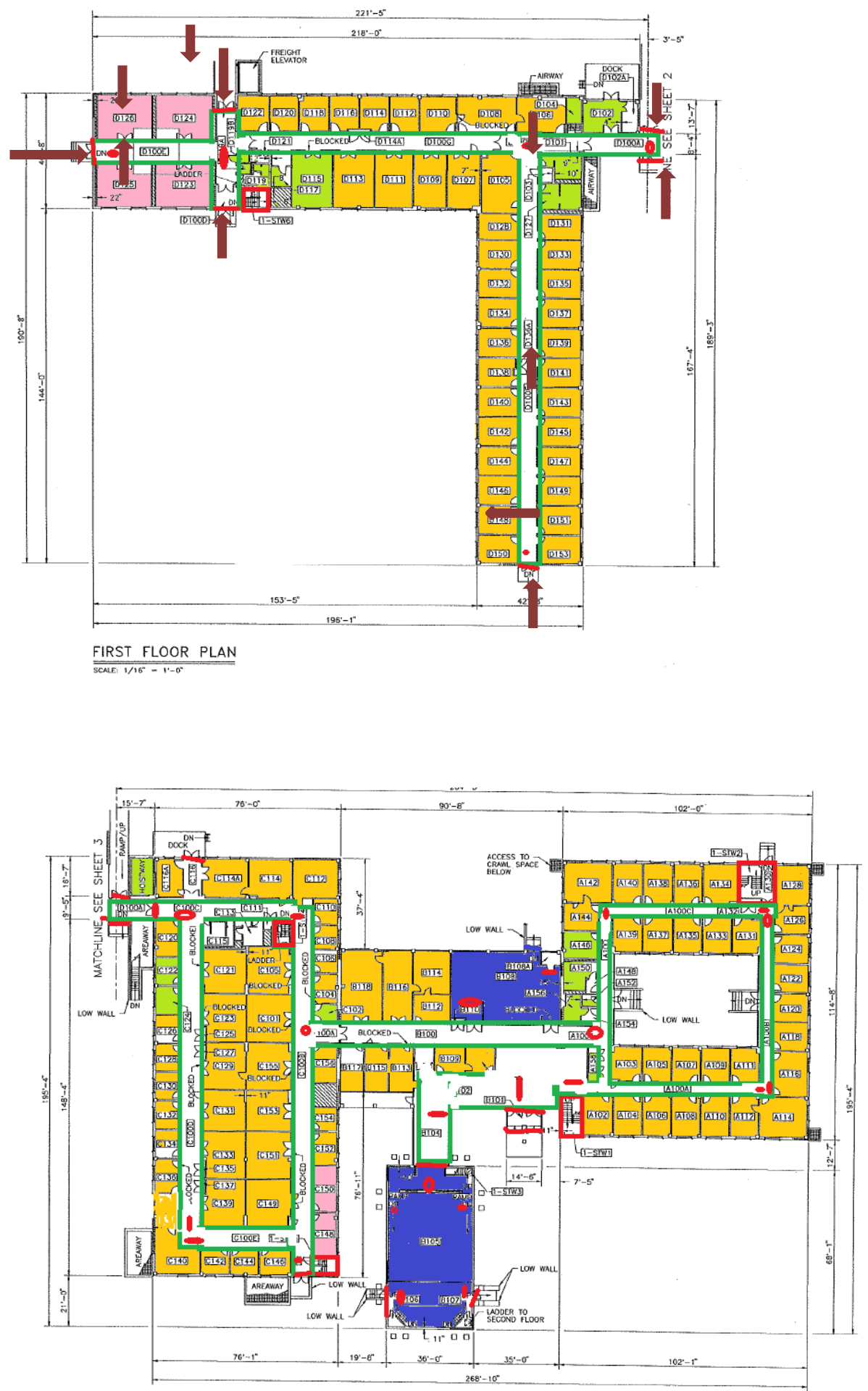
Brett Noakes

June 2015
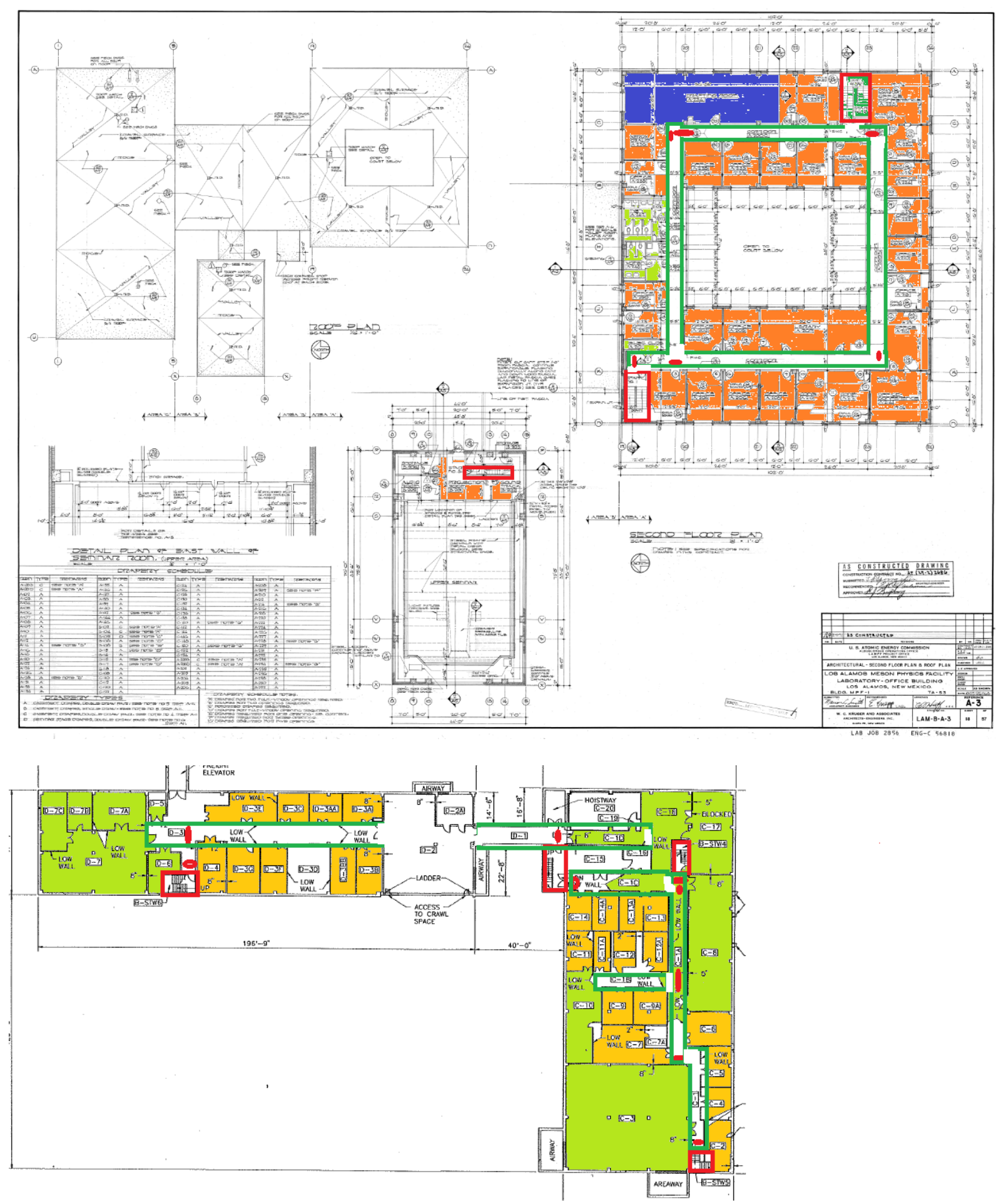


\begin{tabular}{|l|l|}
\hline & $\begin{array}{l}\text { Assembly } \\
\text { Occupancy }\end{array}$ \\
\hline & Business \\
& Occupancy \\
\hline & Business \\
& Occupancy \\
\hline & Mechanical \\
& Space \\
\hline & Corridor \\
\hline & Stair \\
\hline & Lab Space \\
\hline & Exit Sign \\
\hline & Exit door \\
\hline
\end{tabular}


Brett Noakes June 2015

\section{Hydraulic Calculations}


Noakes

HYDRAULIC CALCULATIONS

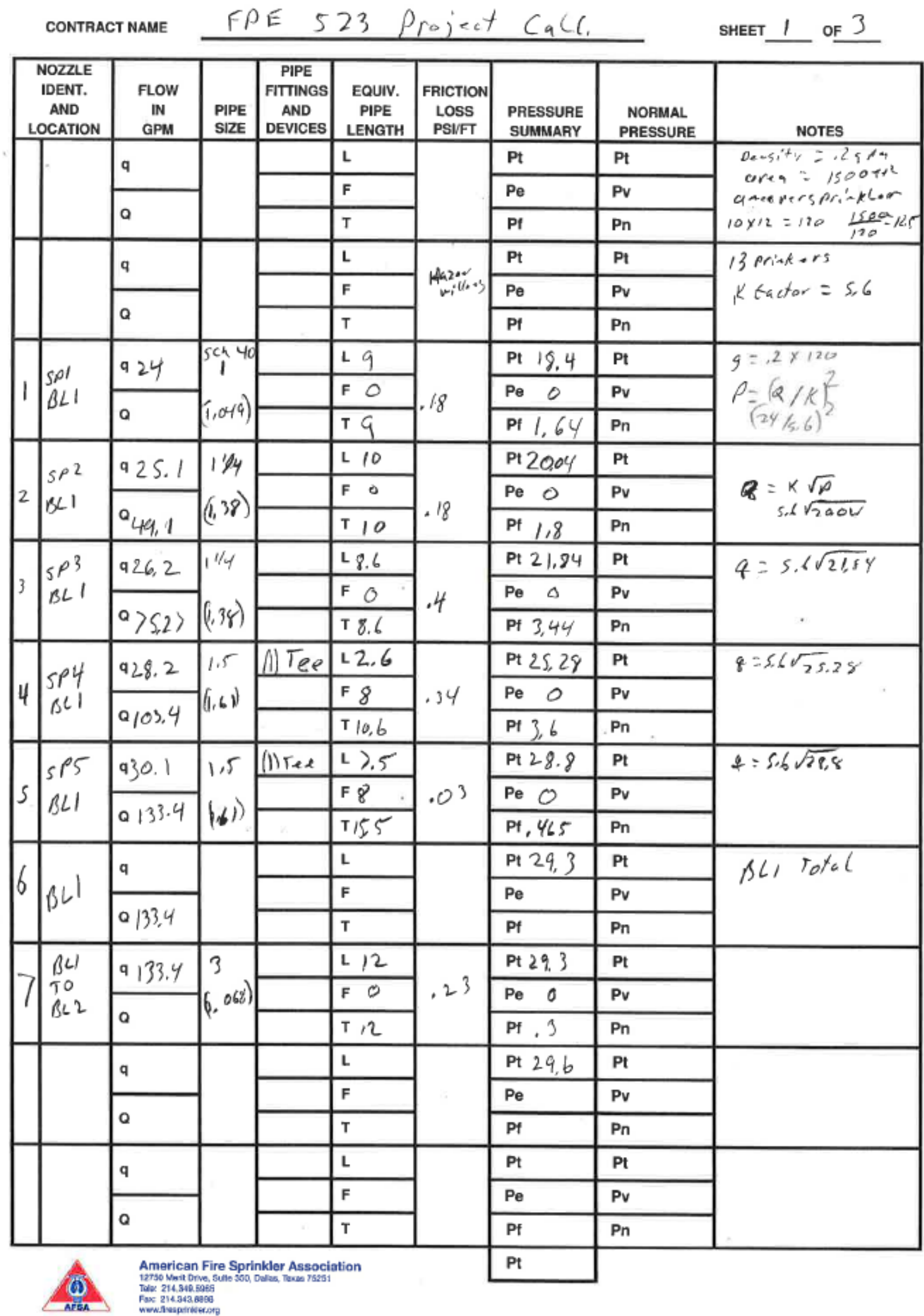




\begin{tabular}{|c|c|c|c|c|c|c|c|c|c|}
\hline & No & $\begin{array}{l}\text { ¿Kles } \\
\text { ST NAME }\end{array}$ & $F P$ & $\begin{array}{r}H Y \\
E \quad S 2 \\
\end{array}$ & $\begin{array}{l}\text { DRAUL } \\
3 \text { Proj }\end{array}$ & $\begin{array}{l}\text { IC CAL } \\
\text { ect } C_{a}( \\
\end{array}$ & $\begin{array}{l}\text { CULATIC } \\
C_{1}\end{array}$ & & SHEET 2 OF 3 \\
\hline & $\begin{array}{l}\text { NOZZLE } \\
\text { IDENT. } \\
\text { AND } \\
\text { OCATION } \\
\end{array}$ & $\begin{array}{l}\text { FLow } \\
\text { IN } \\
\text { GPM } \\
\end{array}$ & $\begin{array}{l}\text { PIPE } \\
\text { SIZE } \\
\end{array}$ & \begin{tabular}{|c|} 
PIPE \\
FITTINGS \\
AND \\
DEVICES \\
\end{tabular} & $\begin{array}{c}\text { EQUIV. } \\
\text { PIPE } \\
\text { LENGTH } \\
\end{array}$ & \begin{tabular}{|c|} 
FRICTION \\
LOSS \\
PSIFT \\
\end{tabular} & $\begin{array}{l}\text { PPESSURE } \\
\text { SUMMAARY } \\
\end{array}$ & $\begin{array}{c}\text { NORMALL } \\
\text { PRESSURE } \\
\end{array}$ & NOTES \\
\hline & spt 6 & 924 & 1 & & $\angle 9$ & & Pt 18.4 & $\mathrm{Pt}$ & \\
\hline 8 & BL2 & & $(0,48)$ & & $\mathrm{F} \quad \mathrm{O}$ & 18 & $\mathrm{Pe} \quad \mathrm{O}$ & $\mathrm{Pv}$ & \\
\hline & & a & {$[(1,24)$} & & 19 & & Pf 1,64 & $\mathrm{Pn}$ & \\
\hline & $|c p\rangle$ & 9251 & $11 / 4$ & & $\mathrm{~L} 10$ & & $\mathrm{Pt} 20,04$ & $\mathrm{Pt}$ & $g=5.6 \sqrt{2204}$ \\
\hline 9 & 302 & & & & $\mathrm{~F} \quad \mathrm{O}$ & .18 & $\mathrm{Pe} \quad 0$ & $\mathrm{Pv}$ & \\
\hline & & $a_{4} q_{1} 1$ & $(6,38)$ & & $T, 0$ & & Pf 1,8 & $\mathrm{Pn}$ & \\
\hline & $1, p 8$ & 926,2 & $1 / 4$ & 2) $E(1 B$ & $L 8,6$ & & $\mathrm{Pt} 21,84$ & $\mathrm{Pt}$ & $\theta=5.6 \sqrt{2.84}$ \\
\hline 10 & 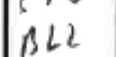 & & $(0,38)$ & & $F \quad 6$ & .4 & $\mathrm{Pe} O$ & $\mathrm{Pv}$ & \\
\hline & & $a>2\rangle$ & & & $T / 4$ & & Pf 5,6 & $\mathbf{P n}$ & \\
\hline & $1, p q$ & 929.3 & $1 \frac{1 / 2}{1 / 2}$ & Altee & $L 2,6$ & & $\mathrm{Pt} 27,44$ & $\mathrm{Pt}$ & $g=\sin \sqrt{2 \geqslant 44}$ \\
\hline II & $B<2$ & & (1, 61$)$ & & $F 8$ & .35 & $\mathrm{Pe} \quad 0$ & $\mathbf{P v}$ & \\
\hline & & 0104,6 & $(1.61)$ & & $\mathrm{T} 10.6$ & & Pf 3,71 & $\mathrm{Pn}$ & \\
\hline & & q & & & $\mathrm{L}$ & & $\mathrm{Pt} 31,15$ & $\mathbf{P t}$ & $12=\sqrt{0} t_{4}($ \\
\hline & Thtat & & & & $F$ & & $\mathrm{Pe}_{\mathrm{e}}$ & $\mathrm{Pv}$ & $B L=107$. \\
\hline & & $0 / 046$ & & & $T$ & & $\mathrm{Pf}$ & $\mathrm{Pn}$ & . \\
\hline & AL2 & 9133,4 & & & $L$ & & $\mathrm{Pt} 296$ & $\mathbf{P t}$ & a erom is $1=133,4$ \\
\hline & BL3 & & & & $F$ & & $\mathrm{Pe}$ & $\mathbf{P v}$ & $p t$ from $B C l=29.6$ \\
\hline & & 2238 & & & $T$ & & $\mathrm{Pf}$ & $\mathbf{P n}$ & \\
\hline & $B+2$ & ${ }^{9} 238$ & 3 & $D E L D$ & 412 & & Pt 60,75 & Pt & \\
\hline 12. & $\begin{array}{l}\text { TO } \\
B / 3\end{array}$ & 230 & $(5.068)$ & & $\mathrm{F} 7$ & .07 & $\mathrm{Pe} \quad \mathrm{O}$ & $\mathrm{Pv}$ & \\
\hline & & a & & & $T / 9$ & 1.01 & Pf 1,33 & $\mathrm{Pn}$ & \\
\hline & & $q$ & & & $\mathrm{~L}$ & & $\mathrm{Pt} 62,08$ & $\mathrm{Pt}$ & \\
\hline & $B<$ & & & & $\mathbf{F}$ & & $\mathrm{Pe}$ & $\mathrm{Pv}$ & \\
\hline & & 0258 & & & $T$ & & $\mathrm{Pf}$ & $\mathrm{Pn}$ & \\
\hline 13 & $5 p^{10}$ & q 24 & 1 & & L 9 & & Pt 18,4 & $\mathrm{Pt}$ & \\
\hline 13 & $A L 3$ & & $(6,40)$ & & $\mathrm{Fo}$ & .18 & $\mathrm{Pe} O$ & $\mathrm{Pv}$ & \\
\hline & & Q & $\mid(1,847)$ & & T 9 & & Pf 1,64 & Pn & \\
\hline & spll & 9251 & $11 / 4$ & & $\begin{array}{ll}\quad 10 \\
\end{array}$ & & $\mathrm{Pl} 20,04$ & $\mathrm{Pt}$ & $0-56 \sqrt{20.04}$ \\
\hline M & $B<3$ & & $(5,38)$ & & FO & 14 & $\mathrm{Pe} \quad \mathrm{O}$ & $\mathrm{Pv}$ & $q=0.020 .04$ \\
\hline & & 049,1 & & & T 10 & .10 & Pf 1,8 & $\mathrm{Pn}$ & \\
\hline$s$ & $s p^{12}$ & 926.2 & $11 / 2$ & & 18.6 & & $\mathrm{Pt}=1,84$ & $\mathrm{Pt}$ & $q=5.6 \sqrt{2} 1.24$ \\
\hline$p$ & $B^{3}$ & & $(1.38)$ & & $F \quad$ & .4 & $\mathrm{Pe} \quad 0$ & $\mathbf{P v}$ & \\
\hline & & $a>5,21$ & & & 18.6 & & Pf 344 & $\mathbf{P n}$ & \\
\hline & & 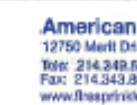 & Fire $\mathrm{S}$ & ar Ass: & & & $\mathrm{Pt} 25,28$ & & \\
\hline
\end{tabular}




\begin{tabular}{|c|c|c|c|c|c|c|c|c|c|}
\hline \multirow{2}{*}{\multicolumn{3}{|c|}{$\begin{array}{l}\text { Nogk es } \\
\text { CONTRACT NAME }\end{array}$}} & \multicolumn{6}{|c|}{ HYDRAULIC CALCULATIONS } & \multirow{3}{*}{ SHEET 3 OF 3} \\
\hline & & & & PPE S & $23 \mathrm{Pr}$ & oject C. & & & \\
\hline \multicolumn{2}{|c|}{$\begin{array}{l}\text { NOZZLE } \\
\text { IDENT. } \\
\text { AND } \\
\text { LOCATION } \\
\end{array}$} & $\begin{array}{l}\text { FLOW } \\
\text { IN } \\
\text { GPM } \\
\end{array}$ & $\begin{array}{l}\text { PIPE } \\
\text { SIZE } \\
\end{array}$ & \begin{tabular}{|c|} 
PIPE \\
FITTINGS \\
AND \\
DEVICES \\
\end{tabular} & \begin{tabular}{|c} 
EQUIV. \\
PIPE \\
LENGTH \\
\end{tabular} & \begin{tabular}{|c|} 
FRICTION \\
LOSS \\
PSIFT \\
\end{tabular} & $\begin{array}{l}\text { PRESSURE } \\
\text { SUMMMARY } \\
\end{array}$ & $\begin{array}{c}\text { NORMAL } \\
\text { PRESSURE } \\
\end{array}$ & \\
\hline \multirow{6}{*}{16} & \multirow{3}{*}{$\begin{array}{l}S^{P 1 B} \\
B L 3\end{array}$} & \multirow{3}{*}{\begin{tabular}{|l|}
28,15 \\
$0 / 03,4$ \\
\end{tabular}} & \multirow{3}{*}{$\begin{array}{l}1 / 2 \\
1,35\end{array}$} & (i) Tee & 14 & \multirow{3}{*}{.8} & $\mathrm{Pt} 25.28$ & Pt & \multirow[t]{3}{*}{$g=5.6 \times \sqrt{25}=8$} \\
\hline & & & & & $F \&$ & & $\mathrm{Pe} \quad \mathrm{O}$ & $\mathrm{Pv}$ & \\
\hline & & & & & $T 12$ & & Pf 9,6 & $\mathrm{Pn}$ & \\
\hline & & q & & & $\mathrm{L}$ & & Pt 34,88 & $\mathbf{P t}$ & \\
\hline & & & & & $F$ & & $\mathrm{Pe}$ & $\mathrm{Pv}$ & \\
\hline & & a & & & $T$ & & $\mathrm{Pf}$ & $\mathrm{Pn}$ & \\
\hline \multirow{3}{*}{17} & \multirow{3}{*}{$\begin{array}{l}\Delta<3 \\
70 \\
40 \text { min }\end{array}$} & \multirow{3}{*}{\begin{tabular}{|l|}
$q_{238}$ \\
$Q_{341,4}$
\end{tabular}} & & & $\mathrm{~L}$ & & Pt 62,08 & $\mathbf{P t}$ & \multirow{3}{*}{$\begin{array}{l}\text { eg froq } B L I+2=218 \\
\text { pt froa } B(1+2=62,08\end{array}$} \\
\hline & & & & & $\mathrm{F}$ & & $\mathrm{Pe}$ & Pv & \\
\hline & & & & & $T$ & & $\mathrm{Pf}$ & Pn & \\
\hline \multirow{3}{*}{$1 / 4$} & \multirow{3}{*}{$\begin{array}{l}\text { BL3 } \\
\text { io } \\
4_{\text {mais }}^{\prime \prime}\end{array}$} & \multirow{3}{*}{$\begin{array}{l}9341,4 \\
0\end{array}$} & \multirow{3}{*}{$\begin{array}{l}3^{\prime \prime} \\
3.068)\end{array}$} & H)ECB(?) & $L 122$ & \multirow{3}{*}{.13} & Pt 9), (8 & $\mathbf{P t}$ & \multirow[t]{3}{*}{$1433 \times 13=\mathrm{Pe}$} \\
\hline & & & & (1) teeris & $\mathrm{F} 43$ & & $\mathrm{Pe} 5,629$ & $\mathrm{Pv}$ & \\
\hline & & & & & 7165 & & $\mathrm{Pf} 21,45$ & $\mathrm{Pn}$ & \\
\hline \multirow{3}{*}{19} & \multirow{3}{*}{$\begin{array}{l}4^{n} \text { main } \\
\text { To } \\
\text { hor }\end{array}$} & \multirow{3}{*}{\begin{tabular}{|l|}
$q$ \\
0341,4 \\
\end{tabular}} & \multirow{3}{*}{$\begin{array}{l}4^{\prime \prime} \\
4,026)\end{array}$} & 3) EUS $10^{\circ}$ & $\mathrm{L} / 05$ & \multirow{3}{*}{.04} & $\mathrm{Pt} 124,75$ & $\mathbf{P t}$ & \multirow[t]{3}{*}{$\theta_{0}=.433 \times 24=$} \\
\hline & & & & Iswehy & $F 54$ & & $\mathrm{Pe} / 0.39$ & Pv & \\
\hline & & & & $15 a+v_{2}$ & 1159 & & Pf 6.36 & $\mathrm{Pn}$ & \\
\hline & & q & & & $\mathrm{L}$ & & Pt 191,5 & $\mathbf{P t}$ & \\
\hline & & & & & $\mathrm{F}$ & & $\mathrm{Pe}$ & $\mathrm{Pv}$ & \\
\hline & & a & & & $\mathrm{T}$ & & $\mathrm{Pf}$ & $\mathrm{Pn}$ & \\
\hline & & $q$ & & & $\mathrm{~L}$ & & $\mathrm{Pt}$ & $\mathbf{P t}$ & systet deand \\
\hline & & & & & $F$ & & $\mathrm{Pe}$ & $\mathrm{Pv}$ & is $341,5 \mathrm{gPm} p 141,5$. \\
\hline & & a & & & $T$ & & $\mathrm{Pf}$ & Pn & \\
\hline & & $q$ & & & $\mathrm{~L}$ & & $\mathrm{Pt}$ & Pt & \\
\hline & & & & & $F$ & & $\mathrm{Pe}$ & $\mathrm{Pv}$ & \\
\hline & & $Q$ & & & $\mathrm{~T}$ & & $\mathrm{Pf}$ & $\mathrm{Pn}$ & \\
\hline & & q & & & L & & $\mathrm{Pt}$ & $\mathbf{P t}$ & \\
\hline & & & & & $\mathrm{F}$ & & $\mathrm{Pe}$ & $\mathrm{Pv}$ & \\
\hline & & Q & & & $T$ & & $\mathrm{Pf}$ & $P n$ & \\
\hline & & q & & & $L$ & & $\mathrm{Pt}$ & $\mathbf{P t}$ & \\
\hline & & & & & $\mathrm{F}$ & & $\mathrm{Pe}$ & $\mathrm{Pv}$ & \\
\hline & & a & & & $\mathrm{T}$ & & $\mathrm{Pt}$ & Pn & \\
\hline & & q & & & $\mathrm{L}$ & & $\mathrm{Pt}$ & $\mathbf{P t}$ & \\
\hline & & & & & $\mathrm{F}$ & & $\mathrm{Pe}$ & $\mathrm{Pv}$ & \\
\hline & & a & & & $T$ & & $\overline{\mathrm{Pf}}$ & $\mathrm{Pn}$ & \\
\hline & & 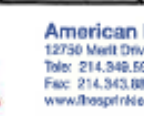 & ire $\mathbf{S}$ & $\operatorname{ler} A 88$ & & & $\mathrm{Pt}$ & & \\
\hline
\end{tabular}


Brett Noakes

June 2015

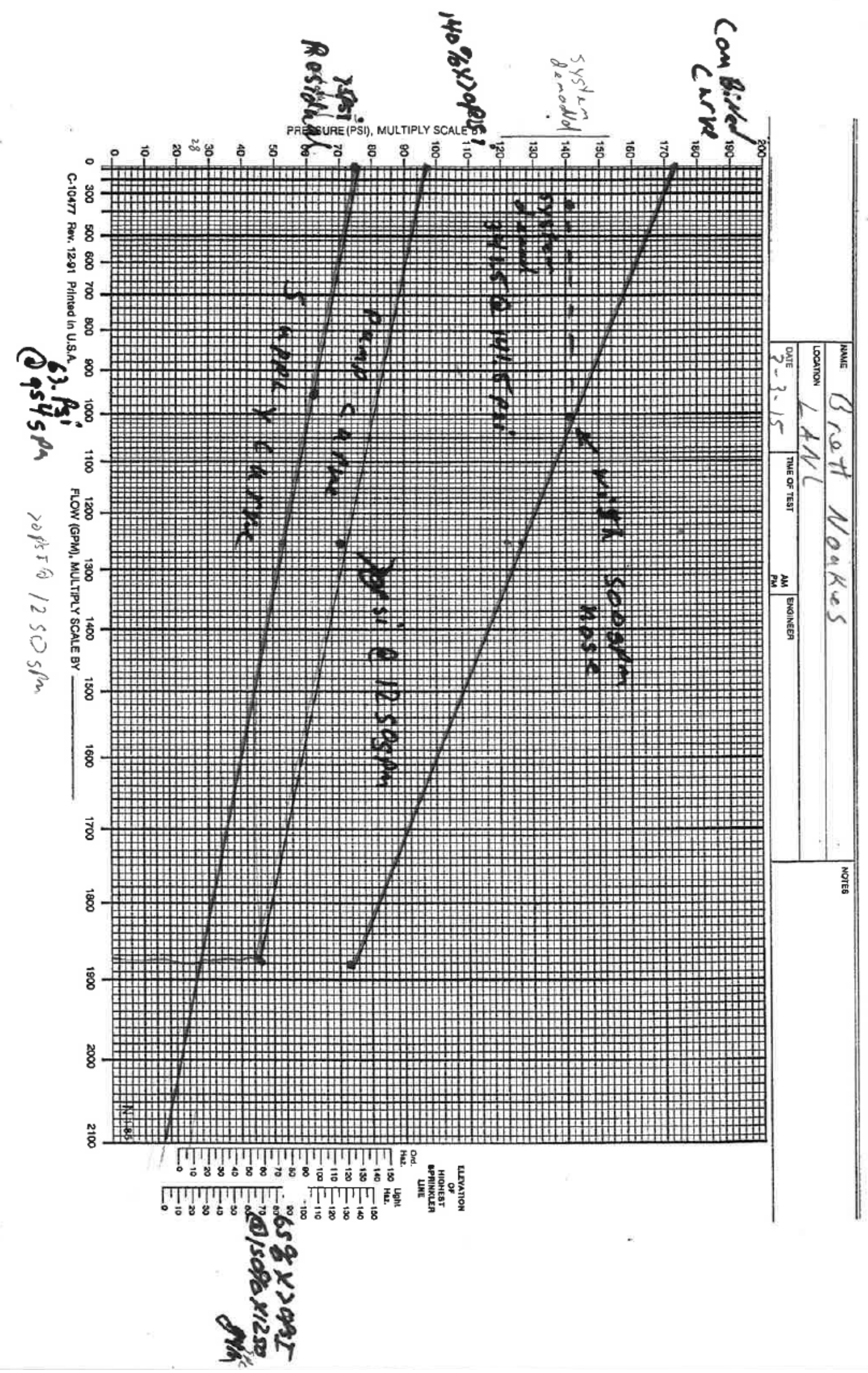

